Florida International University

FIU Digital Commons

$11-26-2018$

\title{
The "New" Black in the New South: Negotiating Race and Space in North Carolina's Immigrant Communities
}

Masonya Joy Bennett

Florida International University, mbenn040@fiu.edu

Follow this and additional works at: https://digitalcommons.fiu.edu/etd

Part of the Public Affairs Commons

\section{Recommended Citation}

Bennett, Masonya Joy, "The "New" Black in the New South: Negotiating Race and Space in North Carolina's Immigrant Communities" (2018). FIU Electronic Theses and Dissertations. 4066.

https://digitalcommons.fiu.edu/etd/4066

This work is brought to you for free and open access by the University Graduate School at FIU Digital Commons. It has been accepted for inclusion in FIU Electronic Theses and Dissertations by an authorized administrator of FIU Digital Commons. For more information, please contact dcc@fiu.edu. 


\title{
FLORIDA INTERNATIONAL UNIVERSITY \\ Miami, Florida
}

\section{THE NEW BLACK IN THE NEW SOUTH: NEGOTIATING RACE AND SPACE IN NORTH CAROLINA'S IMMIGRANT COMMUNITIES}

\author{
A dissertation submitted in partial fulfillment of \\ the requirements for the degree of \\ DOCTOR OF PHILOSOPHY \\ in \\ GLOBAL AND SOCIO-CULTURAL STUDIES \\ by \\ Masonya J. Bennett
}

2019 
To: Dean John F. Stack

Steven J. Green School of International and Public Affairs

This dissertation, written by Masonya J. Bennett, and entitled The New Black in the New South: Negotiating Race and Space in North Carolina's Immigrant Communities, having been approved in respect to style and intellectual content, is referred to you for judgement.

We have read this dissertation and recommendation that it be approved.

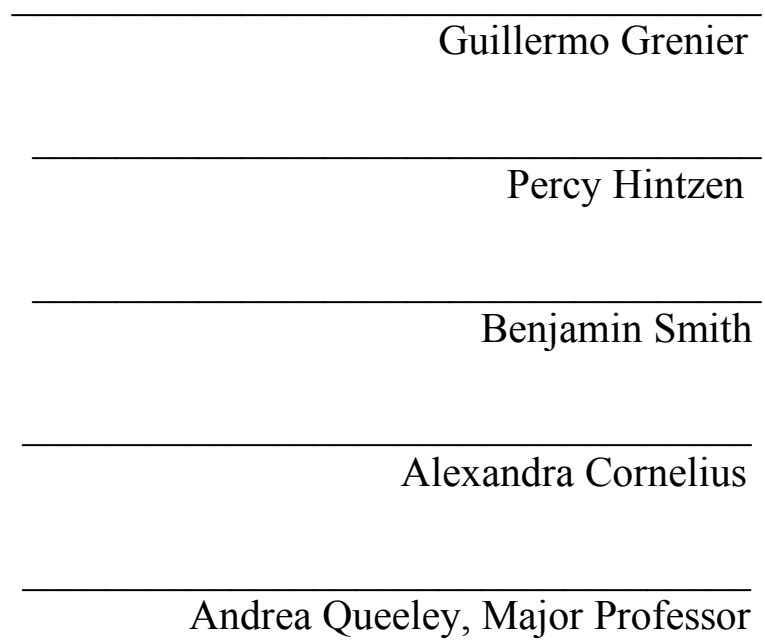

Date of Defense: November 26, 2018

The dissertation of Masonya J. Bennett is approved.

Dean John F. Stack

Steven J. Green School of International and Public Affairs

Andrés G. Gil

Vice President for Research and Economic Development and Dean of the University Graduate School

Florida International University, 2019 
(C) Copyright 2019 by Masonya J. Bennett

All rights reserved. 


\section{DEDICATION}

To my parents, Winnie and Nelson, without their undying love and support, none of this would be possible. To my Grandmothers, their strength lives. 


\section{ACKNOWLEDGMENTS}

The completion of research and writing composing this dissertation was made possible thanks to a two-semester Florida International University Dissertation Year Fellowship. I am also thankful for a Florida International University Dissertation Evidence Acquisition Fellowship that awarded me the opportunity to complete the research presented in this dissertation. I thank the Social Science Research Council's Dissertation Proposal Development Fellowship for assisting me both financially and intellectually in the development of a proposal that eventually flourished into this dissertation. I thank African and African Diaspora Studies and Global and Sociocultural Studies for their continued support.

Since my first semester of classes in the joint M.A/Ph.D. program in African and African Diaspora Studies and Global and Sociocultural Studies at Florida International University, I have been inspired by the expertise, presentation, and drive of Dr. Andrea J. Queeley. I will never be able to thank her enough for believing in me and my project, and for her mentorship, and for each day, each trial, and each chapter shaping me into a better academic, a better professional, a better and stronger black woman.

I am grateful for the support, knowledge and guidance of my dissertation

committee members: Dr. Guillermo Grenier, Dr. Percy Hintzen, Dr. Benjamin Smith, and Dr. Alexandra Cornelius, one of the first people I met in African and African Diaspora Studies, and who always made me feel at home. I must also extend great thanks and gratitude to Dr. Jean Muteba Rahier, who paved the way for me to be in the program by admitting me into African and African Diaspora Studies, and granting me funding. Dr. Rahier also served on my African and African Diaspora Studies M.A. Thesis Committee. 
African and African Diaspora Studies became my family and I am forever grateful to be a part of such a wonderful and beautiful department.

I thank East Charlotte for simply being East Charlotte for all of these years, beginning with my time as an intern at International House while studying at the University of North Carolina at Charlotte; both introduced me to immigrants in Charlotte nearly ten years ago. I am grateful for all of my participants who dedicated their time and their voice to my project, I hope that soon the city and state recognize these people and their voices for what and who they are, the New South. I thank my dear friend Krystle Brown for recruiting participants and Dr. Simone Hunter and Vanita Beavers for tasting, seeing, and feeling East Charlotte with me. I thank Janae Edwards for endless conversations on everything Diaspora, our conversations gave life to this dissertation. I thank Nachéz Saunders and Bria Lamb for being there. To my support system in GSS; Aysha Preston, Abby Gondek, Mariama Jaiteh, and Martin Tsang, I give all of my love.

This dissertation could not have transpired without the love and support of my family. I am beyond thankful for my mother, Winnie Bennett, for being everything a mother can be and more: my best friend, my editor, my therapist, my coach. My father, Nelson Bennett, for being Nelson, he is all powerful. I am forever grateful for the black women that inspired my drive to be an educator and academic: Dr. Linda Strong Leek, Dionnya Pratt, Winnie Bennett, Synetha Pratt and Brenda McNeely Allen. To Sophia Pratt, thank you for everything. My cousins Devonte Hinton and Diondre Pratt, and my sister, Adrienne Bennett, I thank you for all you did from near and far. Lastly, I am forever grateful for my cousin Justin Allen who was my family support system during my time in Miami and who is no longer with us today. 


\section{ABSTRACT OF THE DISSERTATION \\ THE NEW BLACK IN THE NEW SOUTH: NEGOTIATING RACE AND SPACE IN NORTH CAROLINA'S IMMIGRANT COMMUNITIES}

by

Masonya J. Bennett

Florida International University, 2019

Miami, Florida

Professor Andrea Queeley, Major Professor

This dissertation explores identity and subject formation among black immigrant populations in Charlotte, N.C, a non-traditional gateway city. It interrogates claims made by regional scholars and policy-makers that, due to recent demographic shifts and economic development, Charlotte embodies the "New South", a designation signifying the transition from an agricultural to a corporation-based economy and from a racially polarized to a multicultural society. Based upon 18 months of ethnographic research utilizing a mixed method approach among immigrants of African descent in the transethnic enclave of East Charlotte, the dissertation focuses on the role of space, place, material culture and affect in black subject formation, demonstrating that East Charlotte is a trans-ethnic alternative community fostered by affective kinship. It argues that black subjects are compelled to create alternative spaces of belonging and inclusion and that these alternative spaces are representative of what I propose is an "Alternative New South," one that more truly embodies the character of the New South articulated in mainstream narratives. The people, spaces, places and things that compose this 
Alternative New South reflect the alterity, contention, and solidarity that black immigrant subjects in Charlotte encounter, embrace, and embody. By asserting the model of a transethnic-alternative community, my work (re)places the agency of constructing the projected narrative of the New South in the hands of black and brown subjects, not policy-makers and corporate entities. 


\section{INTRODUCTION}

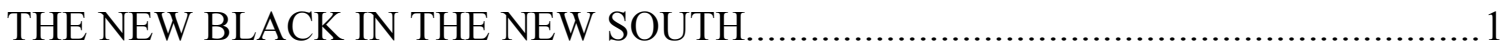

Conceptualizing Black Subjectivities in the U.S. South ............................................

Black Immigrants in a Pre-Emerging Gateway City ……….......................................5

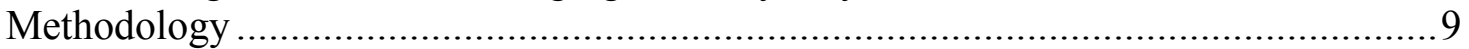

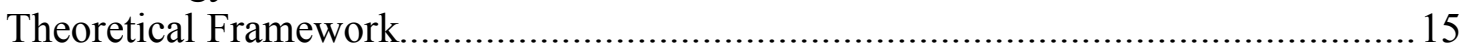

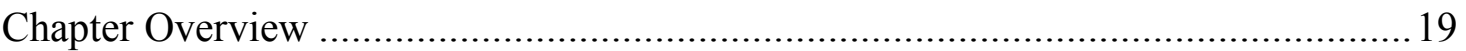

\section{CHAPTER ONE}

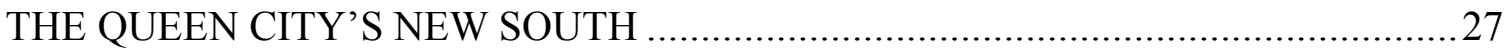

The Birth of a Queen City: Charting a Southern Ontology .............................................. 33

Didn't Think We Had It In Us: The New South, a Dangerous Discourse and a

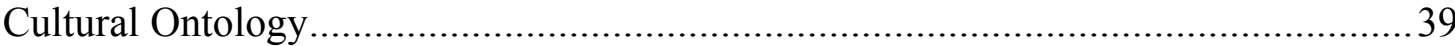

Uptown Charlotte: A Corporate Culture and a Perpetual Identity Crisis ......................52

Queens Versus Queens: Navigating Charlotte's Landscapes as a Black Subject..........65

East Charlotte: A Metaphor for a Real New South................................................... 72

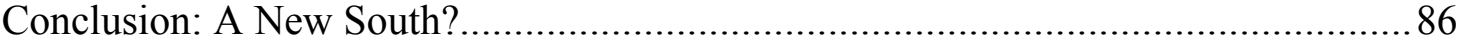

\section{CHAPTER TWO}

BLACK IS BLACK...OR IS IT? UNRAVELEING THE SIMULTANEITY OF

SAMENESS AND DIFFERENCE AMONG BLACK AMERICANS AND AFRICAN

AND CARIBBEAN IMMIGRANTS IN THE U.S. SOUTH ………............................. 88

Navigating Blackness: Theories and Debates Concerning Caribbean and African

Immigrants

Black, African-American, I Don't Know If There's a Difference....Is There a

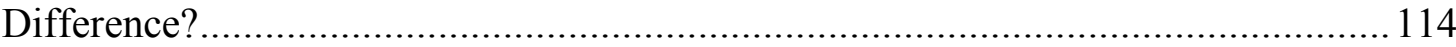

From the Educated Black American to the Model Minority; The Trope of the

Different Black Subject .................................................................................... 133

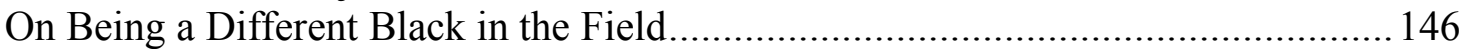

Braiding Hair and Buying on Credit; Inter- and Intra- Ethnic Socioeconomic

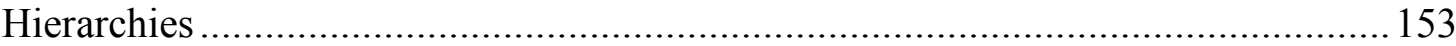

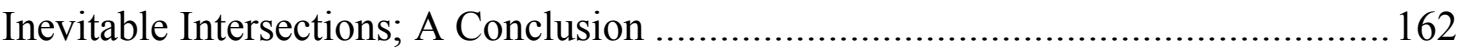

\section{CHAPTER THREE}

WHAT ARE YOU? SEEING THE INVISIBLE AND THE LIMINAL: AFRO-

LATINOS IN CHARLOTTE

We Never Identified with a Race: Perspectives on Race in Latin America and the

Hispanic Caribbean

The Slave Experience Didn't Only Happen in the U.S.!: Maneuvering the Middle

Passage Epistemology 
Do You Consider Yourself a White Person or a Black Person?: Confronting the

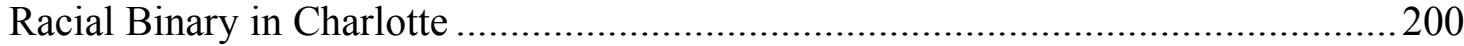

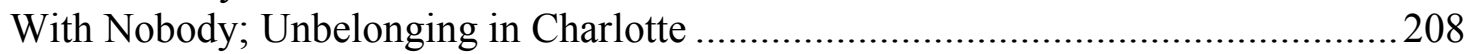

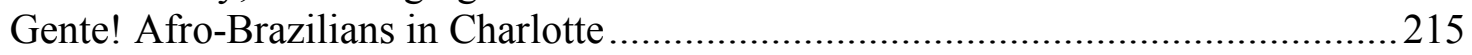

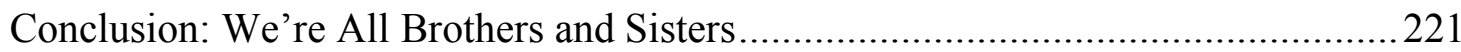

\section{CHAPTER FOUR}

CHITTERLINGS, FUFU, AND CURRY: DIASPORA WARS AND THE

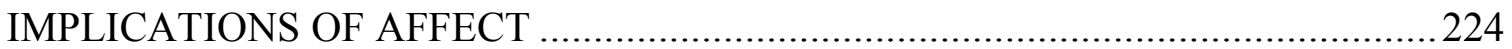

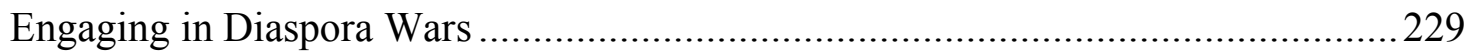

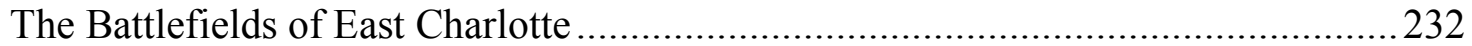

Hanging Out in the Trenches; (Un)Respectable and (Un)Safe Bodies as Boundary-

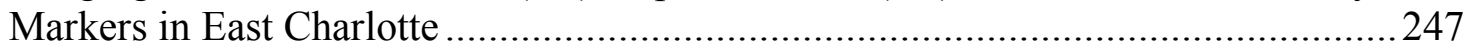

Eating Behind Enemy Lines; Food and Disgust as Boundary-Markers.....................268

A Conclusion: Washing the Wounds .................................................................28

\section{CHAPTER FIVE}

DIASPORA LOVE: INTERSECTIONS, INTERACTIONS, SOLIDARITY, AND

THE MAKINGS OF AN ALTERNATIVE NEW SOUTH.........................................228

Essential Love: The Annual Juneteenth Festival of the Carolinas, an Afrocentric

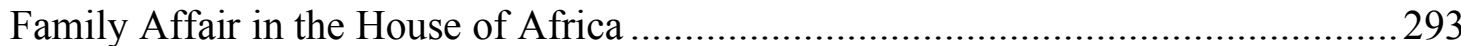

One Love: Reggae Central and the transnational Black Atlantic Family....................319

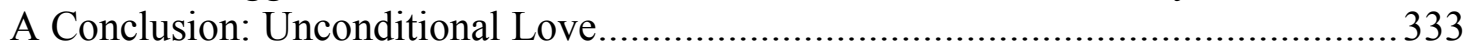

\section{CHAPTER SIX}

EMBODIED BORDERS: FOOD, MUSIC, DANCE, AND THE MAKING OF

DIASPORA IN THE BORDERLANDS OF THE TRANS-ETHNIC ALTERNATIVE

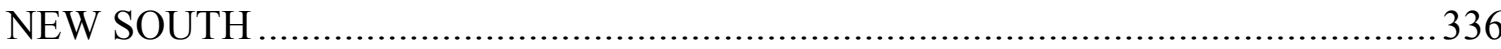

Intersectional Kinship: SuCasa, Queens Collective, and Snug Harbor as Safe

Spaces for Alter-Native Black Subjects

Cultural Expression, Kinship and Commodity: The Brazilian Arts Center and the

Multi-Cultural Familial Bonds of Capoeira and Samba in Charlotte............................368

Embodied Borders: Sustainable Transnational Black Families in the Borderlands ...381

A Conclusion: Ethics and Borders Good for Living ................................................398

CONCLUSION

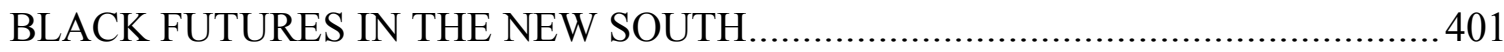

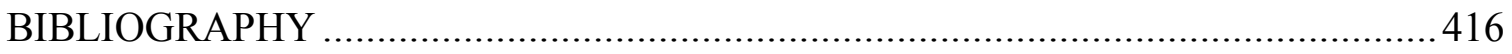

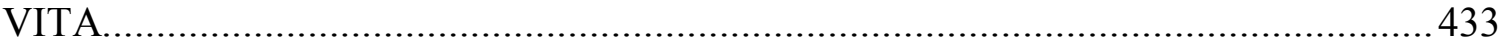


Chart 1. Comparative Demographic Data from District 5 (East Charlotte) and Mecklenburg County overall, Charlotte-Mecklenburg Quality of Life Explorer, Mecklenburg County Planning Department, 2017.

Figure 1.1. Photos: Pain, Anger and Violence Fill the Streets of Charlotte, N.C., Sean

Rayford/Getty Images, National Public Radio, Inc., September 22, 2016. 42

Figure 1.2. The 1957 photo that garnered international news, Dorothy Counts integrates Harding High School (Tomlinson and Sturkey 2016). 45

Figure 1.4. EpiCentre Dress Code posted outside of the center, Photograph by author...58

Map 1.1. Concentration of foreign-born population. The heart of East Charlotte consists of portions of City Council District 5 and 1 . District 4 demarcates University City, middle and upper middle class suburban areas surrounding UNC-Charlotte in Northeast Charlotte. Data provided by Mecklenburg County Planning Department 77

Map 1.2. Black or African American population in Charlotte-Mecklenburg. The highest concentrations of these populations are located in West and Northwest (top left clusters) and East to Northeast (top right). Areas with the least of these populations are predominantly white. Demographic Data and Maps provided by Charlotte-Mecklenburg Quality of Life Explorer and 2010 U.S Census Tract Data........ 78

Figure 1.5. Compare Foods, a Dominican-owned grocery chain at the intersection of N. Tryon and Sugar Creek Rd. Known for its quintessential mid-century architecture, the building was originally home to a Park-n-Shop grocery store in the 1960s. Photograph by author.

Figure 1.6. A Hidden Valley Shopping Center located at the intersection of North Tryon and Sugar Creek in East Charlotte. The strip mall houses a black American-owned barber shop, a Guinean grocer, formerly a Senegalese-owned convenience store, and a Dominican hair salon. Photograph by author. 
Figure 2.1. Caro White Skin Bleaching Products in Tisun Beauty Supply, East Charlotte. Photograph by Author

Figure 2.2. Caro White Products at DeliMart in Port-au-Prince Haiti, demonstrating that the trope of whiteness is transnational. Photograph by Author

Figure 2.3. Members of the NC Brazilian Arts Project perform Samba at the Annual A Night in Rio at the Neighborhood Theatre in North Davidson (NoDa) in East Charlotte. Dance communities in Charlotte are linked by broader social and multicultural networks. Photo by author

Figure 2.4. Hanging out with a fellow Different Black, a Guyanese participant, Kester, hangs with friends of a Mexican rock band after their performance to a mainly all-white audience in Cornelius, N.C. Photograph submitted by participant through Photo-Voice.

Figure 3.1. A Black American man stands at the February ICE protest in Marshall Park in Uptown Charlotte. His top shirt reads, Mexico Will Not Pay for a Wall, the shirt wrapped around his waist reads, $\mathrm{F}^{* * *}$ Donald Trump, Photograph by author.

Figure 3.2. People with flags representing their respective countries (Brazil and Honduras) at the ICE protest, Uptown Charlotte at Marshall Park, Photograph by author. 183

Figure 3.3. White American, Black American and Latino American Students from UNC-Charlotte and Johnson C. Smith University hold signs in protest of ICE at Marshall Park, Uptown Charlotte, Photograph by Author. 184

Figure 3.4. Kurma performs Cumbia, a traditional Colombian dance, at La Tercera Raiz/De Africa a Latinoamerica event at Johnson C. Smith University. Photograph provided by Kurma through Photo-Voice participation 
Figure 4.1. Ned, Ethiopian-born and long-time Charlotte resident, graduate of Johnson C. Smith University explaining the process of Ethiopian coffee preparation as the women prepare in the traditional manner. Photograph by Author.

Figure 4.2. Ned explains how to use hands to eat with Ethiopian Injera bread at Nile Grocery, our second stop on Taste of the World. It is important to note that Ned does not own Nile Grocery but he is well-versed, corporate and trusted among guests. Photograph by Author.

Figure 4.3. Crystals Reggae Club on The Plaza in the heart of East Charlotte. Pictured is the entrance during a daytime festival. To the right is a painting of an island with palm trees, ocean and beach suggesting it's Caribbean vibe. To the far left, a security guard pats someone down. Photograph by author.

Figure 4.4. Reading Facial Expressions of Emotion (Matsumoto and Hwang 2011)....275

Figure 5.1. Outside of House of Africa, on Thomas Avenue. Photograph by Author...296

Figure 5.2. Inside the first portion of House of Africa. Photograph by Author.

Figure 5.3. Mrs. Olita (African American) and Waly (Pap's brother, Senegalese) briefly debate the usage of fans and chew sticks in the Juneteenth Fashion Show. Waly suggests that in order to be truly representative of African women, we (I participated in fashion show) should carry the fans, Mrs. Olita disagrees. All of the models were African American. Inside House of Africa. Photograph by author.

Figure 5.4. Sankofa's stage design and artwork on Juneteenth's main stage.

To the far left are depictions of African nobility in Africa. In the middle, a scene from slavery. To the far right are depictions of liberation from slavery.

Photograph by author.

Figure 5.5. One of the Juneteenth Babies and now, employees of HOA poses in the Living Room of the House. On the mantle above the living area is a photograph of Pap, the paternal figure reigning over the boutique and shop. Photograph by author...312 
Figure 5.6. Women at Work. The women of the planning committee build the African History Tunnel among many things at Juneteenth. Photograph by Author.....

Figure 5.7. Former Mayor Jennifer Roberts grants Pap, the Key to the City, and recognizes Juneteenth Festival of the Carolinas as a city holiday. Standing alongside to the left of Pap is previous mayoral candidate Vi Lyles, now the city's current African American mayor. Surrounding the stage are other prominent African American leaders in the city. Photograph by Author.

Figure 5.8. Pap converses with a local well-known African American pastor (in purple dashiki) of mega-church in front of a business next door to House of Africa during Juneteenth. Photograph by Author.

Figure 5.9. A Black American Family in matching Kente-cloth-Dashiki

patterned-African Inspired outfits poses with their tropical fruit drinks at Juneteenth

Festival. Photograph by Author

Figure 5.10. Another family shows off their designs modeled on the front stage at Juneteenth Festival. The black American mother is the designer and hopes to also publicize her custom-made garments at the festival. Photograph by Author.

Figure 5.11. Reggae Central on Central Avenue. Photograph by Author.

Figure 5.12. Inside of Reggae Central. Photograph by Author.

Figure 6.1. Blame the Youth performs at SuCasa at Petra's Piano Bar in

East Charlotte. Photograph by Author 353

Figure 6.2. Adriana, a Latina (in background) and a young Black Woman, ethnicity unknown (at the forefront), members of the NC Brazilian Arts Project perform Samba for the Queen's Collective crowd at Camp North End. Photograph by Author.. 363

Figure 6.3. Heat in her Heart. Carolina, her Brazilian partner, and Brazilian friend embrace in a moment of love triggered by the music and Carolina's reunification with her girlfriend. Photograph by Author. 
Figure 6.4. After both Samba and Capoeira performances by the NC Brazilian Arts Project, they signal for the crowd to join in on the dance floor, the outdoor concrete dance floor is flooded with footprints of Samba. Photograph by Author.

Figure 6.5. Warming Up. The Intermediate class warms up for Capoeira class at the Brazilian Arts Center in East Charlotte. Contramestre Zumbi observes movements (standing far left center). Photograph by Author.

Figure 6.6. A Life Philosophy. Mural inside of the Brazilian Arts Center depicts images of Rio de Janeiro alongside Uptown Charlotte as well as Capoeira being played in villages/communities in Brazil. The mural speaks to the transnational connections Capoeira has fostered globally and locally. Photograph by Author. 375

Figure 6.7. Fresh Printed Goods. Ndelo hand prints an African graphic pattern on a T-shirt for me at an Afropop Block Part at Camp Northend. Photograph by Author.... 385

Figure 6.8. Hella Black. Hella Proud. A Young Black American Couple, travels from Columbia, S.C to sell their goods, inspired by their study abroad time in Nairobi, Kenya, at Afropop at Morehead Tavern. Photograph by Author .385

Figure 6.9. Refashioning Food and the role of Mother. Jasiatic prepares dinner for a Satisfy Dinner party alongside a sous-chef she'd just met that day at her home.

Photograph by author. .395

Figure 6.10. Dinner is Served. Jasiatic standing to right forefront (sous chef to left back), explains the menu for the night to patrons of Satisfy in her East Charlotte dining room. Photograph by Author 396 


\section{ABBREVIATIONS AND ACRONYMS}

UNCC

JCSU

HBCU

CIAA

NCAA

HB2

BAC

HOA

NASCAR

CMPD

ICE
University of North Carolina at Charlotte

Johnson C. Smith University

Historically Black Colleges and Universities

Central Intercollegiate Athletic Association

National Collegiate Athletic Association

House Bill 2

Brazilian Arts Center

House of Africa

National Association for Stock Car Auto Racing

Charlotte-Mecklenburg Police Department

Immigration and Customs Enforcement 


\section{INTRODUCTION}

\section{THE “NEW” BLACK IN THE NEW SOUTH}

On a summer day in Charlotte, North Carolina, I found myself in an East Charlotte Dominican beauty salon. The salon shares a shopping center with an African American barbershop, a Gambian owned convenience store, a Mexican boutique, and a Guinean grocery store. At one point, according to the current owners of Hidden Valley barber shop, the shops in this shopping center were all white-owned, then later AfricanAmerican owned until an influx of immigrants from Latin America, Africa, the Caribbean, and Asia began to dramatically transform the social, political, and cultural landscapes of East Charlotte. This shopping center is indicative of the many transitions that East Charlotte has undergone within the last ten years as a result of significant demographic shifts brought on by immigration. The Dominican salon, which in contrast to Dominican salons in traditional gateway cities, such as New York City and Miami, caters to a predominantly African American clientele. In the salon, the main stylist MaReyni, is a young Dominican woman who acknowledges her African descent, but also recognized what appears to be her racial and ethnic ambiguity. MaReyni expressed that people in North Carolina often ask, "what are you? You look black but you're not black." She went on to mention that while people often note her accent, people often assume that she is "Black, like African American." Mexicans and Central Americans who represent the overwhelming majority of Latinos in Charlotte presume that she is African American as well. According to MaReyni, this would not be the case in cities such as New York City. When asked what white people see her as, the young caramel 
complexioned stylist asserted that she was unsure since she does not "behave like a black person" or "like a Latino" and recognizes that [white] people may pick up on this aspect in "places like Starbucks" where the constant question of "what are you?" lingers. This account reveals the many nuances of the black immigrant experience in Charlotte, North Carolina. This dissertation interrogates the varying dynamics that influence the subjectivity and identity of those immigrants racialized as black as they navigate and negotiate race, space and place in the U.S South.

This dissertation utilizes a mixed method approach to explore the ways in which immigrants racialized as black, living in the U.S South conceptualize and perform blackness. I examine how immigrants from Africa, the Caribbean and Latin America process understandings of blackness that may or may not contrast with prior conceptualizations held in other destinations, including their countries of origin. This dissertation particularly concerns how conceptualizations and performances of blackness shift as these immigrant populations intersect and interact with black Americans in East Charlotte, a trans-ethnic enclave, and the implications of these dynamics on black identity and subject-formation in the U.S South.

As mentioned, East Charlotte is a trans-ethnic enclave and one of Charlotte's two main immigrant corridors (Schuch and Wang 2015; O. Furuseth, Smith, and McDaniel 2015; Hanchett 2010). Immigrants from Africa, Latin America, the Caribbean, and Asia are undeniably most visible through their small businesses, many of which occupy midcentury shopping centers that once catered to predominantly white middle class residents. By emphasizing the significance of black subject place-making, this dissertation focuses on places of consumption in East Charlotte. I argue that places of consumption such as 
restaurants, beauty salons, barber shops, festivals and events, boutiques, and small grocery stores that would be bounded by race, ethnicity, gender etc. in traditional gateway cities, have become shared spaces among African, Caribbean, Afro-Latino immigrants and black Americans in the U.S South. This dissertation examines how East Charlotte's transitioning landscapes have yielded such spaces and places, and the role that these places of consumption play in the everyday lives of these groups, and the impact these spaces and places have on immigrant subjectivities and identities.

Lastly, this dissertation explores the ways in which particular conceptualizations of blackness and articulations of diaspora are manifested within places of consumption and the goods exchanged in these places. I argue that certain spaces, places and the material culture that is exchanged in them transmit affects that shape and reshape black subjectivities and collective identities. However, I also consider that formations and performances of collective identities are contingent upon space, place, and time.

Therefore, this dissertation contends that the same dynamics that may influence collective identities also work to distinguish and/or separate these groups.

\section{Conceptualizing Black Subjectivities in the U.S. South}

Historically, conceptualizations of blackness among black Americans often stem from what Michelle Wright (2015) identifies as a Middle Passage epistemology, which holds that in order to be "defined" as black in the U.S, one must inherit the experiences of the trans-Atlantic slave trade and the struggle for Civil Rights (Wright 2015). While this understanding has helped foment a strong collective identity in the U.S, some scholars argue that this notion often confines and excludes the diversity of black subjectivities and 
the construction of contemporary collective identities (Wright 2015; Rahier 2003). In turn, many immigrants of African descent experience the process of "becoming black" in what the term/categorization has come to signify in the U.S (Wright 2004; Taiwo 2003:42; Charles 2003). At the same time, immigrants of African descent often bring their own understandings of race and ethnicity as they have undergone varying processes of racialization in their countries of origin. Therefore, newly arrived immigrants of African descent who bear phenotypical ascriptions of blackness but lack the specific linear experiences of black Americans are thrust into competing notions of racial and ethnic identity(ies) (Wright 2004:7; Wright 2015; Rahier 2003:110). This dissertation argues that the dynamics that occur through intersections and interactions between black immigrants and black Americans in the U.S South can operate to produce new understandings of blackness, and in turn (re)produce immigrant subjectivity, identity, and a diasporic consciousness.

Andrea Queeley (2015) puts forth subjectivity as "a sense of self and a way of thinking about others that changes under varying conditions and is informed by social forces and by larger, historically and spatially constituted power relations" (Queeley 2015: 3). I see identity as a more tangible and conscious extension of subjectivity, wherein individuals can express how they see themselves and others (Nassey Brown 2005). Therefore, the presence of other black subjects as well as the perception of others may influence one's self-understanding (Queeley 2015). With this, it is not the goal of this dissertation to assert that all Afro-descendent immigrants see themselves as black, but to instead, explore how their interaction with other black subjects shapes their subjectivity/identity. 


\section{Black Immigrants in a "Pre-Emerging Gateway City"}

While previous studies have explored the growing population of Mexican and Central American migrants in the U.S. South, few have considered the experiences of Afrodescendent immigrants from Africa, the Caribbean, and Latin America now living in the region (Gill 2010; Marrow 2011; Stuesse 2016). Further, the overwhelming scholarship on black immigrants is limited to those living in traditional gateway cities such as New York City, Miami, and San Francisco (Waters 1999; P. C. Hintzen 2001; Stepick et al. 2003; Vickerman 2001; Foner 2001; Rogers 2001). This dissertation explores the impact of space, place, material culture and affect in the production of identities and subjectivities among black immigrant populations in Charlotte, N.C, a non-traditional gateway city. In accordance with the "six immigrant gateway types" defined by The Brookings Institution Center on Urban and Metropolitan Policy (2004), given a range beginning with "former" to "post-World War II" to "emerging" gateway cities, Charlotte classifies as a "pre-emerging gateway city", meaning that the city held very low percentages of foreign-born populations for the entire $20^{\text {th }}$ century (5). Therefore, in contrast to traditional gateway cities, as a "pre-emerging gateway city" immigrant presence is now visible in Charlotte, however the city lacks cohesive ethnic enclaves such as Chinatown in San Francisco, Little Havana and Little Haiti in Miami, or Washington Heights in New York City (Goldfield 2010). Charlotte's most visible immigrant populations are highly concentrated in East Charlotte and/or South Blvd, the city's two immigrant corridors.

Nearly $21.4 \%$ of the city of Charlotte's population is foreign born, with almost $13.1 \%$ of that population identifying as Latino/Hispanic regardless of varying racial and 
ethnic backgrounds (US Census Data 2013). Between 1980 and 2000, the Latino population grew by $932 \%$ in Charlotte, $1180 \%$ in Raleigh-Durham (most likely due to that region's proximity to rural and agricultural based areas) and 995\% in Atlanta (O. J. Furuseth and Smith 2006, 8). According to a 2013 city-wide estimate, out of Charlotte's total immigrant population, about 51\% are of Latin American origins (Immigrant Integration Task Force Report 2013:4). However, U.S Census Data as well as other studies on Latino immigrants in the U.S. South fail to specify the racial backgrounds of these populations, which is a critical factor in their day-to-day experiences and identity/subject formation. In addition, despite little attention given to African populations, Charlotte is highlighted as a new major destination for African immigrants (Arthur 2009). Based upon the Charlotte City Council's Immigrant Integration Task Force Report (2013), the African population, mainly from Liberia and Nigeria, accounts for $10.3 \%$ of the immigration stream into the city. There is also a substantial Ethiopian and Eritrean population, visible through their businesses and community organizations in East Charlotte. However, the city lacks any concrete data on these populations while many refugee organizations are prohibited from providing exact demographic data on these populations. ${ }^{1}$ A great deal of these immigrants either live in or own businesses in East Charlotte. In just the last twenty years, the East Side's population transitioned from mainly white with pockets of black Americans to multi-ethnic with $44.7 \%$ and $35.3 \%$ of

\footnotetext{
${ }^{1}$ At least two of the major refugee organizations that I contacted, along with the City Council, and the East Charlotte non-profit I had previously worked with could not provide exact data on Ethiopian and Eritrean populations despite their visibility in East Charlotte shopping centers. This was a similar challenge with African populations outside of Nigeria and Liberia, although, again, I met Africans from at least every major West African (and some Central) countries throughout my research in East Charlotte.
} 
the foreign-born population concentrated within the area's two major census tracts respectively (Schuch and Wang 2015). These populations are not only evidenced in residential areas, but also heavily represented through small businesses located in the numerous strip malls and shopping centers that line the streets, the Central Avenue Business Corridor being the largest. Nearly all of the East Charlotte sites presented and discussed in this dissertation are located either within or in close proximity to the Central Avenue Business Corridor.
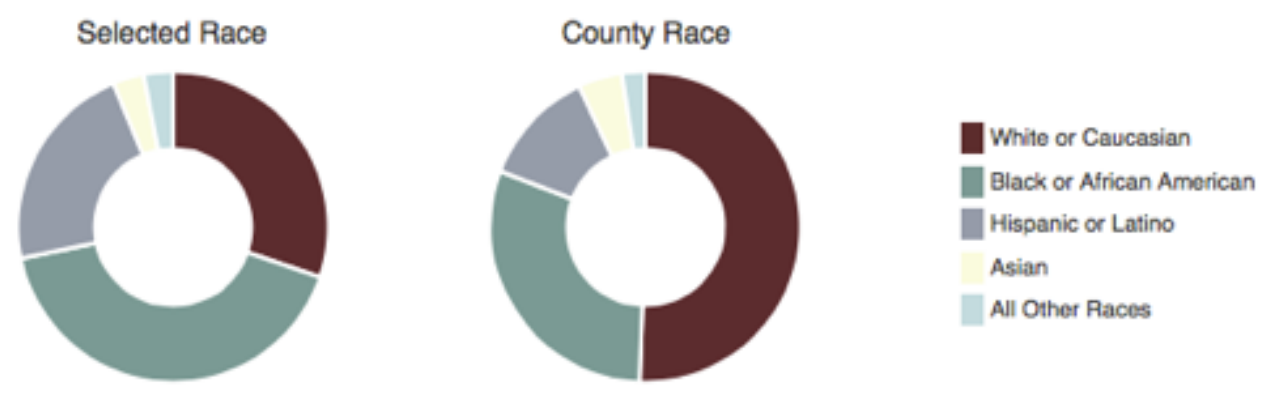

Chart 1. Comparative Demographic Data from District 5 (East Charlotte) and Mecklenburg County overall, Charlotte-Mecklenburg Quality of Life Explorer, Mecklenburg County Planning Department, 2017.

According to regional scholars, policy-makers, and corporate entities, these demographic shifts along with the city's economic growth designate Charlotte as the New South. In contrast to the Old South, this designation signifies Charlotte's transition from an agricultural to a corporation-based economy and from a racially polarized to a multicultural society. However, in 2016 protests erupted in response to the second instance of police brutality, in which an unarmed black man, Keith Lamont Scott, was killed by the Charlotte-Mecklenburg Police Department (CMPD). Further, many 
residents feel targeted by a series of state and federal anti-immigrant legislation, an increase in deportations implemented through Immigration and Customs Enforcement (ICE) raids and checkpoints in the city's two immigrant corridors. Only recently, in 2017, did the state of North Carolina overturn House Bill 2, an anti-LGBTQ bill promoted as the "bathroom bill" that legalized the discrimination of individuals by private companies based not only on gender and sexuality but also race, ethnicity, and religion. These instances counter the harmonious multicultural narrative of the New South. Moreover, the reality of spatial and racial marginalization and segregation enacted through a variety of overt and covert methods by city officials, law enforcement, and businesses further problematizes what the New South signifies for its black and brown residents. By elaborating on my participants experiences and perceptions of the New South as well as my own, this dissertation interrogates claims made by regional scholars, policy-makers, and corporate entities that seek to market and promote Charlotte as the New South.

Existing on the margins of the corporate, neat, new and predominantly white Uptown Charlotte, I argue that in East Charlotte, a racialized landscape associated with blackness and foreignness, spaces and places of consumption represent acts of place-making in which black immigrants assert visibility and belonging and inscribe meaning to places and spaces in response to sociocultural and political exclusion. Based upon 18 months of ethnographic research in East Charlotte among immigrants of African descent, focusing on the role of space, place, material culture and affect in the production of black subjectivities, this dissertation argues that black subjects are compelled to create alternative spaces of belonging and inclusion that contrast with "traditional" racialized 
spaces in Charlotte. These spaces and places reflect the alterity that black and brown subjects in Charlotte confront, embrace, embody and encounter, creating what I call an Alternative New South. The spaces, places, people, things, and affects that construct and compose this Alternative New South, or a trans-ethnic-alternative community represent the many layers of black and brown identity and subjectivity inclusive of socioeconomic status, gender, sexuality, language, culture, country of origin, activism and shifting conceptualizations of blackness and solidarity. In turn, I argue that this Alternative New South more truly embodies the projected narrative of the New South.

\section{Methodology}

This dissertation is the product of a total of 18 months of research conducted between 2014 and 2017 and partially supported by the Social Science Research Council's Dissertation Proposal Development Fellowship and Florida International University's Dissertation Evidence Acquisition Fellowship. Using an interdisciplinary mixed methods approach, I relied primarily upon ethnographic methods of participant-observation and semi-structured interviews. I utilized photo-elicitation methods implemented through a focus group. I also conducted a non-photo-elicitation focus group held at a weekly corporate happy hour. I applied mobile methods such as participatory GIS in which I accompanied participants while they shopped, ate, hung out, and went about other daily routines in East Charlotte. Lastly, I used a free-list method created in order to cater to performers and participants at a performance arts studio. These methods were supplemented by my own photographs while maneuvering through East Charlotte. I recorded and organized field notes, transcribed and coded interviews using Nvivo qualitative data analysis software. 
Through preliminary research, I discovered that the most reliable method of locating participants for this study was open sampling (Jaccard and Jacoby 2010: 65). Therefore, I located participants mainly through the snowball method as well as impromptu encounters with business owners and customers in East Charlotte and my participation in cultural events. The snowball method proved most reliable as it served to increase and maximize the diversity of the sample. The goal was not to obtain full representativeness, as immigrants from Africa, Latin America and the Caribbean are vast and diverse (Jaccard and Jacoby 2010). One of the challenges foregrounding this research, was locating Afro-Latino immigrants for the study. The particular challenge here was that many Latinos of African descent may not identify using the term Afro-Latino/a. Some did not acknowledge African ancestry, even though they appeared to be black in accordance with the "one-drop rule." In fact, when I used the term "Afro-Latino/a) with participants that only spoke Spanish, especially older individuals (age 50+), they did not understand the term, nor did they necessarily understand when I asked what race they identified with. Most said that in accordance with the U.S. Census, they identified as Hispanic or Latino, but personally identified based upon color categorizations such as moreno/a, trigeño, or mulato/a. This aspect evidenced processes of racialization in their countries of origin, which I discuss in Chapter Three. Therefore, all of the participants in this study self-identify as either Afro-Latino/a, Black and Latino, or acknowledged African descendance.

Participants also range in age, socioeconomic status, citizenship status, profession, sexuality, gender and community participation. The diverse sample collected through snowball method provided considerable knowledge on how these layers of identity 
impact participants' relationship with other black immigrants and black Americans as well as their relationships with space, place, and material culture and the particular affects triggered in certain times and spaces. In addition, the abovementioned factors allowed me to interpret participants' social networks.

I initially proposed the use of egocentric social network maps, however, I noticed early on that social networks in Charlotte among black subjects were relatively small and tight-knit, especially among those that convene within the cultural arts and activist scenes. For example, the Brazilian Arts Center and the performers and practitioners involved in Capoeira and Samba represented somewhat of a nucleus within a social network of what I call "cultural workers", or those individuals actively involved in the construction of an Alternative New South. This network is composed of a multi-cultural group of mainly of 23-35- year old individuals and I was able to gauge this network through social media outlets such as Facebook and Instagram. On the other hand, older participants, in the 45 and up category, particularly among both West and East Africans, social networks tended to be based upon region of origin, language and socioeconomic status and were more bounded. Caribbean social networks operated within the greater African American community and revolved mostly around their employment at corporate entities, indicating a corporate black social network ranging in age. Nearly all West Indian Caribbean immigrants attended black American churches, if they attended a religious institution. These networks subsequently provided an understanding of participants' identities, subjectivities and the possibility of collective identities.

I conducted 50 semi-structured initial interviews and five follow-up interviews with immigrants from Africa, the Caribbean, Latin America as well as black American 
residents, business owners, and patrons. I conducted interviews either in participants' places of business if they were business owners, their homes, or I asked participants to select places that were meaningful to them. The places participants chose to meet often indicated aspects of their identities and subjectivities. These places included, again, their homes and/or local cafes, studios, lounges, and their favorite restaurants either inside or outside of East Charlotte, but mainly in East Charlotte. As many of my participants lived outside of East Charlotte, they still convened in the area to either eat, shop, hang out, or participate in various activities. Therefore, the use of ethnographic mobile methods such as participatory GIS proved effective. By accompanying participants while they shopped, ate, and hung out I witnessed the fact that journeys in themselves were important in place-making, selecting and performing identities, and shaping subjectivities (Ross et al. 2009:606). Through participants' movements and their interactions with people, places, and things, I was also able to gauge a range of affects triggered in particular moments (Ross et al. 2009:606).

To further understand aspects of participants' subjectivities and identities, I utilized a photo-elicitation method in which immigrants shared with me personal photos of meaningful moments in their everyday lives. We discussed the photos in a focus group session held at a local grocer/bar in East Charlotte. This session was video recorded. According to Leonard and McKnight (2016) the use of methods such as photo elicitation encourages collaborative research by reducing power imbalances in the research process, allowing those being "researched" to take on the role of expert. For my research, photo elicitation presented the opportunity to tap into experiences that were not easily captured or communicated verbally (Leonard and Mcknight 2016). 
In order to gauge affect in other times and spaces, I relied on Free-List method. In my implementation of this method, I set up a "box of feelings" at the Brazilian Arts Center. I asked patrons and participants to anonymously list feelings, words, or thoughts that immediately came to mind while participating in either Capoeira or Samba at the center. Participants were asked to include their countries/cities of origin in order to better understand the depth of interactions and intersections taking place in that space. The anonymity of the Free-List exercise permitted the freedom to express a variety of personal thoughts, affects and emotions. Through the use of this method, I gained a greater sense of the impact of the space on those who occupy it more than my observations allowed.

Lastly, over the 18-month span of research, I conducted participant observation through "deep hanging out" (Geertz 1973) and patronizing restaurants, small grocery stores, barber shops, hair salons, and boutiques in East Charlotte shopping centers. I participated in cultural activities such as Capoeira held weekly at the Brazilian Arts Center in East Charlotte and attended committee planning meetings for annual festivals such as the Juneteenth Festival of the Carolinas held at the House of Africa. For Juneteenth in particular, I volunteered in the annual Juneteenth Children's Village Day Camp and modeled in the festival's fashion show. I attended monthly events/parties such as Afropop, SuCasa, Queen's City Collective, and other events held in East Charlotte bars and lounges. I attended more intimate events held at participants' homes, such as holiday parties, celebrations and dinner parties. These spaces, places, and events were essential in developing and fortifying the arguments detailed in this dissertation. 
This dissertation was in part inspired by my own confrontations with varying and competing understandings of blackness during my time living and working in Charlotte and other destinations throughout the U.S and the African Diaspora. My own blackness often emerges as a point of reference in the interactions between my interlocutors and I in East Charlotte. In addition, prior to beginning research, I had lived and worked in Charlotte for nearly 15 years and established a number of professional and personal connections. These relationships were key not only in recruiting participants, some of whom entered into or were part of my own social networks, but also in gaining access to additional social networks. My own social network plays an essential role in shaping some of the exchanges that take place between black Americans and black immigrants in the dissertation. My past time in Charlotte also granted knowledge of the city's landscapes, which prompted my interest in the ways in which my participants experience the city's landscapes. Therefore, I often insert myself into the dissertation by reflecting on my own positionality as a black subject in Charlotte and as a black American interacting with black immigrants. My positionality in the research often raised the question of am I a "native" anthropologist?

In her study of Informal Commercial Importers in Jamaica, Gina A. Ulysse (2007) posits her research from an "alter(ed)native" perspective, in which she sees herself as both "alter" as in Other and "native" as she was born in Haiti and ascribed an Antillean identity albeit not Jamaican (7). Similar to Ulysse, I assert that I am native in that I am from the U.S. South and I am black. Yet, while Ulysse seemingly asserts a sense of universal Antilleanismo, I am not African, Caribbean or Latino, and despite encountering similar interrogations as a black subject navigating the Diaspora, I have not experienced 
the dynamic experiences of immigration and migration, other than being an "ex-patriot" abroad. In turn, I take the position of Kirin Narayan (1993) who argues against the "fixity" of distinguishing between the "native" and the "non-native" (Narayan 1993). Moving beyond the paradigmatic emphasis on a dichotomy of native and non-native, Narayan holds that we, "might more profitably view each anthropologist in terms of shifting identifications amid a field of interpreting communities and power relations" (Narayan 1993, 671). Narayan's position is critical to this dissertation as it permitted the opportunity to recruit participants and establish connections while granting participants the opportunity to relate and build their conceptualizations based upon my own subjectivity and identity. As such, I believe that my reflective contributions, mainly captured through photography, that reveal my own self-ethnographic moments, are essential to this dissertation as well as the overall methodology integral to this work.

\section{Theoretical Framework}

Central to this dissertation is understanding the varying conceptualizations and articulations of blackness and Diaspora, the production/reproduction of black subjectivity/identity that stems from these conceptualizations and articulations, the production and construction of place, the politics of belonging and the role of material culture and affect in establishing a sense of place and identity. Keeping with this dissertation's interdisciplinary mixed method approach, the theoretical framework that informs this research encompasses three fields of study. Anthropological approaches to the African Diaspora highlight the significance of black subject-making and identity formation as those in the Diaspora continue to confront global processes that compel 
multiple voluntary and involuntary migrations and movements (S. Hall 1997a; P. C. Hintzen, Rahier, and Smith 2010; Rahier 2010; Clarke 2010; Clarke 2006; M. Wright 2010; Zeleza 2009; Queeley 2015b; Ong et al. 1996; Brettel 2008). Theoretical understandings of Diaspora are critical to an exploration of the black immigrant experience and identity and subject-formation. Blackness is articulated in multiple ways throughout the diaspora (S. Hall 1990; S. Hall 1997a; Rahier 2003; P. C. Hintzen, Rahier, and Smith 2010; Rahier, Hintzen, and Smith 2010; M. M. Wright 2004; M. M. Wright 2015; Wade 2010; Tate and Law 2015). Throughout this dissertation, I explore the implications of the many articulations of blackness as black immigrants navigate the city and intersect and interact with black Americans.

Critical to this dissertation is Stuart Hall's (1997) assertion that it is through the simultaneity of sameness and difference that Diaspora presents a framework for the production of cultural identity as well as hybridity, heterogeneity, and diversity (S. Hall 1990; S. Hall 1997b; S. Hall 1997a). Just as Diaspora is constantly reproduced, invented, and reinvented (Zeleza 2009; P. C. Hintzen, Rahier, and Smith 2010), Hall (1990) contends that identity itself should be thought of as a production that is always constituted within representation (220). Hall offers two interpretations of cultural identity; the first positions cultural identity as a "shared culture, a sort of collective 'one true self' with a shared history and ancestry" (S. Hall 1990, 223). This sense of "oneness" is critical to artistic, visual and cultural representations of the black experience. While the second interpretation of cultural identity recognizes similarity, this position operates through "critical" and significant points of difference in that "we cannot speak for very long with any exactness, about 'one experience, one identity"' without 
acknowledging the "ruptures" and "discontinuities" within the Diaspora (S. Hall 1990, 225). In this sense, cultural identity is always "becoming," and undergoing transformation while also "being" wherein identities "are the names we give to the different ways we are positioned by, and position ourselves within" particular narratives of the past, present, and future (S. Hall 1990, 225). The tug of war between as well as the coexistence and acceptance of sameness and difference is critical to several of the central arguments in this dissertation, particularly in the last three chapters.

Although sociological approaches to the black immigrant experience in the U.S have attempted to shift from assimilation theory, the dominant paradigm in the mid $20^{\text {th }}$ century, a great deal of studies and theories within the field continue to highlight ethnicity and segmented assimilation in emphasizing a contentious relationship between black immigrants and black Americans (Waters 2001; Waters 1999; Portes and Zhou 1993; Portes and Rumbaut 1995; Heisler 2008; Vickerman 2001; Rogers 2001). While these theories and subsequent studies are not completely unfounded, the methodological approach to immigration within sociology often continues to be a "data-driven field" that focuses on a generalized group rather than individual experiences (Heisler 2008). In conjunction with the the field's persistent emphasis on variations of assimilation these sociological approaches to immigration disallow an understanding of the nuances of black immigrant subjectivity and identity (Pierre 2004). I rely on Jemima Pierre's (2004) interrogation of the "discursive" usage of black immigrant ethnic and cultural distinctions that perpetuate a black American "culture of poverty" by scholars such as Mary Waters (2001) Portes and Zhou (1993), Portes and Rumbaut (1995), and Rogers (2001), to further critically assess canonical works within the field of sociology that address black 
immigrants and black Americans. Considering the gaps and debates within sociological and anthropological theories, this dissertation presents a different perspective of the black immigrant experience within a new and understudied context.

Lastly, scholarship within the field of cultural and human geography offers critical and engaging theories on the role of space, place, material culture and affect on identity and subject-formation. Bourdieu's (1984) theory of habitus underlines much of the theoretical contributions to this dissertation's focus on material culture, place and space as well as furthering our understandings of respectability and difference. Daniel Miller (1987) argues that the non-negotiable cultural ordering produced through habitus leads to a sense of identity among those who share a particular habitus (Miller 1987, 104). According to Miller's (1987) assessment of material culture and consumption, objects as a "physical form" mediate between the subjective and objective worlds, as such, objects gain symbolism and become instruments of social strategy (Miller 1987, 106). At the same time, objects possess a "high degree of flexibility" wherein the significance and symbolism of the object depends upon the social positioning of the interpreter as well as the context (Miller 1987, 106). This dissertation presents the ways in which the material culture exchanged and the material setting of places of consumption serve to distinguish group identity and or enact/represent a sense of collective identity. Appadurai (1986) defines commodities beyond a Marxist conceptualization, which views commodities as goods and services exchanged simply based out of utility and necessity. Appadurai views commodities as any good or service with social relevance, that comes attached, most often, with a social biography. 
Nigel Thrift's (2008) presentation of Non-Representational Theory (NRT) helps to emphasize the role non-human actors play in particular moments and fleeting encounters such as shopping, eating and other practices and routines in this dissertation (Thrift 2008). NRT allows a phenomenological approach to understanding the ways in which non-human actors such as food, clothes, art and material setting become embodied and hold the potential to activate human affect. Therefore, through subjective practices such as shopping, eating and "hanging out" affects such as love, happiness, anger, disgust etc. are triggered and transmitted leading to a consciousness beyond the individual (Miller et al. 1998; Thrift 2008; Brennan 2004). These theories come to the forefront in Chapters Four, Five, and Six, each of which center extensively on the ways in which material culture and material setting trigger affects that significantly impact and reflect black subject-formation.

\section{Chapter Overview}

In Chapter One, The Queen City's New South, I interrogate the concept of the New South and present a detailed history of Charlotte, and how it came to be known as the New South. Through a detailed and historical analysis of the city's race relations, transforming cultural and racialized landscapes, economic growth and subsequent demographic shifts, I more critically engage with the multiple meanings and uses of the New South. Situating the accounts of my participants within this analysis, I contend that we must consider the New South beyond the very basic definitions provided by city leaders, regional scholars and institutions and instead understand the New South as an ontological fact, an epistemology, a discourse, an ideology, and a set of practices. 
Presenting the New South through a more nuanced theoretical prism allows a deeper understanding of what the New South means for my participants as they live, work, and navigate the city of Charlotte. I further explore what the current events and policies signify for interpretations of the New South by black and brown subjects. Lastly, I detail the social, racial, and economic transitions of East Charlotte, and how the area evolved into a trans-ethnic enclave. My discussion of East Charlotte engages existing literature on Latino immigrants and place-making in Charlotte (O. Furuseth, Smith, and McDaniel 2015; Schuch and Wang 2015), particularly in East Charlotte and South Blvd. as well as recent demographic data.

In Chapter Two, "Black is Black"...Or is it? Unraveling the Simultaneity of Sameness and Difference among Black Americans and African and Caribbean Immigrants in the U.S. South, I explore the implications of a common phrase used by my participants, "black is black." Participants often used this phrase when relaying their understandings of blackness and the differences in being black in their countries of origin, prior destinations of residence in the U.S., and in the U.S. South. Suggesting both sameness and difference, the phrase often served as a disclaimer before participants expanded upon cultural differences and/or what I highlight as "cultural differences", the latter I argue, is a more loaded term that signifies the deployment of the myth of the model minority, respectability, and the ethnicity paradigm (Pierre 2004; Omi and Winant 1994; P. C. Hintzen 2001). I expand upon the ways in which these concepts and practices underscore what Hintzen (2001) refers to as a discourse of difference. Therefore, in this chapter I further problematize a great deal of immigration theory that has perpetuated and characterized black American culture as a pathology (Waters 1999; 
Rogers 2001; Vickerman 2001; Foner 2001). In doing so, I argue that a trope of difference operates to distinguish black immigrants from black Americans however, black subjects despite ethnicity have historically performed and claimed difference as a strategy to distinguish themselves from the masses. I develop this argument by reflecting on my own positionality in this study and in my interactions with my interlocutors, who often claimed that I was different from other black Americans based on my perceived socioeconomic background and education. Underlining this trope of difference are notions and performances of respectability (Frazier 1957; Queeley 2015a; Greenbaum 2002; P. C. Hintzen 2001). Lastly, I explore the ways in which inter- and intra- ethnic differences establish and reflect socioeconomic hierarchies that ultimately define boundaries and collectivities among black immigrants and black Americans.

In Chapter Three, What Are You? Seeing the Invisible and the Liminal: AfroLatinos in Charlotte, I explore the experiences and accounts of Afro-Latinos as they navigate race in the U.S. South. Posing an anomaly to many native southern residents, Afro-Latinos are oftentimes plagued with the question of, "what are you?" It is important to acknowledge that one of the main challenges in locating Afro-Latino participants for this research was the initial usage of the term, "Afro-Latino" as many may not identify with the term, or with their African heritage, or the term is simply unfamiliar. As a result, I relied on the accounts of those who specifically identified as either Afro-Latino or Black. Critical to this chapter is a discussion of race and processes of racialization in Latin America and the Caribbean and the ways in which these understandings shape and/or reshape Afro-Latinos' understandings of blackness as well as themselves in the U.S. South. U.S. Census Data further complicates identifying these populations as they 
are homogenized under the category of Latino/Hispanic rendering these populations invisible. Based upon my findings, I contend that Afro-Latinos occupy a constant state of liminality (Bhabha 1994). In accordance with Homi Bhabha (1994) within the "liminal space" there is "no singular self-image" and "no necessary or eternal belongingness" allowing for the opening of "new forms of identification that may confuse the continuity of historical temporalities, confound the ordering of cultural symbols, and traumatize tradition" (Bhabha 1994, 257). Lastly, in this chapter, I introduce Carolina, a selfidentified Afro-Brazilian/LatinX who is also part of the LGBTQ community. Carolina initiates a discussion that I bring to the forefront in Chapter 6 that centers upon the implications of citizenship, sexuality, alterity, and blackness in creating meaningful spaces and places of belonging that foster solidarity among black and brown subjects.

Chapter Four, Chitterlings, Fufu, and Curry: Diaspora Wars and the Implications of Affect, begins inside of Sierra International Mart where the owner, Mrs. Tina, elaborates on the disgust displayed by black Americans who walk by or enter her shop and comment on the smell of dried fish that she brings from Africa to sell at her East Charlotte store. I apply the work of scholars such as Sara Ahmed $(2000,2005)$ to demonstrate the ways in which certain smells, sights, and sounds trigger affects such as disgust and fear that ultimately construct boundaries between black immigrants and black Americans. Critical to this aspect of the dissertation is understanding the agency of nonhuman objects in triggering affects and shaping identities and subjectivities (Bennett 2010; Thrift 2008; Miller 1987; Brennan 2004; Ahmed 2005; Duruz, Luckman, and Bishop 2011). With respectability as a critical underlying factor, I build upon E. Franklin Frazier's (1957) argument that black Americans' performance of respectability endeavors 
toward a desire to appear as "Super Americans." I argue that for Black Americans, certain foods and their accompanying smells construct a sense of certain places as not only foreign, but un-American. On the other hand, fear and disgust also establishes intraethnic boundaries between those black and brown bodies deemed unsafe, illegal and foreign and those perceived of as respectable, esteemed, and safe. Building upon the concept of the trope of difference presented in Chapter Two, Chapter Three also holds that black subjects globally find themselves enacting narratives of respectability in order to distinguish themselves from the various iterations of pathological blackness in a quest for acceptance from the dominant group (Greenbaum 2002; Wilson, n.d.; Frazier 1957; Queeley 2015b). Lastly, in focusing on material culture, food, cultural expressions, and affect, I explain what I call Diaspora Wars; on-going cultural wars between black subjects from Africa and the Diaspora over appropriation, respectability, behavior and performance. I contend that Diaspora Wars are painful, yet necessary inter- and intraethnic battles that must be fought and overcome on the road toward building a collective diasporic consciousness.

In Chapter Five, Diaspora Love: Intersections, Interactions, Solidarity and the Makings of an Alternative New South, I begin to unfold the central arguments of this dissertation. Chapter Five begins with an illustration of a night at SuCasa, a monthly party held at Petra's Piano Bar in East Charlotte. Designated not only as a safe space but a diasporic space by the event's creator, Jasiatic, SuCasa offers a space of belonging for black and brown subjects in Charlotte. The sonic and visual elements constructing the space and the affects that emanate from this material setting are indicative of what I define as Diaspora Love. In contrast to Diaspora Wars, I contend that while Diaspora 
Love often manifests itself in spaces, places and times that helm an essentialist Black identity, it is simultaneously "the politics of living identity through difference" or "the politics of recognizing that all of us are composed of multiple social identities, not of one" (Hall 1997:57). In turn, this chapter examines those spaces, places and times in which these two paradigms of blackness and diaspora, essentialist and anti-essentialist, serve the construction of meaningful spaces and places of belonging for black subjects in Charlotte. Further, I utilize Alaí Reyes-Santos (2015) notion of a transcolonial kinship model informed by an affective matrix of "sympathy, empathy, harmony, compatibility" as well as notions of "brotherhood, friendship, national family and extended family" in the Antilles to put forth what I see as an affective kinship among black subjects in East Charlotte. Building upon what Reyes-Santos presents as a transcolonial-alter-native community established through kinship and that shifts agency from the colonizers to the colonized, I assert an East Charlotte trans-ethnic-alternative New South. I base my arguments on my observations at the House of Africa during the planning of the Annual Juneteenth Festival of the Carolinas and the festival itself. I emphasize that the House of Africa and the Annual Juneteenth Festival of the Carolinas demonstrate kinship formations rooted in Afrocentrism. On the other hand, Reggae Central, just around the corner from House of Africa, represents a diasporic space that is more representative of anti-essentialist thought catering to those from across the diaspora. At the same time, at both the House of Africa and Reggae Central, it is the space and material setting that serves to trigger an affective kinship. Also, at both boutiques, women emerge as central figures or, within the realm of kinship, as mothers who foster and nurture the transethnic-alternative New South. 
In Chapter Six, Embodied Borders: Food, Music, Dance, Fashion and Other Things in the "Borderlands" of the New South, I continue to build upon the key arguments put forth in Chapter Five. Chapter Six begins again at SuCasa, this time, focusing on Jasiatic, the mastermind behind the event and a black American woman, similar to the women that emerge in Chapter Five. In drawing more attention to the purpose and intention behind the construction and maintenance of SuCasa, I extend the concepts of affective kinship and a trans-ethnic-alternative New South introduced in Chapter Five. There are several key theories that I use in order to fortify these arguments. First, I rely upon Nassy Brown's (2005) assertion that kinship acts as a "vehicle of racially transgressive practice" wherein race exists as politic constitutive of "racialized geographies of imagination" (Nassy Brown 2006, 34, 76). Second, Gaye Theresa Johnson puts forth the idea of "spatial entitlement." I argue that both kinship and spatial entitlement constitute both ritual and borders. With this, I apply Michel Agier's (2016) reconceptualization of borderlands that moves beyond traditional geopolitical designations to posit the trans-ethnic-alternative New South as a borderland. Conceiving of borders and particular "border situations" as "good for living", leads us to consider what Agier calls "border dwellers", those of whom I would align with cultural workers, agents, mediators like Jasiatic. It is through this conceptualization of borders that I further argue that the trans-ethnic-alternative New South is indicative of a cosmopolitan condition as it is composed and compiled by "the experience of those men and women who experience the concreteness and roughness of the world", the "ordinary experience" of "crossing borders", and those border situations in which "the relationship with the other is put to the test" (Agier 2016, 76). Like Reyes-Santos trans-colonial kinship model, 
this concept (re)allocates the agency of the city, the city's being, and its cosmopolitanism to those black and brown subjects that occupy and create the borderlands of the alternative New South not policy-makers nor corporate entities. I illustrate these arguments with extensive ethnographic moments at SuCasa, Afropop, the Brazilian Arts Center, Queen's Collective, and Satisfy, a monthly dinner party also hosted by Jasiatic. In keeping with the central themes of this dissertation, I emphasize the role of food, fashion, music, and affect in fostering a collective diasporic consciousness that embraces the simultaneity of sameness and difference among black subjects.

The Conclusion culminates these central arguments and reiterates the central contributions and significance of the dissertation. Entitled, Black Futures in the South, I posit the need for additional future research on both black and brown populations in the trans-ethnic-alternative New South. 


\section{CHAPTER ONE}

\section{THE QUEEN CITY'S NEW SOUTH}

"When asked about their perceptions of race in Charlotte and North Carolina, Mark noted that the South had lived down to his low expectations in terms of race, saying that [white] people do not like black people, especially him, who tended to be more outspoken. On the other hand, Clinton felt that it was not as bad as he had imagined prior to coming. Mark suggested this was due to Clinton's calm nature, lighter complexion and ability to get along with anyone."-Bennett, Field Notes from the “Corporate Diverse Happy Hour Crew” Focus Group, 31 May 2017

"The norm in Charlotte is like...racism is still huge. I find out they talk to you any kind of way thinking it's acceptable. They don't think you should have an opinion, just stick with the "yes sir" and the "yes mam" mentality when I feel that you know if we [are] supposed to be a "bible belt" why is there so much racism still in Charlotte? Why can't we just practice what we preach? Racism is not in the bible. I'm used to the social class racism, which is abroad [in Haiti]. However, racism to me, is so shocking because I thought we had overcome those boundaries so [much so] where we have a black president in office. Why is there still so much racism in a place that preaches the gospel, you know? You can't turn on the radio [without] a couple of gospel songs thrown in there so why is it not-why is it not in our daily lives that the gospel is preached?"-Flor, Haitian, June 2015 
The above accounts reveal conflicting black experiences in the New South. While Flor (Haitian) and Mark (Jamaican) experience Charlotte as strikingly racist, Clinton (Jamaican) does not appear to process his experiences in the city in the same manner. According to Mark, this difference in perception and reality is due to Clinton's lighter complexion and calm nature as opposed to Mark who identifies himself as more outspoken and is also of a darker complexion. Further, the above accounts are also underlined by a conflict between New South rhetoric versus New South reality as it pertains to black subjects. Electing to not be recorded during their happy hour, but to instead casually converse without formalities, my first account highlights excerpts from field notes taken during conversations and observations with a diverse corporate happy hour crew at a popular bar/restaurant located in University City, northeast of East Charlotte. Convening each Wednesday after work, Mark and Clinton both from Jamaica, are part of this diverse, predominantly black group of corporate professionals from the same corporation located in University City, the city's other corporate hub. Mark and Clinton transferred to Charlotte from New York City through their corporation but offer different perspectives of the city of Charlotte. Mark suggested that Clinton's "nature" as well as his lighter complexion shifts his lens of the city's sociocultural realities. For Mark, despite the New South image put forth by local leaders and policy-makers, there exists little difference between contemporary Charlotte and surrounding neighborhoods and the staunch racism that defined the Old South. Mark felt that "the South came to his doorstep" first during the 2008 Obama/McCain presidential campaign when a white waitress asked him if he voted for Obama before serving him. Further, Mark asserted that "the most segregated time in the South" is on Sundays between 10am and 12pm, 
where "southern gentlemen hide using the church as a guise for racism and bigotry." Mark continued, recollecting an instance during the last presidential campaign between Donald Trump and Hillary Clinton, in which he went for a walk in his suburban neighborhood and saw "Benghazi" spray-painted on the sidewalk of a neighboring Hillary Clinton supporter's home. My participant Clinton on the other hand, responded, "I don't give a shit about politics," contending that if he's in need of help, he will accept help from a "redneck" if necessary, recalling a time that "rednecks" once helped him when he had car trouble. Clinton's experience and understanding is not unfounded. In fact, Clinton's embrace of, or contingent faith in "rednecks" in contrast to Mark's distrust and low expectations of the region's progression in terms of race relations and politics is very much part of the perplexities that bely the New South. Since the establishment of the institution of slavery in the U.S. South, a paradigmatic coexistence has subsisted between blacks and whites; a relationship characterized by a complex intertwinement of interdependency, intimacy and trust alongside hatred, fear, and violence. The paradox of southern politics and race relations is furthered by the region's stronghold in Christian conviction. A hotbed of Southern-Baptist evangelism, Charlotte could almost be viewed as the capital of the "Bible Belt" as it is the birthplace of Billy Graham, arguably America's most well-known evangelical. Piety, reverence, and an adherence to tradition underline the sociocultural nature known as "southern hospitality"; a cultural phenomenon that continues to define aspects of the New South. Mark and Clinton's diverging experiences correspond with the dialectical combination of historical relationships between the oppressor and the oppressed, the hypocrisy of Christianity and white supremacy, and the notion of southern hospitality, all of which underscore the 
multiple contradictory experiences and realities that black subjects living in the New South confront. In this chapter, I explore these confrontations and the implementations of such on the formation of black immigrant identities and subjectivities.

Flor is a middle-aged Haitian woman who moved to Charlotte from Miami to be with her African American husband, and has lived in the city for about seven years. Charlotte promised a better life at a lower cost of living than Miami. For Flor, remnants of the Old South are evidenced through an on-going treatment of and expectation of black obedience and subservience to whites. This contradicts the very principles of Christianity, which Flor highlights by asserting "racism is not in the bible." Yet, within the paradox of southern society, or the "Bible Belt," religion, Christianity especially, (including Baptist, Presbyterian, Methodist, Episcopalian, African Methodist Episcopal, AME Zion, and [Holiness] protestant non-denominational) is one of the primary prisms through which racism is built and sustained. Intra-racially, the many genres of Christianity within the black community in the South also strictly maintains varying forms of respectable behavior and dress that may or may not adhere to southern black religious stipulations. Still, Flor's relocation to Charlotte from a major gateway city, much like Mark and Clinton coming from New York City, indeed signals Charlotte's growth and position as a "pre-emerging gateway city" and aligns with its designation as the New South. North Carolina is the $9^{\text {th }}$ fastest growing state in the U.S while Mecklenburg, Union and Cabarrus Counties (all part of the Charlotte metropolitan area) are among the fastest growing counties in the state, with net migration as the major cause of population growth, which is predicted to continue at 10 percent. This growth is double the national rate (Gill 2010; Graves and Smith 2010). Further, as of July 2014, Mecklenburg County surpassed 
the 1 million-population mark (UNC Carolina Population Center 2015). Today, nearly $21.4 \%$ of the city's population is foreign born, with almost $13.1 \%$ of that population identifying as Latino/Hispanic "regardless of race" (U.S Census Bureau 2013). Also, the growth of Charlotte's corporate industries and white-collar positions as well as specific programs such as the NC Department of Social Services Refugee Assistance Program and Carolina Refugee has led to a prominent influx of immigrants from continental Africa, specifically, Liberia, Nigeria, Ethiopia and Eritrea. Historically, Charlotte has measured its economic and demographic growth against Atlanta, a four-hour drive south. At the same time, as the South's other major financial and cultural hub, Atlanta's population has remained stagnant over the last 10 years while Charlotte's population has continued to grow, fueled in part by migration, making the new destination city a critical site for research. Further, the higher cost of living in Atlanta has pushed migrants upwards to Charlotte while the lower cost of living in Charlotte has appealed to black as well as white Americans from the North. These changing demographics imply major shifts within the racial, cultural, economic, and political spectrum of dominant southern cities such as Atlanta and Charlotte. Considering these implications within the context of Charlotte, immigrants of African descent are thrust not only into shifting local and regional power relations but into competing notions of Old and New South cultures and ideologies. The accounts provided by Flor as well as Mark and Clinton stand as examples of these conflicting sociocultural realities and the fact that for black subjects the New South is still a distant concept. At the same time, the fact that Flor, Mark and Clinton now call Charlotte home symbolizes the reality that neoliberalism and globalization are indeed at work in producing and fostering another aspect of the New 
South. This chapter unravels Charlotte's legacy of contradictions, the multiple meanings of the New South, the potential implications of these historical and contemporary factors on the formation of black identities and subjectivities, and the construction of space and place.

The Levine Museum of the New South has been exceedingly instrumental in forging and publicizing the concept of the New South. The museum puts forth the following as a description and definition of the New South:

"A Time-The New South is the period of time from 1865, following the Civil War, to the present. A Place-The New South includes areas of the Southeast U.S. that began to grow and flourish after 1865. An Idea-The New South represents new ways of thinking about economic, political and cultural life in the South. Reinvention-The New South encompasses the spirit of reinvention. The end of slavery forced the South to reinvent its economy and society. People- The New South continuously reinvents itself as newcomers, natives, immigrants, visitors and residents change the composition and direction of the region" ("Levine Museum of the New South; Who We Are" 2016). This is perhaps one of the most fundamental understandings of the New South. However, in this chapter I argue that it is necessary to understand the New South as a more complex concept that moves beyond this very basic definition. I argue that we must consider the New South as an ontological fact, an epistemology, a discourse, an ideology, and a set of practices. Presenting the New South through a more nuanced theoretical prism allows a deeper understanding of what the New South means for myself as well as my participants as they live, work, and navigate the city of Charlotte. In order to deliver a healthier 
reckoning of the New South, in this chapter I explore and apply a great deal of diverging theoretical perspectives, primarily those theories within the field of cultural geography. By highlighting my participants' accounts, black American and immigrant, that revolve around their experiences of and relationships with space and place in Charlotte, I aim to present the implications of the varying meanings of the New South on black subjectivity and identity. In addition, demographic and GIS data further complicates the image and notion of the New South presented by the Levine Museum and policy-makers. In turn, this chapter interrogates the murky distinctions between the New South and the Old South and how these realities shape and reshape black identities and subjectivities and the the construction of spaces and places of belonging. In order to disentangle the multiple interpretations of the New South, we must first explore its beginnings, keeping in mind that beginnings are subjective depending on who, what, and when. Critical to my goal in writing this chapter is expressing the constant uncertainty of what and when the New South became/becomes and who/when the concept applies.

\section{The Birth of a Queen City: Charting a Southern Ontology}

The Levine Museum appears to define the New South as a new ontology, separate from that of the Old South. Their definition implies a new idea and a new time; a contemporary and different social, cultural, and political era. Time, here, is not simply a manifestation of numerical years that differentiate an era. Instead, time appears as a layering of social, cultural, and political happenings that distinguish the Old South from the New South. Time as a chronology has been prodigiously conflicted and contested through multiple physical, social, and theoretical studies that yield it as both a concrete 
reality as much as it is a simple production of man, the mind, and structure (M. Wright 2010; Mitchell 1995; Ben Anderson and Harrison 2010; Nassey Brown 2005; Marston, Jones III, and Woodward 2005). For now, I contend that the New South is indeed a new and separate ontology, perhaps making it an ontological fact, albeit extremely limited in its particular ontological conceptualization and existence. A new ontology, or ontological fact would suggest some thing, i.e. concept, agency, or relationship(s) between subjects, objects, or subjects and objects that is completely distinct and separate from others (Latour 2014; Marston, Jones III, and Woodward 2005; Mitchell 1995). To expand upon my interpretation of a new ontology, I look to Latour's (2014) analysis of a potential theoretical "ontological turn." Latour argues that for early philosophers such as Locke, there existed an "ontological distinction between what came to be known as primary quantities - real, invisible, emptied of values - and secondary qualities - full of values, accessible to the senses but unfortunately devoid of any reality. Such a bifurcation of nature, to use Whitehead's (1920) qualification, created for the Moderns a very puzzling and uncomfortable situation, since they now had to choose between a 'conjecture' - primary objective qualities — and a 'dream' - the secondary qualities' (Latour 2014, 302). It is possible to contextualize primary quantities and "primary objective qualities" versus secondary qualities within the contrasts of quantitative and qualitative data demonstrative and interpretative of the Old and New South. In viewing the New South as an ontological fact separate from the Old South, there are limitations. In other words, we can only argue that the New South is an ontological fact based upon economic shifts between an agricultural/textile-based economy to industrial/neoliberal/corporate based economies. A brief history of Charlotte's economic 
growth allows us to better grasp the evolution of the New South into a separate ontology signaled by economic and demographic shifts.

Nested within the rolling hills of North Carolina's central piedmont between the Appalachian mountains to the west and the sweeping coastal plains of the Atlantic to the east, Charlotte was once a small hilltop site that existed at the intersection of two Native American trading paths, now Trade Street and Tryon Street located in present Uptown. The first white settlers arrived in Charlotte in 1753 and established a small village with accessibility to inland trading paths en-route south to the port of Charleston, S.C (present day Interstate 77), and north into Virginia (present day Interstate 85) (Hanchett 1998, 14). The settlers named the new village in honor of England's Queen Charlotte, and would later name the county Mecklenburg, after the Queen's birthplace, Mecklenburg-Strelitz, Germany. In 1768, the official city charter was signed, establishing Charlotte as a courthouse town (Hanchett 1998, 14). After the American Revolution, Charlotte began to grow as a mill town and trading post. Toward the very end of the $18^{\text {th }}$ century, nearly 50 years before the legendary gold rush that drew hundreds of thousands of people to California, gold was discovered about twenty-five miles east of Charlotte and the city became the trade center for America's first gold-producing region (Hanchett 1998, 15). Charlotte's gold strike was short-lived, albeit two banks were erected to manage the surge in wealth. The city's gold rush may have been fleeting, but slavery burgeoned in the U.S. South and king cotton reigned in the rural areas of Mecklenburg County and surrounding counties in the piedmont and coastal plain. With the invention of the cotton gin in 1793, by 1802 Mecklenburg County led the state in the number of cotton gins. The 
construction of the railroad in the mid 1800s would solidify the town's emergence into a center of textile production and agriculture milling.

The end of slavery marked a new era in the U.S South and during the 1870 s until the 1920s, Charlotte would transform itself from a "rural courthouse village" into a trading and financial hub (Hanchett 1998, 2). This economic transformation was due to several critical factors that made Charlotte unique from the rest of the South during this moment in history. Withstanding the devastation that wrought the rest of the South following the Civil War, Charlotte and its railway connections remained largely intact due to its insulated geographical location. In turn, the cotton trade resumed almost immediately after the war and money began to pour into Charlotte while the rest of the South searched for ways to pick up the pieces (Hanchett 1998, 25). Ten years after the war, Charlotte was the busiest inland cotton market in the Carolinas and by 1930, the city would surpass Charleston to become the largest city in the Carolinas (Hantchett 1998, 25,90). Charlotte built its banking credentials on the role that local capital played in financing local and regional textile mills (Goldfield 2010, 12). These realities laid the foundation for Charlotte's population growth, the onset of industrialization and urban development. By the $20^{\text {th }}$ century, these elements would propel Charlotte to a vanguard of "neoliberal globalization" and a pre-emerging gateway city in the South (Ellen et al. 2008). These factors serve to construct a New South ontology separate from that of the Old South. However, as mentioned this designation is limited to its economic and demographic transformation.

According to the Levine Museum, the New South began with the end of the Civil War, blossoming during the Reconstruction era. The museum's definition designates a 
specific time, beginning in 1865 , "following the Civil War to the present" within a region that grew and flourished following this time frame. Yet, for who did it grow and flourish? Further, the museum defines the New South as representing "new ways of thinking" in the South and a "reinvention" that ensued after the end of slavery compelled the South to "reinvent its economy and society. Again, I ask for whom did these definitions apply at this particular and poignant shift in history? Numerous confederate flags that fly in official political places and spaces as well as streets, monuments, and namesakes dedicated to confederate officials in Charlotte and within the region as a whole fail to implicate any concrete ideological or even historical shift. For blacks, the Old South signaled not just slavery but the continuation of physical, sociocultural and political oppression through Jim Crow segregation built upon a racial binary constituted by the "one-drop rule", and a reliance upon agricultural means of production of which they felt the brunt. What the Levine Museum conceived of as "reinvention" was merely a continuation for black people. Hence, for black children who came of age in and around Charlotte, the Old South did not end in 1865. My mother is the youngest of thirteen children born to a share-cropper and domestic worker in Monroe, N.C. about 20 miles from Charlotte. Born in 1952, she would be among the first to integrate Union County's schools in 1966, 14 years after Brown, and only consequentially after the black school burned down. Remarkably, my mother's family would come to own a healthy plot of land right of what is now highway 74, Charlotte's major southeast thoroughfare. My father is the middle of seven children born to a mother who worked as a domestic worker and who along with her husband would move to Youngstown, Ohio during the first Great Migration, where my grandfather worked in a steel factory before becoming partially 
blind. My grandparents would return to Winston-Salem, North Carolina where my grandfather worked in a tobacco mill before going completely blind. They would return to Anson County, which once encompassed what is now Charlotte, Mecklenburg County, located on the outskirts of the Great PeeDee River, a major Native American and later settler-trading route. Born in 1941, my father was only able to attend school seasonally, the remainder of the months dedicated to "cotton pickin' time." Photographs of his younger siblings idly standing, sitting and playing amongst cotton flowers serve as proof. For my father, there was little difference between his childhood and the stories he heard of slavery. This was not the New South.

The Levine Museum's definition suggests that the New South is an "idea" and a "re-invention" both of which imply a shift in social and racial relations after the end of slavery. This assumption veils the distinctions between white southern thought/culture and that of black southern culture and realities. For many white southerners, the Old South represented the "good ol' days" of a precapitalist and feudal society where a hierarchical paternalistic society gave way to decent relationships, manners, and behavior that represented "joviality and conviviality" with whites atop of this hierarchy monitoring these relationships and behaviors (Hoelscher 2006:47). The New South attempted to challenge this, however white southerners have continued to cling onto the collective memory of a "white-pillared past." The erection of various statues and street names dedicated to those icons of the Old South, like Stonewall Jackson and Jefferson Davis continue to mark cultural and racialized landscapes (Hoelscher 2006, 47). In Uptown Charlotte, Stonewall St. runs parallel with Martin Luther King Jr. Blvd. and Stonewall Jackson Fire Station stands alongside Central Avenue in East Charlotte. Further, the 
surge in racial violence, particularly lynchings, beginning during the Reconstruction era in conjunction with Jim Crow laws that besought the early $20^{\text {th }}$ century can all be understood as white southerner's response to what was becoming the New South. Therefore, in many ways the ideas and changes proposed by the New South does seem to stand as an ontology that threatened and signaled the demise of an Old South ontology. However, the ideological and physically violent weaponry of the Old South continued to ooze into the New South. This reality confuses the notion of separate ontologies, or hinders the designation of the New South as a new "idea" and "re-invention" in terms of sociocultural relationships. However, economic and demographic shifts could indeed mark a separate New South ontology. Attempting to understand or define the New South as an ontology beyond these measures poses a threat to the social makeup of Charlotte society, as it minimizes the social and cultural realities that impact black and brown subject-formation as well as the ramifications of physical and racial segregation.

\section{"Didn't Think We Had It In Us": The "New" South, a Dangerous Discourse and a Cultural Ontology}

On the last day of Black History Month in 2017, I attended a discussion centered around the Levine Museum's latest exhibit “K(NO)W Justice, K(NO)W Peace.” The exhibit was a community organized exposé documenting the Charlotte protests that erupted in response to the September 2016 killing of Keith Lamont Scott as well as the numerous other black and brown lives shattered by police brutality. Upon entering the display room, a large photograph of a white queen looking into a broken mirror posed the question of "how did we get here?" Beneath this very powerful inquiry, a description asserts that the death of Scott and the subsequent events that took place over those few 
days were part of a larger complex history. The exhibit's introduction cited a 2014 study entitled, "The Equality of Opportunity Project" (O. Furuseth 2016). According to this study of upward mobility in the 50 largest cities in the U.S., Charlotte ranked dead last, making it the nation's "worst big city for climbing out of poverty" (O. Furuseth 2016). Moreover, in accordance with a 2018 study by the North Carolina Justice Center, Mecklenburg County is the number one most segregated school district in the state of North Carolina. Thus, the answer to "how did we get here?" initiates a larger interrogation of the New South.

Before entering the exhibit that evening, Brenda Tindal, the Levine Museum's first black woman Lead Historian led a discussion on the exhibit. Beginning the discussion, she posed the question to the small mostly black audience, "What is the New South?" Some responses suggested its economic transition as well as its demographic evolution from black and white to multicultural. Then, a black man spoke loudly from the back saying the New South was "a window dressing," a curtain that falsely veiled the past. Tindal nodded her head in agreement, and this assertion heralded the ensuing discussion. After relaying the signature definition of the New South presented by the Museum, Tindal recalled the aura of the city in the days following the Scott killing once the protests and riots were set in motion. She described a quietness and stillness in Uptown Charlotte never encountered in all of her years as a Charlotte native. Tindal went on to ask the crowd about their perspectives surrounding the protests. In an honest admission, a black man in the audience stated, "I didn't think we [the city] had it in us." For the Charlotteans in the room, this statement seemingly stood as a collective confession as the September 2013 killing of Jonathan Ferrell, another unarmed black 
man, and the subsequent 2015 acquittal of CMPD officer Randall Kerrick garnered little protest. The decision in the 2015 Kerrick case received minimal national media coverage, while the small group of people that gathered Uptown to protest appeared derisory to the public. Ferrell had been in a car crash in a wealthy southeast Charlotte neighborhood, after running to the nearest house, he banged on a door for help. An older white woman on the other end of the door called police to report a threatening black man banging on her door. Once the police arrived, Ferrell ran toward them asking for help. In response, he was tased by police and in accordance with police cam footage, Ferrell on his hand and knees debilitated by the taser was then shot at twelve times by Kerrick. Watching the local coverage and small-scale protests in response to this overwhelmingly tragic injustice, Charlotte citizens, myself included, all shared the unfortunate opinion that "we" didn't have it in us. September 2016 proved this dismissal wrong. Black Charlotteans could no longer be quelled by the lullaby of the New South. Still, the New South as a "window dressing" presents a poignant understanding of the ways in which the New South operates as a discourse that for its citizens, creates a particular way of knowing and ultimately of being. In other words, I argue that the New South functions both as a discourse and an epistemology. The September protests attempted to dismantle this discourse, or in other words, to raise the curtain. The idea of "I didn't think we had it in us" in many ways demonstrates the ways in which the New South discourse has shaped not only the perspectives of Charlotteans, but their identities and subjectivities as well. 


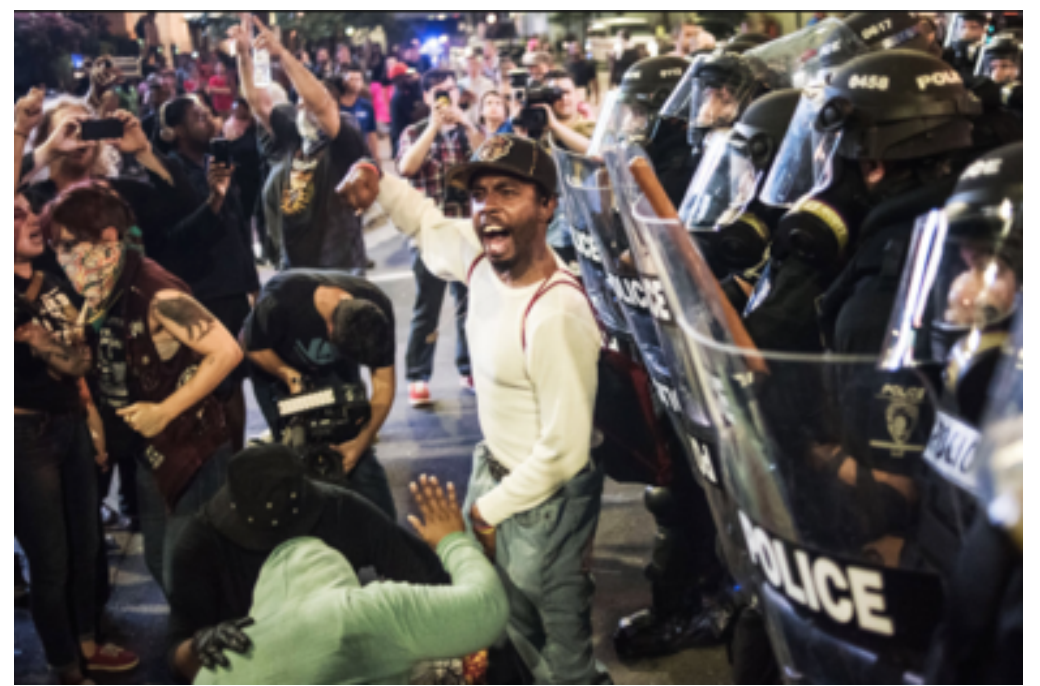

Figure 1.1. "Photos: Pain, Anger and Violence Fill the Streets of Charlotte, N.C.", Sean Rayford/Getty Images, National Public Radio, Inc., September 22, 2016.

Designating the Old South as the past and the New South as present when in fact Old and New South realities are intertwined represent what Willems-Braun calls "buried epistemologies" or "bad epistemic habits" that become naturalized as "common sense' in everyday relations and in social, economic, and political institutions" (Willems-Braun 1997, 5). Further, if we consider the New South as a culture, or a way of life and set of practices, then the construction of hierarchies of culture and the distinctions made between cultures are often a way to represent power, and culture itself becomes a discourse (Mitchell 1995, 108). Language, and in turn, discourse "structures the world by suppressing meaning" and instates "univocal and discrete meanings in their place" (Butler 1990, 108). Both the culture and language of the New South articulated by city officials, the Levine, corporate entities, and those invested in attracting tourists, and even 
accounts from middle class white and black residents alike suggest that it's diversity and warm, almost passive sociocultural relations, distinguish it from the Old. However, the Old and New South both mean different things to whites, blacks, immigrants, and to the city. In turn, the New South is interwoven as epistemology, discourse, and ideology. In other words, even if ideology operates in presenting a falsehood, discourse promotes ideologies that in turn become epistemologies and ways to explain particular ways of life; it is difficult to not perceive and discuss the concept of the New South without demonstrating how these aspects are entwined. To expand upon these conceptualizations of the New South requires further understanding of the social cultural, political, and economic history of Charlotte.

The city's post-Civil War ascendance in contrast to cities such as Savannah, Richmond and Charleston contributed to a discourse that upheld Charlotte as a nontraditional city while other southern port cities continued to cling onto a "faded past and eschewed new ideas" (Goldfield 2010, 12). Cities like Charlotte, Atlanta, Birmingham, and Nashville held the potential to represent the future of the South. However, as the Jim Crow era reached its peak in the 1950s and 1960s, Charlotte began early on to distance itself from the volatile confrontations that erupted in cities like Atlanta, Birmingham, Little Rock, and New Orleans. For Charlotte businessmen, the primary concern revolved around the issue of modernizing a region with a substantial black population. During the era of Jim Crow, Charlotte's black demographic represented almost $47 \%$ of the population. Today, black Americans are still 35\% of the population (Hanchett 1998; Goldfield 2010; US Census Data 2010). As a "solution," instead of utilizing the overt language of white supremacy that denoted the rhetoric of cities like Birmingham, the 
Chamber of Commerce applied a "progressive philosophy" that put forth the city as an "American city which is proud of its American people" despite race, religion, and class (Lassiter 2010, 27). Still, racial conflict and segregation were just as much of an issue for Charlotte as any city.

In September of 1957, Dorothy Counts was one of four black students to integrate all-white Harding High School, now a predominantly black school in Charlotte's West Side; photographs of her first day would make international headlines. Meanwhile, in the city of Monroe located about 20 miles southeast of Charlotte in Union County, now an extension of the greater Charlotte-Mecklenburg region, several major events transpired between 1958 and 1960. In the "Kissing Case" of 1958, two young black boys, ages 9 and 7, were accused of and found guilty of kissing, and ultimately the rape of a young white girl. The boys were sentenced to a potential term lasting until they were 21. After the case gained international attention as well as that of former first lady Eleanor Roosevelt, the young boys only served about three months in an adult jail where they were regularly beaten and abused by police officers. With the 1959 acquittal of a white man for the rape of a black woman and heightened harassment of local black Civil Rights leaders, the Freedom Riders made a stop in Monroe, although the Ku-Klux Klan almost immediately chased them out. These events compelled Robert Williams to form the Black Guard who took up arms to protect the black citizens of Monroe. Williams was eventually forced to live in exile in Cuba where he established Radio Free Dixie. In 1960, about 40 miles east in Greensboro, students from North Carolina Agricultural and Technical University staged the first major sit-in in the state. These sparked subsequent sit-ins in neighboring Rock Hill, South Carolina (about 20 minutes from Charlotte) and 
eventually among students at Johnson C. Smith University in Charlotte. Simultaneously, beginning in the 1960s "urban renewal" projects ensued through redlining and other methods that served to remove Charlotte's Uptown African American communities, then viewed as a stain on the progressive image of the city by politicians and investors (Ingalls and Heard Jr. 2010). Therefore, while the violent realities of other major southern cities did not come to full fruition in Charlotte, the city was not removed from racial confrontations.

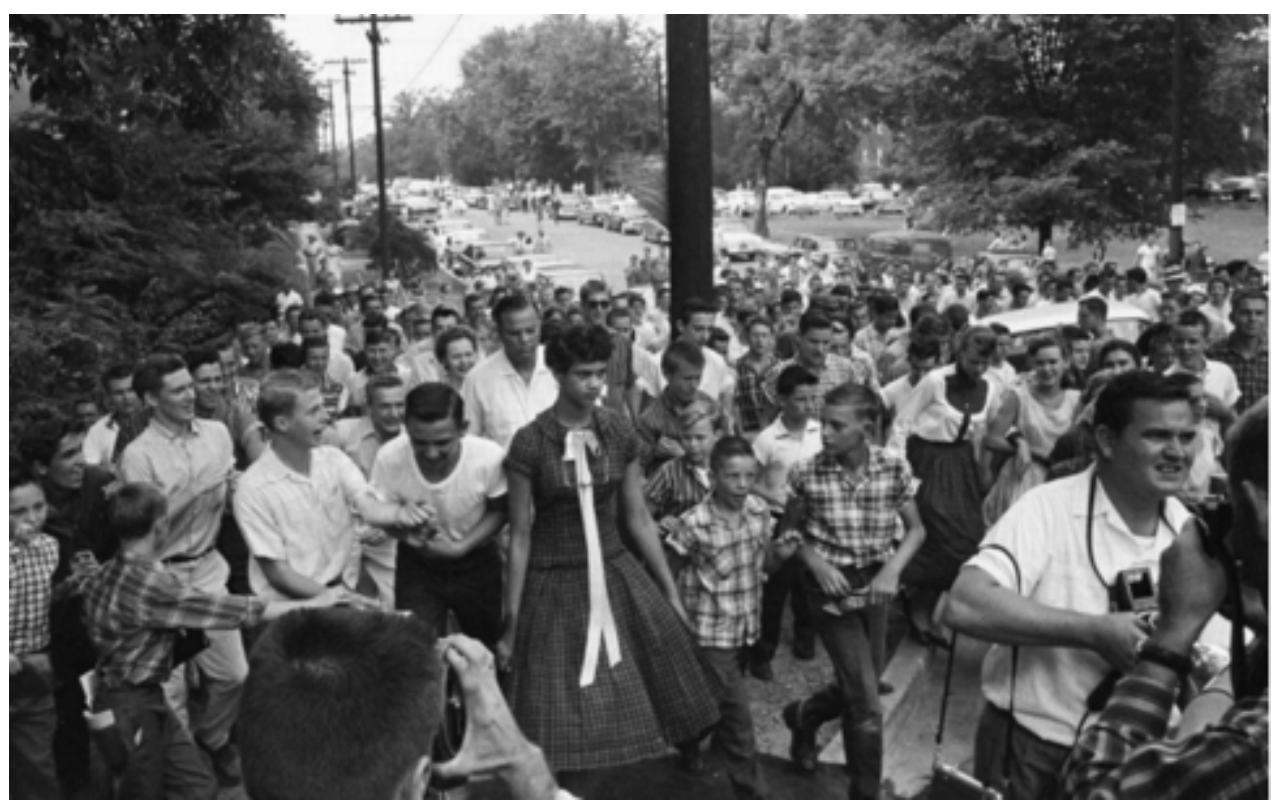

Figure 1.2. "The 1957 photo that garnered international news", Dorothy Counts integrates Harding High School (Tomlinson and Sturkey 2016)

These issues were conveniently omitted as Charlotte came to be seen as a potential player in the national economic panorama of the mid 1950s. (See Figure 1.2, angry mobs of white citizens in Charlotte attempt to discourage Dorothy Counts from integrating Harding High School). During this time, the Charlotte Chamber of Commerce created the motto "Spearhead of the New South," which emerged simultaneously with the 
rise of the Civil Rights Movement. Following the decision in Brown v. Board of Education, the Chamber of Commerce avoided any overt mention of civil rights as well as any recognition of the African Americans that constituted nearly one-third of the population at the time (Lassiter 2010, 29). Behind the scenes, the Chamber helped to organize a biracial forum that negotiated civil rights issues, established accommodations for the Civil Rights Movement in Charlotte, and facilitated desegregation before the passing of the 1964 Civil Rights Act (Lassiter 2010, 29). The Supreme Court decision with Swann v. Mecklenburg County, which successfully implemented busing to further desegregate Charlotte schools propelled Charlotte toward national acclaim as a city of "peaceful desegregation" marking the city as the "highest and best example in matters of racial transition" (Lassiter 2010, 29). The national applause from Swann fostered the city's encouraging dictum of "Spearhead of the New South" that both eloquently and conveniently draped the deeper more complex realities of its black subjects.

Nevertheless, desegregation in Charlotte marked a critical shift in the conceptualization of the New South. City leaders in the late 1960s, most notably, Mayor Stanford Brookshire, began to link economic growth with racial harmony while at the same time, corporate leaders acknowledged that their drive to recruit new industry to the Carolinas required a moderate stance on race relations. However, for many blacks, racial harmony remained distant. Despite this reality, the endeavors of Brookshire and corporate leaders birthed almost in conjunction with the city's sociopolitical acclamations concretized a New South ideology. Charlotte appeared to have effectively implemented a successful and peaceful racial transition with desegregation and in turn, successfully distanced itself from the images of vehement racists and victimized blacks that permeated 
national perceptions of the South while still maintaining a sense of southern hospitality and moderate climate. These aspects undoubtedly contributed to the establishment and proliferation of a New South ideology that became more and more attached solely to Charlotte than any other southern city. Charlotte's New South ideology emphasized an “enthusiastic willingness to abandon history altogether" (Lassiter 2010, 26). Without a past, Charlotte could now be whatever it wanted to be, which furthered the possibilities of the New South to be and build even more intricate facades.

Benedict Anderson argues that all communities are imagined. He famously declares that "communities are to be distinguished, not by their falsity/genuiness, but by the style in which they are imagined" (Benedict Anderson 1983, 6). For Charlotte, this imagining was measured against Atlanta. The first of these competing ideals was the concept of "Metrolina," which envisioned Charlotte-Mecklenburg as an encompassing twelve county perimeter that actualized its economic, cultural, and social importance that would compete with the geographical spans of Atlanta. The concept proved too vast geographically and perhaps culturally as Charlotte came to rely more and more on its peaceful and harmonious race relations as its mark of distinction (Lassiter 2010, 32). In 1983, Charlotte elected its first black mayor, Harvey Gantt. Gantt's election signaled another step toward progress as well as a legitimization of the New South ideology. Attempting to catch up to Atlanta, an emerging business and demographic competitor, business leaders promoted the mantra of Charlotte as a "world class city" focused on centering corporate businesses within the Uptown limits. Gantt's mayorship emphasized building a corporate center city aimed at a friendly environment for pedestrians and commuting bankers. Yet, the "perceived guluf between New South progress and Old 
South bigotry" was so entrenched that in the 1980s and 1990s civil rights groups struggled to draw attention to patterns of reemerging residential segregation and racial inequality (Lassiter 2010, 37). The overturning of Swann in 1992 was a major implication resulting in Charlotte schools now being more segregated than they were during Jim Crow (Godwin et al. 2006). Growing migration streams coming in from whites in the Midwest, blacks and whites from the North, and Latinos from Mexico and Central America began to lead to shifting residential patterns that played a critical role in the reversal of Swann. Whites from the Midwest and Northeast were not accustomed to fully desegregated schools. It was also difficult for this New South city to completely shake its association as part of the Bible Belt. Early on, "Sweet Daddy Grace" ironically a black Cape Verdean immigrant, established the House of Prayer in Charlotte while the most prominent evangelists Jim and Tammy Bakker as well as Billy Graham would be based in the city (Lassiter 2010, 38). (See Figure 1.3). Given the tug of war between Old and New South, Mayor Gantt stated that, "Charlotte should have been Charlotte without North Carolina a long time ago" (Lassiter 2010, 25). Therefore, central to Charlotte's "identity crisis" and its imagination were the realities of persistent racial segregation and inequality, religious ideologies, and an on-going ideological and political battle with the state. 


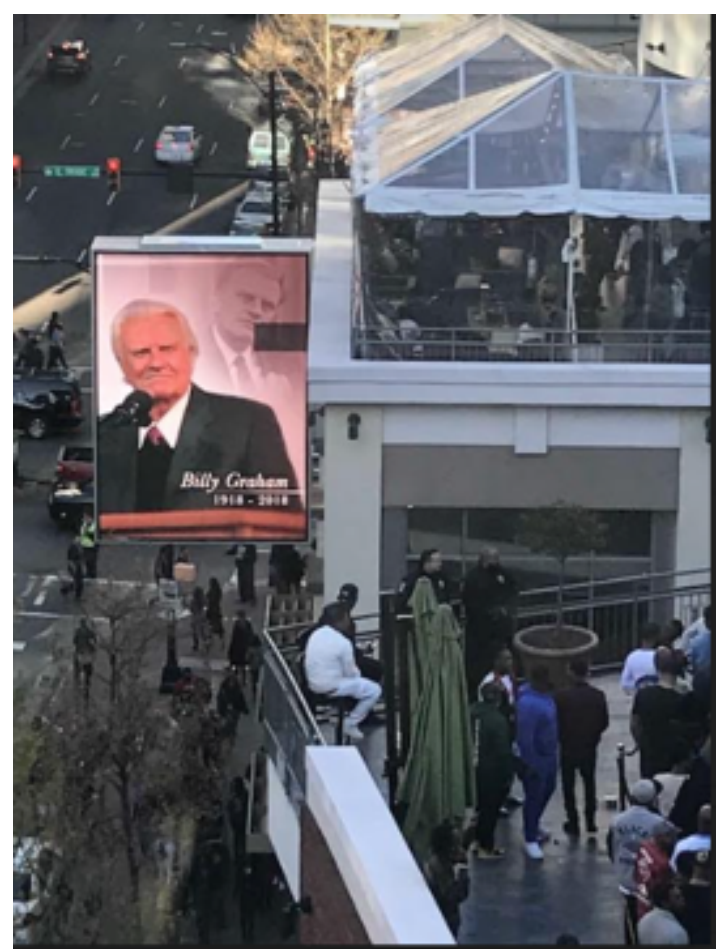

Figure 1.3. "His Last Crusade; The Spirit of Billy Graham Watches", a digital billboard at CIAA (HBCU Basketball Tournament Celebration) at the EpiCentre, Uptown Charlotte. Photograph by Author.

Thus far, my intention has been to reveal the contradictions of the New South, the evolution of the significance of the term and the language used behind it in order to demonstrate the ways it functions as an ontological fact, an epistemology/discourse, an ideology, and a set of practices, or culture. I want to return to the idea of the New South as an ontological fact, as a culture and consequentially an identity, and a landscape, all of which are still intertwined with economic progression and demographic shifts. In revisiting the possibilities of a New South ontology, we must again reconceptualize time. Post-Modern studies necessitate the collapsing of space and time. Simultaneously, postcolonial theory assumes a "temporality that suggests colonialism is something that can be relegated to the past, or equally problematic, generalizes first, a colonial discourse, and second, a subsequent postcolonial condition (Willems-Braun 1997, 3).

Conceptualizations of Old and New South operate in a similar manner. This calls upon 
what Willems-Braun has asserted as a need to "renovate our conceptions of historical time" and to shift from a "singular" and "unified" interpretation of time to one that supersedes a subsequent stage in history, for him, this would be colonial to post-colonial, and for this study from Old to New South (Willems-Braun 1997, 4). Further, WillemsBraun argues that there is no singular time and space, but only the "transient moment of many intersecting temporalities and spatialities" (Willems-Braun 1997, 4). While for Willems-Braun there appears to be no global theory of a colonial culture, however there does seem to be an Old South culture indicative of one sect of colonial culture. We need look no further than the characters and themes of the most popular films at the turn of the century such as "The Birth of a Nation" and later, "Gone With the Wind" among others. Still, interpretations of Old and New South are "localized and historically specific" which guides Willems-Braun's argument that "politics of decolonization" and in this case, New South, "must be attentive to multiple temporalities and spatialities, and thus to multiple forms" of practices and interpretations" (Willems-Braun 1997, 4). To consider the New South as an ontological fact solely based upon economic progress as I do above limits its potentials as an ontology. Yet, the intersections of the past and the present require us to again reconceptualize and reconsider the New South as a cultural ontology, which Don Mitchell (1995) does in his evaluation of discursive culture as ontology.

A New South culture, and way of life brings to mind a set of signifying images and systems, black passivity, subservience and calm race relations being among those as mentioned above. These particular images and systems were constructed by a New South discourse and ideology that resulted in an encompassing New South culture that nevertheless holds different implications for whites and blacks. According to Mitchell 
(1995) culture can be understood as "a way of life - encompassing ideas, attitudes, languages, practices, institutions, and structures of power - and a whole range of cultural practices: artistic forms, texts, cannons, architecture, mass-produced commodities, and so forth" (Mitchell 1995, 105). At the same time, culture as socially constructed, "explains action, behavior, resistance or social formations in a way that 'economics' or politics' cannot" (Mitchell 1995, 103). While certain aspects of New South culture may contrast with Old South culture, the fact is that many practices of Old South culture continue to linger, particularly through institutions like religion and race. The distinction between Old and New South culture also depends upon who one asks.

For many blacks, the New South does not begin until the passing of the 1964 Civil Rights Act, making the New South a political conceptualization. However, Old South institutions persisted socially and culturally. The notion of "southern hospitality," an Old South creed that continues to dominate New South culture stands as a prominent example. For the New South, "hospitality" signifies a set of practices, constitutes a regional identity, and shapes terms of belonging (Alderman and Modlin Jr. 2013, 11). In one way, a native Charlottean or any other southerner visiting New York City may find New Yorkers rude because they do not smile and speak when passing. On the other hand, as hospitality legitimizes social categories and identities while "delegitimizing" others, a black person, particularly a black man may be considered disrespectful or threatening for not speaking to or recognizing a white person in the South. Peaking this paradox, southern hospitality requires that southern whites are "polite" to black people despite underlying racist principles. This strange requirement is summed up in patronizing and condescending phrases such "darling", "sweetheart" and of course, "bless 
your heart", withstanding the fact that black southerners rely heavily on the latter, this phrase is still often used in a condescending manner. As a black woman, and southerner, the disdain drawn by many women from the usage of "sweetheart" by men draws less attention for me than the term being gushed through the deep southern drawl of a white woman. The complex irony of "southern hospitality" allows the flying of the confederate flag, pays homage to confederate soldiers under the guise of "heritage," and permits the generational transfer of racist stereotypes, while it simultaneously authorizes age-old familial ties between blacks and whites and draws in new residents because "everyone is just so nice." Ultimately, southern hospitality epitomizes the contradictions underlying the New South. Southern hospitality idealizes images of the past, in which hospitality signaled a subservience of African Americans to whites, and therefore, African Americans had little place in this conceptualization of hospitality. Nevertheless, southern hospitality is an ironic shared culture between blacks and whites and as such presents a key aspect of marketing the New South as a destination for visitors and new residents.

\section{Uptown Charlotte: A Corporate Culture and a Perpetual Identity Crisis}

“Charlotte is such a financial, banking type city-I don't know-but there's something about it—-that doesn't seem very welcoming or true to diversity—there's a fight that's going on--I mean there are still clubs that won't let--or try to find a way to not let you in for whatever reason. I had an issue at this club a while back, they tried to say that I had on white sneakers and I'm like, I had to go over and take my shoes off like, 'Look at them!' At the time, I was a manager at a shoe store--and I'm like these are not sneakers! 
He finally let me in, but I had to argue with him like these are not sneakers. "-Rossano, Greek-Ethiopian-Black American

Questioning what drew them to Charlotte, my participants often responded with the following key words; jobs, diversity, climate and a more affordable cost of living. We cannot conceptualize the New South as a culture, inclusive of "southern hospitality," without considering the extent to which this culture is interwoven with a corporate and neoliberal sense of being. The majority of my participants either transferred to Charlotte through corporate jobs from larger traditional gateway cities or decided to move to the city and/or area for more affordable entrepreneurial endeavors. Other participants were part of working class immigrant streams due to refugee status. Many other working-class immigrants I spoke with oftentimes occupied an illegal status but nevertheless either came directly to Charlotte from their countries of origin, or moved to the city/region equally for its affordability. However, the majority of black immigrants in this study are young and middle-aged entrepreneurs or corporate professionals working in one of Charlotte's many multi-national corporations in Uptown or University City. Therefore, it is necessary to focus on the particular corporate culture that has come to distinguish Charlotte. As this section continues, it is equally important to consider how Charlotte's corporate culture has both realized and failed its New South title.

I have lived in Charlotte on and off for nearly half of my life and have witnessed firsthand many of the city's dramatic transformations. As a result, during the first month of my research I sometimes went about day-to-day activities such as running errands or hanging out with friends away from my official field sites in East Charlotte without realizing that day-to-day ventures were very much part of this research as an 
ethnography. In the first months of spring at an annual uptown event, "Alive After 5" at the EpiCentre, I was reminded of how much my personal life was part of this research. In the past, I decided to avoid the EpiCentre at all costs, for reasons that will become clearer. The EpiCentre is a four-level center located in the heart of Uptown Charlotte. As much as I attempt to dodge Epicentre visits, there are times when it is difficult. During large-scale events like Alive After 5 a weekly spring and summer happy hour, the center attempts to cater to a multicultural corporate crowd. While the Alive After 5 crowd is somewhat broad and multi-cultural including middle- and upper- middle class people of color, there is still a majority of young white professionals. This is perhaps most evident in the musical selections and selected DJs present during Alive After 5, which is in many ways indicative of the corporate culture the EpiCentre embodies, or at least strives to maintain. From $5 \mathrm{pm}$ until around $11 \mathrm{pm}$, draft beers and a small wine selection are served on the first floor as khaki-laden professionals mingle and chat with one another in their release from a day's work in corporate America. The selected DJs and live performances who cover popular songs at Alive represent what I call "safe music" that in turn creates an environment in which young white Americans can feel "safe" and/or maintain the same multicultural "safety" that their corporate atmospheres offer. I identify "safe" music as a genre of pop music, inclusive of old school Hip Hop, Rhythm and Blues, other traditional pop songs, and popular country songs that can both appease black Americans and fulfill southern white Americans' need to attest diversity, inclusion, and recognition of the Other. White Americans' corporate happenstance relationships with black people and culture in the South attest to a perceived absence of racial apprehension. At least individually, enjoying black music in public serves self- 
affirmations of "I have a black friend" or "I'm not a racist" of which a great deal of southern whites rely upon to sustain both non-racist liberal and conservative identities that in many ways typify the encompassing Charlotte New South culture.

Zukin (1995) notes that the culture of a city is a powerful means of controlling the city and symbolizes just who belongs and who does not (1). Through the creation of powerful images and policies of multiculturalism the city creates an aesthetic and is able to manipulate a symbolic language for exclusion and entitlement (Zukin 1995b, 3-12). As this culture is often indicative of capital and identity, the city comes to represent a symbolic economy that unifies practices of finance, labor, art and performance. This often leads to the production of cultural landscapes that can generate other commodities (Zukin 1995b, 14). For Charlotte, Uptown becomes a powerful representation of the city's culture and in turn, symbolic economy. Further, museums play a critical role in constructing and propositioning a public culture as museums possess the ability to arrange visions and orchestrate images of diversity (Zukin 1995b, 14). The opening video displayed at the Levine Museum's exhibit From Cottonfields to Skyscrapers presents powerful images that reflect Charlotte's identity; the city's growing skyline contrasted against former textile mills represent economic progression, happy children of all races playing together signifying diversity, the voices of Latino migrants narrating aspects of the montage in Spanish symbolizing the city's demographic shifts, and then there is NASCAR. NASCAR is a critical aspect of New South culture and is promoted as a top tourist attraction. In fact, NASCAR headquarters is located in Uptown Charlotte, 
ironically in the same building that formerly housed Chiquita Banana headquarters². However, in Alderman and Modlin Jr.'s (2013) exploration of North Carolina tourist brochures, African Americans are visibly absent from NASCAR tourist brochures, despite the industry's attempts to diversify and despite Charlotte's proposed image as a multicultural New South city (17). While this may be perplexing, it is not surprising. Historically, many African Americans have felt unwelcomed at NASCAR events, and it is a shared sentiment among many African Americans to avoid the area surrounding Lowe's Motor Speedway in general as drunken whites waving confederate flags on the back of pickup trucks flood the area. It is also common to see southern religious fanatics holding anti-LGBTQ, anti-abortion, anti-Muslim, and in the past, anti-Obama posters during NASCAR events. On the other hand, Uptown can distance itself from the racist and xenophobic white culture displayed about 15 minutes from Uptown, and can instead benefit from the corporate aspects of NASCAR.

The infusion of corporate culture into the image of the New South began especially with Mayor Gantt's emphasis on growing the center city as a financial hub that caters to bankers. Over the years, Uptown's corporate culture has become not only a symbol of economic progression and modernity, but also the epitome of Charlotte's New South discourse. In turn, corporate culture has in many ways become the "theme" of Uptown. Urry (2011) draws from the Foucaultian concept of the panopticon to suggest that not only are themed spaces "conspicuous for cleanliness and newness" as Uptown

\footnotetext{
${ }^{2}$ The irony of NASCAR and Chiquita Banana's headquarter sharing a building lies in the fact that Chiquita has historically become a symbol of U.S. imperialism and oppression, particularly in Latin America and the Caribbean while NASCAR has historically been associated and in many ways, symbolic of racism and racial exclusion of black Americans in the U.S South.
} 
Charlotte is, but they also enact levels of visual and electronic surveillance that often controls the types of dress and behavior present in order to maintain this "cleanliness" (Urry and Larsen 2011, 132). Posted on the outside of the Epicenter is a strict dress code prohibiting "construction boots" including "the Timberland style or brand", "athletic wear and hats", white T-shirts, and baggy jeans. Many African Americans argue that this dress code is directed specifically towards African Americans. Further, refusing "suggestive or overtly sexual clothing" requires us to question what clothing on what bodies are perceived of and policed as sexual; I reference the over-sexualization and fetishization of black women's bodies in particular. In 2011, Phillip Agnew, a young black man was escorted out and arrested for refusing to turn his backwards baseball cap to the front in an act of civil disobedience at the Epicentre. Agnew's arrest confirms the fact that those who do not adhere to the corporate (white) culture of Uptown are excluded and oftentimes even wrongfully policed and punished. 


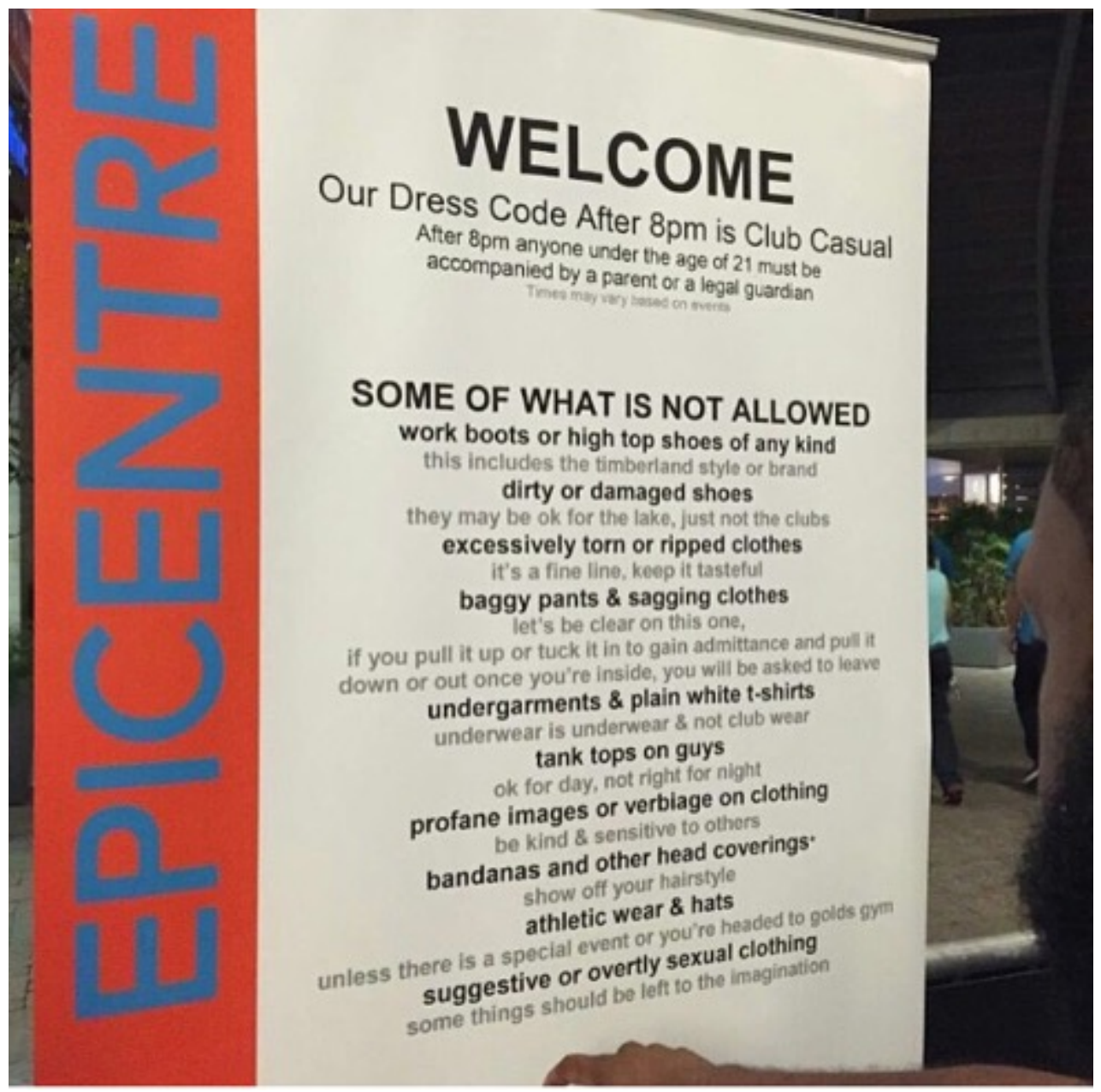

Figure 1.4. EpiCentre Dress Code posted outside of the center, Photograph by author.

The dress code (Figure 1.4) symbolizes a subvert form of control and policing of black bodies. It then becomes difficult to demarcate the lines of Old and New South. As a result, New South as a culture signifies an "artificial distinctiveness" where in reality "there is contest and flux" (Mitchell 1995, 108). If we come to see cultural hierarchies without scale, and in turn, "human geography without scale", or as a multi-scalar practice as New South is enacted in Charlotte, we can apply the theory of a "flat ontology" to understanding the New South, and to Charlotte (Marston, Jones III, and Woodward 2005; Mitchell 1995; O. Furuseth, Smith, and McDaniel 2015). Marston et. al. proposes "flat 
ontology" as an alternative form of viewing vertical and horizontal continuums of "local to global" or past to present. In viewing the New South (encompassing economy, politics, and culture) as a flat ontology, it is possible to discard essentialism and to instead see how and where particular dynamics "produce a multiplicity of complex relations and singularities that sometimes lead to the creation of new, unique events and entities, but more often to relatively redundant orders and practices" (Marston, Jones III, and Woodward 2005, 422). The contradictions embedded within the New South such as excluding those who do not fulfill the aesthetics of corporate culture, or exclusion in general, are consequences of the broader phenomenon of neoliberalism and globalization that have produced the New South.

Michael C. Hall (1997) contends that Post-Fordism signaled an era of flexible production, expanding production and commodification beyond the assembly line. An intimate aspect pushing the strength of a neoliberal and global economy, flexible production allows for the production of places as commodities. In the production of places as commodities, the city must create and manufacture new images that replace negative ones in order to compete with other places in the global economy (C. M. Hall 1997, 65). Combatting reemerging ideologies and images associated with the Old South seems particularly important for Charlotte's competition in the global economy. Over the last fifteen years or so, several national events and international corporations have been attracted to Charlotte because of the city's New South image. Among the city's largest corporate sponsored events, the annual CIAA tournament, an NCAA sponsored regional Historically Black College and University (HBCU) week-long basketball tournament draws in hundreds of thousands of mainly Black Americans from around the country, not 
restricted to HBCU attendees and alumni. Over the week, there are basketball games, parades, job fares for current students, social networking events for alumnus, Greek step shows, free concerts, and awarding of scholarships, all of which concludes with a major weekend of partying and the final game. Cities such as Norfolk, Richmond, Greensboro, and Raleigh hosted the event in the past. However, in 2006, Charlotte successfully outbid these other regional competitors to host the event where it has remained for the last 13 years, generating over $\$ 325$ million in revenue for the city (CIAAtournament.org 2018). The event is set to remain in the city at least until 2020. Charlotte's ability to outbid other city competitors and the success of the event in the city speaks to the city's New South image, status, and growth. At the same time, the racial polarization and extreme policing of actual activities, spaces and places that culminate the weeklong event outside of basketball suggests a city still conflicted by race.

During the CIAA, black Americans as well as others of African descent, are allowed by Uptown business owners and city leaders to be visible, present and/or represented in Uptown Charlotte. Considering that the neat, new, clean Uptown skyline and city center epitomizes Charlotte's city identity, I turn to Carolyn Finney’s (2014) argument regarding the ways in which spaces and places that reflect U.S. national identity have historically undergone processes of representation and racialization (Finney 2014, 28). Finney focuses specifically on African American's relationship with the outdoors, particularly national parks and forests in South Florida. She argues that representation and racialization are not "passive processes" but instead they hold the power to determine who participates and who does not (Finney 2014, 3). Visual images, textual representation, narratives, and stories that we "tell about ourselves, others, and the 
places we live" inform our reality as well as our relationships and interactions with the environment (Finney 2014, 3). For Finney, the dominant environmental narrative in the U.S. is "constructed and informed by white, Western European, or Euro-American, voices." Finney further contends these narratives and the subsequent racialized experiences of the natural environment were mediated by institutions, legislation, and "the social mores and beliefs of the dominant culture" (Finney 2014, 35). Similarly, I argue that Charlotte's narrative is informed by white American neoliberal/capitalist voices wherein black and brown populations are excluded from the white corporate narrative. The absence of black Americans in the city's corporate narrative has yielded spaces where African Americans as well as other non-whites "experience insecurity, exclusion, and fear" (Finney 2014, 3,28). This is evidenced by my participants' accounts, especially black men, who do not normally feel comfortable venturing Uptown due to ongoing covert and not so covert methods of policing like dress codes. Another example of the active attempt to exclude is Alive After Five, where often the DJ refuses to play any other genre of music except country. Several of my black friends revealed that they left Alive After Five specifically because of the music.

CIAA disrupts Charlotte's white, corporate, and neat narrative. There is also a stark and visible absence of white bodies in Uptown during the event, and it is wellknown that these populations either avoid Uptown or leave the city all-together to avoid the onslaught of black bodies. This one-week completely disrupts the normalcy of young white professionals dressed in suits and khakis and invades white southern comfort. I have come to view the last weekend of the CIAA tournament as a sort of bacchanalian festival or Carnaval-like event for black southern Americans as well black northerners 
who attended HBCUs. It was a much smaller/intimate event while in other cities. Black men and women begin to prepare for the week-long festivities months in advance beginning with lining up places to stay. My own home is usually filled with relatives and friends who come in and out throughout the day and night. As such, food and drinks are usually set out in advance along with sleeping accommodations for whoever needs to intermittently rest up for the next party or activity. HBCU homecoming weekends in either Charlotte or other southern cities are similar, yet CIAA is one massive homecoming and reunion. It is possible to walk through a sea of hundreds of people, or attend an event and see friends that you have not seen in years, or even celebrities riding or walking past.

In addition, like Carnaval, black southerners start to save money for parties that can range anywhere from outright free to more than $\$ 200$; oftentimes people attend both day parties and night parties everyday beginning Thursday night through Sunday. People also plan and purchase new outfits, shoes, hairstyles, and even car rentals specifically for the final weekend. In fact, if one opts out of attending actual parties, it can be just as fun and entertaining to surf the EpiCentre to "people watch" and survey the vast array of fashion and attire. It is a parade of people without floats. Despite this very familial and fun-filled weekend of events, police presence is overwhelming and way more dominating than other citywide events. Over the last few years of the event, while some fights and/or violence have erupted, these have not been at official CIAA sponsored events, nor have they involved black students or alumnus. This has not stopped the local media and white residents from attaching and associating potential violence and disturbance to the entire 
event and its attendees. These are indicative of additional processes of representation and racialization serve to marginalize and exclude black people from the Uptown space.

In 2017, Charlotte announced that the city would host the NBA All-Star Weekend. Cities like Los Angeles, Miami, Houston, etc. have hosted the annual event in past years. NBA All-Star weekend signaled a huge step in further staking Charlotte's claim as a major global city. Residents, business-owners, and city leaders felt that NBA All-Star Weekend would solidify the city's status by advancing the city's ability to compete with other southern cities to garner even more corporations and subsequently more jobs and people. The projected growth of the city is most evident in the massive construction of new condominiums and apartments as well as the soaring cost of living currently giving way to an emerging housing crisis for which I will discuss later in this chapter. Here, I want to emphasize the ways in which contradictions of New South rhetoric are embedded within a tug of war between the state and the city.

In March 2016, the state of North Carolina overturned the city of Charlotte's non-discriminatory policy regarding LGBTQ communities, with the passing of NC House Bill 2. The bill was heavily promoted and popularized as the "bathroom law" seeking to prevent transgender individuals from entering gender specific restrooms. In actuality the bill was both a measure used to refute the rights of not only those in the lesbian, gay, bisexual, transgender, and queer communities to file discriminatory lawsuits against private businesses who discriminate against them, but of all persons who have been discriminated against due to race and religion, etc. In response to HB2, major investments like the NBA All Star Weekend pulled out as well as other NCAA sponsored events like the semi-finals of March Madness. In addition, other major corporations 
either pulled out or halted their investments in Charlotte and the state as a result of HB2. Among the city's major corporate losses were Amazon's second headquarters and Pay Pal. As of recent, Amazon elected to place its second headquarters in Atlanta despite bids by both Charlotte and the Raleigh/Durham area. The Charlotte Observer estimated the current losses to be from 70-200 million dollars, predicting that the total losses from the HB2 bill could result in up to nearly 500 million dollars over the years following (Doran 2016). The issue of HB2 begs to ask, was Harvey Gantt correct in his presumption that Charlotte would be a better Charlotte without North Carolina? The November 2016 election furthered this on-going debate. While the state voted for Trump as president, Democrat Roy Cooper was elected governor, although this win was staunchly contested by Republicans and former governor Pat McCrory, who called on a recount. Further, Charlotte elected the city's first black woman mayor in 2017. This political shift along with the extensive economic loss led to a repeal of HB2 in March 2017, bringing the NBA All-Star events and others back to the city.

The on-going contradictions between Old and New South ideologies underscore Charlotte's perpetual identity crisis, a multifaceted manifestation that significantly impacts the day-to-day lives of black immigrants and black Americans. Striving for belonging, visibility and the inclusion that New South rhetoric promises reaches beyond the limits of Uptown parties, events, and the city's corporate culture. In fact, the reality that Charlotte is a multicultural city that caters instead to an Uptown corporate ideal while excluding those who actually reflect the basis of its image, ideology, and discourse furthers the contradictions of the New South. One gains an even better understanding of 
the stark marginalization of the city's black and immigrant populations as they navigate the actual streets and neighborhoods of Charlotte.

\section{Queens Versus Queens; Navigating Charlotte's Landscapes as a Black Subject}

One of my most tedious routes, paying my rent, entails maneuvering through the dramatic racial, spatial and economic landscapes of Charlotte. I often begin my drive down Eastway Drive, which runs southeast from the heart of East Charlotte until it becomes Wendover Road, bringing one into areas such as Southpark, Park Road/Montford and Quail Hollow (where I end to pay my rent). These areas are known regionally for events such as the annual PGA Golf Tournament held there, for their affluent shopping, with boutiques such as Louis Vuitton and Burberry in the lush Southpark Mall, and lastly for Montford, the up and coming/ seemingly all white strip of bars, restaurants, and bowling alley. The tiny dots of blacks that accompany the predominantly white young professional crowd in Montford, along with the overwhelming sounds of Hip Hop provide regulars with the edginess and accessibility of the "Urban", without the inconvenience of being too close to "unsafe" black and immigrant bodies (Forman 2002; Osumare 2005; Khabeer 2016). It is within barely 4 miles that the scenery shifts from shopping centers dotted by Latino restaurants, fast food joints, and discount stores such as Family Dollar, into multi-million dollar homes and high-end shopping boutiques. In turn, while essentially travelling down the same street, within a 3-4 mile radius, one can traverse distinct racial, cultural and social boundaries beginning in an area demarcated by crime, blackness, and foreignness into an area praised for whiteness and affluence. 
Eastway to Wendover is only one example of the muddled ways Charlotte city streets have been designed. Unlike other cities, Charlotte's city streets lack a numerical or alphabetical grid to mark directional coordinates such as due east-west or north-south (Hanchett 2017). The maze of Charlotte streets, many of which are of the same name, often intersect one another at different points in the same neighborhood. A prominent example of this is Queens Road, which intersects multiple times with Queens Road and runs through the Southeastern neighborhood of Myers Park into the Uptown suburb of Dilworth; both neighborhoods are predominantly upper middle class, white, and two of the oldest suburbs in close proximity to Uptown. The layout and design of Queens Road has long puzzled both newcomers as well as long-time residents. Even as someone that has lived in Charlotte for more than ten years, I often end up lost and forced to use GPS in order to find my way out of these areas. In fact, if I did not have to venture through these parts of town to pay my rent, or the occasional eat-out, I would perhaps not even be in the area. After multiple times of getting lost in these neighborhoods, I began to ponder the idea that city streets in this area are specifically designed to keep insiders in, and to keep outsiders out.

According to Hanchett (2017) in the late $19^{\text {th }}$ century, while Charlotte relied on an early grid that followed the original Indian trails, Trade St. and Tryon St., by the early 1900 s, the grid format was abandoned and streets were designed around the natural topography and enhanced by the use of trees, shrubbery, and "semi-rural" parks that distinguished the suburbs from the bustling city. Through this method, access to suburbs was limited. Further, while official zoning laws were not enacted until the 1950s, informal covenants were written into deeds, particularly in Dilworth, Myers Park, and 
what is now Southpark, that specified that lots could only be owned by whites (Hanchett 2017). This separation remains utterly visible and reveals one of the many aspects of the city's racialized landscapes.

Space and place have always been critical in shaping the individual experiences of black subjects as well as the collective identity of the black community. We can look to the significance of the plantation, the urban "ghetto" or "the corner"; spaces that are also indicative of racialized landscapes (Walters 1993: 23; Schein 2006; Duncan and Duncan 2006). Richard Schein cites Peirce Lewis' conception of the cultural landscape, or a "material artifact" that "invokes our way of knowing the world" and as such, is "our unwitting autobiography, reflecting our tastes, our values, our aspirations, and even our fears, in tangible, visible form" as well as collective memories, narratives of community, and "invented traditions" (Schein 2006, 5; Duncan and Duncan 2006, 159). At the same time, we cannot presume cultural landscapes to be innocent of their implications; their duplicity suggests that we can study them as material artifacts with "traceable and documentable empirical histories and geographies" using them to ask questions about societal ideals as they pertain to race, ethnicity, class and life in the U.S and it's distinguishable regions (Schein 2006, 5). In turn, "racialized landscapes" draws upon Omi and Winant's (1994) conception of racial formation, which seeks to put forth "the sociohistorical process by which racial categories are created, inhabited, transformed and destroyed" (Schein 2006, 6; Omi and Winant 1994). It is through cultural landscapes that racial processes and racial categories are made, which constitute the usage of "racialized landscapes" (Schein 2006, 6). To this description, we can also add that "environmental 
ideals and fears as well as varying social, economic, political, and legal practices" have evolved to attach such varying ideals to landscape (Duncan and Duncan 2006, 159). Cultural landscapes, as racialized landscapes are further implicated in defining and negotiating just who belongs to a community and who does not. Further, aesthetics and the "look of landscape" plays a critical role in defining landscape and is central to the performance of place-based social identities, community values, and social distinction (Duncan and Duncan 2006). For areas like Uptown and Montford, the effort to maintain and protect a particular landscape, or perhaps, "the seemingly innocent pleasure in the aesthetic appreciation of landscapes" as well as efforts to "maintain" and "protect" them can act as a "subtle" and "highly effective excluding mechanism" to reaffirm class and racial identities (Duncan and Duncan 2006, 160). These "subtle" and "highly effective excluding mechanisms" include those mentioned above regarding the dress code of the EpiCenter in Uptown as well as in other areas such as Montford. This policing of black bodies through subtle acts of exclusion like dress codes undoubtedly shapes black subjects' relationship with space and place in turn shaping their subjectivities and identities in Charlotte.

Many of the younger participants in this study almost instantly attest to the areas of the city they avoid as well as those they elect to visit, hang out, patronize and/or live. Uptown and Montford are the two most notable spaces that individuals avoid, opting instead for small venues and monthly parties such as SuCasa in East Charlotte. Their ability to name specific places and spaces that they avoid and more importantly to provide feelings as to why, allows us to not only gain a sense of Charlotte's cultural and racialized landscapes, but the impact of space and place on the formation of black 
subjectivity and identity. In the following exchange, one of my participants, Maf, a 30something black American man, explicitly discusses the places he avoids in Charlotte and why. Maf's account offers an entrée into the ways in which sociocultural marginalization imposed through racialized landscapes leads to the construction of alternative spaces of belonging that ultimately require protection in order to maintain.

MB: Okay, when you hang out, if you hang out in Charlotte, where do you choose to hang out, what places do you avoid?

Maf: Yea. I avoid going Uptown.

MB: Okay, why?

Maf: I mean, and I avoid going to like the Montford area...it's like Park Rd. I just avoid going to really white washed bleached places...they're really devoid of any culture... a lot of times they're devoid of intelligence and I-I tend to like culture and intelligence you know...so the places I go more are often the places that I find those things more often. So that just means that a lot of times I hang out in the general Plaza-Midwood area (East Charlotte) because you'll find different groups. Like you can go--like I can go to Petra's [Piano Bar] like everyday of the week, and see a different community having an event at Petra's every night. Each one will involve an artistic mind or an artistic flare from that particular community, what they're interested in, how they see things...so I'm getting intelligence, I'm getting variation of culture all in--the same--I can go to that one bar 5 days a week but I don't--so I just go to different places. Once this sort of mainstream starts to take over an area--because first thing they do is shut down all of the stuff that 
you can get--all that culture or whatever--and the only thing that's left is beer--and then they start sliding in stupid shit--like beer pong and what's that game called?

MB: Cornhole?

Maf: Yea...once they start sliding in that shit, I'm out

MB: Yea...that's happening a lot in Charlotte now...

Maf: Yea, that's why I don't hang out in NoDa [North Davidson, East Charlotte] anymore...they did that.

Based upon the above exchange, we can gather that Maf avoids Uptown and Montford for similar reasons. Maf's decision to avoid these areas centers racial/spatial homogenization and encroaching gentrification suggested by his description of "whitewashed bleached places" and what he perceives of as spaces devoid of culture. Provided Maf's account, we cannot presume that all those placed in a racial/ethnic/religious category all speak with one voice, nor can we or should we deny the fact that identities are multiply constituted i.e. race, color, ethnicity cannot be the only axis that we understand the intersections of subjectivity, identity and space and place (Schein 2006, 7). Intersectionality, particularly as it applies to black queer subjects and space has proven vital in the layering of subjectivity/identity, the construction of space and place, and the prefaced and succeeding affects triggered by subjects' spatial experiences in Charlotte.

I visited Montford shortly after I spoke with Maf along with another black American male friend. Much like the discomfort I feel at the EpiCentre outside of the CIAA events, Montford area restaurants and bars evoked these same feelings of exclusion and discomfort. Briefly, I recall walking into a chic tapas restaurant, and being 
the only two black people in the packed eatery, we were met with intense stares by the all-white crowd. Afterwards, my friend and I decided to walk to one of the area bars. Before entering another predominantly white space with only a handful of black and brown faces, my friend was asked by the bouncer to tuck in his gold chain. This gold chain was not a gaudy gold chain by any measure, yet even if it was, what did his gold chain signify? What threat did it pose to the safety of the crowd? I personally did not want to even enter at this point, but we proceeded. Ironically, or perhaps not so ironic, the first thing we encountered was a young white man with an equally sizable gold chain. The true paradox of Montford was the fact that there were mainly heavily intoxicated young white upper middle-class professionals attempting the latest Hip Hop dance moves and rapping every word to the latest songs, loving black culture while simultaneously actively attempting to exclude actual black people. With this realization, I resolved to completely avoid hanging out in that area again.

White spaces in Charlotte are almost all patterned according to the same homogenized prototype; they are happy, carefree, and safe; devoid of complexity, color, and racial diversity. They are dog-friendly breweries and bars filled with fun-filled games like beer pong and corn hole, a sort of new-age horse-shoe. Within these spaces, there is no need to contemplate the ways in which the racial homogeneity of that space is enforced and maintained. In contrast, there exists an alternative New South that fosters diversity, intersectionality, culture, activism and artistic expression. These alternative spaces are primarily located in areas of Plaza-Midwood and NoDa (North Davidson) both areas of East Charlotte. While West Charlotte has historically been a predominantly black neighborhood, East Charlotte has transitioned into one of the city's main 
“immigrant corridors" compiled of Asian, Latin American and African immigrants as well as a healthy population of black Americans. At the same time, portions of East Charlotte are also in danger of being swallowed by whiteness as gentrification encroaches into some of the only spaces black and brown subjects have left in Charlotte. In turn, our journey through Charlotte leads us to East Charlotte.

\section{East Charlotte: A Metaphor for a Real New South}

At the time of its construction in 1975, Eastland Mall located in Charlotte, North Carolina was the state's largest mall, housing some of the premier department stores, one of the first food courts in the country, and an ice-skating rink. It serviced a predominantly white middle class customer base. By 2003, the major department stores

closed down, black American-owned "urban" boutiques, Asian-owned beauty stores, and African and Caribbean-owned apparel shops took over the former retail spaces that once housed the Gap and the Limited, while the ice-skating rink became an indoor soccer field. In 2013, the city voted to demolish Eastland Mall. A series of socioeconomic and political events transpired to lead to the demise of Eastland Mall and the property being ceased over to the city; significant demographic transitions, which led to an increase in low-income rentals as opposed to prior middle class home ownership; a significant increase in crime, including a shooting inside the actual mall and a "deadly drive-by" taking place near the mall; the renovation and continued construction of Southpark Mall, located in the upper middle class neighborhood by the same name, and significant debt on the part of the mall's owners, arguably a result of the aforementioned factors. Today, 
a QuickTrip gas station stands on a portion of the land. ${ }^{3}$ Eastland Mall remains a poignant metaphor for the racial, cultural, and spatial transformations of East Charlotte as well as a window into the ways in which racialized subjectivities are negotiated amidst a context of significant rapid demographic shifts.

My curiosity and affinity for East Charlotte can be traced to my own first-hand observations of the area's transition over the last twenty years. As a child, my mother brought me to Eastland Mall each year for school shopping. Located an hour and a half west, Charlotte was the nearest city that offered malls with a large variety of name brand stores. Even better, we could treat ourselves to "fine dining" at TGI Friday's, The Olive Garden, Darryl's or Red Lobster, all formerly in East Charlotte and all of which are now closed down. Throughout the mid- to late 90 s, my mother allowed me to stay weekends with my older cousin who lived in various apartment communities in the area among other 20 and 30 somethings, who were mainly black Americans during this time. I was unaware of the fact that I was witnessing one of East Charlotte's first major demographic transitions.

During undergraduate, Eastland Mall had transitioned from a mall of middle and upper middle class whites to that of a more affordable mall that catered to young black, Latino, and Asian Americans; we'd go there to purchase the latest Jordan and Nike sneakers at the many shoe stores, the latest "urban" gear or brands such as Rocawear, Baby Phat, and Parasuco "skinny jeans", and for those of us who were deemed as "militant" or "pro-black" we could find Rasta tri-colored scarfs and flags, incense and

${ }^{3}$ See Charlotte Magazine "Essay: The End of Eastland Mall" and WSOTV and WBTV local news sources 
statement T-Shirts with photos of Marcus Garvey, Bob Marley and Malcolm X emblazoned on the front. Later, while completing my Master's degree at the University of North Carolina at Charlotte, I briefly worked for a national after-school program that works in conjunction with lower-income Title I schools. I also interned at an East Charlotte based non-profit organization that assisted newly arrived immigrants and refugees with their transition to life in the Carolinas. I begin this dissertation by recalling my experiences working at an East Charlotte middle school years before this research study began. Struck by the impact and implications that geographic and demographic transitions in the area held on young immigrant children, my time at the school as well as that instance of a multicultural group of middle-school aged kids banning together under an umbrella of "blackness" to contest a racist white family, stayed with me as I began to ponder the potential effects and affects of these transitions on adult immigrant identity and subjectivity. Reflecting on East Charlotte transitions, over the last twenty years that I have come to know the area, I also recognize that varying perceptions of the area depend upon the person/group as well as what these perceptions suggest about one's identity/subjectivity.

Although West Charlotte, a historically black American neighborhood is undergoing significant transformations mainly as a result of gentrification, it has not transformed into an immigrant corridor in the same way that East Charlotte or South Boulevard, Charlotte's other immigrant corridor have. In fact, both East Charlotte and South Boulevard's historical, social, cultural and physical transformations are extremely similar. Yet, what makes East Charlotte unique is the area's size, which runs a great deal of the expanse of North Tryon and includes corridors alongside Central Avenue, The 
Plaza, Sharon Amity, Sugar Creek and Eastway Drive, all of which intersect or are adjacent with one another, sectioning off smaller neighborhoods within the area. Some of these smaller neighborhoods include Plaza-Midwood, Hidden Valley, North Davidson (NoDa), Grier Heights and Belmont-Villa Heights. Residents may also refer to their area of residence based off of the street name, for instance "Central" or "The Plaza"; this reference has shifted over the years as particular neighborhoods have undergone the process of gentrification becoming Plaza-Midwood or NoDa. References to certain neighborhoods are often based on the race/ethnicity of the resident and the extent of time in which one has lived in East Charlotte. For example, certain parts of NoDa and PlazaMidwood are simply considered "The Plaza" by black Americans who associate parts of these areas with "the hood" versus some young white hipsters just moving into the area, or other newcomers to Charlotte. Highlighting these specific neighborhoods and geodemarcations contingent upon race/ethnicity is critical to understanding the complexities of the East Side's demographic make-up and transformations over the last thirty years.

Understanding specific neighborhoods, perceptions of neighborhoods, and the history of neighborhoods illuminates East Charlotte's distinctiveness. In addition, East Charlotte has maintained a significantly higher black American population than South Boulevard since the 1970s. These earlier black middle class populations were pocketed in neighborhoods such as Belmont-Villa Heights that in the last ten years has come to be occupied by a noticeable Cambodian population, and currently, undergoing gentrification (Hanchett 2010). However, other neighborhoods like Hidden Valley, a completely white middle class suburb during the 1970s, is now completely black and heavily associated with crime, drugs, and gangs. In recent years, the gang "Hidden Valley Kings" was 
featured on A\&E's hit crime series, “The First 48." Currently, there are endeavors to gentrify and remarket Hidden Valley. At the same time, the student demographics such as that of the middle school students mentioned in the introduction as well as the transformation of Eastland Mall are all indicative of what Charlotte historian Thomas Hanchett calls "salad-bowl suburbs." Hanchett (2010) describes East Charlotte as a "salad-bowl suburb", a phenomenon that in the past has been described with terms such as “ 'ethnourbia, melting pot suburbs, heterolocalism'—-terms that have previously failed to truly capture the "multiplicity of old and new cultures coexisting side by side" (Hanchett 2010, 248). In other words, the metaphor of the salad-bowl, first coined by Carl Degler, better depicts neighborhoods in which cultures and ethnicities do not simply melt or merge into one homogenous American neighborhood. The term also better delineates the construction of a trans-ethnic enclave in contrast to ethnic enclaves like Little Haiti and Little Havana of Miami, Little Italy of New York, and Chinatowns around the world. Moreover, while immigrants, mainly Latinos, Africans, Middle Easterners and Asians, are highly visible through their businesses, native-born whites and blacks continue to make up the majority of East Charlotte's population (Hanchett 2010, 248).

Until the 1990s, the city of Charlotte experienced little foreign population growth (Hanchett 2010, 255). The introduction provides additional data regarding the foreignbased population in Charlotte based upon recent U.S. Census Bureau data. Still, it is important to remind the reader that within the last twenty years, the East Side's population in particular has transitioned from mainly white with pockets of black Americans to multi-ethnic with $44.7 \%$ and $35.3 \%$ of the foreign-born population 
concentrated within the area's two major Census tracts respectively (Schuch and Wang 2015). (See Map 1.1 and Map 1.2 below). These populations are evidenced in residential areas as well as more predominantly in commercial zones located in the numerous strip malls and shopping centers that line the streets; the Central Avenue Business Corridor is among the largest. (See Figures 1.5 and 1.6 below). These dramatic changes compel us to explore exactly how East Charlotte became a prime destination for immigrant residents, immigrant-owned businesses/place-making as well as the ways in which these social, cultural, and political landscapes and the inter- intra-ethnic relationships that emerge from them shape black immigrant identity and subjectivity.

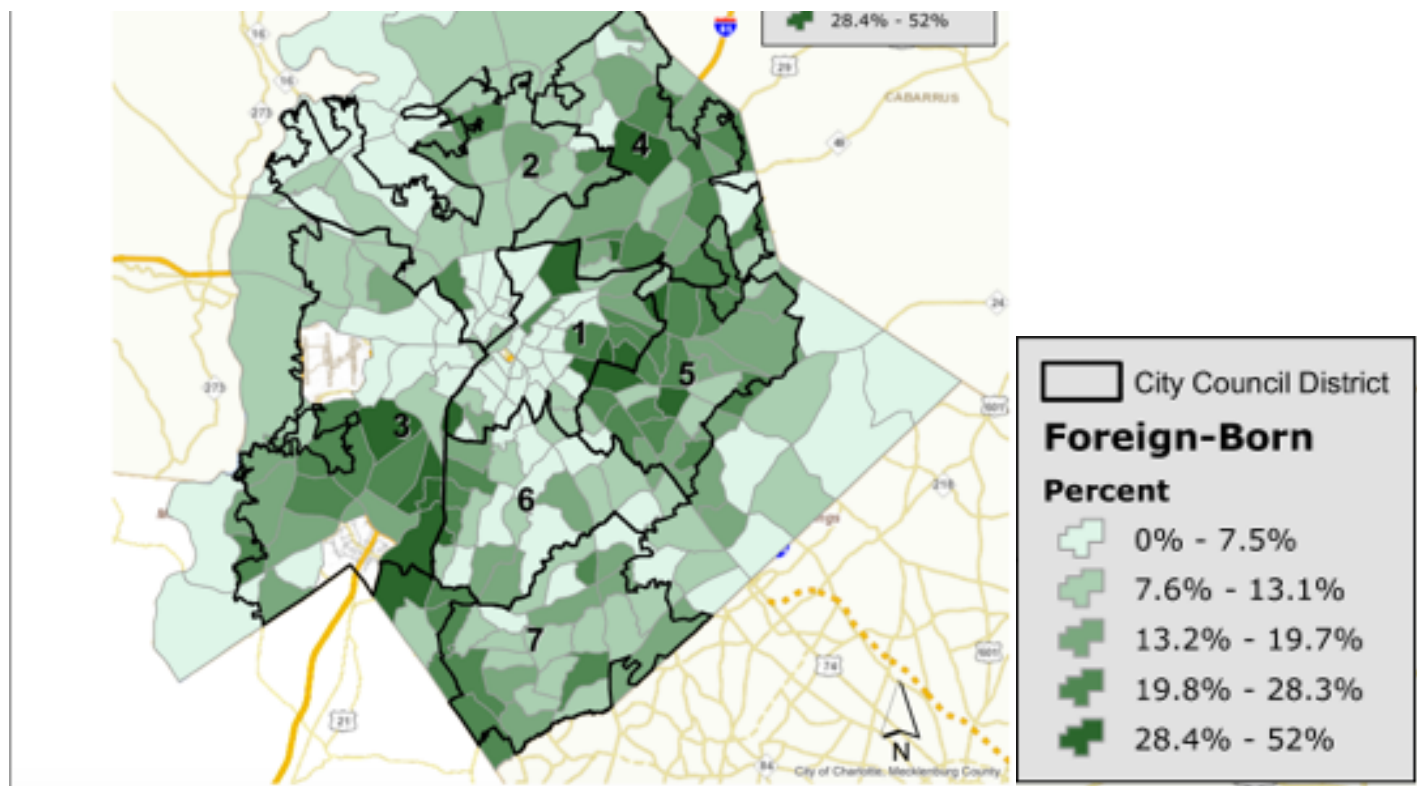

Map 1.1. Concentration of foreign-born population. The heart of East Charlotte consists of portions of City Council District 5 and 1. District 4 demarcates University City, middle and upper middle class suburban areas surrounding UNC-Charlotte in Northeast Charlotte. Data provided by Mecklenburg County Planning Department. 


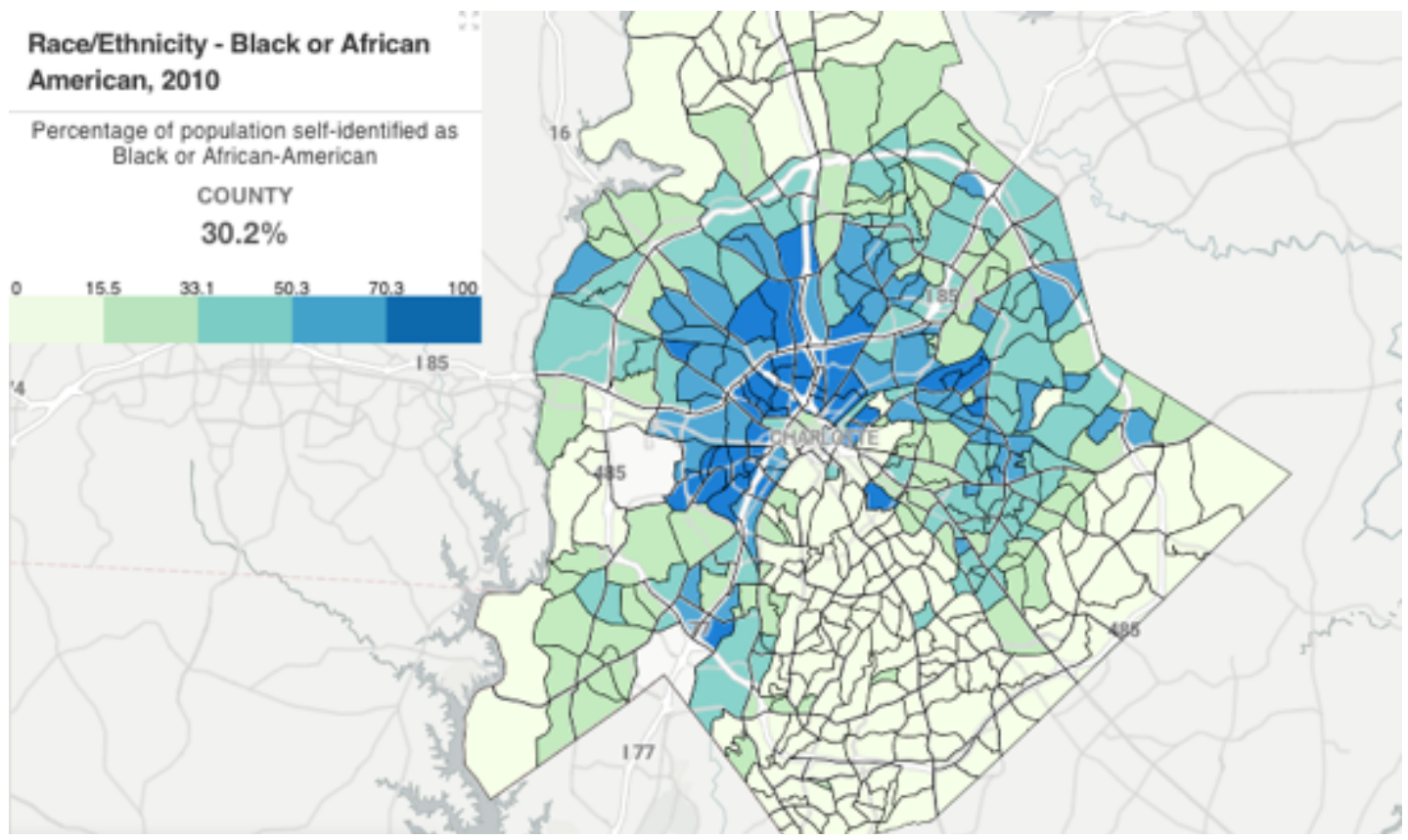

Map 1.2. "Black or African American population in Charlotte-Mecklenburg." The highest concentrations of these populations are located in West and Northwest (top left clusters) and East to Northeast (top right). Areas with the least of these populations are predominantly white. Demographic Data and Maps provided by Charlotte-Mecklenburg Quality of Life Explorer and 2010 U.S Census Tract Data. 


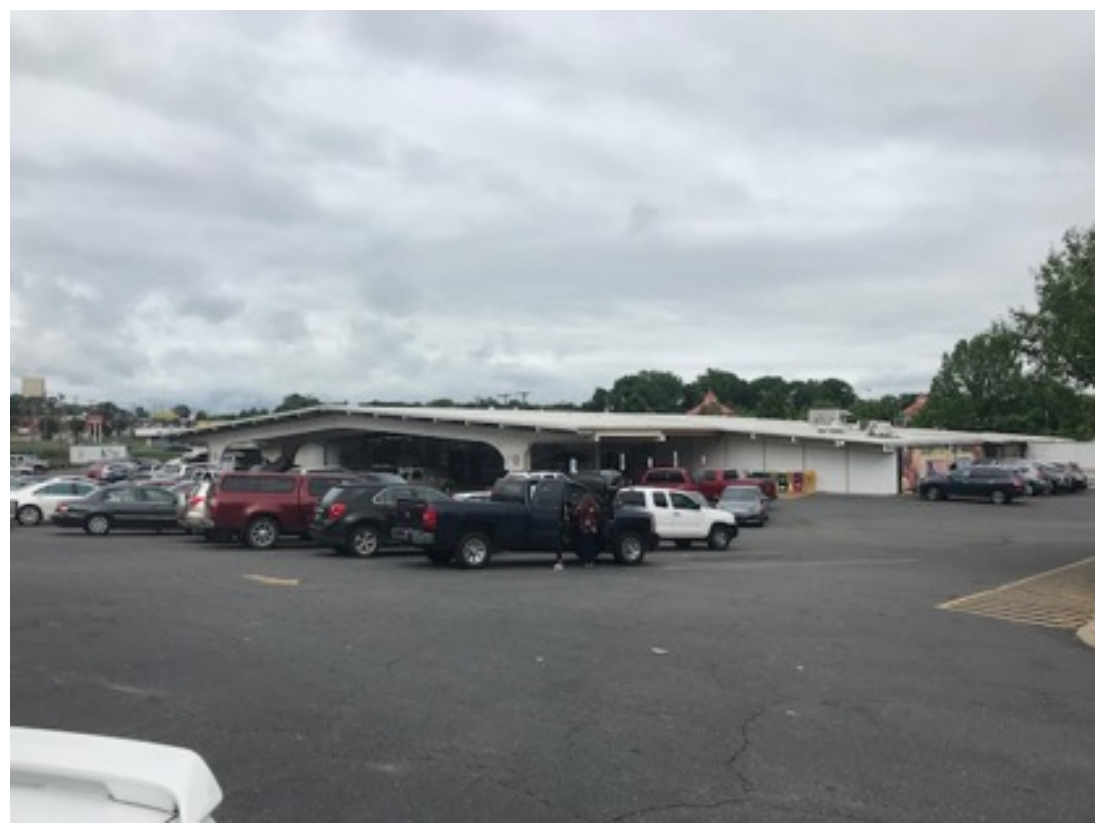

Figure 1.5. Compare Foods, a Dominican-owned grocery chain at the intersection of N. Tryon and Sugar Creek Rd. Known for its quintessential mid-century architecture, the building was originally home to a Park-n-Shop grocery store in the 1960s. Photograph by author.

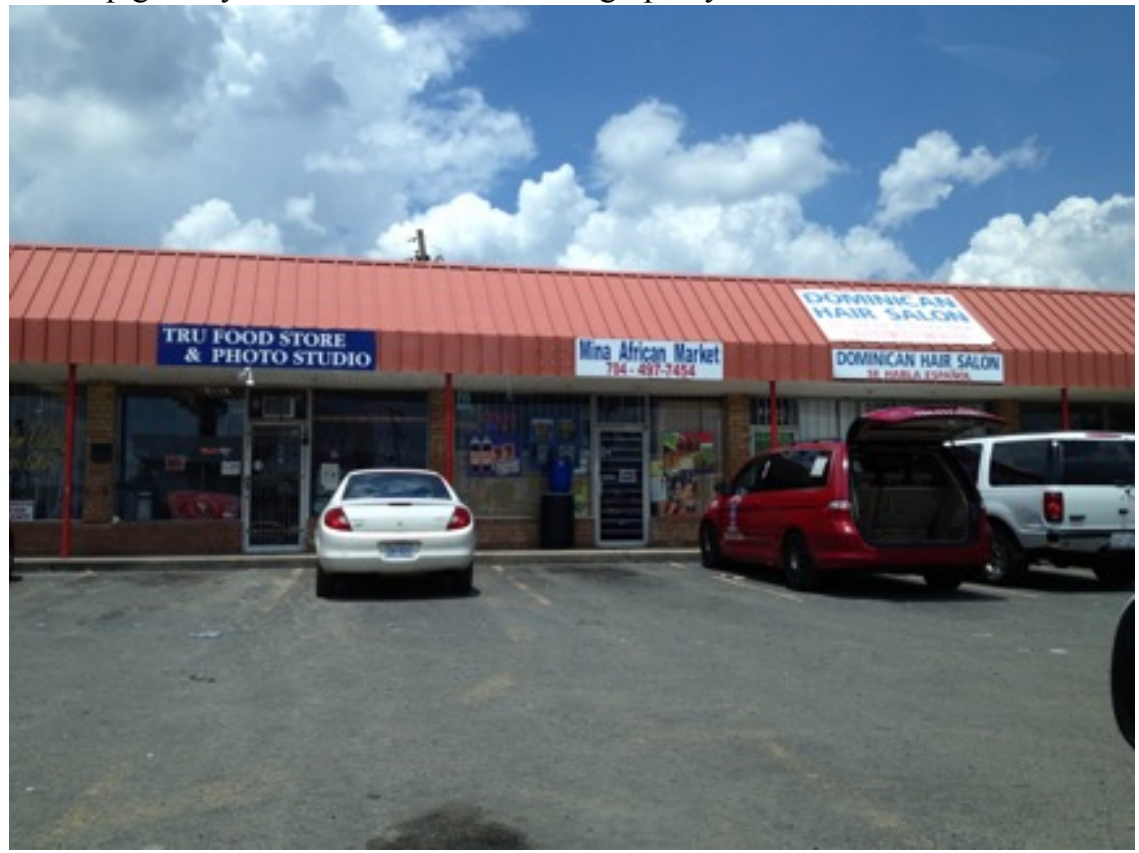

Figure 1.6. A Hidden Valley Shopping Center located at the intersection of North Tryon and Sugar Creek in East Charlotte. The strip mall houses a black American-owned barber shop, a Guinean grocer, formerly a Senegalese-owned convenience store, and a Dominican hair salon. Photograph by author. 
“How do I feel about East Charlotte? I feel like it's—I wouldn't say it's dangerous, 'cause any part of Charlotte is dangerous, but [the] East Side is more known for shootings, stuff like that. I can say they get rowdy over here."-Black American patron, Hidden Valley Barber Shop, June 2015

"East Charlotte is underdeveloped as far as—compared to South [Charlotte]—like Ballantyne - the Southeast side of town. [If] you go on that side, everything is brand new. You're not going to see nobody walking around with a shopping cart or begging for money with signs, [you're] not going to see that. Over here, you're going to see the dirt and the dust, [not in] like Providence, Ballantyne - the more - the richer part. I mean even if you go from Beatties Ford Road [West Charlotte] straight through town and then end up on the opposite [side], you're going to see a complete contrast. [MB: Why do you think that is] I think 'cause of how they've got the housing, the Housing Authority, because you've got Section 8 in these areas, or pushing them out to [Highway]485, and so they're [whites] keeping their sides. But on this side, you see like pawn shops, check cashing, that's the kind of stuff you see on this side and the West side, you don't see that over there. "-Black American barber, Hidden Valley Barber Shop, June 2015

The accounts positioned throughout this section expose the reality that, East Charlotte is complex. The area oftentimes evokes an intriguing coexistence of fear, nostalgia, love, and belonging; an assemblage of affects that define and designate places and spaces as well as sociocultural relationships and identities of those who either live in or traverse through East Charlotte to shop, eat, hang out, or manage businesses. See Figures 1.5 and 1.6. These accounts reflect the past and on-going transformations of East Charlotte as 
well as additional contradictions and inequalities underscoring the idea of the New South in relation to housing, accessibility, and infrastructure.

When relying on the term "salad-bowl suburb", we must consider that the notion of suburbia takes on a slightly different meaning in Charlotte than it does in most nonsouthern cities. Relatively speaking, the built environment of Charlotte's suburbs, particularly of older suburbs like East Charlotte reflect those of other cities, neighborhoods characterized by ranch houses, garden apartment complexes, and small strip shopping centers built mostly during the 1950s and 60s. However, state laws in the South more easily allow cities to annex outlying territories, therefore, as Charlotte has grown to include the areas that make up the greater Charlotte-Mecklenburg region, more rural areas now constitute Charlotte suburbs in addition to more wealthy areas in the Southeast that have historically maintained suburban imaginings (Hanchett 2010, 251). I contend that while East Charlotte was once a quintessential suburb, a great deal of the area has been swallowed by the urban belly, with the exception of those pockets that remain mainly white, and the current efforts to gentrify other all-black or historically racially mixed working-class neighborhoods, such as the one I currently live in.

In many ways, East Charlotte epitomizes old Charlotte. As discussed, Charlotte burgeoned in the years following World War II. Until the mid-1940s, the city boundary barely progressed beyond a two-mile radius that ran alongside Central Avenue and The Plaza to the East around to South Boulevard and Remount Road to the South and West respectively. In contrast to the well-to-do posh white neighborhoods southeast of the city, both South Blvd. and East Charlotte neighborhoods emerged during the midtwentieth century as workers in the city's textile mills and factories moved outward into 
modest new suburban homes that were still in proximity to the city's Uptown mills. Following the victories of the Civil Rights Movement, these majority white working class families were joined by upwardly mobile black Americans during the 1970s, which eventually resulted in some all-black as well as mixed-race neighborhoods (Hanchett 2010, 248). The Fair Housing Act of 1968 granted "equal housing opportunity" which for Charlotte, preceded the 1971 Swann decision. City civic leaders especially stressed the need to welcome integration post-Swann in order to maintain its progressive image of successful desegregation; in 1970, Charlotte was ranked as the fifth most segregated city in the U.S., by 2000, it was the nation's second least segregated urban destination (Hanchett 2010, 254). Of course, as this chapter has sought to demonstrate, these accomplishments are, and continue to be complicated. Still, by the late 90 s, these historic processes would give way to affordable housing opportunities attractive to new immigrants arriving in the city (Hanchett 2010, 248). Affordable housing provided "Zones of Emergence" that allowed immigrants to prosper within the two pie-shaped wedges of neighborhoods in the East Side and South Boulevard corridors.

The mid-century national craze with shopping centers as well as the trend of "apartment communities" in the 70s and 80s established themselves in the arteries of East Charlotte and South Boulevard, making them even more desirable. As integration became more and more evident in East Charlotte in particular, southeast Charlotte clamped down by preventing new construction as "politically well-connected citizens" held the power to block new development and the encroachment of less affluent arrivals, a feat that would maintain the area's marketability in contrast to the west and east side (Hanchett 2010, 253). Meanwhile, in its transition from "all-white to racially mixed" 
tensions arose in areas such as Hidden Valley. Even following that neighborhood's transition from all-white to all-black, it was still known as a black middle-class neighborhood before its reputation plummeted into one associated with low-income and crime. Currently, the efforts to "revive" the neighborhood market its centrality to Uptown and University City as well as its accessibility to I-85. Hidden Valley exemplifies the multiple segmented transitions undertaken in East Charlotte over the years. During the mid- 60 s, the entire area was completely segregated with the six Census tracts along Central Avenue being almost 100 percent white. While demographic shifts are notably a product of the Fair Housing Act, they are just as much due to the funneling in of black American citizens displaced by "Urban Renewal" projects that destroyed prominent well-to-do black neighborhoods Uptown. Many of these displaced families moved into East Side neighborhoods like Belmont-Villa Heights. Many whites in East Charlotte were able to preserve their space; by the 80s, the PlazaMidwood neighborhood became 77 percent white and 21 percent black, maintaining this "mixture" until the early 2000s.

Today, hidden boroughs within Plaza-Midwood reveal what I have come to view as "secret white spaces" comprised of small parks, clean neat sidewalks, and extravagant suburban homes that can range into the millions in price. Many of these hidden spaces are accessible from the side streets of the street where my own little mid-century duplex stands. Therefore, the history of housing and access to affordable housing is not only representative and indicative of East Charlotte transitions over the years these histories of neighborhoods within East Charlotte is also further suggestive of the tug of war between Old and New South ideologies. By this assertion, I am suggesting that Urban Renewal 
policies that displaced black subjects from thriving black communities Uptown initially brought them to the East Side beginning in the early 1970s following the Fair Housing Act. Despite urban renewal, the Fair Housing Act allowed Charlotte to maintain a rosy image of race relations by further desegregating the city, at least in East Charlotte; wealthy whites in Southeast effectively managed to keep blacks out. Yet, as East Charlotte became more black and brown, residents and city leaders/representatives from the area assert that the city essentially abandoned major parts of the area, particularly those with higher concentrations of black and brown people, leading to what these individuals perceive of as a lack of infrastructure and an overflow of crime and poverty, these were aspects that the men at the Hidden Valley barber shop lamented in the above accounts. In chapter 4, I expand upon my conversations with an East Charlotte city councilman and former Eastland Mall business-owner who holds similar views. Lastly, as of recent black and brown subjects in East and West Charlotte are confronting newer forms of displacement, primarily that due to gentrification that is giving way to an impeding affordable housing crisis. The latter again begs the question, who is the New South "new" for, if it is "new" at all?

To the left of my duplex are multi-million dollar homes, and to the right and behind, are mostly smaller mixed-raced families. The main street, The Plaza, is a busy thoroughfare that evidences the rapid changes of East Charlotte. Riding along The Plaza one witnesses the stark juxtapositions of homelessness, run-down laundry mats, Crystal's Reggae club, car garages and gas stations alongside hipster wine and beer shops, bars and restaurants. For a two-bedroom, I pay one of the last affordable rents in Charlotte at $\$ 900$ a month. This price increased $\$ 25$ once my landlord informed me that young 
professionals found the apartment ideal and that he could be receiving more money for the property. As of recent, the average rent for a one-bedroom home is $\$ 1,100$ in Charlotte (Barber 2017). East and West Charlotte are at the forefront of the city's current housing crisis and renewed efforts toward gentrification. Over just two years, I have witnessed gentrification from my front porch. I have observed a noticeable shift in food products at the local Food Lion, which now sells organic fruits, vegetables and snacks. Each day more and more white patrons stand in the line with me. I patronize new local wine and beer shops that sell craft beers and organic meats, even the local Seven-Eleven gas station now stocks a section of craft beer, kombucha, and yerba mate. Still, the homeless maintain their corners three blocks ahead, the deep base of dancehall from Crystal's rocks me to sleep on the weekends, a sleep sometimes interrupted by gunshots and sirens, while loud conversations in Spanish dance along the sidewalk. More and more, I see young white hipsters and professionals walking their dogs and their babies replacing both working class whites and black Americans that can no longer afford or are either bought out of their small ranch style homes or apartment complexes. Almost every month, I notice a new home for sale or a brand-new apartment complex being constructed. These dramatic realities speak not only to gentrification in Charlotte, but also to the city's current housing crisis.

The reality of gentrification in Charlotte and its ensuing housing crisis intensifies the complex historical and on-going sociocultural and physical transformations of East Charlotte. Moreover, these factors are among many that further compel and justify the marginalization of black and brown populations in the city. At the same time, the marginalization of these populations encourages the need and desire for place-making, or 
the construction of meaningful places of belonging. In East Charlotte, these spaces and places range from restaurants, boutiques, and small grocery stores to nightclubs, bars/lounges and dance studios. Black and brown subjects, including immigrants as well as those groups and individuals whom I define as "cultural workers", who I expand upon as the dissertation unfolds, are part of a broader social network of individuals and organizations that take on the collective task of building, maintaining and protecting spaces and places of belonging. The majority of these spaces and places are located in East Charlotte, mainly within the Central Avenue corridor. The intersections of black American and black immigrant populations prompted by these spaces as well as the spaces themselves represent an alternative New South, a New South that more accurately aligns with the projected narrative and rhetoric of multiculturalism and inclusivity.

\section{Conclusion: A New South?}

This chapter carries the task of deconstructing the meaning and function of the New South. Beyond the very basic definition provided by the Levine Museum, which outlines the New South as a tangible and discernable time, place, idea, reinvention, and people, I argue that the New South is a much more intricate and compound conception. Instead, I explore the New South an ontological fact, as an epistemology/discourse, as an ideology, and as a set of practices. As such, the region builds upon a long historical paradoxical set of racial, social, and cultural relationships and occurrences. The city and region's economic and demographic growth fostered by both domestic and international migration as well as the impact of globalization designates the New South as an ontological fact separate from the agricultural-based economy and black-white racial 
populace of the Old South. However, North Carolina state policies and ideologies as well as local reactions and reluctance to diversity demonstrated by police brutality, adherence to anti-immigration policies, policing of predominantly black events, and maintenance of social de jure segregation through dress codes and other forms of policing blurs the possibility of a separate New South ontology. Nevertheless, the New South persists as a discourse, an extremely dangerous discourse that interferes with the realization and advancement of black American and immigrant activism and social justice as subjectivities are born and culminated by a historical discourse of benign race relations. Part of the difficulties in dismantling the New South is that many black and brown subjects have been injected into a corporate culture initiated and fostered by the New South discourse. The New South as discourse stands as the most accurate definition, as it underlies the possibilities of ontology, and enacts a culture, a corporate culture that is indeed an ontology of its own. There would be no New South without its corporate ontology. The New South's corporate cultural ontology is extremely profound in that it continues and fosters migration, promotes economic growth, and maintains the clean and neat city streets through pervasive policing of black and brown bodies, all of which ironically markets and sells the city as a place to be and become. The becoming, transformation(s) and existence of East Charlotte, a trans-ethnic enclave of immigrants and native-born black and white Americans then simultaneously compromises and cultivates the New South. Standing as a metaphor of the contradictions and realities encompassing the New South, East Charlotte demonstrates and constructs the true potentials of the New South, that of which I call an Alternative New South. 


\section{CHAPTER TWO}

"BLACK IS BLACK"...OR IS IT? UNRAVELEING THE SIMULTANEITY OF SAMENESS AND DIFFERENCE AMONG BLACK AMERICANS AND AFRICAN AND CARIBBEAN IMMIGRANTS IN THE U.S. SOUTH

"Solon believes that, "Black is Black", but he is also Haitian, and while 'he's just another black man', 'culture' is what keeps him out of trouble”-Bennett, Field Notes, January 2017

In Chimamanda Adichi’s novel Americanah, the main character Ifemelu asserts, "In America, you don't get to decide what race you are. It is decided for you. Barack Obama, looking as he does, would have to sit at the back of the bus fifty years ago. If a random black guy commits a crime today, Barack Obama could be stopped and questioned for fitting the profile. And what would that profile be? 'Black Man' (419)." Here, Adichi addresses the complexities of being black and Other in the U.S. In one instance, she confirms the arguments of scholars such as Hintzen (2003), Rahier (2003), and Wright (2015), who contend that the United States' definitions of blackness often obscure the diversity of black subjectivities. At the same time, providing the example of Barack Obama who is the product of a white mother and Kenyan father, Adichi insinuates that despite what Pierre (2004) calls the "ethnicity paradigm" or an attempt to separate black immigrants from a pathologized black America, ultimately "black is black" and as a consequence, black immigrants are subjected to the same sociopolitical inequalities as black Americans. Black immigrants from Africa and the Caribbean often confront these definitions in varying ways that are sometimes heightened within the 
context of the U.S. South and significantly impact the production of black identities and subjectivities.

As I often did during my research, I sat in my bed one night typing field notes and craving Haitian food that was once easily accessible while I was living in Miami. In that moment, I thought about the jar of pikliz, a Haitian relish composed of cabbage, carrots, hot peppers, etc., that my Haitian participant Flor had sent me off with after our interview a couple of years prior. Given my research to this date, I had not found any Haitian restaurants in the city. However, based upon Flor's account as well as several Haitian churches, Baptist and Seventh Day Adventist institutions marked by concrete signs in both English and Kreyol, I knew there was a substantial Haitian presence in the city. Inspired by my taste buds, I did a Google search for Haitian restaurants in Charlotte. There it was, a blue underlined link, almost too good to be true, Island Hub Restaurant and Lounge, "offering the best in Caribbean food" located right on Monroe Road in East Charlotte. Still unsure if it was actually Haitian as it was labeled simply "Caribbean" I knew it would be my first stop the following day.

Upon arriving at Island Hub, I was actually unsure if I was at the right location as it was somewhat lodged next door to a garage off of the busy Monroe Rd., which was once Charlotte's main highway before the construction of Independence Blvd. Still, Monroe Rd. remains a busy thoroughfare running from the southeastern city of Monroe through suburban Mathews and then through East Charlotte into Uptown. On my first visit, I walked up to a slightly ragged door to see a small plastic sign with the hours listed. I was sure to come back during the listed hours. My next time at Island Hub, I walked in during lunch hours to meet a loyal Haitian customer sitting at the bar eating his 
favorite griot de porc, and the bartender, a young Haitian-American and the son of Solon, the owner. After discussing my research, his son called Solon from the back to come and talk with me. Solon was happy to talk with me but refused to be recorded as he "joked" that I may be an "undercover." Solon is from Port-au-Prince, Haiti and had previously lived in Montreal for ten years as well as New York City before finally deciding to settle in Matthews (a suburb of the Charlotte metro area) where he has lived for the last 17 years working as a city bus driver alongside mainly working-class black Americans and a barber to mostly black American men.

When I asked about the clientele in his restaurant Solon noted that about $60 \%$ of his clientele are other Haitians, but "everything he does, he does it for everybody" further mentioning that "everyone is welcomed here, white, black, 'niggas', and Spanish." Upon using the word "nigga", the Haitian customer sitting at the bar laughed. I did not initially take Solon's use of "nigga" to be offensive, instead I took this usage to signal a sense of comradery or sameness with other black Americans. However, referring to "blacks" separate from "niggas" led me to consider that perhaps Solon was referencing class distinctions, or worse, distinctions between black Americans and black immigrants, suggesting that "niggas" is a term regarded to black Americans. In that moment, I concluded that his body language suggested that he was referring to class distinctions or attempting to connect with me based upon my black Americanness or his perceptions of my own socioeconomic status. Solon is also a musician and as such, he loves music. Indeed, on my later visit to Island Hub in the evening, the Kompa and Zouk blasted from the speakers on the small stage set up at the center of the restaurant and lounge. Solon sees music as something to express his culture and as a way to take action in identifying 
and legitimizing his culture in Charlotte. At the same time, for Solon and many of my other black male participants, there is a need to "stay out of trouble" as they face the constant risk of being targeted for "fitting the profile" of a "Black Man." Working on or perfecting a talent or an art seems to take away from time spent navigating the streets; being occupied with a talent, job, or art shields one from the potential voluntary and involuntary risks a black man may encounter each day. As I expand upon Solon's account, the idea of "staying out of trouble" due to a talent or job, foregrounds a sense of superiority, or an ideal attached to the politics of respectability that distinguishes black immigrants from black Americans. Solon went on to suggest that his culture keeps him out of trouble while "African Americans are missing culture." When asked to clarify what he meant, Solon stated, "when you have culture, you do things differently." Solon used family values and tradition as examples of those aspects of culture that black Americans lack. For Solon, this lack of culture contributed to what he saw as the deficient state of black America.

I asked Solon what being black meant to him, and if there was a difference in being black in Haiti and being black in the U.S. In response, Solon argued, "Black men have hardships and hard times globally; they will always face discrimination." Solon himself had faced hardships opening his business, stressing the difficulty in allocating loans and investment, which more than often fell at the hands of white men that did not believe his business could thrive. According to Solon, "it's not about America, Haiti, Africa, the Black Man is the Black Man everywhere, everything is a challenge." He went on to mention the current state of black men trapped within the Prison Industrial Complex noting, "look at America, the majority of men in prison are black and the rest [are] 
Latinos." As a result, his advice to black men, including his son, was to "work hard," "keep your nose clean" and "sacrifice" and as a black person, one must possess "the heart of a lion" to combat a system "built for you to fail." It is critical to note the very gendered way in which Solon perceives and defines blackness. For Solon, blackness is almost completely rooted in the experience and notion of the "black man." From his perspective it is possible to gather that the black man is indeed the source of blackness, a blackness rooted in oppression. Yet, identifying methods to escape it, Solon's culture seems to offer an escape not necessarily presented to other black men. Here, Solon identifies with the plight of the black man, attesting to a specifically gendered oppression, while simultaneously erecting his culture above that of black Americans, who in his eyes, lack a culture that could potentially keep them out of trouble.

Solon further contended that if his business was a white business, the chairs would be full but as a black business, he could not garner the same support from the black community. This contention uncovers the challenges many black business owners confront despite ethnicity, these owners maintain that a great deal of blacks do not support black business. As a result, many black businesses fail. Indeed, toward the end of my research, the thought of stewed goat once again directed me to Island Hub and I made plans to go along with other participants and friends. This time, unfortunately, Island Hub was permanently closed. My friends had arrived beforehand, saw that it was closed, and upon hearing gunshots nearby called to decide on another place. We went for Dominican instead. I have not had contact with Solon since.

Throughout our conversation, Solon simultaneously referenced collectivity as well as difference between black Americans and black immigrants. This simultaneity of 
sameness and difference demonstrates the complex identities black immigrants take on as they navigate the multiple racial, ethnic, and cultural hierarchies in the U.S. Adichi's character along with the research participant accounts relayed above reveal the complexities of simply being black and Other-immigrant—in the U.S. While it may appear that "Black is Black" to some black Americans and black immigrants alike, interracial, intra-racial and inter-ethnic sociocultural, political, regional and economic structures further complicate the intricacies of blackness in the U.S South. This chapter explores the ranging interpretations and performances of blackness among black Caribbean and African immigrants.

Based upon my participants' intersecting and conflicting responses concerning blackness and identity, I argue that their multi-layered identities are produced as they navigate processes of racialization in their countries of origin, multiple destinations in the U.S. and in the U.S. South, in Charlotte. In the following chapter, I make similar claims regarding Afro-Latino populations. I contend that Afro-Latinos find themselves more deeply conflicted not only by the black-white racial binary, but by an expanding blackwhite- "Mexican" tertiary racial grouping emerging in the New South. I argue that in the U.S. South, Afro-Latinos occupy a constant liminal state that involves the rejection of group membership into certain communities but paradoxically coincides with options to elect varying social and cultural identities based upon language and nationality as well as local and national definitions of race in the U.S. On the other hand, this chapter contends that for black Caribbean and African immigrants in Charlotte, blackness is neither a question nor an option: black is black. 
The black-white racial binary of the U.S. South heightens the sense that "black is black" and further renders Caribbean and African populations invisible as Caribbean groups in particular are ensconced by the larger African American population. The United States Census Data reifies the notion that black is black by collapsing the categories of African American and Black and dismissing the need for black ethnic differentiation. This fact poses a particular challenge to gaining actual figures on African and Caribbean populations in Charlotte. At the same time, there is a healthy presence of black Caribbean and African immigrants who appear to form their own respective relationships with black Americans depending on socioeconomic status and location. Many of the intersections and interactions among Caribbean and African immigrant and black Americans are complex and are either centered in East Charlotte businesses/organizations, University City (northeast), or Southeast Charlotte residences. Oftentimes, members of both African and Caribbean communities travel into East Charlotte from outside neighborhoods to run their businesses and to eat, shop or hang out. This critical aspect is indicative of socioeconomic status as a great deal of middle and upper middle-class black Americans as well as black immigrants live in either University City or Southeast Charlotte. Further, these immigrant populations respectively compile either a Pan-Caribbean community (West Indian, Guyanese, Haitian, inclusive of some East Indian Caribbean individuals) nested within the African American community as well as a trans-ethnic Pan-African community. While African immigrant's membership/relationship with the Black American community is often contingent upon spouses, family members, socioeconomic status, and occupation, Caribbean immigrants appear to be more embedded within and connected to the black American community. 
Cultural difference remains essential in deciphering the multiple conceptualizations and performances of blackness among Caribbean and African immigrants. The term "culture" in one sense expressed by participants—as Solon does above by highlighting that his culture is what keeps him out of trouble — becomes a moniker of sorts signaling the deployment of the myth of the model minority and/or black respectability. The usage of culture in this sense belies notions of work ethic, education, skill, and talent, which black America as a whole do not possess in the collective imagination. As Caribbean and African groups intermingle and at times ultimately become one with black Americans, this usage of culture continues to define underlying aspects of their identities. Therefore, in this chapter, I argue that while "black is black", concerning Caribbean and African immigrants, intra-racial and inter-ethnic sociocultural and socioeconomic hierarchies construct complex identities responsive to the context of the U.S. South, where cohesive ethnic enclaves do not physically exist, or are in the early stages of construction and where notions of "culture" both binds and separates black subjects (Pierre 2004; M. M. Wright 2015; Rahier 2003; P. C. Hintzen 2001).

According to Hintzen's (2001) ethnographical study of West Indian immigrants in the Bay Area, blackness affords West Indians a "location" within the "racialized space of the African American" while their foreignness presents an option for either a location occupied by "undesirable" Mexican and Latino immigrants or the "model minority" designated by Asian immigrants (P. C. Hintzen 2001, 17). I contend that the latter option of foreignness and in turn, the model minority — the idea that different groups "receive what they have earned and deserved" overcoming poverty through work ethic, rooted in an ideology of meritocracy—are concepts that Hintzen suggests serve as a basis for a 
"discourse of difference" in the U.S. Like Hintzen argues regarding West Indian immigrants in the Bay Area, Caribbean immigrants in particular, rely upon and take advantage of the African American community for its institutional value found in churches, politics, businesses, and local colleges and universities as middle class African Americans in Charlotte are extremely visible and hold a substantial amount of power (P. C. Hintzen 2001, 17, 18). Still, a "discourse of difference" allows many Caribbean and African immigrants in the South to distinguish themselves from black Americans. Yet, I argue that efforts to assert difference and perceptions of one as different is not just a phenomenon concerning black immigrants. Instead, certain black Americans occupy a space of difference among black subjects as well. In other words, the discourse of difference in the U.S. is just as critical in the development of black American subjectivity as it is for black immigrants. Actively striving for or subconsciously occupying a category of difference ultimately serves to establish intra-racial and inter-ethnic socioeconomic as well as imagined cultural hierarchies among black subjects in the U.S. South.

Hintzen recognizes that West Indian performances of difference and foreignness in the Bay Area take place outside of the "racial space" of African Americans, where blackness "does not count" in order to further define boundaries between these groups (P. C. Hintzen 2001, 22). I hold that, in Charlotte, while expressions of cultural identity like cooking, eating and family gatherings in the home offer spaces that exclude African Americans, other critical public expressions of culture and performances of identity cannot take place without the support of the African American community, underscoring an undeniable interdependence that exists between middle class black Americans and 
Caribbean and African immigrants. There are few spaces where blackness "does not count" in the South. Hintzen also distinguishes working class West Indian immigrants in New York burrows like Brooklyn from those in the Bay Area that have gained more socioeconomic success through their geographic relocations (P. C. Hintzen 2001). Gaining upward mobility through multiple geographic relocations is a critical aspect of my participants' experiences as several grew up in working class households in traditional gateway cities like New York, Miami or their countries of origin and may have lived in additional U.S. destinations before arriving in Charlotte.

As these middle- and upper middle-class immigrants find themselves in Charlotte they more than often align with the middle-class African American community as they are able to take advantage of the political and economic strength of African Americans. In contrast, much of the working-class African population remains separate from the black American population due to linguistic and cultural boundaries in their everyday interactions in places of business such as African hair-braiding salons that are heavily patronized by black Americans. The strong presence of an African working class in contrast to that of a Caribbean working class in Charlotte also underscores an intra-racial and inter-ethnic socioeconomic hierarchy in which upper middle-class Africans are able to maintain both a separate relationship with fellow Africans as well as a significant relationship with the African American community. Therefore, I argue that class emerges as a critical factor mediating processes of black immigrant and native black American subject formation in the city of Charlotte. The larger population of Africansaccounting for $10.3 \%$ of the immigrant stream in Charlotte compared to little concrete data on Caribbean immigrants - reveals the early stages of the construction of bounded 
trans-ethnic enclaves ("Immigrant Integration Task Force Report; Presented to Charlotte City Council” 2015, 5). Caribbean immigrants on the other hand more than often assimilate into the middle-class black American community. By placing the central concerns of this chapter in conversation with Hintzen's arguments regarding West Indian immigrants in the Bay Area, I seek to highlight the implications of sameness and difference (S. Hall 1997a; S. Hall 1990; Edwards 2001; M. M. Wright 2015; P. C. Hintzen and Rahier 2010). Despite the idea that "black is black", difference emerged in expressions, performances, and practices throughout my encounters with my African and Caribbean participants. Yet, the difference I speak of in this chapter encompasses Hintzen's assertion of the U.S.'s “discourse of difference" by expanding and applying the idea to the formation of black American subjectivity and identity as they interact with whites and other black immigrant subjects. I contend that this trope of difference is central to the production of identity and subject-formation as it serves to establish and designate class status and ultimately operate in the construction of situational collectivity among black Caribbean and African immigrants and black Americans in Charlotte. Further, this chapter considers the ways in which black subjects distinguish themselves or come together based upon conceptualizations of culture.

With the idea of cultural difference(s), I refer to culture in the traditional sense, or as a shared set of practices, system of beliefs, social formations, etc. among a particular ethnic/religious group. I also reference "culture" as an evocation of more superficial discourses of difference including the myth of the model minority and respectability. Distinguishing cultural differences from "cultural differences" permits a more intricate unraveling of the complexities that underline the idea that "black is black." Moreover, as 
the reigning notion of "black is black" simultaneously renders Caribbean and African populations invisible through U.S. Census Data as well as in everyday interactions, culture and "culture" become eminent signifiers that consciously and subconsciously differentiate black subjects in the South. Equally critical here is the fact that oftentimes black immigrants contest intra-racial difference in order to challenge the imposition of difference by white Americans with the idea that "black is black."

The assertion of "black is black" in response to white Americans' attempt to distinguish black subjects then signals black solidarity as these populations navigate the black-white binary in the U.S. South. Therefore, while culture and "culture" distinguish black subjects, myself included, black-white interactions in the South coagulate black subjectivities and identities into a collective "black is black." Further, socioeconomic status is perhaps the most visible defining factor in understanding when and where "black is black." Therefore, in this chapter I contend that while black is black, socioeconomic status, inherently intertwined with culture versus "culture," operate to decipher and define intra-racial and inter-racial interactions that impact black subject-formation and black identity among black immigrants and black Americans in the South.

\section{Navigating Blackness: Theories and Debates Concerning Caribbean and African Immigrants}

There exists an abundance of scholarship concerning the experiences of Caribbean and African immigrants in the United States (Waters 2001; Waters 1999; Shaw-Taylor and Tuch 2007; Okpewho and Nzegwu 2009; Rogers 2001; Vickerman 2001; Foner 2001; Hintzen 2001; Smith 2014; Anderson 2005; Stepick et al. 2003; Hintzen and Rahier 2003). However, the overwhelming majority of these studies focus 
on black immigrants in traditional gateway cities such as New York City, Miami or the Bay Area. Sociological studies within this realm explore first and second-generation immigrant identity formation among West Indians and their attitudes toward black Americans while those anthropological studies offer more in-depth presentations of subject and identity formation among Caribbean and African immigrants, particularly how these populations confront and process blackness in the U.S. Bobby Vaughn's (2005) (2007) exploration of Afro-Mexicans in Winston Salem and John A. Arthur's (2009) study on African and Caribbean immigrants' perspectives on the American judicial system are among the few to query black immigrant experiences in the South. Arthur only briefly mentions that he derived his findings through surveys and semistructured interviews collected in Minneapolis-St. Paul, Toronto, and Charlotte. The fact that Charlotte was a research site alongside Minneapolis-St. Paul and Toronto highlights the significance of the growing African immigrant population in North Carolina, and more specifically Charlotte.

Arthur's (2009) findings suggest that older generation African immigrants often hold greater trust in the judicial system than black Americans. Many of the older African and Caribbean participants in this study relayed similar views, asserting that black Americans should just be respectful of police officers. Participants expressed these perspectives in response to questions that centered upon the September 2016 killing of Keith Lamont Scott that sparked protests and gained national and international attention. Many of my participants that witnessed the unfolding of the Scott and Ferrell killings in Charlotte as well as other nationally recognized incidents such as the events in Ferguson and Baltimore blamed misunderstandings between black Americans and law enforcement 
for the unfortunate outcomes. These differing perspectives of the relationship between black subjects and law enforcement and the judicial system in the U.S. underscore elements of the myth of the model minority that distinguish one's "culture" or ethnicity from the depths of Black American pathology. To present a better understanding of the ways in which culture, ethnicity, and sociological theories of assimilation have theoretically discerned relationships between black Americans and black immigrants, we must consider previous scholarship and debates.

The assertion that "black is black" signifies a shared racial consciousness inasmuch as it acts as a disclaimer that often precedes notions and perceptions of a pathological black American culture expressed by black immigrants. These distinctions are more than often rooted in "culture" as well as ethnicity (Pierre 2004, 143). The reliance upon ethnicity and "culture" to discern black Americans from black immigrants is central to what Omi and Winant (1994) call the "ethnicity paradigm." According to Omi and Winant, the ethnicity paradigm holds that race is only one of a number of determinants of ethnic group identity while ethnicity is the result of group formation based upon culture and descent comprising a range of factors including religion, language, customs, nationality, and political identification (Omi and Winant 1994, 15). Rooted primarily in the European immigrant experience, the "ethnicity paradigm" fueled on-going developments of assimilation theory. When theorizing these aspects of life concerning black subjects, scholars more than often focused upon and emphasized a comparison between Caribbean and African immigrants and black Americans. E. Franklin Frazier was among the first group of scholars to predicate the need for the assimilation of black Americans based upon a European model, who in the U.S. had been 
absorbed by American culture after being eventually granted rights (Omi and Winant 1994, 17). Some twenty years later following Frazier's critical assessments, Daniel Patrick Moynihan proposed that there existed a "pathological" component of black American culture that only full assimilation could remedy (Omi and Winant 1994, 17). Portes and Zhou (1993), Portes and Rumbaut (1995), and Waters (1999) are among those scholars to make further contributions to assimilation theory and consequently, the ethnicity paradigm. Building upon assimilation theory, scholars derived the notion of "segmented assimilation." Mostly focused upon the experiences of second-generation immigrants, Portes and Zhou argued that post-1965 immigrants' experiences differed depending on the parents' social class, which led children to assimilate into different segments of the existing class structure (Brettel 2008, 91). According to Portes and Rumbaut's (2001) research centered in New York City, children of black immigrants risked the danger of "joining the urban underclass consisting of African Americans and Puerto Ricans in a 'new rainbow underclass' located 'at the bottom of society"'(Brettel 2008, 20). Despite this very weak assertion, Portes and Rumbaut's and Portes and Zhou promote an assimilation theory girded by an ethnicity paradigm.

Mary C. Waters' (1999) Black Identities: West Indian Immigrant Dreams and American Realities builds upon these highly problematic theories of assimilation, mostly those of Portes and Zhou (1993), and Portes and Rumbaut (2001) and John Ogbu's scholarship that distinguishes the experiences of voluntary versus involuntary black immigrants in the U.S. Among Waters' most concerning arguments delivered in this work is that West Indian immigrants, and other "voluntary minorities" hold a "greater trust" for white Americans than African Americans and that these groups place a greater 
emphasis on the value of education and work ethic. Waters claims that African Americans are threatened by assimilation as it supposedly requires them to sacrifice their "minority identity and security" as well as solidarity (Waters 1999, 143). Consequently, according to Waters, African Americans possess and assert "oppositional identities" that discourage education and a strong work ethic (Waters 1999). Ultimately, Waters holds that distinguishing attributes - in contrast to African Americans - among mainly first generation West Indian immigrants merit success while many second-generation immigrants succumb to the unfortunate circumstances of African Americans. Within the sociocultural political imaginary, these theories serve not only to challenge the reality that it is racism that impedes upon social mobility for black subjects in the U.S., but to also further crease the superficial sociocultural divisions between black subjects. Jemima Pierre's (2010) work on black immigrants and cultural narratives of ethnicity in the U.S holds that immigration studies, specifically the work of Waters', reinforces cultural narratives that continue to pathologize black Americans. According to Pierre, the "ethnicity paradigm" in U.S immigration studies has served to highlight particular groups' adeptness to assimilate to American cultural norms and values while reinforcing the narrative of black American pathology in exchange. While the focus on ethnicity works to emphasize black cultural distinctiveness against a homogenous black ethnicity and culture, it also privileges ideas such as the myth of the model minority. The concept suggests that black immigrants are more inclined to assimilate into "American" culture because of their work ethic and cultural beliefs while black Americans remain subsumed by a "culture of poverty", an underlining notion of a pathologized black American culture presented and perpetuated by scholars such as Daniel Patrick 
Moynihan, Portes and Zhou (1993), Portes and Rumbaut (1995), Waters (1999), Rogers (2001), and Vickerman (2001). In turn, black Americans possess an inability to assimilate. However, the model minority myth omits the socioeconomic and educational background of black immigrants, many of whom voluntarily chose to come to the U.S. versus black Americans who were forced to migrate involuntarily to then be historically and systemically constrained by varying forms of oppression (Shaw-Taylor 2007). While the 1965 Hart-Cellar Act, part of a series of civil rights legislation, promoted immigration from the Caribbean by eliminating quotas and limitations that restricted immigration from non-European countries, later immigration legislation such as the 1986 Immigration Reform and Control Act (IRCA) and the Immigration Act of 1990 introduced "lottery" systems and a "diversity program" designed to attract more professional and skilled immigrants, which has particularly been the case with the flow of African immigrants into the country (Shaw-Taylor 2007, 9). There is an imminent need to further interrogate those theories and scholars who perpetuate the ethnicity paradigm in order to recognize the cultural and statistical discrepancies of their work as well as recognize the on-going sociocultural, political and economic contributions of black Americans not just to the U.S. in general, but to black immigrant success.

Further, those scholars who perpetuate the myth of the model minority ignore the early presence and involvement of Caribbean immigrants in the black American community, most notably during the Harlem Renaissance and the Civil Rights Movement, pre-1965 Hart-Cellar Act (Shaw-Taylor 2007, 9; C. W. Smith 2014). Indeed, it must be noted that activists such as Marcus Garvey, Stokely Carmichael, and Shirley Chisholm were all first and/or second-generation immigrants from the Caribbean who 
actively formed a collective of black Americans, Caribbean and Latino immigrants in New York City and Los Angeles to protest a common enemy. There was no "greater trust" in white Americans as Waters suggests and each of these populations were equally victimized and oppressed by the same systems as black Americans. The amalgamation of cultures and ethnicities, those who are simultaneously similar but different, are the progenitors of modern prominent sociocultural and political movements that amass in the form of Hip Hop, art, black cinema and TV series that present commentary on shared oppression and experience. The historical relationship and collective resistance shared amongst these populations further counters the arguments of scholarly promoters of assimilation theory and the ethnicity paradigm.

Pierre (2010) argues that authors such as Waters treat ethnicity and race as "discrete categories" and present ethnicity as a "matter of choice" that yields particular behaviors and cultural practices that contrast to "pathological" African American practices and behaviors. Therefore, in works that examine concepts of assimilation and performativity among black immigrants, these theories become the root of what often appears to be a contentious relationship between black Americans and black immigrants. Utilizing these debates, this chapter further problematizes the reliance on the myth of the model minority, contending that in particular spaces in the U.S South, ethnicity and race are more heavily interrelated and in turn, impact black identity, subjectivity, and collective identity. In order to understand the construction of black immigrant identities and subjectivities in the U.S. South, it is critical that we consider processes of racialization that these groups undergo as they navigate the globe, beginning in their countries of origin. 
In the most straightforward sense, racialization is defined as "the process of making or becoming racial in outlook or sympathies" (Barot and Bird 2001, 602). Physical differences become signifiers for social and economic categories that construct racial identities and meanings (Barot and Bird 2001, 608). These ideas are intimately tied to Foucault's concept of the power/knowledge relationship in which the body is controlled through processes of subjection. In turn, racialization represents a process of subjection wherein the body is subjected to biological, hygienic, cultural, environmental hierarchies as well as structural, social, and psychological exclusion (Barot and Bird 2001, 609). Silverstein (2005) elaborates upon this definition by suggesting that racialization refers to "the processes through which any diacritic of social personhoodincluding class, ethnicity, generation, kinship/affinity, and positions within fields of power — comes to be essentialized, naturalized, and/or biological" (364). Therefore, racialization is the dynamic and "dialectical representational process of categorization and meaning construction in which specific meanings are ascribed to real or fictitious somatic features" (Silverstein 2005, 364). For Silverstein, this process enacts a "homogenizing magic" that compels racialized subjects into fixed categories. The United States is often presented as the paradigmatic model of racial homogenization and consequential oppression (Sawyer 2008, 138).

Understandings of race in the U.S have revolved around a stringent black-white racial binary that stems from the "one-drop rule" which was a biological basis for measuring the purity of white blood versus "tainted" black blood, signifying the inherent sociocultural and genetic inferiority of those racialized as black (C. W. Smith 2014, 21). The scientific racism that produced the concept of the one-drop rule was infused within 
U.S national rhetoric and in turn, its political and bureaucratic institutions. Through this, the exclusive boundaries between whiteness and blackness were solidified. In the U.S, both "blackness" as a concept and a "black racial identity" have been distinguished as a "particularly and peculiarly totalizing" identity applied to anyone of African descent despite their diverse heritage, histories, and experiences (C. W. Smith 2014, 21).

Understandings of race in the Caribbean are often conveyed as a pigmentocracy, or a social hierarchy based upon skin color (C. W. Smith 2014; Tate and Law 2015). At the same time, in Caribbean nations like Jamaica and Haiti, blackness remains a critical aspect of national identity and as a result of the majority black population in these countries, blacks regardless of complexion often occupy spaces at the higher end of the socioeconomic structure. Nevertheless, as a result of global white supremacy, whiteness and proximity to whiteness remain the ideal standard for social mobility (C. W. Smith 2014; Tate and Law 2015; Pierre 2013). In countries such as Trinidad and Tobago, and Guyana, race and processes of racialization are complicated by the large presence of East Indian populations.

Tate and Law (2015) highlight the established sociocultural complexities and conflict existent among East Indians and blacks in Trinidad and Tobago that stem from notions that East Indians were more inferior than Africans during colonialism resulting in the acceptance of mixture between Africans and Europeans but not of Europeans and East Indians (Tate and Law 2015, 74). As conflict between these populations was heightened through narratives of competition within the labor market, "Indian cultural alterity and aversion to Africans produced by the caste system and Hinduism" resulted in less racial mixing in these countries and a preservation of cultural, ethnic and racial 
boundaries (Tate and Law 2015, 75). This racialized construction underlines many of my participants' shifting understandings of race in the U.S.

Pierre (2013) contends, "racialization processes in various locations are interlinked and occur in relation to one another within the global context of white supremacy" (72). Pierre's work in Ghana explores the ways in which the historical, political, social and cultural interactions between Ghanaians and Black Americans in Ghana illustrate how conceptualizations of blackness are constructed not only in the U.S, but in Africa and throughout the Diaspora. The trope of whiteness in Ghana in which whiteness is a signifier for wealth and progress has functioned in similar ways as it has in Latin America and the Caribbean. See Figure 2.1 and 2.2 below. Black Americans in Ghana are perceived as located near ideological whiteness, and therefore, "lucky", although this perception shifts once Africans are in America. Expanding her argument on the impact of the trope of whiteness in Ghana, Pierre explores the phenomenon of skinbleaching that many Ghanaian women practice to appear more desirable and achieve socioeconomic ascendance. In Ghana, as well as other parts of Africa, racial rule was operationalized through processes of ethnicitization and tribalization in which race, ethnicity and culture were conflated, serving to obfuscate white racial power in a predominantly black society (Pierre 2013, 20). Meanwhile in U.S. traditional gateway cities, ethnic distinctions may remain in-tact, for example, a Yoruba or Igbo community in New York. However, in the U.S. South these distinctions appear to be blurred as a general "African" identity supersedes greater ethnic distinctions, at times giving way to a collective Pan-African identity. At the same time, socioeconomic and linguistic distinctions indicate hierarchies that remain rooted in nationality and ethnicity. 


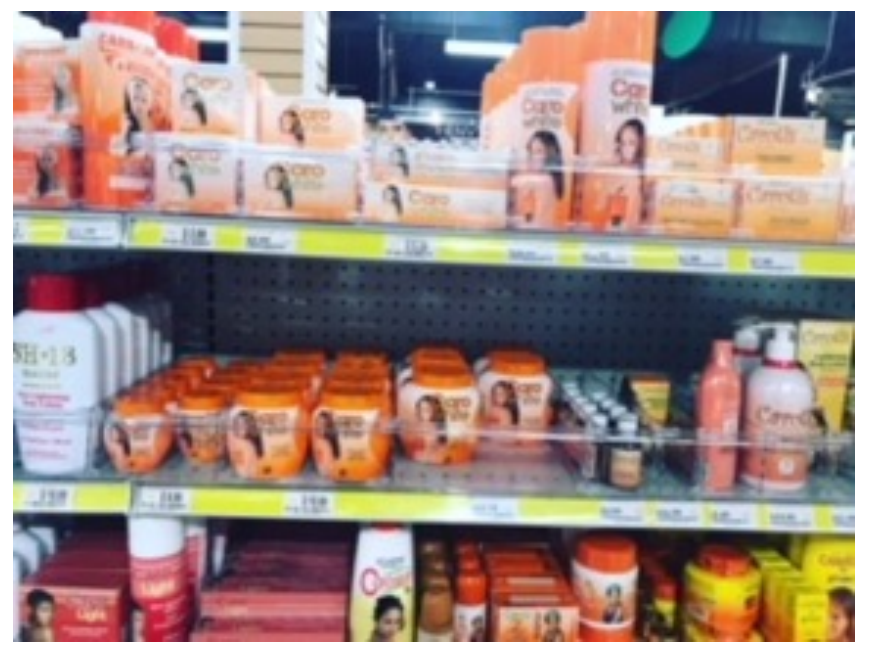

Figure 2.1. Caro White Skin Bleaching Products in Tisun Beauty Supply, East Charlotte.

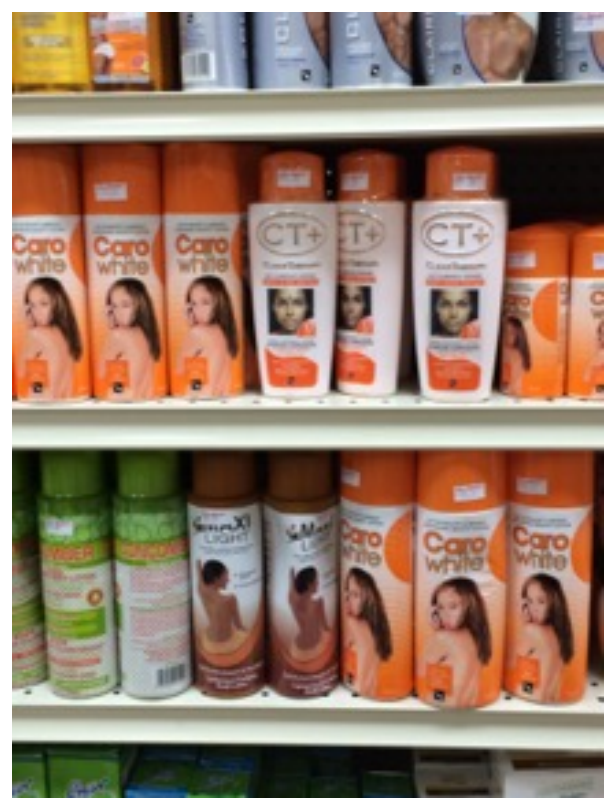

Figure 2.2. Caro White Products at DeliMart in Port-au-Prince Haiti, demonstrating that the trope of whiteness is transnational. Both Photos by Author.

Stuart Hall (1997) defines blackness as a "historical category, a political category, and a cultural category" that becomes a signifier inscribed in subjects' skin (Hall 1997a:53). Yet, it is "not because of their skins that they are Black in their heads" (S. 
Hall 1997a, 53). Hall speaks of race as a "floating signifier" which coincides with the experiences of many black and brown subjects as they navigate the globe. Rahier utilizes this concept to describe his multiple experiences maneuvering through Africa, Europe, Latin America and the U.S., in which he defines race as a floating signifier by suggesting that race means "different things at different times, in different places" (Rahier 2003, 101). Hall asserts that drawing a collective identity based upon skin color is problematic, in that those racialized as black are not necessarily "black" in their minds. Instead, it is through political systems and categorizations that individuals "learn" to be black, making blackness a process of identification (Hall 1997a:55). Hall (1997) himself recalls in Jamaica that very rarely did he hear people call themselves or anyone else "Black" despite the fact that there existed a very visible color stratification system wherein one could "compute and calculate anybody's social status" based upon hair texture, physiognomy or complexion (S. Hall 1997a, 53). This chapter considers blackness as a process of identification wherein subjects "become" black, or simply through "being" black, subjects develop new understandings of blackness as it signifies different things throughout their journeys.

Michelle Wright (2004) begins her work, Becoming Black: Creating Identity in the African Diaspora, with an excerpt from Jamaica Kincaid's prose poem "Blackness" in which Kincaid states, "the blackness is visible and yet it is invisible" (M. M. Wright 2004, 1). For Wright, Kincaid's words signify the "in between" space of blackness as a constant state of contradiction within "the material and the abstract", "the struggle between Black identity's individual and collective aspects" and "the inherent fluidity of Blackness" that is able to both "harm and heal the Black individual" (M. M. Wright 
2004). Central to the formation of black subjectivity in the West, is the constant and ongoing negotiation between these extremes and contradictions, particularly concerning the "hypercollective", or an essentialist identity versus the "hyperindividual" which "grants a wholly individualized self in exchange for the annihilation of "Blackness" as a collective" (M. M. Wright 2004, 2).

In this chapter, I am concerned with the ways in which these extremes are not only negotiated, but displayed through performance and representation. Further, "reading" one's status through only one categorization, particularly that of race, which is heightened in the U.S. South versus subjects' own racial identifications and multiple histories and mobilities demonstrate the ways often compel subjects to (re)produce the same structures of exclusion that have been implemented by the dominant western white hegemony (M. M. Wright 2004, 6). As such, Wright holds that it is necessary to intertwine the implications and definitions of blackness with those of gender and sex. By considering these alternative categorizations, Wright contends that those defined by the "same racial category can be rendered Other in different ways"(M. M. Wright 2004, 7). With this, Wright presents the notion of "becoming black" as a "complex negotiation" between the dominant and minority culture, often requiring one to reject cultural identity(ies), that one must undertake in order to survive either physically, psychologically or both. Like Wright, my usage of "becoming black" does not assume that the subjects in my study did not hold individual or collective identities based on blackness in their countries of origin or prior to their arrival in the U.S. South. However, the experiences and accounts of my participants in this study communicate their intricate 
and complex negotiations and contradictions of blackness that have been layered as they travel throughout the West and build lives in the U.S. South.

Olúfémi Táíwò's and Carole Charles’ self-ethnographies in the co-edited (P. C. Hintzen and Rahier 2003) volume Problemetizing Blackness; Self-Ethnographies by Black Immigrants to the United States respectively entitled, "The Prison Called My Skin: On Being Black in America" and "Being Black Twice." Taiwo makes several points that significantly contribute to this dissertation. First, Taiwo addresses what he calls a "spurious" "black individuality" that functions to reinforce the idea of a homogenous group that lacks variation, with singularity predicated on the existence of a group (Taiwo 2003, 40). Even more critical to this discussion, Taiwo asserts that upon arrival in the U.S., he "became black." Taiwo acknowledges that this assertion is puzzling to some, since as a black man from Nigeria, it is presumed without question that he is simply black: in the assumption that "black is black", his blackness is not open to doubt. Yet, for Taiwo this "becoming" speaks to his assertion that being black in the U.S., "is not a given, an ontological, factitious category, but a historical construct, the product of sociogenesis" (Taiwo 2003, 42). He expands upon this construct of blackness asserting that "as soon as I entered the United States, my otherwise complex, multidimensional, and rich human identity became completely reduced to a simple, one-dimensional, and impoverished nonhuman" (Taiwo 2003, 42). In many ways, Taiwo's account both reifies and complicates the notion that black is black in that his blackness as in the color of his skin is unquestionable yet the idea "black is black" simultaneously homogenizes the complex and multidimensional aspects of his identity, for which blackness is just one. 
The warring ideals and implications of blackness in the U.S. and blackness in immigrants' host countries yield a particular layering of identity, what Charles (2003) identifies as black immigrants' "cultural baggage of blackness informed by participatory experiences in their countries of birth" (Charles 2003, 171). Carole Charles expresses this sort of layering as "becoming "black twice." For Charles, in Haiti, blackness is a central and critical aspect of Haitian national identity as the first black republic in the Western hemisphere, yet as mentioned, class and ultimately a color caste system operate to mediate and employ a "language of race." Growing up in the States during the 1970s at the height of the Black Power movement, Charles came to embrace and adopt expressions of political and cultural solidarity with the black American community by wearing an Afro, one of the most poignant examples of this expression. It was Charles' adoption of a black American identity parallel with her Haitian identity through which Charles became "black twice", an idea which Charles argues is "the center of the construction of black immigrant Caribbean subjectivities" and "the root of the process of reshaping and expanding the meanings and boundaries of blackness by immigrants of African ancestry" in the U.S. (Charles 2003, 173). Building upon Charles' and Taiwo's experiences and central arguments, I assert that not only do black Caribbean and African subjects "become black" but also depending upon their multiple destinations in the States as well as their interactions with black Americans in the U.S. South through business, friendships, marriages etc. subjects may become black not just twice, but multiple times, representing the multiple layers of their identities.

In her ethnographic study of West Indians in Cuba, Andrea Queeley (2015) found that her interlocutors emphasized "alternative" ways of "being" Black. These alternative 
ways of being sought to deny degrading stereotypes associated with blackness, giving way to notions of "middle class respectability," instrumental in the construction of an Anglo-Caribbean subjectivity that could at times distinguish itself from the rest of the Cuban population (Queeley 2015, 4). Aspects of this respectability are often dependent upon or actualized through performance, including the use of language, dress, ideology, and mannerisms; all of which are situational as subjects maneuver through varying spaces and places (P. C. Hintzen 2001; Rahier 2003; Queeley 2015b; Greenbaum 2002). Respectability as an instrument utilized by racialized subjects is a noticeable shortcoming of scholarship on black immigrants in the U.S., particularly within sociological studies. Respectability acts as a feature in the deployment of the myth of the model minority. Yet, it is critical to acknowledge that respectability also functions inter- and intraethnically as all racialized subjects are subjected to stereotypes associated with blackness and must strive against these in the face of global white supremacy (Greenbaum 2002; P. C. Hintzen 2001). Respectability presents itself as perhaps one of the more outstanding themes of this dissertation and operates to both foster both sameness and difference.

\section{"Black, African-American, I Don't Know If There's a Difference...Is There a Difference?"}

Many of my interlocutors express their racial and ethnic identification as well as their understandings of blackness in varying ways depending on their countries of origin. For example, Kester a participant who I discuss below, understood his blackness in relation to that of East Indians in Guyana, not white American southerners. This left Kester feeling somewhat naïve about southern race relations after moving from New York City to the South where he discovered he was one of the only black men working at 
a corporate headquarters for one of the most well-known motorcycle companies in the world. This experience made Kester more aware of his blackness than ever before. At the same time, expressions of blackness revealed that while the idea of "black is black" operates as an overriding principle, understandings of blackness and racial/ethnic identification shift between ideas of "cultural difference", constructs of processes of racialization, Afrocentric ideals, and socioeconomic status. Terminology was key in defining identities; for some participants, there was confusion on if they should use Black or African American, for others there was no question about terminology, they were firm in their designation. For others, terminology/categorization reflected their layered identities. Nevertheless, it is clear that the U.S. South critically shaped/reshaped these understandings.

I first officially met Pap, a Senegalese immigrant and owner of House of Africa and founder of the Annual Juneteenth Festival of the Carolinas at the start of my research in the summer of 2014. Pap is very well-known for his involvement in the African American community and his boutique House of Africa that sells African artwork, jewelry, herbs, lotions, potions and clothing, a great deal of which is very expensive. House of Africa is also one of the longest standing businesses on Central Avenue in the heart of East Charlotte. In Chapter Five, I expand upon my time and observations at House of Africa during the planning of the Annual Juneteenth Festival of the Carolinas. In that chapter, I present the central findings of this dissertation by building upon Alai Reyes-Santos (2015) model of affective kinship to argue that House of Africa and the Annual Juneteenth Festival of the Carolinas represent the construction of a space and place with foundations rooted in kinship ties that allow black subjects to move beyond 
differences to assert solidarity and belonging rooted in Afrocentrism. In accordance with Reyes-Santos, kinship "entails caring, having an ethical concern for the well-being of those who belong to a family or community, and being willing to put ourselves at risk by standing next to those who may be different from us"(Reyes-Santos 2015, 3). Pap's relationship and immersion within the upper middle-class black American community, as I have witnessed at the House of Africa and interactions at the Juneteenth Festival represent this sort of kinship. The fact that Pap as a Senegalese immigrant saw the need for and established the Juneteenth Festival celebrating the end of slavery in Texas, a black American holiday, is also representative of this type of kinship. In response to my first question of how Pap classifies or identifies himself in terms of race and ethnicity, he simply responded, "black" followed by a matter-of-fact chuckle. Yet, he revealed the following when I asked him if he had additional Senegalese family members in Charlotte: MB: I want to ask, do you have any family members here in Charlotte? Pap: Hmmm...not really but my African American family--I have my family. MB: Your African American family, like black Americans?

Pap: No, not black, do not call them black, they're Africans born in America, that's the only difference between you and me MB: Okay... Pap: You are [an] African born in America, that's the only difference Through my later observations at House of Africa, I gathered a better sense of what Pap meant by his affirmation of his African American family as the boutique and the Juneteenth Festival are indeed familial events, with many of the African Americans involved having built a $20+$ year relationship with Pap. Pap is also involved in several 
prominent African American organizations including the Afro-American Cultural Center and the Urban League. Further, even though Pap is a practicing Muslim, he attends University Park Baptist Church, Friendship Missionary Baptist Church and Little Rock A.M.E. Zion, three of the largest black American religious institutions in the city, indeed, the first two could be considered mega-churches, where some of the wealthiest black American Charlotteans attend. The pastor of Friendship Missionary Baptist happens to be a family friend and based upon our conversations, Friendship hosts a significant membership of upper middle class African and Caribbean attendees. ${ }^{4}$

In Chapters Five and Six, I focus on Reyes-Santos's theorization of alternative kinship. Equally important is Copeland-Carson's (2004) ethnographical study focusing on kinship formations among Africans and African Americans at the Cultural Wellness Center in Minneapolis. Pap's understanding of blackness coincides with CopelandCarson's findings in which some in her study identified as "Africans born in America" signifying an "African cultural memory" retained in the body through skin, although this identification is not based upon skin-color alone (Copeland-Carson 2004, 42). Through this understanding of blackness, "blackness" and "Africanness" are interchangeable although not necessarily synonymous at all times. The interchangeability of blackness and Africanness indicates what scholars like Hall, Wright, Rahier, Gilroy and others critique as those aspects of Afrocentrism that are inescapably essentialist. Yet, as

\footnotetext{
${ }^{4}$ Despite preliminary research that highlighted African American churches in Charlotte as spaces/places of intersection, for the sake of time, I opted to focus primarily on more explicit places of business. Religious institutions, places of worship and black immigrants in the U.S. South is deserving of a separate more in-depth research study (Ehrkamp and Nagel 2012). There is a need for future research on these intersections in places of worship as well as ethnic -based religious institutions, for example, there are about four to five Haitian churches of differing denominations in the city.
} 
Copeland-Carson asserts, instead of dismissing Afrocentrism as unworthy of scholarly analysis, we must proceed from the position that "any act of human cultural creativity is a legitimate area of academic study" (Copeland-Carson 2004, 22). As my initial conversation with Pap went on, I inquired how he maintains his culture here in Charlotte. For Pap, maintaining his culture included his continued practice of Islam. Reminding me that my ancestors were probably most likely Muslims before being brought to the Americas, this aspect appeared to be another realm of establishing and maintaining similarities with African American on a deeper ancestral level. In addition, Pap felt that the Juneteenth Festival bridged the cultural gaps between Africans and African Americans in Charlotte. Therefore, Pap's identification and understanding of blackness is underlined by a strong notion of Afrocentrism as well as collectivity, a collectivity that operates within a black American middle-class context. Despite potential sociocultural and religious differences, Pap affirms a connection to all black subjects despite origin as these populations are linked through ancestry and blood.

The black American middle-class context has proven to be central to the development of many of my participants' identification and interaction. Their expressions of blackness and identity vary and shift depending upon how deeply they are entrenched within the black American community. Patrice ${ }^{5}$, an older Togolese immigrant

\footnotetext{
${ }^{5}$ I met Patrice during preliminary research in 2015 , his name was listed on International House's website as the president of the Neighborhood Good Samaritan and the Togolese Community Association. International House is a local non-profit that assists new immigrants in their transition, and where I interned and worked in the past. Patrice would emerge in later phases of research, in 2017 with Mrs. Tina, the owner of Sierra International Mart. Mrs. Tina received a letter one day from the African-Caribbean Political Action Committee, of which Patrice is the head organizer. Before then, in 2015, Patrice referred me to Ogunrinde. I'd meet with Patrice again on a follow-up interview in
} 
and founder of the Neighborhood Good Samaritan Center and African-Caribbean Political Action Committee both of which operate from his East Charlotte business office, referred me to Ogunrinde. Ogunrinde is a Nigerian real-estate developer and former president of the African Chamber of Commerce and member of Brothers Abroad. Ogunrinde mentioned that even though he still works on some projects in Charlotte, most of his businesses are located in Africa and Asia. Ogunrinde also attends Friendship Baptist Church and is married to an African American woman. Ogunrinde came to the U.S in 1985 to attend college at Southern University in Louisiana, an HBCU, and moved to Charlotte in 1991, where he worked for Harvey Gantt, an architect and Charlotte's first African American mayor. Brothers Abroad is a small social organization founded by African men from around the continent living and working in Charlotte. The men often meet at East Charlotte restaurants like Zoewee's Liberian restaurant, Motherland Cuisine (Nigerian owned), Spice Lounge (Nigerian owned), small grocery stores, and Patrice's (Togolese) office. Ogunrinde and Patrice mentioned that many of the men involved represent the countries of Togo, Cameroon, Sierra Leone, Ghana, Liberia, and Nigeria. In fact, Patrice mentioned in our initial interview that through his multiple organizations, he has encountered at least one person from all 54 countries in Africa... in Charlotte. I found this extremely interesting, but unfortunately did not have the time to confirm this data as I never received a complete roster of countries represented. Nevertheless, the array of African businesses I encountered undoubtedly represented a diverse African population in Charlotte beyond what I had initially imagined.

2017 where we discussed more specifically his work with the ACPAC, which I was unaware of in the first phases of preliminary research. 
The African Chamber of Commerce was initiated about ten to twelve years ago to encourage transnational business flows/exchanges from the U.S. to the continent, instead of one-directional flows of aid from the West. The Chamber also consisted of a PanAfrican, trans-ethnic group of African entrepreneurs, businessmen, engineers, doctors, lawyers, etc. The organization first started meeting at Johnson C. Smith University, the local HBCU in Charlotte and held events at the Afro-American Cultural Center, now called the Harvey B. Gantt Center for African American Arts and Culture. The African Chamber of Commerce also worked closely with the Black Chamber of Commerce. However, according to Ogunrinde overtime, both fizzled out although not completely defunct. Ogunrinde attributed the reason to a smaller membership and in turn, lesser membership funds that could not compete nor uphold that required by the city-wide Charlotte Chamber of Commerce. Ogunrinde's multiple cross-cultural and transnational involvements seemed to manifest in his identification. When I asked Ogunrinde about how he identifies in terms of race and ethnicity, he responded:

"I identify with my Nigerian culture and then the next layer, I identify with my African roots, then the next layer, I identify with being Black in this city and in this country, and then finally I identify as an American. I'm a naturalized citizen, married to an AfricanAmerican woman but there's something about where you're originally from that never leaves you, no matter how naturalized, and how your accent changes, whatever, you're still African, you're still Black, and ultimately, you're still Nigerian. So, primarily, Nigerian, African, American, all that.”

Ogunrinde’s layered identity speaks to Queeley’s (2015) visualization of a Russian doll that contains multiple dolls within it. Ogunrinde's identity and subject- 
formation is representative of multiple mobilities garnered by variations of travel and being throughout multiple destinations in Africa and its Diaspora before finally arriving and living in the U.S. South. For Ogunrinde, these mobilities are on-going as he travels back and forth between Africa and Charlotte. Further, Ogunrinde's past education at an $\mathrm{HBCU}$ as well as his later involvement with the African Chamber of Commerce and Brothers Abroad, both of which were at times intertwined with the black American community reveal Earl Lewis' (1995) concept of overlapping and layered diasporas (Queeley 2015a, 13). Ogunrinde's establishments and personal connections are indicative of the multiple layers of his identity; one layer connects to his Nigerian nationality, another to a Pan-African community, and another to the African American community. Thus, Ogunrinde's identification occupies and speaks to multiple subject positions (Queeley 2015a, 13).

In accordance, The Chamber and Brothers signify the creation of a larger PanAfrican, trans-ethnic and transnational African community, with Brothers being based out of various meeting locations in East Charlotte. It is important to note that Ogunrinde like many of the others I interviewed who were involved with Brothers and the Chamber do not live in East Charlotte, establishing East Charlotte as a sort of nested nucleus for the multiple identities that emerge (Queeley 2015a). Lastly, Ogunrinde is very much immersed within the black American middle class. This is evidenced by his work with Harvey Gantt and other former black American mayors like Anthony Foxx, the former U.S. Secretary of Transportation and Patrick Cannon, who was the mayor at the time of this interview. Ogunrinde mentioned that one of the advantages of living in Charlotte is that he could casually call the mayor's office and other councilmen to personally speak 
with them, play golf or have lunch to discuss issues. Ogunrinde represents the ways in which solidarity is often rooted within the context of the black American middle class while at the same time, maintaining his Nigerian culture as well as a broader African network, he pledges to his multiple identities. Based upon the accounts provided throughout this dissertation, particularly during my observations at the House of Africa discussed in Chapter Five, Black American foundations prove essential in forming core collective communities and identities among black and brown subjects.

One of the most interesting factors that connected many of my participants was the fact that they attended HBCUs. This factor is intriguing because despite being immersed in a black American institution of higher education surrounded by other educated black Americans, their understandings of black Americans continued to revolve around "cultural differences" that counter the history and mission of HBCUs. Historical Black Colleges and Universities were established strictly to attend to and elevate the educational needs of young Black Americans in the wake of the Jim Crow South. These institutions were/are pivotal in the development of African American institutions in the U.S South. Even as someone who did not attend an HBCU, they were critical to my development and as such, I was somewhat dismayed by the accounts of black immigrant alumni of these institutions who appeared to disassociate the historical achievements of black Americans from their own ability to ascend at a Black American institution in the U.S South. In addition, the concept of diversity emerged as a critical aspiration central to their identities in the South, as they noted that in the South, black Americans tended to only congregate amongst other black people instead of forging diverse groups of friends. Seeking friends beyond that of solely black Americans, seemed to be an active venture 
for black immigrants and respectable black Americans as well. It is necessary to explore this aspect of black immigrant identity, especially of those that attended or are affiliated with HBCU institutions.

I was introduced to Donnaree, a young Jamaican woman, by my friend Crystal. Both work at TIAA Financial Services. I began to jokingly refer to Crystal as my research assistant as she introduced me to several co-workers from the Anglophone and Spanish-speaking Caribbean who participated in this study. I even started attending TIAA "work crew" happy hours at Bar Louis in University City and continue to join the TIAA crew at times. The different crews, separated by the various departments, such as Human Resources, IT, etc. each meet every other Wednesday after work and sit at different tables depending on their respective departments. Bar Louis during Wednesday happy hour is predominantly black and corporate. After corresponding through email, on the way out from a TIAA happy hour one evening, I met Donnaree in person. She was sitting with her IT crew, a group consisting of two middle-aged Jamaican men, a white gentleman, and two other people of color. After my subsequent interview with Donnaree, I organized a focus group that I call the "Diverse Corporate Happy Hour Crew" where I met Mark and Clinton, whose accounts I discuss throughout this dissertation. My initial interview with Donnaree was held at Caribbean Hut, a Jamaican restaurant located in University City.

As Donnaree and I sat down for a Red Stripe and a beef patty, we discussed her time in the U.S. and in Charlotte and how this potentially affected her racial and ethnic identification. Donnaree was born in New York City to Jamaican parents, and then moved back to Jamaica as a baby where her grandmother raised her for seventeen years. 
She moved to Charlotte from Savannah, Georgia, her first stop back in the U.S., where she attended Savannah State University, an HBCU. However, Donnaree did not realize that the school was an HBCU until she arrived; Jamaica does not have similar institutions nor a history of Jim Crow that would warrant the need of such institutions. In the following exchange Donnaree explains her racial and ethnic identification.

MB: How do you identify?

Donnaree: I identify as Other.

MB: Okay, why Other?

Donnaree: Because in Jamaica we go by out of many, one people. With that being said, no one person is fully black because of the melting pot right? The integration of the different cultures so...my family, as far as settlers, there were two brothers who went to Jamaica

MB: They went to Jamaica from where?

Donnaree: England. Yea so...one went to the middle part of the island and the other went to the Eastern part, and then from that, I'm like the third or fourth generation, somewhere right in that bracket...they [the two brothers] were white and then my grandmother is Syrian mixed. So really, within my family, [there are] what an American would identify as brown people and white... and every generation there is this one black person, so yea I'm the [black] child amongst my mother's siblings' [other children/cousins]...but I prefer the term Other MB: Okay, so tell me about your experience identifying as Other being in the South, and going to an $\mathrm{HBCU}$

Donnaree: [Sigh] It wasn't much really, you know, like you go and say you're Other, and 
nobody really asks you or anything but if there's a form and somebody else is filling it out, they're going to mark black because they see me as black so not necessarily what I want to identify myself as so I just go with it...it doesn't bother me.

From this account, Donnaree's racial and ethnic identification stems from the Jamaican national motto "out of many, one people" which signifies the country's multiracial heritage and Donnaree's own familial roots. Yet, in the South, particularly at an HBCU, other people classify her as black based upon her darker complexion and natural kinky hair despite her personal identification as Other. As our conversation continued, Donnaree's identification as Other and upbringing in Jamaica also significantly impacts the group of friends she has selected while living in Charlotte. Donnaree's roommate is Liberian and while she joked that, "I promise I don't go out looking for foreign people, they just find me." I asked her to expand upon this.

Donnaree: My group of friends is diverse. I'm all for diverse groups. I don't necessarily stick to one culture just because. My prior years of course growing up in Jamaica, I [was only] exposed to the different cultures within [Jamaica]. We got a strong Indian culture, Asian, whites not as much and then you have black. Like I went to school with a lot of different sets of people, not that I was really hanging out with them but with just that, I came here and I'm always open to people learning new cultures and all that stuff. When I was in college, I became involved in the international student association where I was really involved in the coordination of events, and all of that different stuff. And then when we had events, we had it where you can go and try different foods from different cultures. Then, I worked at a Japanese restaurant so I love sushi [laughs]!! 
So doing all of that, and then here, like I told you my roommate is Liberian, she came to America when she was ten, so she has a different experience but now we live together. I met her when she was just starting at the company [TIAA] when I was an intern. Yea, so that was back in 2014 when I came back, she had met a lot of people. And the one person I introduced her to, she's from Ghana, so now it's like Germans, and all these people that we all hang out with. [There are] Germans, Africans, me, the Jamaican, plus an English guy. So yea, we're all diverse.

Here, it appears that Donnaree has internalized Jamaica's discourse of a creole multiracial nationalism (Thomas 2004). Deborah A. Thomas (2004) holds that the nationalist slogan, "Out of Many, One People” serves as an "aspirational slogan" that “reproduces colonial social hierarchies by parenthesizing blackness" hence Donnaree's claims to being the "one black person" of her generation of cousins (Thomas 2004, 12). We could also align her desire for "diversity" with the requirements of respectability that underline many middle-class Jamaican adherence to the values that creole multiracial nationalism aspires toward. According to Thomas creole multiracial nationalism operates alongside what she terms, "modern blackness, another aspect of Jamaican nationalism wherein a reemergence and celebration of Jamaican folk culture rooted in both mythological and actual facets of Africa that are associated with the working class and rural sectors (Thomas 2004, 6, 13). Whereas "modern blackness" operating as a "subaltern aesthetic" situates blackness within the present and always mobile (transnationally, spatially and temporally), creole multiracial nationalism posits blackness as something of the past and the future, with future blackness signaling a progression to a "tamed" blackness that mirrors the values of the creole professional middle-classes 
(Thomas 2004, 13). Both inside and outside of the country, Jamaicans "use" America to "simultaneously critique, selectively appropriate, and creatively redefine those aspects of the dominant capitalist ethos that they believe benefit themselves and their communities, both materially and psychologically" (Thomas 2004, 14). These ideals undoubtedly influence Donnaree's identity and in turn, her experiences here in Charlotte, including the places she eats, where she hangs out and who she hangs out with. Her diverse group of friends in Charlotte in many ways reflect her interactions in her country of origin as well as her desire to not be confined to one racial/ethnic category. The diversity of Donnaree's group of friends also indicates her corporate position and socioeconomic status. Yet, what I found most interesting in her account is that although Donnaree identifies as Other, which coincides with Jamaica's multi-racial roots, she still recognizes black people as a group in Jamaica as well as her own blackness by noting that she is the one black child in this generation of her family. As such, Donnaree's notion of blackness appears to be cognizant of diverse histories and experiences in contrast to essentialist perceptions of blackness, like the one-drop rule. Still, these diverse histories and experiences, at least as Donnaree articulates them through her identity, reinforce hegemonic ideologies particularly concerning race and class (Thomas 2004; Thame 2017).

I utilize hegemony here in the same way as Thomas, who, quoting William Roseberry (1994) refers to hegemony as "a common material and meaningful framework for living through, talking about, and acting upon social orders of domination" (Thomas 2004, 8). At the same time, Donnaree has also experienced racial discrimination "almost weekly or monthly" which she says is a result of stereotypes attached to black people in 
the States. Further, having attended a historically predominantly white high school with pockets of diverse student populations, Donnaree says that upon arriving at Savannah State, she experienced culture shock. In recounting this experience she reveals, "I mentally remember this thing of me saying, Oh my god, how am I going to do this? I'm going to school with all black people! I'm like, I'm not used to this! I [was] so used to being with the white folks that I was mentally disturbed, like dude this is what's going to happen? Well, what you have are the American black people, and most of them they're pretty privileged right? Believe it or not, yes you do have white privilege and they're superior because most of them they [are] born into wealth or something...but you have the black folks, and they come to college and they come there and live on student loans and all that. They get this refund check [student loan disbursement], and they blow it, instead of paying it back! Like reduce your debt at the end right? I don't know if that could tie into just financial literacy or what, but I feel like, they come, and some of them, their folks got some money and all of this, and when they come, they don't pay attention to their grades and they graduate without jobs and want to blame somebody else you know, but it's nobody else' fault you know?!"

This convoluted reasoning and articulation suggests a "cultural difference" between West Indians and black Americans underscored by a perceived sense of privilege and lack of financial literacy that somehow represents black Americans' lack of work ethic. In this instance, black American's lack of work ethic is not necessarily associated with being lazy, but a perceived privilege. Below, I discuss another participant holding similar views of black Americans. In both cases, I found it ironic that even in a predominantly black institution of higher education, where black success is concentrated and 
encouraged, there are still sweeping generalizations of black Americans. There is also an assumption that black Americans resort to blaming others when they do not attain immediate success. Therefore, in addition to Donnaree's attraction to other foreigners most likely because of shared experiences and interests, it could be that "cultural difference" also influences her selection of friends from other backgrounds. In other conversations with Caribbean and African participants, black Americans' lack of financial literacy and other inklings of "cultural difference" continued to emerge alongside shifting understandings of blackness from countries of origin to the U.S as well as an emphasis on diversity.

Part of another TIAA happy hour crew, is Kester who was also introduced to me by my friend Crystal. Kester is in his early 30s and was born and raised in Guyana before moving to Brooklyn where he attended high school. Kester then attended ClarkAtlanta University, an HBCU located in Atlanta, Georgia. After graduating college Kester took on several different positions with national and multi-national corporations in Alabama and Milwaukee before landing in Charlotte with TIAA. Like Donnaree, Kester's understanding of race derives from his experiences in his country of origin and shift as he travelled throughout the U.S. The exchange below displays Kester's shifting understandings of blackness.

MB: So, tell me, how do you identify? In terms of ethnicity or race?

Kester: Black...African-American, I don't know if there's a difference....is there a difference?

MB: I don't know, you tell me...

Kester: So, okay, before I left Guyana, this whole racism thing took on another form. It 
was Black people in Guyana feuding like the Blacks and Whites feud here in the States, but the Black people in Guyana were feuding with the Indians, against the East Indians. And that was due, obviously to poverty, I think, economics, poverty, social economics, social prestige and just- - I think the government, the political climate of the country was very unstable and is still unstable today. So, I guess I identify as Black.

Unlike Donnaree, Kester does not see the presence of East Indian populations in Guyana as indicative of a harmoniously multi-racial society even though Guyana's national motto, "One people. One Nation. One Destiny" is very much similar to that of Jamaica. Instead, the presence of East Indians for Kester, shaped an understanding of blackness as something that exists in contrast to something/someone else, suggested by his comparison between blacks and East Indians in Guyana to that of blacks and whites in the U.S. Kester's understandings would continue to shift while navigating the U.S. Upon arrival as an adolescent in Brooklyn, Kester felt like a "fish out of water" recalling, "I guess most people today would call it bullying. It was from people who looked like me. I spoke differently, I probably acted different, didn't get involved in certain things that were normal like gangs and smoking and all that stuff in high school, so the kids picked on me, but I was cool with it."

Being taunted and bullied as a result of cultural differences by black Americans is an aspect that emerged in many of my interlocutors' experiences while growing up. In chapter four, I examine how cultural differences ultimately influence the construction of "cultural differences" that establish boundaries between black subjects. Here, I want to focus on how cultural differences and "cultural difference" influence understandings of blackness. According to Kester, "being Black from that perspective [in Brooklyn], I 
didn't get a whole lot of attention from Black people. And probably because I didn't grow up-I wasn't raised in Brooklyn and the other community, the Black community, I was treated differently." From this, Kester's nationality, culture, and experience fails to conform to or accommodate essentialist notions of blackness. However, this begins to shift beginning with his attendance at Clark-Atlanta and later as he took on a job with Harley Davidson in Talladega, Alabama. Kester recalled that Harley Davidson was 90\% Caucasian male and could remember seeing only one other black male, who was a custodian. Kester recalled that during his time working at the Speedway, he would see confederate flags, and now realizes that at some point he was probably "close to being lynched" but at this time, he had not yet completely grasped the history of the U.S. South. Of all of the places that Kester has lived, he prefers Charlotte, noting its diversity as one of the reasons he has decided to stay in Charlotte as it offers him an opportunity to "expand his network" by having friends who are Asian, white, as well as other races and cultures. In the following sections as well as chapter four, I expand upon the ways in which this desire for diversity compels what Queeley calls "alternative ways of being black" and in turn, requires certain levels of performance. Attaining diversity then becomes criterion for what I later define as the "trope of difference" that designates and connects socioeconomically mobile black subjects while excluding others.

As Kester comes full circle in his discussion of shifting understandings of himself and his blackness, he returned to the initial question of identification, this time in response to a question I asked of whether he considered himself to be "different" from other black subjects in the U.S. South because he was Guyanese.

Kester: So, here's what I get from people. They look at me and then they squint their 
eyes and then they say, I hear an accent. Especially, from people that are from the Caribbean, I think they can detect— they can detect something different in my accent. I think other people that are not from the Caribbean, they can detect something but they never ask. The Caribbean people tend to ask [where I am from] but people for the most part they can't really tell. What I get most of the time is, 'you speak really well.' So, I don't think - unless they're really listening, people just think I'm Black. I don't get the distinguishing remarks that much, except from if they can tell a twang [accent]. Otherwise, I don't know, I don't get any difference from being an immigrant and being Black or an African-American in the States.

MB: And what would you be in Guyana?

Kester: Just Black, a Black person in Guyana. So, when you say African-American here or Black, I think, there's a slight chance that somebody might get offended by being called a Black person or African-American. I don't think that there's a difference between Black and African-American. I don't get offended by it, I guess. I'm willing to be educated on it, if there's a difference in it. Is there a difference?

MB: It's a question that's up to the person. We all have our own definitions...

Kester: Yeah, I don't see a difference.

MB: Yes, but some people would see a difference.

Kester: Yes, I know people that would get offended, and sometimes when I'm in a setting, I think I need to go with the more classical term. I think, let me say AfricanAmerican, so people won't get offended, but you're Black! That's it.

MB: Who do you think would get offended?

Kester: Other Black people. That's something that I impose on them. I just feel like, in a 
[particular] setting, let me just go with my main intuition and say African-American

rather than Black people. I choose my settings. If I'm in a buttoned-up conversation with people in tuxes and suits, just go with African-American, because that seems to be more smoothed and polished...but in my head, it's like the same thing. I just choose where I use the word.

Based upon this exchange, for Kester "black is black" in the sense that there is no difference in being black in Guyana and being black in the U.S. or from being an immigrant and an "African American" in the States. Kester's perception of, or perhaps questioning of difference lies in the actual usage of "Black" versus "African American", the latter appearing to be the more "smooth and polished" response depending on the particular space and time. Kester's shifting usage of "black" versus "African American" is also indicative of his shifting performance. Yet, based upon Kester's experiences coming of age in Brooklyn, this latter expression of a collective black consciousness seems to have developed overtime and through multiple mobilities in the U.S. As Kester and I's interactions move beyond this initial interview, the idea that black is black is further complicated.

\section{From the Educated Black American to the Model Minority; The Trope of the "Different" Black Subject}

I asked them about being "different" than other blacks [Americans] because they were immigrants or Jamaicans, if they had heard this before, and if that idea had provided a shield for them. Mark recalled that at work, they used to try and argue that he was different than other black Americans because he was Jamaican, to which he would 
respond, "No! I'm Black!" At the same time, he did mention that he preferred not to live in predominantly black neighborhoods. For Mark, this was not due to the fact that he didn't want to be around Black Americans, but instead that black neighborhoods do not receive the same resources and government funding as other predominantly white or more diverse neighborhoods, noting that race and poverty were related, and systemic in the states, and he prefers for his children to receive the best education-Field Notes from the "Corporate Diverse Happy Hour Crew" Focus Group, Bar Louis University City, April 2017

Ike felt social class was a main point of distinction between Black Americans and Africans, he felt that when Black American men and women don't go to school this makes them difficult to be around, BUT when they DO go to school and/or "get educated" they are the "best people to be around." While Ike's office is located in East Charlotte, he lives close to Pineville, he feels more safe there, and noted in our conversation that he often felt unsafe walking out of his office late at night._-Field Notes, Interview with Ike [Nigerian] at his Office in an Office Complex on Albermarle Road

To be the exception, to be different; these are integral principles of the black bourgeoisie (DuBois 1996; Frazier 1957). These principles remain critical survival tactics as well as strategic responses to the complex systems of political, social and cultural repression confronting the black American community. W.E.B. DuBois' concept of the "Talented Tenth" was one of the first theoretical manifestations of these ideals. DuBois' master's thesis outlined in 1903, argued that it was the duty of the small black middle class, whom possessed the necessary resources, to establish itself as the beacon of 
leadership for the entire race (Marable 2005, 5). More critically, DuBois held that, "The Negro race, like all races, is going to be saved by its exceptional men. The problem of education, then, among Negroes must first of all deal with the Talented Tenth; it is the problem of developing the Best of this race that they may guide the Mass away from the contamination and death of the Worst, in their own and other races" (DuBois 1903). Much of DuBois" “Talented Tenth" was dedicated to laying out a fundamental counter argument to Booker T. Washington's position that "we shall prosper in proportion as we learn to dignify and glorify common labor" emphasizing ideals of industriousness and thrift (Frazier 1957, 75). Though DuBois' qualm with Washington centered upon the latter's dedication to common labor and technical skills, Washington still held that "there is a beauty, a transformation, as it were, a regeneration, that takes place in the physical make-up of a young man or young woman who gets into the habit of living on the high side of life rather than on the lower side" (Frazier 1957, 77). Therefore, while Washington relied on developing a strong moral constitution and appreciation for common labor rather than intellectual aptitude or artistic expression both men established a need for members of the black race to distinguish themselves from the so-called masses.

Several other notable black artists and intellectuals from Langston Hughes to Carter G. Woodson to Zora Neale Hurston have proposed ideas, theories, solutions and concepts to ascertain dignity and ascribe humanness in the place of what Alain Locke holds as, “something to be argued about, condemned or defended, to be 'kept down' or 'in his place' or helped up' to be worried with or worried over, harassed or patronized, a social bogey or a social burden" in the mind of America (Locke 1925, 5). Locke offers 
this definition to distinguish the "Old Negro" from the emergence of the "New Negro" during the Harlem Renaissance. In this transition from Old to New, there is a maturing of a group psychology in which one begins to shed the skin of mental, social and physical oppression and comes to react to "proscription and prejudice" through intellectual and artistic expression (Locke 1925, 11). Class distinction and the advancing of cultural capital linked to racial pride underlie DuBois' Talented Tenth and Locke's emerging New Negro in particular. I am drawn to DuBois', Washington's, Frazier's, and Locke's early theories as they demonstrate the legacies and debates of respectability, class and distinction that have historically existed within the black American community as we strive for recognition and citizenship. Further, the debates between DuBois and Washington as well as Locke's New Negro and DuBois' Talented Tenth constitute a foundation for what I have come to view as a trope of difference among black subjects.

There are layers to what I have come to see as this trope of difference. Here, the different black is the ideal manifestation of the Talented Tenth and the New Negro as it functions intra-racially in that he or she has seemingly come to stand out from the masses. He or she may also be an indication that one can indeed pull themselves up by their bootstraps to attain the so-called American Dream. On the other hand, in interactions with the dominant white majority, the trope of the different black may serve to construct an image of the "non-threatening negro", or an extension of the "magical negro"6 perpetuated in popular American cinema, and other displays of tokenism. These

${ }^{6}$ The Magical Negro is a character trope depicted in popular American cinema and portrayals of black images in the media. The Magical Negro is a supporting character who plays the role of friend and assistant to the main white character, who more than often possesses a supernatural mystique. Donald Bogle lays a foundation for this 
different blacks appear to counter the pervasive cultural narrative of pathology attached to the masses of black America. They are model citizens, despite being black. As such, the trope of the different black is just as much layered and interwoven by color, language, culture and ethnicity as it is situational and contextual (Pierre 2004).

The following details an account from an interview with the tall attractive light caramel complexioned Rossano at a local hipster restaurant on Central Avenue, the most transformed and gentrified area of East Charlotte. Rossano identifies as Greek-Ethiopian and Black American, spending most of his life between Greece and the Carolinas. He is also deeply involved in the Charlotte Latino dance community. In the account, Rossano discusses his experiences in the club scene in Charlotte, and one in particular where he was previously denied entrance.

Rossano: Sunset Club, on South Blvd. I don't know what it is now. The owner happened to be a Turkish guy named Sonny and after I befriended him - he befriended me a lot easier once he found out I was Greek. Then I [didn't] have any problems gettin' up in there. So, I definitely use my Greek connections a lot, and the fact that I'm Greek, I have to use that a lot to make friends or connections you know? So that I don't have to deal with certain things that I probably would deal with if I didn't have that [nationality] because they would perceive me totally different in how they would hate on me, or find

understanding in his (1973) work, Toms, Coons, Mulattoes, Mammies and Bucks: An Interpretative History of Blacks in Films. Director Marlon Riggs explores this phenomenon as well as other character tropes and anti-black stereotypes in his 1987 documentary Ethnic Notions. We can also consider Ronald Jackson's (2006) Scripting the Black Masculine Body: Identity, Discourse and Racial Politics in Popular Media which further explores the ways in which stereotypes concerning black body politics are constructed and understood within the popular imagination. 
some--not let me in[to the club]--I don't know. But the fact that I'm Greek helps me out because there are a lot of Greek owners around Charlotte who own restaurants and so, luckily I have that--that kind of sets me apart. Then I have the Latin dancing, and people will say they've seen me somewhere or, you know I was on Fox News once, teaching a class, so stuff like that, it kind of helps...but they still see the color on the outside first, here [in Charlotte]. And I sense it. You can sense it. When I had cornrows it was worse. I had long cornrows and I sensed it way more until someone's guard was up--and I started speaking to them--then it would change because they would realize like oh, this dude is educated. Still even after I cut the cornrows off, I did get more attention from women-white, Greek, whatever...but I still say [my] intonation or what have you changes. I still would never have to deal with that in New York... even in Greece, when I had cornrows, it wasn't like this guy is--it wasn't like a hesitation because of fear--it was more like wow! How's your hair like that? It was more of a fascination...it was fascination because they don't see it on a regular. They would say, "oh let me touch it", "it's so cool”, not like "he's [going to] shoot me."

Rossano is then not only educated, he is also magical as people are fascinated with his looks and hair, and has been on TV, a black man, dancing perfectly to Salsa. Depending on his actual hairstyle, language and whether he decides to assert his nationality, he can be non-threatening, although in other instances people may fear him because he is a black man. How people perceive Rossano as well as his own style and performance shifts as he navigates the globe, between Greece, New York, and Charlotte. As he is aware of the potential power that these factors can hold in distinguishing himself, or providing a shield against discrimination, being the different black entails 
varying levels of conscious performance and behavior. His active involvement and interest in the Latino Dance Community also represents Rossano's attained cultural capital. My participants often summated their cultural capital with the term "openmindedness." The ability to be "open-minded" in this sense is something that is garnered through exposure, travel, and taste and as such, distinguishes certain black subjects from the masses. Rossano disclosed that he often feels most comfortable in the Latino dance community as it is one of the most diverse settings in Charlotte, and is a multicultural atmosphere that contrasts to having to select between traditional white spaces, where he may be denied entrance, or all black spaces, that are predominantly black American in terms of music, dance, and dress or according to Rossano, potentially dangerous. This perception of potential danger of black spaces was expressed when Rossano discussed his disdain for the segregation Uptown and the issues that the lack of parking may present, stating that he feared, "something happening or breaking out when-black people be acting up, and I don't want to be associated with that, or involved with that, so I try not to deal with it." The idea that black people may "act up" reifies a pathology of black American culture and in turn, the necessity to stay away from these spaces. I explore the implications of disdain and fear of other black bodies further in Chapter Four. I asked Rossano to tell me more about the parties held within the Latino dance community. MB: Where do [you all] usually have your [events]?

Rossano: We might rent a studio, have a party there, pay 5 or 10 dollars to get in or you know. People at a restaurant may ask me to come and do a party there, so they can generate some more people...but that's just fun-loving, because everyone is just loving, and the passion--just passionate about dancing. That's where I feel the least division and 
racism. I don't--everyone who dances salsa--like for the most part—-they're so openminded. I mean you [have to] be open minded if you do it. You [have to] be openminded to even explore doing something like that. So usually, they're not racist at all, from what I've seen. I'd be surprised--you may find a couple of people that have that mindset you know, still...yea, but they won't be like that with ALL black people...if they know you, then you may get a pass but obviously, if they don't know, they'll be quick to form a stigma.

According to Rossano, the more diverse a space or group is, the less division and/or racism one experiences. However, it appears that in order to be accepted into such as space, black subjects must be perceived to be different from other black subjects. They must be exceptional. Further, while the atmosphere may be accepting, there is still a possibility for stigmatization based upon skin color for those who do not "get a pass." The "pass" then, is retrievable through performances of difference and through one's cultural capital, their "open-mindedness." It is important to note that many of the cultural arts communities in Charlotte, like the Salsa community, the Samba community, and the Capoeira community (which are interconnected) require membership fees for courses and participation, which can range from $\$ 30$ to $\$ 120$ monthly, not including uniform fees for performances and competitions. See Figure 2.3 below. Therefore, many of the staple members of these communities, like Rossano and others I later introduce, are middle to upper middle class. In other words, these are not your everyday salsa meet ups at the corner discoteca, although a handful of those do exist in Charlotte. This aspect of the cultural arts communities in Charlotte calls for an exploration of the significance of class. 


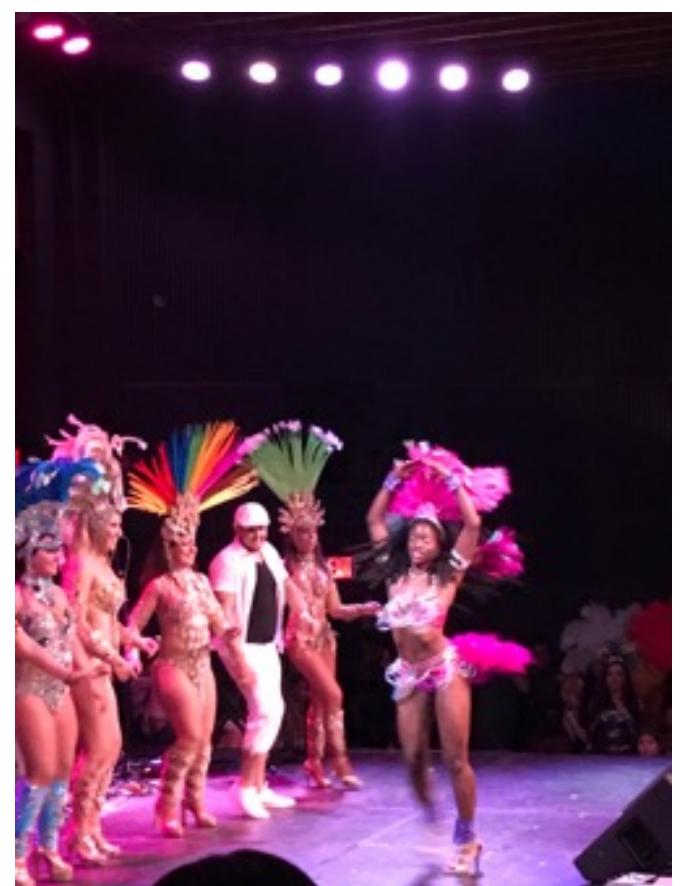

Figure 2.3. Members of the NC Brazilian Arts Project perform Samba at the Annual "A Night in Rio" at the Neighborhood Theatre in North Davidson (NoDa) in East Charlotte. Dance communities in Charlotte are linked by broader social and multicultural networks. Photo by author.

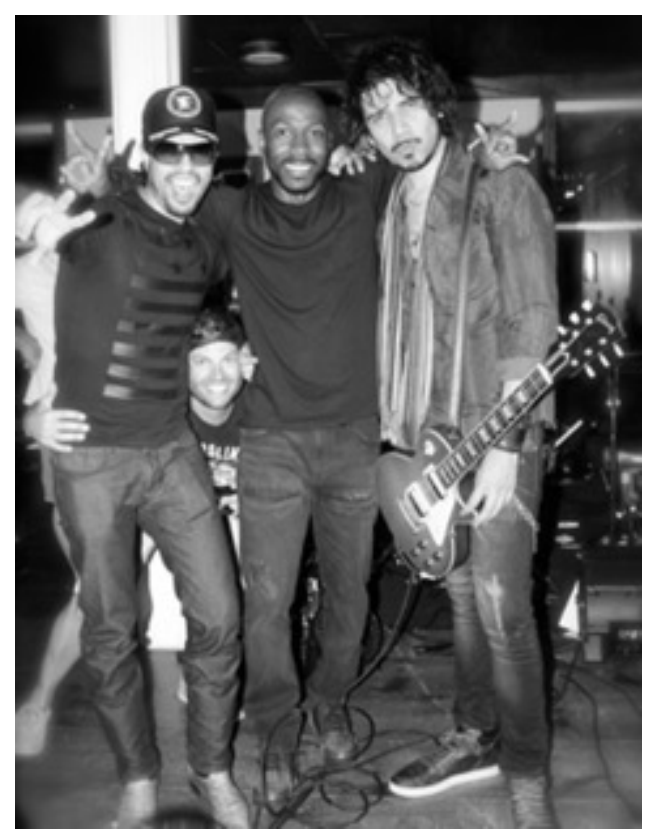

Figure 2.4. "Hanging out with a fellow 'Different' Black", a Guyanese participant, Kester, hangs with friends of a Mexican rock band after their performance to a mainly all-white audience in Cornelius, N.C. Photo submitted by participant through Photo-Voice. 
Culture, language, ethnicity, and skin color are all critical elements to the performance of the "different" black subject. Performance can include facial expressions, demeanor, and speech intonation. As quickly as an individual can gain acceptance or stand out by their conscious and subconscious performances of difference, they can just as easily sink back into the dark cover of the masses or confront judgement, persecution and exclusion based upon their skin color. In the summer of 2017, Jay-Z released his album "4:44" an assemblage of public apologies to his wife Beyoncé, courses on financial literacy and fiscal responsibility and a blue print for "black excellence." The first hit single released from the album was entitled "The Life of O.J." With a background sample of Nina Simone's classic "Four Women", which recounts the experiences of four different black women of varying skin tones, Jay-Z sarcastically begins with the lyrics, "O.J like, 'I'm not Black, I'm O.J." This is a reference to the famous words of O.J. Simpson, who saw himself as having elevated beyond race as a result of his then legendary prestige. O.J. would later fall below the ranks as an accused murderer. Jay-Z cynically culminates O.J.'s rise and descent with the unfortunate confirmation of "still a nigga." The week of the album's release, I sat with Kester and my friend Crystal, before we headed out in Kester's Porsche Panamera to see his Mexican friends perform in Cornelius, a staunch southern conservative town just north of Charlotte. Before we headed out, we sat in Kester's home listening to the album. Kester expressed that while he enjoyed the album, he wished Jay-Z did not use the word "nigga" so much, as he could not comfortably blast the music while riding in his car without potentially offending anyone. I could only think that he would offend either white people by making them confront the reality that black men are treated as though they are "still a 
nigga" and in turn causing discomfort or older black people that are offended because of the word's history and do not agree with the reclamation of the word by younger black generations. To whatever extent, he felt the need to turn down his stereo when this song came on in his car while in public. I use this instance to unmask the irony of Jay-Z's lyrics, in which Jay juxtaposes his own difference as an extremely intelligent and wealthy black entrepreneur with his continued subjection to his criminal past and other racialized stereotypes associated with black men, asserting that despite wealth, complexion, etc., one is "still a nigga." The phrase "still a nigga" expresses another aspect of the encompassing idea that "black is black."

For Kester, even though he is a successful upper middle-class black man, the peak of his "difference" manifested and presented to the world by his Porsche Panamera, he must constantly monitor himself, strive for acceptance, and avoid persecution, which he does in the simplest acts including turning his music down as to not offend others. More importantly, Kester's act demonstrates the depths of performance black subjects must consciously and subconsciously undergo in the U.S. South.

Upon arriving at his friend's band's performance in Cornelius, located about 30 minutes North of Charlotte in NASCAR-Trump country right off of Lake Norman, we found ourselves to be the only people of color in attendance, of course with the exception of his Mexican friends performing. Despite being able to sing along to most of the lyrics of the band's cover of the Red Hot Chili Peppers, my personal discomfort was confirmed through several interactions that involved the three of us. This was after all my first time being in an all white southern space in about five years after living abroad and in Miami. In addition, my research provided a shield from these types of spaces in Charlotte. Much 
like Rossano, I was accustomed to being a sort of exotic attraction abroad, however, I had become detached from the ostentatiousness of white fascination with black bodies. A series of bizarre exchanges offered a reminder.

It began with an older white couple staring as I replaced my lipstick, fittingly titled Lady Danger. The white man nudged his wife, saying "look that's how she gets that on" and seemingly captivated by my bright red lips, asked, "what's that color" as I responded with the name, their eyes lit with conspiring joy. Crystal was the next to be barraged with a series of questions by whites in the crowd approaching to ask "how did you get your hair so curly", "do you use coconut oil?" and "I’ve tried coconut oil, but it didn't have the same effect, what should I do to get my hair curly like yours?" The same woman intrigued by Crystal's natural curls then directed her inquiries to me. Upon asking my name, the white woman chimed, "wow your name is just as exotic as your look!" In perhaps my first reentry into the intensity and bizarreness of southern white spaces, I realized the simple act of being present became a spectacle. Aware that many of those fascinated by our "beautiful skin," facial features and natural hairstyles were most likely conservative Trump supporters, we simply nodded and smiled at their paradoxical curiosity. Essentially, we were in many ways forced to be passively polite in our responses despite the ridiculousness of their questions to avoid confrontation in a space where we were literally the minority. At the same time, I am unsure as to whether Kester was as bothered by these instances as he did not express this in our conversation on the way home. It could be that Kester was also not approached in the same manner as Crystal and I because he is a black man. Nevertheless, not offending white people in predominantly white spaces undoubtedly impacts black performance in the South. 
The mask...the pass .... when do these become discernable? Or are they forever interchangeable for black subjects, part of the "different" black subject's everyday survival? A required aspect of black subjectivity further impacted and layered by their existence in the U.S. South? These questions are central to DuBois' concept of "double consciousness." Goffman's (1959) theorizations of performance, interaction and demeanor serve to somewhat satisfy these inquiries and illuminate the complicated experiences of my interlocutors as well as myself. Scholars such as Jean Muteba Rahier (1999) contend that identity is fluid, "constantly enacted and reenacted," and "performed and performed anew (xv)." As such, identity is constructed through "complex processes of relationality and representation" and constantly under renegotiation (Rahier 1999, xix: Wade 1997, 81-82). Further, identity politics are not just attached to the body but instead, serve as a "constellation of resources in the cultural negotiation of the ideal" (Alexander 2006, xiv). In turn, competing cultural performances are "endowed with variable amounts of economic, cultural, and symbolic capital to pursue their interests" and secure certain aims and objectives as individuals cross boundaries that necessitate varying negotiations of identity (Alexander 2006, xv). In the cases of Kester and Rossano, I am drawn to Bryant Keith Alexander's (2006) usage of the notion of "passing" that he applies not to a "cross-racial movement" in the sense of black individuals "passing" as white, but to acknowledge the "performative nature of assuming particular and expected racial-cultural-gender traits, and to the process of having performances deemed appropriate or inappropriate" (71). For Alexander, cultural performance emphasizes and privileges one social marker over others and reveals expected norms of behavior for the purpose of social agency, inclusive of "the fulfillment 
of cultural traditions that build community or reappropriating racial stereotypes to advance beyond social roadblocks" (Alexander 2006, 72). As dramatizations of codes and ethics of living, cultural performances are "designs for living." In this sense then, passing "assumes the identity and the specified benefits of being the other within a particular context" and depends on the success of not overacting or risk calling attention to the actuality of the performance. As a result, passing "always resides in liminality" hence Jay-Z's phrase that one is "still a nigga" despite performances that may gain them temporal agency (Alexander 2006, 73). Thus, Rossano's intonation, hairstyle, and his ability to dance salsa allow him to avoid potential fear and/or discrimination and grant him social agency in certain times, spaces, and places. For Kester it could be simply turning down his music in his Porsche Panamera: it would be unbecoming of a welldressed, corporate, manicured black man driving a luxury car to be blasting the word "nigga" from his speakers. These elements of their cultural performances as black men in particular allow them to be at times, considered a "Good Black Man" that contrasts with the problematic and pathologized images disseminated in the media, yet their performances also reveal that they fear the reality that they could be easily perceived of as "Bad [Black] Man" (Alexander 2006, 74). At the same time, like our time at the concert in Cornelius, I became aware of my own "difference" and consequential performance as my positionality often took center stage as my participants' discussed their perceptions and understandings or race and ethnicity in the U.S.

\section{On Being a "Different" Black in the Field}

In the first chapter, I reveal that my own experiences growing up in rural North Carolina and later attending college and living in Charlotte greatly influenced this 
dissertation. It was not until I read Jean Muteba Rahier's (2009) self-ethnography, “Métis/Mulâtre, Mulato, Mulatto, Negro, Moreno, Mundele, Kaki, Black,...” in the edited volume Problemetizing Blackness and Andrea J. Queeley's (2010) essay “The Passing of a Black Yanqui: Field Notes from a Wannabe Santiaguera" that I began to more closely process my own shifting blackness in conjunction with that of my interlocutors. Until my travels abroad and my interactions with my participants, my so-called "difference" had mostly emerged in encounters with white Americans, as I describe above. However, my education, appearance, and complexion often became a basis through which my participants discussed their own understandings of blackness as well as their relationship with black Americans.

In the very early stages of my research I began to notice this when asking participants where they were from. In response to this question, I was initially given simply "Africa" and then prodding deeper, offered a region such as "West Africa" or "Central Africa." When I asked specifically which country, their faces often illuminated with surprise as if it was rare that a black American, or any American, possessed knowledge of specific countries. Puzzled and surprised faces were even more visible as I inquired about their specific languages or ethnic groups. Through these conversations, I began to understand the significance of difference within inter-ethnic relations among interactions between Africans and black Americans. In fact, I had witnessed several verbal and non-verbal skirmishes between these groups, mainly in working class spaces like braiding salons. Unfortunately, I recognized that these quarrels that I discuss in more detail later often led black immigrants to confirm the stereotypes of black Americans. Through these observations at salons, I found myself attempting to spark a conversation 
with my stylist, not just for research purposes, but in some way I was trying to remedy this contentious relationship. In these moments, I discovered that perhaps I was both consciously and subconsciously activating and performing my own difference. Difference for me, became a deeply rooted internal conflict in which I found myself burdened with a need to defend other black Americans by simultaneously maintaining sameness while activating difference to remedy stereotypes or to ultimately say that "not all black people are like that" through performance.

When I was not actively performing difference, my positionality was equally central to discussions with my interlocutors. In many instances, they used me as a point of reference in responding to questions regarding blackness as well as the relationship between black immigrants and black Americans. Mrs. Tina, a middle-aged Sierra Leonian woman, emerges as one of the central interlocutors in this dissertation as her small grocery store Sierra Leone International Mart was a critical field site. Mrs. Tina possesses a slightly intimidating demeanor housed by a sometimes unreadable face until she lets loose a sly smile to imply a joking nature that reminded me of many other older black women in my personal and research life. In our first encounter, I asked Mrs. Tina a series of questions, including those that attempted to capture aspects of her identity. As with most of my participants, questions were often bounced back to me or initially posed to establish a sense of and confirmation of my position as a student. In the subsequent account, Mrs. Tina utilizes my racial identification as a basis for her own understandings of blackness in the U.S. This account builds upon a more extensive conversation regarding race, ethnicity and nationality.

MB: Okay, so what does it mean to be black...or to be African to you? 
Tina: It all depends [on] what you guys call black. Are you black?

MB: Do you think I'm black?

Tina: That's what I think. Even though you are light skin [laughs]

MB: I think I'm black [both laugh]. I identify as black.

Tina: So that's why I say, I don't know what people consider--basically when they say somebody's black [in the U.S.] they mean your ancestors are black or maybe your father is black...[is that] the case with you?

MB: Yes, both of my parents are black

Tina: Okay, so then you are black.

MB: What do you think black in the United States means?

Tina: Black in the United States...those are the slaves that came back--that were brought here during the slavery times right--and those that maybe their grandfathers were slaves...so those are the ones I consider to be black and black is black, even though I was born in Africa, and my great great grandfather was born in Africa--we consider ourselves black too. So I just feel, if you're black, you're black. [It doesn't] matter where you're born.

Mrs. Tina and I's conversation underlines the varying definitions and understandings of blackness. It seems that Mrs. Tina's understandings are based upon not only a patrilineal bloodline, but a shared understanding of U.S. blackness stemming from a one-drop rule, as well as possible shifting understandings revealed through the phrase "depends upon what you guys call black." Mrs. Tina and I developed a rapport revolving around our ethnic and cultural differences as well as my position as a researcher. As customers and friends walked in to either shop or take a seat and chat with 
Mrs. Tina, she introduced me as "the researcher." In the following chapter, I expand upon Mrs. Tina and I's initial conversation as it pertains to food, smell and affect as a boundary-marker between black Americans and Africans. Here, I want to highlight a brief portion of that discussion in which Mrs. Tina suggests that I am "different" given that I came into the store to respectfully inquire about the food and later on, the smells that appear to draw disgust from many black Americans. In a prior portion of our interview, she also alluded to another aspect of difference that distinguished myself from other black Americans.

MB: Okay, how do you feel about the relationship between black Americans and Africans in North Carolina?

Tina: Black Americans and Africans... to be really honest, I don't really mingle--well let me see, I don't mingle with them too much because I don't have-when I was in school, I used to live in Nashville and the African Americans I met there, we are-it's like I met my brothers and my sisters I have a good relationship with them and I love to be around them. But in general you see, I'm always here at my store, I don't see them [black Americans], I don't mingle with people, especially here in Charlotte. I don't go out because my store is [open] from 10-8, so I'm always here. So I don't really know, I don't really know how—sometimes it's like they have this stereotype - the African Americans have about Africans, and Africans have it too against them. So it's Vice Versa. Because maybe your parents or grandparents are born here, some of them think they are better than the Africans and that's why the Africans are coming out in full force, going to school, getting an education, learning, doing something positive for ourselves. I cannot 
come sit and complain when I don't do something positive. Like now you here trying to get a $\mathrm{PhD}$, that's a good plus for you but if you just stay home and depend on food stamps you're not going to tell me nothing because I'm going to confront you and I'm like, I'm working! Like the ex-president before [said], "don't boo, go vote." If they [black Americans] would've gone to vote, all this commotion and confusion maybe would not be here now! But when you stay home and you just believe that booing is going to help you to go forward, it does not help you to go forward. Let all of us work together as a team. For me, I think we should work together as a team. Nobody is better than nobody.

Before I unravel the many layers of Mrs. Tina's assessment of black Americans, I want to recall another conversation with a central interlocutor. I met Noah about three years ago, when I first began preliminary research in East Charlotte. Noah, an Eritrean immigrant and owner of Queen Sheba Ethiopian Restaurant also owns a neighboring Latino bar in the same East Charlotte shopping complex, which he bought after realizing the need for a local Latino hangout in the area. Noah is an active member of the Eastland Area Strategies Team (E.A.S.T) and we have talked on multiple occasions: in an official interview, and mostly while just hanging out at Queen Sheba and the neighboring bar. When I first met Noah, I described my research, which led us to a discussion on race and identity. Noah feels that blackness should be understood through a spectrum of varying perceptions and experiences, holding that blackness is not solely the history of slavery in America. Noah referenced my own ethnic ambiguity to argue that I, like him, should consider that it is possible that to others, I may not appear to be black. He noted that this has been the case with him as we were the same complexion with similar facial features. 
For Noah, though "black" is "the first thing" an immigrant hears upon arrival in the U.S., it should not be the dominant factor. However, in a separate conversation, as Noah expanded upon his work with E.A.S.T, he discussed how he often holds workshops on financial literacy and entrepreneurship geared toward black Americans. During this conversation, he asked me, "Why can't other black Americans be like you?" He suggested that when the black immigrant comes to the U.S., they take on a task to make the black American image more positive. Noah then asserted that, black Americans have to change our own image, indicating that I was, in contrast to other black Americans, at the forefront of "changing the black American image." While Noah did acknowledge that racism did "eat at the black community", he equally asserted that "if you have a child, take care of them, teach them."

Both Mrs. Tina and Noah posit an American black culture that is linked to pathology. This pathology allows little room to escape; very broad generalizations of black Americans that are dependent on food stamps, are lazy, are absentee parents, or are simply ensconced by a dark cloud including being the reason that Donald Trump was elected president (which data has demonstrated as not the case) subsume the spans of Black Americans despite individual circumstances. Black Americans, based upon this view, have failed to take advantage of the "narrative trope of the American Dream", which supposedly offers limitless opportunities for socioeconomic success for all (Pierre 2004, 143). Pierre (2004) argues that "the ethnicity concept", or "ethnicity theory" consists of "cultural narratives" utilized to maintain the myth of the American Dream and "to place immigrants (and other ethnics) into the ideological framework of the nation" (Pierre 2004, 143). In turn, these narratives establish racial and ethnic hierarchies in 
which black Americans remain at the lowest in the socioeconomic hierarchy, ensconced by a culture of poverty. Further, a great deal of scholarship geared toward black immigrants in the U.S. has continued to revolve around a model of European immigrant incorporation, or an assimilation model, what Omi and Winant see as the "bootstrap model" in which "the success with which an "ethnic" group is incorporated into the majority society depends upon the quality of specific cultural norms it possesses" (Pierre 2004, 146; Omi and Winant 1994). This notion underscores Noah's contention that not only must black immigrants take on the task of repairing the "image" of black Americans, but other black Americans should strive to "be like me" in order to recuperate our own image. Sadly, both black Americans and many of my black immigrant participants alike share the consensus that the black American masses are a burden for other black subjects.

\section{Braiding Hair and Buying on Credit; Inter- and Intra- Ethnic Socioeconomic Hierarchies}

Socioeconomic status has emerged as a critical factor throughout this chapter, particularly as it pertains to establishing a trope of difference underscored by what I see as "cultural difference" or superficial generalizations that distinguish black Americans from one another as well as black Americans from black immigrants. This "cultural difference" often relies upon notions of work ethic and adherence to civic duties as well as cultural capital and education. With this, I have attempted to explain the ways in which socioeconomic status maneuvers difference while simultaneously advancing collectivity among black Americans and black immigrants whether this be evidenced by membership/affiliation within particular social organizations and institutions, as co- 
workers in particular corporations, certain neighborhoods of residence, or as a coping method to resist stereotypes and/or shield oneself from methods of discrimination. Of course, socioeconomic status and "cultural difference" are more than often performed, inclusive of very subtle actions to opulent living and actual performances such as dance. However, as of yet, I have not fully disclosed socioeconomic hierarchies in action or the implications of visibly active socioeconomic hierarchies in the construction of space and place. In the first section of this chapter, I introduce organizations such as the African Chamber of Commerce and Brothers Abroad as Pan-African, trans-ethnic organizations that bring mainly Charlotte-based African businessmen into East Charlotte businesses to meet, discuss business, politics, and comradery.

The central focus of organizations like the African Chamber of Commerce was to promote transnational flows or business from the U.S. to Africa, sponsored by other Africans, in the place of a reliance of foreign aid. In other words, the intentions of the African Chamber of Commerce was not only to establish a presence of African-owned businesses, businessmen, entrepreneurs, and intellectuals in Charlotte, but to share this wealth and establish an on-going shared economy with those in Africa. These transnational exchanges then, not only yield an impact in Africa, but in Charlotte, particularly in the accumulation of wealth and formation and solidification of an African upper middle class that ultimately bonds with the black American upper middle class, even if situational. On the other hand, working class Africans remain relatively separate from the African American community, living and working within trans-ethnic enclaves in East Charlotte. These spaces and places reveal the inter-workings of boundary-making as well as intra-ethnic socioeconomic hierarchies in action. 
I first began to notice these boundaries and hierarchies in Aabies African Hair Braiding during the long hours of getting my hair braided. At first glance, language emerges as the most visible boundary within this space. As mentioned above, black American women's demands that the African women communicate in English establish a linguistic hierarchy suggestive that English is the more culturally and socially appropriate language, even though the black American women are essentially outsiders within this space. The black American women are also paying customers, which establishes a socioeconomic hierarchy in that the black American women can refuse to pay, sometimes even mid-way through the completion of a hairstyle, failing to compensate the African women for the long hours of work they have completed to that point. This dynamic represents a larger sociocultural hierarchy in which black American women place themselves above the African women, even if they are also working class. The black American women sitting in the chairs who monitor every move of the braiders hands, are quick to demand any change or redo, display disgust, and command the stylists to speak English. By this, black American women attempt to establish themselves in a higherranking position than the African stylists.

The second hierarchical structure I noticed was that between the Latina women who swept the hair and kept track of the hair stock room. Again, these hierarchies centered first upon language; the Latina women spoke Spanish amongst themselves and those among them who could speak English communicated with those African women who could speak English regarding the hair stock, prices and occasional jokes. In rare instances, with customers like myself, the Latina women communicated with me in Spanish to better convey the braiding technique, process and payment. This was done 
with a style such as faux locs, a style I never had before. This interaction signaled a growing and interesting familiarity between Latina women, the woman I spoke with was from El Salvador, and African hair braiding, and in turn, African culture. The closer relationship and familiarity between the Latina women and African women than that between the black American clientele and the African women braiders exposes budding inter-ethnic and inter-racial connections rooted in the construction of a working class trans-ethnic enclave in East Charlotte. This connection between working class Latinos and Africans appeared in other spaces in East Charlotte, such as restaurants in which Latinos were waiters, workers and cooks in African restaurants. However, in these other spaces there is a more amicable relationship between Africans, Latinos and black Americans that I discuss in Chapter Five. There is a more broad third layer within this hierarchy, which involves the secretive legal status of many of the Francophone African women. On several of the occasions I patronized Aabies, I attempted to ask questions regarding how and why the women came to Charlotte. Some of the stylists avoided this question others implied they had come on "student visas" even though they were clearly older women and were presumably not in school. I began to consider that there was an established broader social network of Francophone African women from West and Central African countries that brought the women to Aabies. Yet, atop of this entire empire was Aabie herself.

Aabie is a Nigerian woman and business-owner based upon my conversations with the workers and other clients. She is as mysterious as she is inaccessible. I only caught rare glimpses of her briefly gliding through the salon in purple and gold Nigerian attire prior to my research. Somehow I just knew and felt it was Aabie, the queen of 
Charlotte's African hair braiding empire, a community staple for the last 15 years, when African hair braiding in Charlotte was just becoming a thing. Aabie's online mission statement states that, "Aabies African Hair Braiding owes its emergence and existence to fate in this increasingly globalized world. These days, time and geographical distances no longer constitute hindrances to cross-pollination of events and happenings across the globe. The spread of the authentic undiluted African Hair Braiding Styles in the United States of America is the avowed mission of Aabies African Hair Braiding. Thus, within its short period of existence, Aabies African Hair Braiding has revolutionized African hair braiding within the Southeastern part of the country." I actually delved as deep as possible into actually who and where Aabie was initially so that I could get permission to conduct research (outside of getting my hair braided) in Aabies. As much as I asked the women if I could sit and hang out, I was told to contact Aabie, and given a phone number which was a direct line to the shop where Aabie never answered because she was not there. Other times I was left on hold for hours at end, when I questioned the difficulty in contacting Aabie, and asked other head women if I could sit and talk to the women, the response was no, "they have to work and cannot be distracted." The inability to contact Aabie, the fact that the other women could not be distracted, and the fact that Aabie is Nigerian and in turn, Anglophone running a business with mainly Francophone (some undocumented) workers signaled a broader socioeconomic hierarchy at work. Further, Aabie's mission makes hair braiding a transnational global commodity and in turn establishes Aabie's African Hair Braiding as a transnational space.

My observations at Aabie's African Hair Braiding greatly differed from those at African Twin Braiding, owned by Bendu, a Liberian woman, who migrated to Charlotte 
as an adolescent. African Twin is also located in East Charlotte, in perhaps the most gentrified section of the area. It is hidden upstairs in a small space right above Reggae Central, the entrance to the staircase protected by a large gate with a chain and lock attached. I imagine the cost and/or rent of the location is quite pricey as this strip is prime East Charlotte real estate, within walking distance to several hipster restaurants and bars. While getting my hair braided at African Twin, my braider, also from Liberia, and I occasionally conversed. I also felt more comfortable and able to communicate with her my braiding needs such as avoiding pulling the edges of my hair too tightly. Otherwise, I would have faced extreme pain afterwards and at worse, my hair falling out later on. On this particular occasion, I was in African Twin from around $11 \mathrm{am}$ until 8:30pm, taking a break around 2:30 so that the braider could take a brief break to eat her Liberian prepared okra and rice, and for me to take an additional visit to the ATM to pay for the extra length of the hair, raising the total cost of my hairstyle to $\$ 220$, about $\$ 25$ per hour, a portion of which would be later paid to Bendu. Around 4pm Bendu and her daughter, a teenager, came in to braid another black American customer's hair. Once Bendu came into the shop, she turned the radio on, which was already tuned to 105.3 the local old school Rhythm and Blues station. A 5 o' clock mix of Roxanne Shanté, Naughty By Nature, Eazy-E, Snoop Dogg, George Clinton and other artists, played while Bendu started braiding the hair of her black American client, who was getting the same "box braids" as myself. As old school Hip Hop and R\&B jams played in the background, some of us often humming or singing along, Bendu told us about the purchase and now decoration of her new home. We all participated in multiple conversations that either ensued as us clients navigated social media on our phones, delivering recent celebrity gossip and 
polling the other women's opinions. Bendu's daughter in and out from her own cell phone, approached the chair to help her mother braid, contribute to conversation, and fulfill other tasks that Bendu asked her to complete around the shop, such as sweeping up hair and boiling water to cap and stick the ends of my braids. Bendu and my stylist also held conversations with one another. They discussed Bendu's home and family, but also my stylist's family, as her husband was from Ghana. Bendu asked her about the differences between Liberian food and Ghanaian food, my stylist responded that no one could prepare a particular stew like Liberians; even though her in-laws prepared a similar stew, it was not good and spicy like that of Liberians. They also briefly addressing the differences in Jollof rice and FuFu.

In my initial interview with Bendu and her husband George, both from Liberia, George responded to most of my questions as Bendu focused on braiding another black American client, but did mention at the time that most of her clientele were black American women. In our first encounter, George also referenced the fact that he had been forewarned about the stereotypes regarding black Americans, but after moving to Charlotte in 1995, his second location after living in New York City for about two years, escaping civil war in Liberia, he realized the following;

"You know...Liberians...Africans...let me just say-and this is from speaking to other Africans [like] myself, you know [they say] black Americans-[but] when you come to America, you realize that you are no different from black Americans. Because Africans feel black Americans have so much opportunity that they don't use, but it's not the black Americans. I think it's the system that keeps them grounded, unless you rise above that system, you're [going to] find yourself in that same situation, see what I'm 
saying? But if you don't come to America and experience it for yourself, you're not [going to] know, so I think if you ask anybody outside of the U.S, any black person, they will feel that black Americans are not ambitious--not as ambitious as the rest of the black people, or don't [want to] do this, don't [want to] do that. I don't think that's the case. I think the system keeps black Americans grounded so much, that unless you think out of the box, or think out of the norm, [you're going to] find yourself in the same place."

George's account reveals a dismantling of the myths surrounding black Americans, suggesting again that "black is black" in that other black African immigrants could easily face the same systemic racism as black Americans. As a result, George asserted that he always attempts to speak his "best English" not just in response to what white Americans would perceive him as, but also in response to black Americans. Language was a significant aspect for what George saw as both acceptance and mobility within the Charlotte community, despite race. This is perhaps something that Bendu also shares, particularly in establishing a hair braiding business that competes with not just Aabie's, but other African salons that are dominated by Central and West African Francophone women.

When the conversation was directed toward Bendu's identity, George chimed in that, "She's American!" followed by laughter. Bendu responded that they had just been discussing this aspect of her identity in contrast to his, noting that, "I always say I have two Independence Days, the 4th and the 26th, so yea...I guess I'm both.” Here, Bendu portrays the duplicity of her identities through Independence Day celebrations, one of which being the United States' and the other, Liberia's. This seemed to be reflected in Bendu's relationship with her clients. When asked about her relationship with her 
predominantly black American clientele she responded, "Yea, I have a lot of my customers I've been doing their hair-[they've] been coming to me for years. So I've been doing it over 12 years, I have a lot of [customers] some I have a personal relationship with, some just business. But yea - I like to really get to know my customers because it's good for business, its good for you, you know? And it's good to see them in the street and say 'Hey Girl!' so instead of just business I like to get to know them." Bendu's response in many ways coincides with other black American stylists' in which stylists attempt to establish an on-going relationship with customers. Bendu's account further counters the studies by scholars such as Waters (1999) that hold that second-generation immigrants experience negative consequences of assimilating into black American culture. Instead, Bendu's relationship with black Americans and her duplicitous identity as both Liberian and black American suggest that assimilation is advantageous.

Bendu's form of relationship building stands in significant contrast to the relationships witnessed in Aabie's or other African Hair Braiding Salons, owned and/or operated by predominantly Francophone African women. This again, demarcates language as perhaps the most critical surface barrier between African and black American women. The fact that Bendu is both Liberian and Black American (she possesses citizenship) in Charlotte, is not just an essential part of her own identity, but that of her shop. She can play music and connect with music appeasing to black American clientele and easily and readily communicate with them on issues that move beyond simply hair and money. Bendu's linguistic, social and cultural accessibility to black Americans in many ways also permits her to charge more with fewer workers than Aabie's and others. 
Based upon my observations, I found that connection and communication have proven to be critical within the hair braiding community. Bendu's shop demonstrates one of the many ways socioeconomic hierarchies are established among African populations in the South.

\section{Inevitable Intersections; A Conclusion}

The presence and population of black Caribbean and African immigrants in Charlotte continues to grow at an astonishing rate. Yet, few scholars, city leaders and U.S. Census data accurately document this presence. Many of the shortcomings in scholarship as well as official data dedicated to these populations, with the exception of Nigerian and Liberian populations, can be attributed to the fact that many, particularly those within the Caribbean community find themselves enmeshed within the middle class black American community, or under the category of African American/Black. The invisibility of these populations reifies the notion that "black is black." Beneath this shallow layer, exists a very rich African and Caribbean population who hold intricate and complex understandings of blackness that impact black immigrant identity, subjectformation and place-making in the U.S. South.

Nigerians and Liberians emerge as one of the most visible black immigrant populations. This is most likely due to their growing/higher socioeconomic status, legal citizenship, language capability as part of Anglophone Africa, and their consequential proximity to middle class black Americans in Charlotte. Nigerians and Liberian businesses are among the most prominent African businesses in East Charlotte and individuals from these communities are well-known in the corporate and medical fields. Class, race and the idea that "black is black" often shapes and reshapes middle and upper 
middle-class Africans' relationships with black Americans in Charlotte. The collective relationship fostered within a black American middle-class context undoubtedly influences African identity and subjectivity. In accordance with Hintzen's (2001) arguments regarding West Indians in the Bay Area, these African and Caribbean populations have accumulated more wealth and higher socioeconomic status as they have navigated residential destinations throughout the U.S. On the other hand, many Francophone Africans, who come directly to Charlotte under uncertain legal circumstances or as refugees occupy positions within the East Charlotte working class. Members of this group in East Charlotte oftentimes form closer relationships with other working-class immigrant populations, such as Mexican and Central Americans instead of working black Americans, who at times attempt to establish a hierarchy based upon "cultural difference." This "cultural difference" stands in contrast to cultural differences, and further contributes to the warring ideals underlying the notion that "black is black." Black immigrants on the other hand utilize "cultural difference" to insinuate myths of the model minority to distinguish themselves socially, culturally, and economically from black Americans.

The notion that "black is black" is extremely complex in that it serves as a disclaimer for "cultural difference," acts as a conscious layer of identity indicative of a shared racial consciousness and obscures performances of "alternative ways of being black (Queeley 2015)." Hintzen (2001) highlights a "discourse of difference" in the U.S. that operates to distinguish West Indian and other immigrants from black Americans. Relying upon historical black American scholarship, I argue that it is a trope of difference that compels all black subjects to utilize methods and performance that distinguish 
themselves from the masses, not just black immigrants. This particular trope of difference can at times create a situation for collective blackness rooted in notions of black middle-class respectability, at least in the South. While this trope of difference may distinguish black subjects from the masses, the reality of the sameness we share in skin color, or the idea that "black is black," remains.

For black Americans, maintaining sameness is critical, yet at times for those deemed as "different," sameness can present both a conscious and subconscious burden. A great deal of this stands for black immigrants as well. For black immigrants in East Charlotte, and as a burgeoning population, sameness allows a broadening of ethnicity giving way to a trans-ethnic, Pan-African community. Accepting differences through recognized sameness has permitted the early stages of a trans-ethnic enclave among Africans in East Charlotte that both competes with and coincides with that of Latinos. By premising this chapter upon the notion that "black is black," I have sought to convey the ways in which the inevitable intersections of black immigrants and black Americans yield identities and subjectivities built upon "cultural difference" as well as cultural differences. Yet, through these differences whether superficial or not, black subjects more than often find sameness despite their search for difference, a sameness buried deep within those very elements that distinguish them. 


\section{CHAPTER THREE}

“WHAT ARE YOU?" SEEING THE INVISIBLE AND THE LIMINAL: AFROLATINOS IN CHARLOTTE

"Once I moved to Charlotte, because diversity here is so low, you kind of hear it [questions concerning racial identification] even more. Especially when I talk to other people here, even white Americans or black-African Americans, they always ask me like, oh so what are you? This or that. And I'm like, Why?! Why does it even matter? I had someone straight ask me that at work, he asked me like,' who do you associate more with? Do you consider yourself a white person or a black person?' And I'm like, what the frik kind of question is that? Like I'm Dominican!'-Patricia, Dominican, 14 March 2017

The extreme humidity of summer in Carolina locked in the aroma of carne asada, holding hostage the bellows of smoke plowing from large charcoal grills in the June evening air. Reggaeton blasted from a large speaker under a tent and the muffled base of salsa playing inside the auditorium could be felt pulsing counter to the sharp deep Spanish raps of Nicky Jam as my friend and I walked up to the second annual Ritmo y Sabor Caribbean Festival, sponsored by the Latin American Coalition and held at the Midwood International and Cultural Center on Central Avenue in East Charlotte. As we walked up to the outside section of the festival, we made a B-line straight for the Mexican tacos and quesadillas. Although we were expecting Dominican carne guisada and moros, I am convinced that North Carolina has the best Mexican food in the U.S. outside of California and Texas, so we were happy to settle for quesadillas. Just beside 
the food stand, we purchased T-shirts from Yiselle, an Afro-Cuban woman who works with the Coalition. The shirts were imprinted with Charlotte's skyline, and across the center of the shirt it read, "A City of Immigrants." On a completely different day, while standing in line at Panera Bread, an older white woman approached me after reading my shirt, to confirm that the skyline was indeed Charlotte's, noting that she had no idea Charlotte was a "city of immigrants." After finishing our food, we ventured inside the former high school gymnasium to listen to the live salsa, merengue and bachata as we watched couples, friends and children dance. The DJ interrupted the music for a brief call and response to acknowledge the countries represented at the festival. The DJ enthusiastically yelled, “Cuba!”, "Dominican Republic!”, "Puerto Rico!” "Venezuela!”, and "Colombia!" All of which were met with confirmative screams from pockets of the crowd signaling the location of each group within the auditorium. An older black woman sitting on the sides then stood up to excitingly yell, "Panama!!" as the DJ had omitted this country from his list. I noticed that despite the dominant population of Mexicans and Central Americans in Charlotte, the DJ did not "shout out" Mexico, Nicaragua, Honduras or Guatemala even though these countries do share a portion of the Caribbean.

Ritmo y Sabor presents itself as a purposely constructed Pan-Latino sociocultural space which not only allows the general Latino population to stake claims of ownership and representation in the city but to specifically offer a collective outlet of belonging and expression for Latinos from the Caribbean region. Over the course of my research, the event stands as one in which the diverse Afro-Latino population was most visible. Otherwise, with the exception of Dominicans, Afro-Latinos remain largely invisible either merging into the dominant Latino population or ensconced by the black American 
population. This chapter explores the multiple identities that Afro-Latinos in Charlotte come to embody, interrogating when/how/where Afro-Latinidad is visible or "shouted out", invisible/muted, enacted, embraced, compromised, negotiated or simply abandoned. These factors are all dependent upon interaction, performance, and perception as AfroLatinos intersect with the dominant Latino (Mexican and Central American), BlackAmerican, and white-American population. The complexities and intricacies of AfroLatino identity and subjectivity in the U.S. South seem to be most evoked through internal contemplations and reactions to the question of, "what are you?"

Homi Bhabha (1994) asserts that, within a liminal space, there is "no singular self-image" and "no necessary or eternal belongingness." This cultural space allows "for opening up new forms of identification that may confuse the continuity of historical temporalities, confound the ordering of cultural symbols, traumatize tradition" (Bhaba 1994: 257). Afro-Latino presence in the U.S. South confuses "historical temporalities" of those ideals and definitions attached to Old South conceptualizations of race and ethnicity. Afro-Latinos also counter "cultural symbols," or popular perceptions and/or stereotypes that define what it means to be Latino/a and Hispanic in the South; the most basic of these being language and skin color. The murky temporalities between the Old and New South have permitted new, albeit, limited designations that expand the racial binary from black-white to a conflated tertiary racial/ethnic categorization that is, BlackWhite-Mexican. Local and popular understandings of race, ethnicity, and in turn language, Spanish in particular, confine Latinidad to simply Mexican, the dominant Latino/a population. This represents only one aspect of the liminal space in which AfroLatinos/as occupy. 
I found that all black subjects, whether native or immigrant, seek some form of citizenship and/or belonging within sociocultural arenas. However, with the exception of Muslim Africans, most Latinos must prove or demonstrate legal citizenship in the U.S. South. The quest and eminent need for legal citizenship is critical for many Mexican and Central Americans in the U.S. South. On the other hand, a great deal of Hispanic Caribbean and South American Latinos in the South, already possess legal citizenship status. Therefore, queries and threats surrounding legal citizenship present a greater obstacle for non-black Latinos/as from Mexico and Central America than those from the Hispanic Caribbean and South America (Gill 2010). Charlotte is most often a second or third destination for these populations, who more than often gained citizenship while in previous cities like New York and Miami, or middle-man countries like Puerto Rico. These factors do not minimize Afro-descendant Latinos/as' need to prove legal citizenship when confronted with the threat of being perceived of as Mexican or Central American because they speak Spanish.

In my everyday interactions, I met several Central Americans that came directly to North Carolina, some smuggled in the bed of a pickup truck and driven straight to the state from the border, after crossing by foot from Mexico into Texas. There are also two Latino bus companies that offer travel directly from East Charlotte to border cities along the Texas-Mexico border. Other than Dominicans who illegally cross by sea into Puerto Rico, or Haitians who cross illegally into the Dominican Republic, the majority of AfroLatinos and other Caribbean immigrants do not relate to nor fit into this narrative of immigration. Through word of mouth, it was suggested by my interlocutors that some working- and middle- class Dominican immigrants over-stay their Visas, I never 
knowingly met anyone with this experience. As such, remaining detached from the narrative of illegal immigration is especially critical to Hispanic Caribbean identities in the South.

Nevertheless, Afro-Latinos and/or self-identified Black Latinos still fear other threats from authorities based upon their skin color and, I argue, this fear of racial and ethnic profiling in spite of citizenship status acts to shape Afro-Latino subject formation. Ong et. al. (1996) considers citizenship as a "cultural process of 'subject-ification' in the Foucaldian sense of self-making and being made by power relations that produce consent through schemes of surveillance, discipline, control, and administration"(Ong et al. 1996, 737). They define "cultural citizenship" as "the cultural practices and beliefs produced out of negotiating the often ambivalent and contested relations with the state and its hegemonic forms that establish the criteria of belonging within a national population and territory", asserting that it is then a "dual process of self-making and being-made within webs of power linked to the nation-state and civil society" (Ong et al. 1996, 738). AfroLatinos and other black immigrant subjects in the South must then negotiate and maneuver through several aspects of hegemonic criteria of belonging ranging from the one-drop rule that has resulted in a stringent black-white binary, racial ideologies from host countries, legal citizenship as Latinos, socioeconomic hierarchies oftentimes based upon legal citizenship within the Latino community, and the control and surveillance applied to both black and Latino bodies. This chapter argues that these factors contribute to and construct a liminal space that Afro-Latinos occupy in the U.S. South in which again, there is "no singular self-image" and "no necessary or eternal belongingness." This liminal space greatly informs Afro-Latino/a/X identity and subject formation as well 
as place-making in the city of Charlotte. In fact, liminal space in which AfroLatinos/as/X occupy emerged almost immediately during preliminary research while attempting to locate participants through snowball method.

As I mention in the Methodology section of the Introduction, one of the main challenges in locating participants for this research, which was done by word of mouth, was the use of the term "Afro-Latino." The fact that many Afro-Latinos do not identify with the term, with their African heritage or are unfamiliar with the term, or simply prefer other terms and classifications reveal the ambivalent relationship many Latinos of African descent have with their African ancestry. This relationship reflects processes of racialization in Latin America and the Hispanic Caribbean that have emphasized mestizaje, hybridity, and racial mixture underlining national identities that simultaneously assert an absence of racial discrimination that has resulted in harmonious race relations, while also using racial mixture as a tool for whitening the nation at the expense/exclusion of darker Latinos (Wade 2010; Sagas 2000; Candelario 2007; Telles 2004; Sansone 2003). I expand upon these notions in the following section. These realities bring us to a second theoretical claim informing this chapter.

Tiffany Joseph's (2015) sociological ethnography, "Race on the Move: Brazilian Migrants and the Global Reconstruction of Race" explores shifting understandings of race among return immigrants in Governador Valaderes, a small city in Minas Gerais, Brazil. In her analysis, Joseph introduces the concept of the "transnational racial optic" as "a lens through which migrants observe, negotiate, and interpret race by drawing simultaneously on transnationally formed racial conceptions from the host and home societies" (Joseph 2015: 7). This concept applies to the accounts of most of my 
participants mentioned in this chapter either through concrete comparisons of the relationship between Dominicans and Haitians in Hispaniola, or between whites and blacks in Brazil, or more generally when speaking of prior experiences in New York. The "transnational racial optic" functions in varying ways depending upon the individual subject's identification, classification, age, gender etc. For example, in one instance, an older Dominican woman participant acknowledged her African descendance but only speaking Spanish, identified more with the greater Latino community. This was not the case with her daughter, MaReyni, who I introduce in the Introduction and who I further discuss below. In this chapter, I contend that incorporating the idea of the "transnational racial optic" allows us to better understand the impact of shifting processes of racialization on Afro-Latino subjectivity in Charlotte, and the ways in which these populations come to situate their identities among the dominant Latino populations, the black American population and within the black-white binary.

Locating and identifying some participants in East Charlotte businesses required my own perceptions of if someone "looked black." Oftentimes this was simply based on skin color. In these instances, we discussed how they identify, which at times, depending mostly on age and generation operated through color classifications such as morena, mulata, trigeña, etc., that are common in their countries of origin. Each of these classifications signify ranges of brown skin complexion that in the U.S. would signify blackness highlighting Stuart Hall's designation of race as a "floating signifier." Opting in some instances to use these color caste classifications while recruiting from Latino organizations, I quickly learned that in the South, these classifications were also unreliable. I discovered that the general Latino population used moreno to classify black 
Americans. Even when I used the term "Latinos morenos", it was often met with uncertainty by mostly Mexican and Central American organizers. For example, while searching for Afro-Latino participants who were not Dominican (the most visible), the Community Outreach director at Hola Noticia, could only direct me to one AfroColombian, Kurma Murrain, who I discuss below. However, events such as Ritmo y Sabor as well as other participants, who were mainly small-business owners confirmed these populations were indeed present in the city. It appears then, that within the context of the U.S., moreno comes to signify African Americans despite the presence of AfroLatinos, indicating an erasure of morenos within Latino populations. In turn, blackness is equated with Americanness. This chapter explores the impact of equating blackness with Americanness on Afro-Latino/a/X identity and subject-formation. For these reasons, the men and women that I discuss in this chapter all self-identify as an Afro-descendent, as black Latino/a/X, or as Afro-Latino/a/X.

I begin this chapter with an account from Patricia, who is a young Dominican woman that had only been living in Charlotte for a year at the time of our interview. Patricia's account uncovers several dilemmas concerning racial and ethnic identification for Afro-Latinos as they carry understandings of race, ethnicity, and nationality from their countries of origin and confront those of the U.S. South. Despite color classifications ranging from negro, pardo, moreno, trigeña, indio oscurro, indio claro, etc. in countries such as the Dominican Republic and despite the prominent emphasis on national identity for many Latinos, which Patricia displays by exclaiming "I am Dominican", Patricia, like all other Afro-Latino/a participants discussed in this chapter, have been at one point or another conflicted by the existential question of "what are 
you?" This question further speaks to the liminal space that Afro-Latinos occupy. Patricia, despite her obvious light brown complexion, is plagued with the question, "who do you associate more with? Do you consider yourself a white person or a black person?" Patricia is the same complexion as myself, what U.S. black color classifications would deem "light skin" or "red bone," depending on the season. I have been asked what I am "mixed" with. Yet, even with my hair straightened, I have never in the context of the U.S. South, been offered the option of considering myself as white. As noted in Chapter Two, African, West Indian, and Haitian immigrants are not presented with this option, "black is black" despite cultural and ethnic differences, therefore, this is an aspect further dissected in this chapter.

At the same time, Afro-Latinos/as are often denied membership into the black American community based upon language and nationality as well as the general Latin American community based upon cultural and linguistic distinctions in the context of the U.S. South. More than any other racialized group, I argue that Afro-Latinos occupy a designated space in the socio-racial landscape that is simultaneously hybrid, contingent and liminal. These populations are either rendered invisible, constantly forced to choose a side in the racial binary, or emerging tertiary racial/ethnic categorizations, or as I argue in this chapter, must intricately negotiate and adamantly announce their identity in order to gain visibility and acknowledgement. Reared in contexts that foster processes of racialization that are highly intertwined with constructs of national identity in their countries of origin, Afro-Latinos/as struggle for both racial and national belonging and recognition as the Panamanian woman in the opening description of Ritmo y Sabor does; demanding that the DJ "shout out" Panama is not necessarily a consequence of her racial 
identity and quest for racial/ethnic/cultural recognition, but her national identity as Panamanian. Further, most Latinos in the U.S. are compelled to be Hispanic based upon federal and state categorizations through institutions like the U.S. Census, job and school applications and/or other organizations. However, individuals may not personally identify as Hispanic, because like blackness in the U.S., "Hispanic" is a one-dimensional classification that denies other aspects of one's identity. This chapter interrogates the intricacies and legacies of being mulata, morena, trigeña, indio oscurro, indio claro, etc. and national identity in countries or origin, Latinidad in other cities in the U.S. while being and/or becoming simply Hispanic...black...or white?... in the U.S. South.

\section{"We Never Identified with a Race": Perspectives on Race in Latin America and the Hispanic Caribbean}

While there are significant historical factors that contribute to the unique conceptualization and implementation of each nations' process of racialization, in contrast to the U.S, many countries in Latin America utilized aspects of racial mixture to foster national ideologies such as mestizaje, racial harmony, hybridity and transculturation to assert their own forms of modernity (Ortiz 1947; Sagas 2000; Wade 2010; Telles 2004; Degler 1971). Yet, racial mixture not only excludes those who are unmixed, racial mixture historically functioned alongside other apparatuses of eugenics, including genocide and European immigration to promote blanquemiento or whitening in Latin American nations (Stepan 1991; Wade 2010, 90). The presence and permission given to some blacks of lighter complexion and mulattos to elevate into positions of power, also known as the "mulatto escape hatch," was offered as a fundamental difference between Brazil and the U.S and furthered the idea that race relations in Latin 
America were less restrictive than those in the U.S (Degler 1971; Freyre 1933; Freyre 1963; Skidmore 1974; Telles 2004; Wade 2010). Degler (1971) asserts the notion of the "mulatto escape hatch" one theory among many in the comparative debates among scholars that analyze the differences and similarities between race relations in the U.S. and Brazil. Many studies go as far as to falsely suggest that slavery was more benign in Brazil and other Latin American nations than the United States, this was particularly the case in Brazil with nationalists and scholars such as Gilberto Freyre's (1933) work, The Masters and the Slaves (Casa Grande e Senzala), which set the tone and the basis for Brazilian national identity.

Freyre's work made a list of far-fetched and bizarre claims that became fact within the national narrative of Brazil, among these was the idea that African slave women enjoyed rape because of sadomasochist tendencies while Portuguese men grew up with a sexual desire for African women since African women nursed them as children (Freyre 1933). The idea of racial harmony was also nurtured by Freyre's concept of Luso-Tropicalism, which offered a range of myths to suggest that the Portuguese were essentially better colonizers than other Europeans (Freyre 1963). The many ideas that promoted and fostered the myth of racial harmony only served to reinforce the racial hierarchy and encourage whitening. For black subjects in Latin America and the Caribbean, this often meant "marrying up" and disassociating from darker skin individuals (including family members), establishing a vast range of color caste systems that would be enacted throughout Latin America and the Caribbean. Similar cultural behaviors and attitudes in regards to color remain in the U.S. as well, but have been well restricted through the "one-drop" rule, or the idea of hypodescent. This rule of 
hypodescent was developed by pseudo-scientific communities and emphasized notions of contamination by "black blood" that were ultimately infused into American legal and social institutions (C. W. Smith 2014, 21). The supreme court decision in Plessy v. Ferguson of 1896 solidified the one-drop rule by upholding "separate but equal" that legitimized the institution of Jim Crow. In most Latin American countries with Afrodescendent populations, the presence of African descendants and their cultural contributions were utilized by national leaders and scholars only when convenient to national rhetoric, presenting "the opportunity for inclusion in the same time and space as the opportunity for exclusion" (Wade 2010, 94). Therefore, racial mixture in Latin America and the Caribbean masked racial injustice, promoted ideologies such as "racial harmony" and/or "racial democracy" and commissioned a false consciousness among racialized subjects, most notably in countries such as Brazil, the Dominican Republic, and Colombia (Sagas 2000; Telles 2004; Stepan 1991; Wade 2010; Smith 2014; Applebaum, Macpherson, and Rosemblatt 2003; Hanchard n.d.; Tate and Law 2015). Further, the current and past presence of indigenous populations provided a basis for indigenismo.

Studies of indigeneity operated on a basis of ethnicity while studies of Afro descendant populations operated on a basis of race (Wade 2010:37). For scientists, scholars, and politicians, indigenous or indio did not depend on certain phenotypical signifiers but instead cultural signifiers such as clothing, language, and place of residence while the boundaries and signifiers between indigenous and mestizo were both crossable and malleable (Wade 2010, 38). These ideologies provide a basis for conceptualizing 
processes of racialization throughout Latin America and the Caribbean and more critically, how they come to be negotiated in the U.S. South.

The island of Hispaniola poses a unique case for understanding processes of racialization. On the Eastern half of the island, Dominican national identity originated from the desire to contrast itself with its neighbor Haiti. Torres-Saillant (2006) notes that the overwhelming majority of inhabitants on the island of Hispaniola, including the Dominican Republic, are of African descent. However, Dominican nationalism is premised on anti-blackness and more specifically, anti-Haitianismo. This has justified the genocide of Haitians in the Dominican Republic as well as other forms of exclusion and expulsion. Further, like the rest of Latin America, the usage of indigenismo has presented an outlet for the denial of African ancestry. The irony of the Dominican Republic is the fact that the majority of its indigenous Taino and Arawak populations were decimated during colonization. Despite this significant detail, Dominicans continue to rely on the "racial" category of indio as well as variations based on color such as indio claro and indio oscurro to define themselves. Terms such as mulatto have historically been avoided as this categorization implies African descent (Sagas 2000; Howard 2001; Torres-Saillant 2006).

Further, the Dominican-Haitian relationship in Hispaniola often emerges through the accounts of my participants as a point of comparison for their understandings of race and ethnicity in the U.S. South between blacks and whites and between Dominicans and Mexicans/Central Americans. Here, the Dominican-Haitian relationship serves as an anecdote to describe notions of superiority that whites hold regarding blacks, and as I 
discuss later in the chapter, that Dominicans come to possess regarding Mexican and Central Americans based upon their association with illegality.

Many Dominicans carry anti-black ideologies from their country, and may attempt to refute their own blackness in the U.S. However, demographics in the U.S. South position African Americans as the dominant minority. As such, African Americans hold substantial political and economic power in the U.S. South. Other studies have found that this power along with African American demographics influence black immigrant's processes of identification and racialization in the U.S. Candelario (2007) notes that in New York, where there are visible Dominican enclaves, bounded by language and culture, most Dominicans continue to distinguish themselves from African Americans. In Washington D.C, however, where black Americans are the majority and hold political and cultural power, the majority of Dominicans identify as black. I use the latter instance to suggest that similar processes are taking place in the U.S South where identifiable ethnic enclaves do not yet exist. Candelario contends that in Washington D.C, Dominicans as well as other black immigrants were often an invisible community within the broader African American community (Candelario 2007, 133). This is mediated by the political climate of the U.S at the immigrants' time of arrival. For example, many Dominicans who arrived in D.C during the height of Jim Crow utilized code-switching to shield themselves from discrimination directed at African Americans (Candelario 2007, 157). On the other hand, Hannah Gill's (2010) examination of the Latino experience in North Carolina reveals that Dominicans in North Carolina often rely on the use of English and cultural performance to appear African American in order to avoid the stigma of being perceived as "illegal." However, based upon the accounts of 
my interlocutors, Afro-Latino/a identity in the South is dependent upon a myriad of factors, confrontations and negotiations that do not necessarily adhere to Candelario's or Gill's findings. Charlotte is often the second or third destination for most Afro-

Latinos/as. As a result, the time of arrival and experience in other cities impacts AfroLatino racial identification. I find that their experiences and understandings of race are oftentimes conflicted by perceptions of race and ethnicity in the U.S. South. Nevertheless, my participants continually draw from their previous conceptualizations of race, ethnicity and national identity as they process their own self-understanding in the South.

\section{Being While Black/Mexican/Immigrant/Etc. in the South; Surveillance, Control and Citizenship in the Trump Era}

"So, I'm afraid of protesting, I went to one protest, but then all this travel ban and stuffI started being afraid. I deleted everything I had on Facebook against Trump, because my cousin was coming [from Brazil], and they're checking phones and stuff, I didn't want her- her connection to the US is me. I didn't want her to have trouble [getting] into the country because of shit I was saying on Facebook. Yeah, I'm really afraid, although I have-like I'm documented, but because of-I don't know. I'm afraid. Yeah, I'm afraid of participating [in protests], but I wish that I could, I wish I didn't have this fear so that I could participate more”-Carolina, Brazilian, 8 April 2017

"I stopped to check in with my participant Liceth, an older Cuban woman, self-identified morena and owner of La Caridad Cafeteria and Grocery Store in East Charlotte across from the old Eastland Mall. This was my first time back in the store since I conducted 
preliminary research a year ago. I went over to the cafeteria side where several Latina women were behind the counter cooking and cleaning. I first asked the women if Liceth was there that day, and they quietly responded no. As I sensed the women's apprehension to talk to me or even to disclose whether Liceth was actually there that day, I told them about my research. I was still met with blank stares. It then dawned on me that I left out a critical factor; I was a student and affiliated with a university. Upon revealing this to the women, an instant expression of relief took over their faces. They all then laughed as one woman said, "Ayy niña!! Pensemos que tu era La Migra!!”Bennett, Field Notes, 8 March 2017

Anti-immigration policies, Islamaphobia and police brutality were well in effect before the 2018 election season. However, the election of Donald Trump as president on November 8, 2016 solidified and catapulted fear and anxiety among certain populations of people already marginalized economically, politically, and socially. Following the 2016 presidential election, anti-immigrant and Islamaphobic rhetoric surrounding the Trump campaign seemed to almost immediately come to fruition. In addition to Executive Order 13679, titled "Protecting the Nation from Foreign Terrorist Entry Into the United States", otherwise known as the "Muslim Ban," issued in January 27, 2017, ICE (Immigration and Customs Enforcement) raids and deportations targeting Mexican and Central American immigrants began to surge in the Carolinas and other southern states, most notably, Georgia. East Charlotte and South Boulevard, Charlotte's two immigrant corridors were deeply impacted.

On February 16, 2017, nearly 8,000 immigrants and supporters marched Uptown in solidarity with the national Day Without Immigrants while hundreds of local 
businesses in East Charlotte and South Blvd. closed their doors to demonstrate the economic and social significance of the immigrant community. On February 17, 2017, hundreds of students walked out of Charlotte-Mecklenburg schools in protest of Donald Trump's proposed immigration policies that would dramatically affect North Carolina's immigrant communities. On February 27, 2017, about 200 protestors gathered to march to city hall to protest the surge in ICE (Immigration and Customs Enforcement) raids and deportations that have left many children without parents. A portion of the Charlotte Observer captured these events with the subtitle, "A community on edge." Based upon my observations and interviews, this is felt throughout not just the Latino communities, but the immigrant community as a whole. While the city of Charlotte has denied claims that CMPD in conjunction with ICE are "terrorizing” Charlotte's East Side, residents of that area feel differently.

The morning of the ICE protest, I sat with Liliana Morena, a Colombian woman, in a Dunkin Donuts on South Blvd., where the majority of workers and customers were Latinos of varying shades. Liliana stated that it was now a "tiempo de persecucion." Weeks earlier, I interviewed a group of African women in a hair braiding salon on the East Side. As they sat and created each intricate plait of the African American woman's hair sitting in their chair, the women, who were all from different Francophone African countries and practicing Muslims, revealed that they are now afraid; a feeling never felt before, especially given that they are legal residents.

In my participation in the smaller ICE protest, I noticed that among the countries represented, there was Mexico, Honduras, El Salvador, and Brazil. At the same time, most of the "black" people present were Black American students, who held signs stating 
"Black/Brown Solidarity" as well as "Black and Immigrant Lives Matter." There seemed to be an absence of darker Afro-Latino immigrants or, a noticeable presence of those countries in which there is a prominent African descendent population, other than Brazil. I reference the below photographs taken at the ICE protest, which display Latino groups represented as well as black Americans standing in solidarity. I attempted to survey the crowd by asking individuals where they were from and I discovered that the group of students were mainly black Americans from UNCC and JCSU. This stands in contrast to the larger Day Without Immigrants protests, which saw the presence of immigrants from Africa, Asia, and Latin America as well as black and white Americans standing in solidarity. Even still, based upon a survey of the photographs from the Day Without Immigrants protest, the most visible populations, again represented by flags, were Mexican and Central Americans. None of my Afro-Latino participants attended either of the protests, however it was a topic that emerged in our conversations.

I became interested in what their absence from the ICE protests signified; did Afro-Latinos' engagement with blackness provide a shield in particular situations? Or was the conversation concerning immigration simply viewed as an issue for Mexican and Central American immigrants and not Afro-Latinos, and if so, why? In the March 5, 2017 edition of the Charlotte Observer, Tin Nguyen, a Southeast Asian immigrant reported that, "there is a feeling that it has become dangerous to walk outside your house, or go to work, go to the store, or go anywhere. It's a feeling of having a target on your back, based on your nationality or color." Many Black Americans have felt this for years, but especially now, so I began to ponder, what does this mean for Latinos who also happen to be black? 


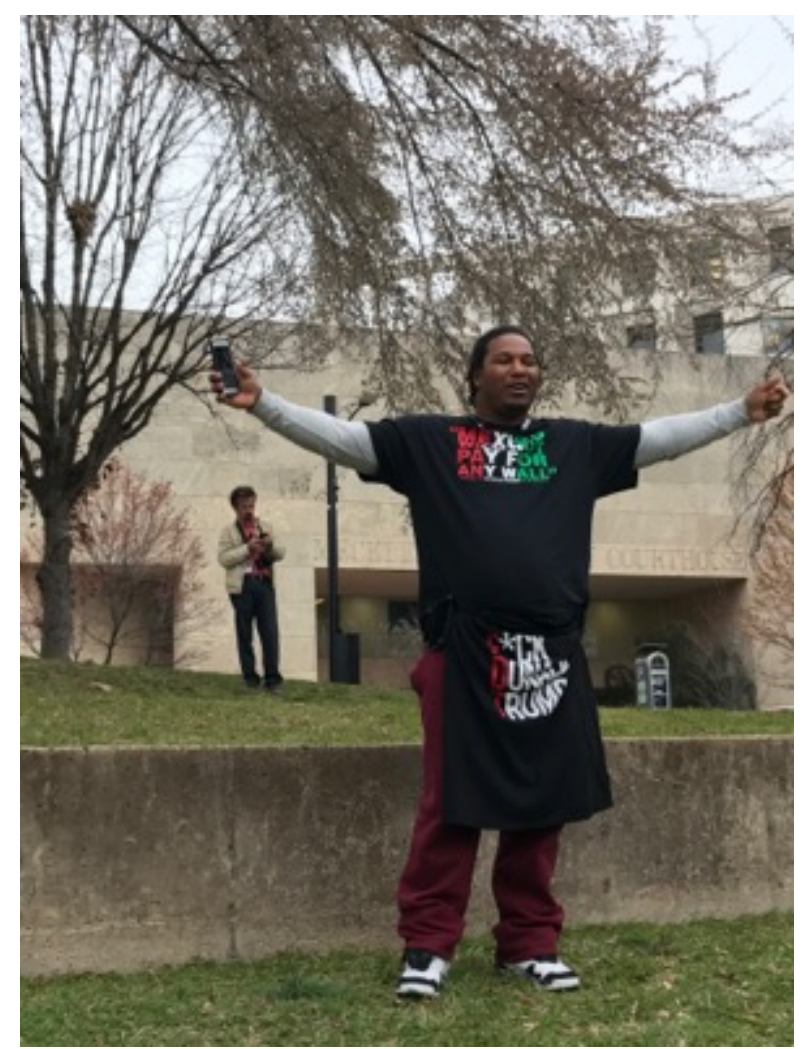

Figure 3.1. A Black American man stands at the February ICE protest in Marshall Park in Uptown Charlotte. His top shirt reads, "Mexico Will Not Pay for a Wall", the shirt wrapped around his waist reads, "F*** Donald Trump", Photograph by author.

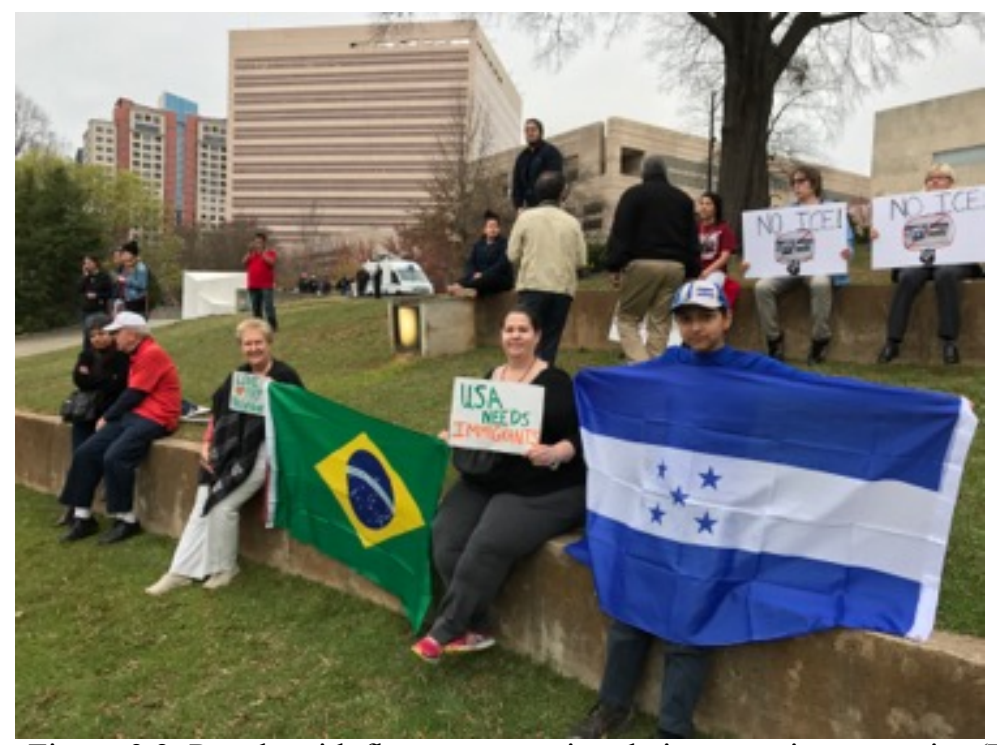

Figure 3.2. People with flags representing their respective countries (Brazil and Honduras) at the ICE protest, Uptown Charlotte at Marshall Park, Photograph by author. 


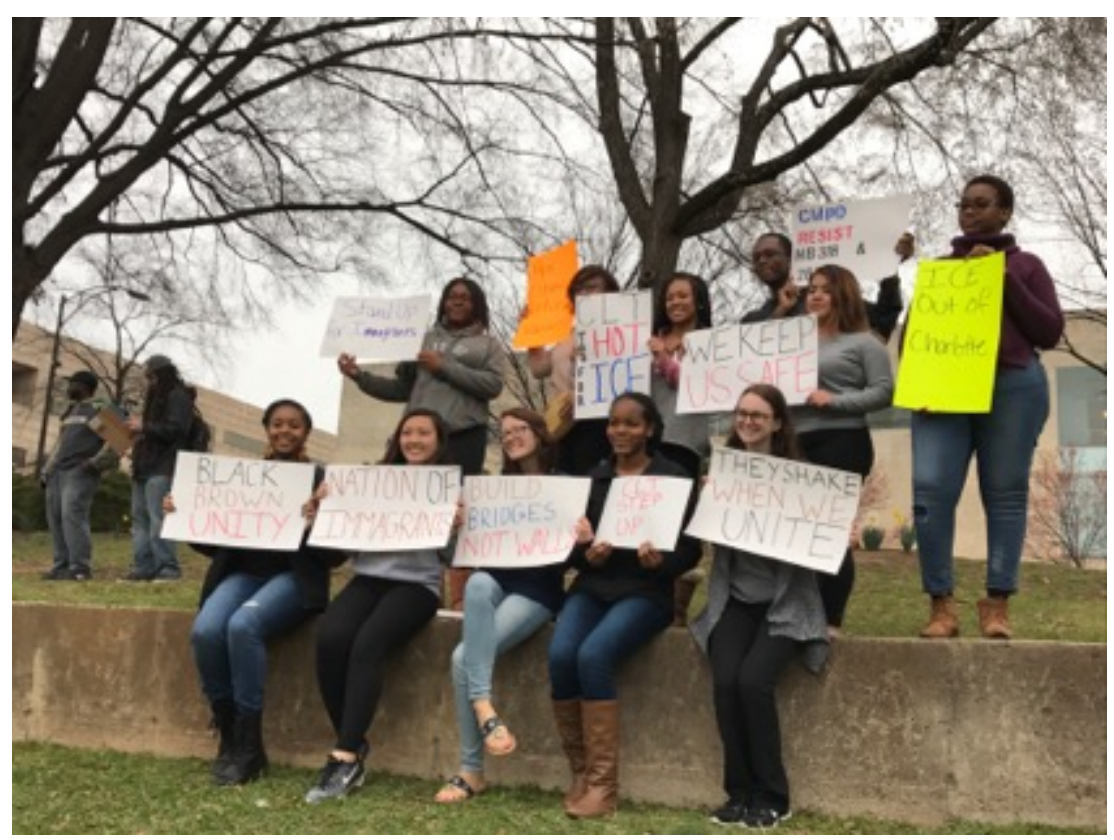

Figure 3.3. White American, Black American and Latino American Students from UNC-Charlotte and Johnson C. Smith University hold signs in protest of ICE at Marshall Park, Uptown Charlotte, Photograph by Author.

I met with one of the main organizers of both the ICE protest and Day Without Immigrants, we briefly discussed the absence of Afro-Latinos, he could only refer me to one that was visibly active in the Latino community, Kurma Murrain, an AfroColombian. On several occasions, Latino/a and Black American participants could only refer me to this one Afro-Latina in the entire city of Charlotte. See Figure 3.4. Kurma and I met via Facebook as she was out of the country at the time working in China and would later return during summer. Very active in the general North Carolina Latino and more specifically, the Colombian community in Charlotte, Kurma directed me to her blog entitled, "My Journey as a Black Latina (And What That Represents in the New America)", which documented her time in Charlotte. In her blog, she poses the question, "If I don't open my mouth nobody would know I am from South America, but if I do, would a police officer think I'm not black and spare my life because they're only 
targeting African Americans?" Kurma's question resonates with the overall questions of this chapter and as such it also reveals the experiences of other participants, who discuss in more detail in the following sections. Further, Kurma's questions underline a common fear that many black Americans confront, which is a critical aspect of black Latino subject-making in the U.S. South. North Carolina is at the forefront of deportation policy and Mecklenburg County (which includes Charlotte) is one of the eight counties in the state, and the first in the nation, to implement the ICE $287(\mathrm{~g})$ program in 2006, which allows certain state and local authorities to enact federal immigration enforcement (Gill 2010). Since 2006, the program has mandated that any person jailed on felony or driving while impaired have their immigration status checked. This has led to Latinos being unlawfully targeted for "Driving While Mexican" a phrase that derives from the sentiment of "Driving while Black" (Gill 2010: 6). The law has also resulted in extensive checkpoints in East Charlotte and South Blvd., evidencing strategies of control and surveillance that go beyond an individual's criminal activity.

At the beginning of my research, I had no idea of the protests that would transpire in response to the Keith Lamont Scott killing. After all, the September 2013 killing of Jonathan Ferrell, another unarmed black man, was met with minimal protest and media coverage. As a result, many of Charlotte's native and long-term residents did not feel "like the city had it [protest] in it", a perception that I discuss in the first chapter. Returning post-September 2016 however, the events that took place those few days and

\footnotetext{
7 This quote was one of many of the responses presented from the audience at the Levine Museum of the New South's sponsored Black MBA Association's presentation on the opening of the exhibit "K(no)w Justice, K(no) Peace" a historical and photographical exhibition on race/ race relations in Charlotte leading up to the Keith Lamont Scott killing and subsequent protests
} 
nights emerged as a central aspect in conversations with my participants. I quickly realized that for Afro-Latinos, there was another unfortunate reality; not only did they risk the "normal" police violence black Americans face, they also faced other dire consequences due to illegal, pending, or what had become uncertain legal status under Trump. This fear was expressed even by those who were documented, if they did not possess full citizenship, some participants were on Student Visas, or work visas, despite having these forms of legal documentation, there was now uncertainty. In other words, many of my participants felt they could now be a target regardless of having documentation simply because they were immigrants.

The most recent reported case (only locally publicized) in Charlotte, was again, in September 2017, with the killing of Ruben Galindo, who was killed after calling 911. Again, instead of responding to Galindo's call for help, the officers at the scene shot and killed Galindo reportedly because of his "demeanor" and his inability to "clearly" answer officer's questions in the moment. Galindo did not speak English. Despite having his arms raised when approached by police as evidenced in a police bodycam video, in November 2017, it was announced that the officers would face no charges. The collision of local and national events among the black and Latino community became an inescapable aspect of my research in my return in October 2016 onward. In the following exchange, Carolina, an Afro-Brazilian participant (quoted in the opening of the section) expands upon her fear of protest, whether it be marching or via social media:

"The Keith Lamont killing, I participated in some actions at the University, it's a safe space. I don't think anyone protesting at the university is going to change anything, but it's like, it was considered safe for me. [The killing] was so bad, and I was talking to 
my girlfriend in Brazil and she was seeing the news on TV, and everybody got scared. I got scared because my friends [in Charlotte] are very involved with organizations and protests and stuff, so seeing their views [and] not only the newspaper's views, its like, oh, these people are not criminals or anything, they're just protesting! It happened in Brazil too, so having this other side of the coin, it was good for me, and my girlfriend she was seeing the news on TV [in Brazil] and she was like, "be careful, because the police don't like Black people”, but I [was] like, I'm a woman. And she said, yeah, but no one can tell if you're wearing a hoodie, and I was like yea, you're right. So, nobody's safe, you know? I feel like that. If the cops pull the car over, for example, I wouldn't be like, it's all good because I'm not doing anything wrong, I have all my stuff. No! I would be afraid. Because you never know..."

In the opening quote of this section, Carolina revealed that she feared her participation in local protests and deleted her social media posts criticizing the presidency as she worried that these could potentially jeopardize her own status as well as her cousin's entry into the country. In this second account, Carolina uncovers that she realized that she could be racially profiled or subject to police brutality even though she is a woman, a realization that has heightened her fears. Carolina goes on to draw comparisons between racial profiling and police brutality in the U.S. and in Brazil, signaling the underlying similarities of race relations between Brazil and the U.S as well as the ways in which subjects experiences in host countries influence their understandings in the U.S., and the U.S. South. Carolina's comparison of race in Brazil and in the U.S. demonstrates the "transnational racial optic" in action. Joseph (2015) contends that 
migrants receive initial racial socialization in Brazil that provides a foundation for the understandings that develop in the host country. However, migrants ethno-racial backgrounds, "looking white, brown, or black" greatly influence their experiences in the U.S. (Joseph 2015, 7). According to Carolina's account, there is not a stark difference in what is happening in the U.S. and Brazil as far as racial profiling and police brutality. Further, through Carolina's account, we also understand the significance of transnational media in communicating shared realities of black subjects in the Diaspora as among her friends and family in Brazil their concerns are realized through the shared idea that “police do not like black people." Here, we see that "transnational ties between the home and host countries" are constantly informing migrants' knowledge and experience of race at every stage of migration (Joseph 2015, 7). Below I discuss Carolina's denied entry into the black American community based upon her nationality, food and language. However, as a result of her color as well as her legal status, which appears uncertain under the Trump administration, Carolina's confronts duplicitous fears that impact her subjectivity. Carolina's fear of being targeted for not only being black but also an immigrant both reinforces and nuanced the idea of Afro-Latino/a/X liminality.

\section{"The Slave Experience Didn't Only Happen in the U.S.!": Maneuvering the Middle Passage Epistemology}

"Well in New York, we were just Dominican, and they knew you were Dominican. We didn't have to explain." --Mayra, Dominican, 22 April 2017

The United States Census Bureau and Department of Homeland Security's racial and ethnic classifications further complicate what it means to be Afro-Latino. Kurma Murrain, a self-identified Black Latina from Colombia living in Charlotte recounts the 
process of gaining citizenship in her blog, "My Journey as a Black Latina (And What That Represents in the New America." Murrain recalls applying for her green card and noticing, to her amazement, that officials had marked her race as white. The officials explained that they marked white because she was from South America, and was therefore, Latina as the boxes indicate Latino/White or Black/African American, and she was not "American", another arguable assertion. Murrain's experience here reveals that people in the U.S. are "involuntarily ascribed" racial identities by U.S. institutions such as state legislatures, the Supreme Court, the Department of Homeland Security, and the U.S. Census that may or may not represent what the individual or group identifies as (C. W. Smith 2014, 47). U.S. racial classifications and categories have changed over time in conjunction with immigration laws.

While the U.S. Census defines a Black/African American person as one "having origins in any of the black racial groups of Africa" making terms such as "Haitian" or "Negro" interchangeable with Black or African American, individuals from North Africa are categorized as white (C. W. Smith 2014, 48). The latter categorization of North Africans as white and Kurma's experience in which certain cultural, regional, and linguistic signifiers can make one white, reveals the haphazardness of racial categorizations in the U.S. and the ways in which they reinforce racial and ethnic hierarchies (C. W. Smith 2014, 48). Further, Hispanic/Latino is defined as an ethnic category regardless of one's race (U.S. Census Bureau). This is problematic as Hispanic and Latino could be seen as regional identifications that encompass a range of ethnicities: not all Latinos share the same culture or even language. According to Murrain, being black and Latina "seems to trouble many Americans", both whites and blacks alike. 
Murrain recollects an instance in which she spoke before a group of African American students, in which she thought that she would "fit in" as her complexion was just as dark, if not more, than many of theirs. However, the students insisted on asking her, "What are you?" "Are you Black?." The students, like the officials, had reached the same conclusion; Kurma was not black because she was from Latin America. U.S. racial and ethnic classifications mirror the very one-dimensional way in which race, nationality, and ethnicity are projected in the country; these categories are often portrayed and understood as mutually exclusive disallowing any comprehension of the layers of one's identities. At the same time, in Latin America, nationality/national rhetoric has functioned to minimize the significance of race by obscuring African ancestry, and this invisibility manifests within U.S. racial and ethnic classifications. These narrow understandings are unfortunately shared and internalized by the majority of the population in the U.S. South.

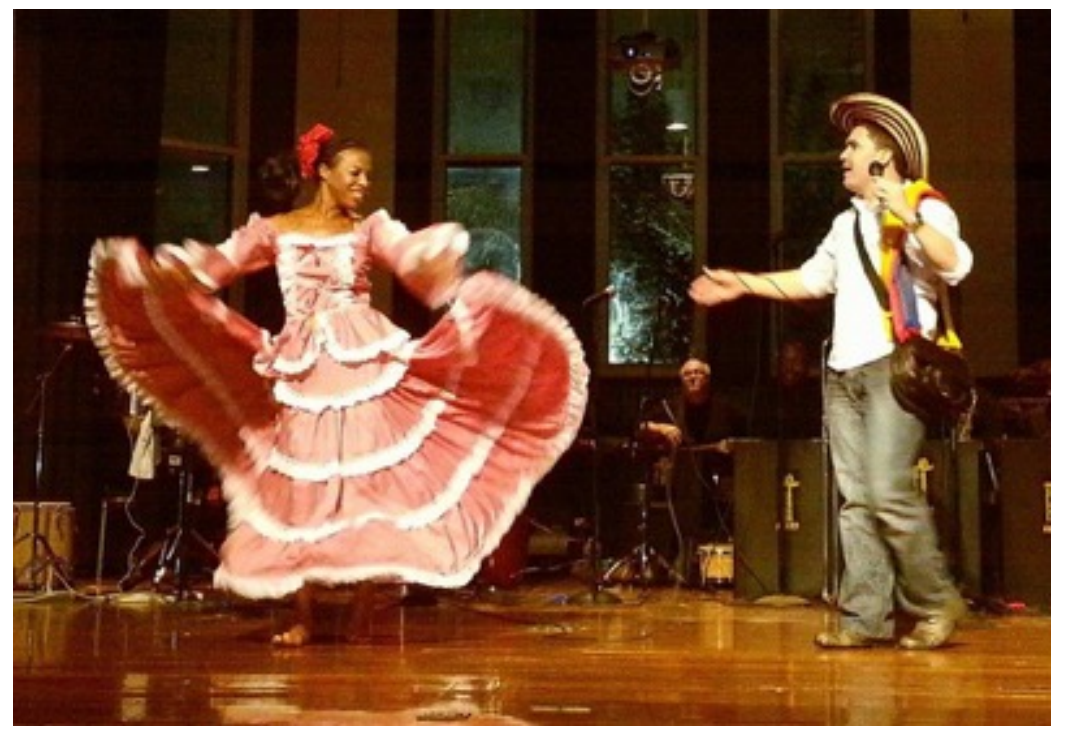

Figure 3.4. Kurma performs Cumbia, a traditional Colombian dance, at "La Tercera Raiz/De Africa a Latinoamerica" event at Johnson C. Smith University. Photograph provided by Kurma through PhotoVoice participation. 
Michelle Wright (2015) argues that conceptualizations of blackness in the U.S often stem from what she terms a Middle Passage Epistemology that holds that in order to be "defined" as black, one must inherit the experiences of the trans-Atlantic slave trade and the struggle for Civil Rights in the U.S. While a Middle Passage Epistemology has sourced a collective identity and resistance for black subjects in the U.S., Wright argues that this conceptualization confines the diversity of black subjectivities that have not experienced the linear trajectory from the Middle Passage to post-U.S. Civil Rights Movement (M. M. Wright 2015). Wright asserts that it is a "deeply frustrating truth" in that "any fixed stipulation for membership, whether national, biological, cultural, political, social, or otherwise, initiates a simplistic framework with essentialist consequences" (M. M. Wright 2015, 68).

Joe and Mayra, a Dominican couple that has resided in the Charlotte area for nearly 12 years, expressed one of the most poignant examples of not fitting into what Wright sees as the linear trajectory of African Americans' definitions of blackness although they identify as black. Joe is adamant in recognizing that slavery did not just happen in the U.S., which is the root of his affirmed black identity. He and Mayra expand upon this in the following exchange:

Mayra: You know it's very controversial — the whole thing — and we still have this argument with coworkers-I say you know what, you might take it offensive that I'm not African American. I'm not saying I'm not Black! I'm saying-Joe: The culture!

Mayra: Yea, there is a difference, culturally! There is difference! 
Joe: If you ask me, I will tell you that I'm not African American from a perspective of culture.

Mayra: That's not how I grew up! I'm a Black Dominican!

Joe: And I tried to tell my friend you know, the slave experience did not only happen in the U.S!

Joe: The first person who was African descendent who came to Dominican Republic didn't come by choice, that's what I'm saying. Everybody else did. Let me finish--so the difference is--that I cannot identify [with] an African American experience, the 200 years of slavery that they went through, then the Jim Crow experience that happened until 1963.

MB: You say that you cannot identify with it?

Joe: I can't identify with it because I didn’t pass through it. However, coming here in 1974, I remember someone called me the N-word, but I had no idea what that meant! And it was like you're telling me—calling me something I don't even understand. So that's what I have to try to tell people, there is an experience that my family didn't go through. We weren't part of [the experience]. Now that we've been here [in the U.S] a lot of years, 40 something years, then I can identify somewhat [with] the native American experience because this is the--are you recording? [MB: Yes] This is the fucked up part, because I speak Spanish, they will say, "oh, you're not black, you're white" and I go, What?! 
Mayra: And I'll tell you one thing, we've had this discussion...people say, oh there's a lot of racism down there [the U.S. South] but when they say that, they're referring to whites being racist...and I really can't say I've felt discriminated against but Joe has said, "I have felt more discrimination from black people than by white people"

Joe: But not discrimination--

Mayra: Ok, no not discrimination, but almost like-

Joe: Ok so what I've gotten at TIA, there is a--there was a group that was for African Americans, an African American group that would get together, and so someone said, 'oh we should invite Joe' and they said, Joe is not black. So that's what I'm saying...I don't mean it in a bad way

Joe and Mayra's account exposes the ways in which black U.S. definitions of blackness that stem from a Middle Passage Epistemology exclude other black subjects as well as how other tedious assumptions compromise and narrow definitions of blackness. Joe asserts and acknowledges that his ancestors endured the Middle Passage, however, his disconnection with African American blackness lies with his inexperience with the particularities of enslavement and post-emancipation racial oppression and resistance in the U.S. It is not at all far-fetched to argue that many African Americans are unaware of the shared history of enslavement in Latin America and the Caribbean. This unfamiliarity unfortunately guides African Americans' misunderstandings of Joe's blackness and selfidentification as Black, but not African American. This is also the case with Kurma. However, Joe and Mayra, like Kurma, also confront the idea that it is somehow linguistics somehow defines (or minimizes) assertions of blackness; in addition to Joe, Mayra, and Kurma other participants revealed that they were perceived of as black until 
speaking Spanish, at which point, they became either Mexican, white, or simply nonblack. In Chapter Two, I argue that "black is black" among African and Caribbean populations, holding that their blackness is never questioned. For West Indian and Anglophone Africans, they fulfill the linguistic requirements, however here, we must posit the inconsistencies of linguistic requirements: Francophone Africans' and Haitians' blackness is never questioned locally nor in the popular imagination/consensus. The latter further speaks to the inconsistent constructions and perceptions of race and ethnicity and the establishment of racial and ethnic hierarchies in both the U.S. and Latin America.

As neither Joe nor Mayra completely adhere to the linear trajectory lined out by the Middle Passage Epistemology, they are often denied membership into the black American community. Further, the dismissal of or offensive reaction to Joe and Mayra's identification as Black but not African American by black Americans reify the notion that U.S. definitions of blackness establish race, culture, ethnicity and nationality as mutually exclusive classifications. The term African American in itself is a highly problematic classification for many black Americans in that it suggests a direct lineage to a very culturally and ethnically generalized Africa, which most black Americans do not possess. At the same time, Joe and Mayra's confrontations with blackness in the U.S. South demonstrate an essentialized framework of blackness and race that coexists with malleable delianations based upon nationality and language. By this, I am suggesting that unlike African and Caribbean black subjects who "become black" or become "black twice" as it pertains to undergoing processes of attaining the social and cultural meanings 
of blackness in the U.S. (Taiwo 2003; Charles 2003; M. M. Wright 2004), Afro-Latinos are presented the alternative to un-become black.

Based upon Patricia's account presented at the beginning of this chapter in which she is posed the question of who she identifies more with/as black or white by a white colleague, Kurma's racial classification as white ascribed by Homeland Security, and African Americans' assumption that Joe is not black, both black and white Americans do not necessarily see Afro-Latinos as black based upon either linguistics or nationality. It seems that, despite shifting between an essentialized black-white binary, black Latinos, despite their skin color have the alternative to "become white" for the simple fact they speak Spanish. I am not suggesting that one "becomes white" wholly in the sociopolitical definition that whiteness holds, but attaining the social and cultural meanings of whiteness in a similar way that North Africans are ascribed whiteness. Still, North Africans face persecution for religious beliefs or even despite religious beliefs (not all Arabs are Muslim) yet, their whiteness further constructs of racial and ethnic hierarchies among people of color.

The murkiness between sociocultural whiteness and sociopolitical whiteness again demonstrates the very arbitrary ways race and ethnicity are defined and constructed in the U.S. and especially in the U.S. South. I am drawn to think of the ways in which historically marginalized groups such as Jewish, Irish and Italians, who also can range in complexion, became white over time and over the course of new immigrant legislation and sociocultural and racial assimilation (Brodkin 1998). There are limits to unbecoming black. These limits redirect us again to Pierre's (2010) criticism of the ethnicity paradigm. For whites, Afro-Latinos as possibly identifying more as white 
attempts to distinguish Afro-descendent immigrants not only from the stigmas attached to black Americans, but to also refashion race in a way that appeases dominant white Americans by somehow demonstrating a tolerance for people of color that contests their relationship to and perception of black Americans. Pierre (2010) contends that with the killing of Amadou Diallo, while his African immigrant status may have served to convince the media and popular white imagination of his innocence in contrast to the rest of pathologized black America, the fact remains that the police did not see Diallo as an immigrant or African first, he was black first. This coincides with the accounts of Kurma and Carolina, yet it also plunges deeper into Mayra's experiences raising a black daughter in the predominantly white town of Concord, right outside of Charlotte. Joe and Mayra's experiences as first-generation immigrants rotate on a complex axis of race, nationality and culture, yet their children's identity is often narrowed down to just black. In a very intimate moment Mayra disclosed an incident with her adolescent daughter recalling:

'I've had incidents where she has come to me and said, 'oh mommy'they [the kids] were somewhere they wanted to play like princesses and knights--there was two white girls, a boy--a white boy-and [my] girl. They decided the two white girls were going to be princesses and her [Mayra's daughter] and the boy were going to be knights. So, she came to me and at first I was like (inhales deeply)...so, 'why do you think that was sweety?' And she goes, 'Because I was the only black one there.' I have to sit her down and constantly tell her-it's almost unfair that you have to reassure-and I said, you know, 'do you think your mommy is beautiful?' She was like yea. I said, 'you think you look like your mommy?' She was like yea. So, I said, 'you're beautiful too.' So it has nothing to do with beauty. And I was like, you know your skin color-you think that 
because they're white and you're black, that that makes them better? Does that make them smarter? No, it doesn't. And it's sad."

Despite often being denied membership into the Black American community based upon a failure to adhere to a linear trajectory, Mayra sits down every other day and has the same conversations with her child as other black mothers do. Yet, because she is Dominican, this aspect of her identity is questioned or denied in the U.S South. The same stands for her husband who works and interacts in a predominantly white corporate environment each day, and perhaps seeks interaction with those who look like him or can relate with him. To be offered an entrée into whiteness, or some form of alternative coloredness, but to also be denied membership into the black community by black Americans are difficult challenges for individuals that must continually encounter barriers based upon their blackness.

Conceding to sociocultural whiteness or distinguishing themselves ethnically, or what underlines the ethnicity paradigm would not grant them exemption from being black unless they speak Spanish, yet the abovementioned case with the Galindo murder by CMPD, proves that Spanish may not alleviate the threat of racial profiling and consequential violence. Joe and Mayra would not necessarily face these challenges, at least having to explain to their children their simultaneous blackness and Dominican nationality, if they were in certain neighborhoods in New York City, where populations are a more diverse range of colors, cultures, and ethnicities and where others are more familiar; at the beginning of this section, I quote Mayra, who held that in New York, "we were just Dominicans" yet, this changed after coming to North Carolina, and especially 
to the predominantly white suburbs of Concord. In other words, Dominicanness is simply understood in New York City versus the U.S. South. Through their own experiences as well as the conversations had with their children, who identify as Black, American, and Dominican, or what Joe now calls "ABCDs", "American-Born Confused Dominicans", a generation raised amongst the racial conceptualizations and confinements of the U.S. and the U.S. South, are presented with more conflicting challenges than New York City. Dominicans, other Afro-Latino populations like them, and their second generation offspring occupy a middle grouping, a liminal space mediated by language, phenotype, time and space in the U.S. Throughout the rest of this chapter and this dissertation, I continue to question whether these populations are expanding or displacing the racial binary of the South and/or if their influence is only situational.

The intimate conversations between Mayra and her daughter designates the "Confused Dominican" American woman as a point of intersectional inquiry drawing us back to Wright's (2015) Physics of Blackness in which she acknowledges the need to recognize the "symbiotic blend of melding between our human categories" (M. M. Wright 2015, 82). Based upon Wright's (2015) assertion that black ancestral lineage in the U.S. and the Diaspora is "comprised of not just victims" but victimizers, I hold that this is one aspect of those that are "confused" whether it be young and older Dominicans grappling with the terms and impact of national rhetoric versus racial categorizations in the U.S. or black Americans coming to terms with the realities of their blackness as well as that of others.

Dominicans provide a unique case based upon the fostering of a national identity solely and directly rooted in anti-Haitianismo, or anti-blackness. As such, it can be 
argued then that Dominicans (and to an extent other Afro-Latinos in the South), are "confused" by processes of racialization in host countries that include U.S. Census classifications, denials of membership into the black American community, and southern ideologies that put forth a more stringent black-white binary. Considering the intersections of race, gender, nationality, ethnicity and numerous other aspects of one's black being, we must bring to the forefront Wright's horizontal alternative, that stands in contrast to an essentialist linear progress narrative. With this, Wright calls on us to recognize the potential for alternative space-times. In a non-linear space-time, blackness "faces obstacles" but blackness itself does not present itself as an obstacle (M. M. Wright 2015, 66). Developing and presenting an alternative to vertical conceptualizations of black identity, Wright (2015) builds upon not only Gilroy, but Deleuze and Gattari, suggesting a "rhizomatic structure for interpellation" of black subjectivity, or an "epiphenomenal time" that contrasts to "vertical relationships" like woman/man, mother/child, leaders/followers, or black/white etc. Therefore, within Wright's epiphenomenal time the multiple experiences, histories, and trajectories that black subjects carry with them and build upon as they navigate the globe can be more clearly understood through a multi-dimensional spectrum of blackness.

I see this dissertation as a way to unravel the layers of identity that black subjects in the South carry with them. Joe and Mayra offer a window into the ways in which many Afro-Latinos confront definitions of blackness within the black American community. However, racial ideologies in the South hold social implications that compel many black subjects to "choose a group" between whites and blacks, whether it be racially, socially, ethnically, or culturally. While this pending decision may exist to an 
extent in other regions in the U.S., Joe, Mayra and others contended that their social groups in other cities were allowed to be more diverse, but remains something they grapple with in the South. An exploration of these experiences are necessary in order to understand why Charlotte's physical, social, and cultural landscapes are unique.

\section{"Do You Consider Yourself a White Person or a Black Person?": Confronting the Racial Binary in Charlotte}

"So, I was in DR for five years, and after five years of being surrounded by people who are of the same race as you, you get to North Carolina, especially, like a small town, and it was really weird to me to see how separated people were because even in New York City, there are so many different things going on there, that I had never really experienced that. It did kind of remind me of the issues that Dominicans have with Haitians and so yea, it was just really -I have found it hard because I felt that most of the Latinos in North Carolina are Central Americans and I did not really feel like I could identify with them. I had a hard time mixing into that group. On the flip side, I really could not mix with the white population because there was just this open, very outward, hostile-like I just don't get your kind, and I felt it was easy for me to get into African American communities. I guess I don't have the language barrier because I've lived here, and then two, I've always identified as an Afro-Latino, so I felt they were more accepting, Ifelt that the society in general was more similar to Dominican society. "Daniel, 29, Dominican,

A sunny Saturday afternoon in February, I dashed out of my remodeled duplex in Plaza-Midwood and headed to Compare Foods, a Dominican-owned grocery chain in Charlotte. There are three Compares in East Charlotte and six total in the Charlotte area. 
The original store is located not even a mile from my home in the heart of East Charlotte, where rugged narrow streets expose the boundaries of gentrification. This Compare occupies a building that was originally a Park $\mathrm{n}$ Shop and catered to a predominantly white working-class neighborhood. The old Park $\mathrm{n}$ Shop building has been hailed for its mid-century modern architectural design and is one of the many existing shopping centers in East Charlotte that serve as physical reminders of the early to mid 1960s shopping center boom. Refer to photos in Chapter One. Today, the busy parking lot of Compare Foods is typically packed as young Latino and African families come in and out the sliding doors that, along with the store's windows, are plastered with advertisements for discount products.

Just in front of the store's doors and under the large cement shading are taco, churro and raspao stands. Earlier that week my friend Miranda, a black-American transplant to Charlotte from California, invited me to a Dominican Independence Day celebration at the home of her co-worker, Patricia. I could only think of one thing to bring to the festivities, Presidente, the Dominican national beer. I started shopping at Compare years ago, for the cheaper prices, fresh produce and the range of products I had grown to love while abroad. Almost all of the participants in my study, from Africa, the Caribbean, and Latin America, mentioned Compare Foods as one of their top go-to stores given that they could rely on the store for specific foods, meats, fruits, vegetables and seasonings from their host countries. So, I knew exactly where to go to find Presidente. Running behind as usual, I rushed into the store focused on Presidente.

Despite my rush, in this particular Compare Foods location, it is difficult to ignore the immediate sensation that one has just entered another country, especially upon 
catching a whiff of the odd mixture of fresh fruit and raw meat from the butcher. In combination with the bright colors, crowds of people in extremely narrow aisles, and the range of languages one hears spoken, Compare is a sensory overload.

I quickly grabbed a case of Presidentes and stood in line to make my purchase. As I stood there, the gentleman in front of me noticed my case of Presidente, pointed and asked, “Te Vayas por la Fiesta?” To which I laughingly responded in Spanish, that I was indeed going to a Dominican Independence Day celebration. Afterwards the woman at the register gave me my total in Spanish, I paid and headed on my way. Through this exchange, it became clear that the gentleman in front of me as well as the cashier, both assumed that I was Latina perhaps simply because I was in Compare Foods but more so because of the product I was purchasing. Although all of my participants mention Compare Foods, it is a predominantly Latino space; here people not only find products from their host country, but based on my time accompanying participants while shopping in the store, they feel comfortable speaking Spanish, and can trust that almost everyone there speaks Spanish as well. Outside of other smaller Latino businesses, this is really one of the only spaces where the majority of workers and customers speak Spanish. While I expand upon the specific relationship that my participants have with Compare in a later chapter, I mention it here because it is one of the most visible locations in which one can identify the visibility of not only the general Latino population, but Afro-Latinos as well. Compare Foods shares the lot with D'Stylo Dominican barbershop, and DominicanCuban owned Riva's Coffee Shop, making the lot in itself somewhat of a small Hispanic Caribbean island. 
After purchasing my case of Presidente, I then headed to Miranda's home in NoDa (North Davidson), the other gentrified area of East Charlotte also located less than a mile from Compare Foods, where she drove us to Patricia's Dominican Independence celebration at her home in gentrifying West Charlotte. In a city on the cusp of reinvention, renovation, and gentrification, I am still surprised by the extent of physical alterations and construction in the city.

As we pulled up to Patricia's home, with her Dominican flag proudly flying on her porch, I was shocked to find that Patricia, Miranda, my friend Crystal, and myself were the only people of color at this Dominican Independence Day celebration. It was then that I was reminded, after being in Miami and living, conducting research, and hanging out mostly in East Charlotte, how uncomfortable I was around southern whites all in one space. In Chapter Two, I express that it is relatively uncommon to find completely integrated groups of friends in the U.S. South; most black Americans' friends are composed of other black people because of the racialized atmosphere that the legacy of segregation has fostered. While I do not want to project my feelings onto Patricia, Patricia's group of friends seemed to indicate Charlotte's lack of diversity and the need to choose a group. Patricia's group of friends in attendance at her Dominican Independence Celebration also reveals her inability to locate a cohesive Latino/Hispanic Caribbean group, which we discuss below. It is also important to note that Patricia's husband is white. This fact has undoubtedly impacted Patricia's perceptions of race relations in the South as interracial couples, mostly in smaller towns are still somewhat taboo. In the following exchange, Patricia discusses her qualms with racial identification in the South as well as her social groups in New York and Charlotte. 
MB: How do you identify in terms of race, ethnicity, etc.?

Patricia: It's funny, here...and I consider that an American thing, which is, how do you identify yourself. Since I didn't grow up here, I grew up in my country and the people-and everyone that I grew up around, we never identified with a race--it was never something that is asked, especially part of my culture--you're either Dominican or you're not and in DR, where I come from, its mostly either you're poor or you're rich--whatever your skin color is--whatever you know, your complexion or whatever doesn't really play much in my country. All of that became something I mostly discovered here. So, saying that, it's hard for me to find a group to identify with just because of the people that are in my circle, like in a sense, it's white or white American. So if anything, if I were to identify with Afro-Latino, I wouldn’t mind calling myself that, BUT it annoys me sometimes to call me that because I feel like I'm being placed in a box but I feel closer to that than I would feel to any white people and that sounds bad too, but that's the reality. MB: Okay, so I guess--so, was that an issue in New York or was it something that became more of something once in Charlotte?

Patricia: I think more here, just because a lot of my friends that are Dominicans [in New York] are similar to me, they grew up there, came here, so they grew up with the same mentality like I had that is, oh I'm Dominican period. But in New York, you have different circles. Like you have Dominicans that associate a lot with black-African Americans and feel that that's their way and that's it, and they even become hateful towards people that get together with white people or other ethnicities so I always try to stay away from that and since I had a very small circle, I never thought of it. Once I 
moved to Charlotte, because diversity here is so low, you kind of hear it even more. Especially when I talk to other people here, even white Americans or black-African Americans, they always ask me like, oh so what are you? This or that. And I'm like why?! Why does it even matter? Like I had someone straight ask me that, at work, he asked me like who do you associate your more with? Like do you consider yourself a white person or a black person? And I'm like, what the frik kind of question is that? Like I'm Dominican, but yes, if I were to identify myself, and check a box, if I see AfroLatino or African American, I'll probably pick that because clearly my skin is not white so but--I think its more apparent and more prevalent down here just because of the diversity pool. Like you're either/or and that's all.

MB: Do you think that has affected you in any way, since you've been here, maybe I guess, in where you hang out and the people you hang out with?

Patricia: Well, not really but then it's also because I haven't yet found that community of Latin Americans here too, so that's why I haven't seen it as an issue outside of the fact that the majority of people I hang out with are white and part of the same circle, and they came from somewhere else, and they are very young, and they don't see that, but I don't know if it would be different like once I find a core Latin American group of friends, and see how they feel about it. But it's interesting cause a few that I have met, that are Latin American here in Charlotte are mostly Mexican or South American, like Ecuadorian or from other places, and they do ask that question...

MB: They ask where you're from? Or what are you?

Patricia: Exactly. Exactly. 
Unlike Joe and Mayra who are adamant about their black identities, or being both black and Dominican, for Patricia, nationality seems to supersede a racial identification, which again underscores the significance and prominence of Dominican national identity, rhetoric and processes of racialization. Patricia's denial of race or complexion being significant in DR could be based upon a number of factors, or simply perhaps that her light brown complexion and straightened hair shield her from the realities of many darker Dominicans that do indeed encounter racism. Later in our conversation, she mentions the Dominican-Haitian relationship as a basis for comparing the relationship between Dominicans and Mexicans in North Carolina, stating that the issues in DR are, "just because we have that history, from how Haiti took over and we had to liberate ourselves from it" but not necessarily that race is a critical aspect of Dominican-Haitian relations; an ideology again rooted in Dominican nationalism. Further, as mentioned, race, color and class in Latin American and the Caribbean are often conflated in ways that socioeconomic status appears as the determining factor in discrimination, without acknowledging that these factors are intertwined. Although simply asserting her national identity in New York could suffice, in Charlotte, Patricia is almost forced to reluctantly accept an identity as Afro-Latino. At the same time, Patricia recognizes that in New York, accepting full membership into the black American community signifies that one inadvertently agrees to not hang out with predominantly white groups, or receive disdain in response. It is possible that Patricia's interracial relationship heightens this perceived disdain, as often times, both black and white Americans frown upon interracial relationships. 
At Dominican Independence Day, Patricia had neatly labeled each Dominican dish and drink to inform her guests, who would otherwise be unfamiliar with her cultural practices. Patricia's social group in Charlotte is comprised mostly of white Americans. For Patricia, who is opposed to befriending white Americans born in the South, her group of friends are mostly from other states like California, New York, etc., and are therefore "different" and more understanding than southern born white Americans. This suggests that Patricia perceives southern whites as intolerant of her being both black and Latina as well as her interracial relationship. Still, Patricia seems to long for a Latino community in which she does not have to respond to the looming question of "what are you" by others in the dominant Latino population. As a semi-recent arrival to the U.S. South, Patricia appears to be still searching for a group of complete belonging. In the meantime, her particular group suffices, yet as Afro-Latinos individually undergo varying negotiations that continue to simultaneously disrupt and further support the social order, they remain in a liminal space, compelled to choose a group among Black and White Americans and the dominant Latino population.

However, it also seems that within the spectrum of Afro-Latino identification options, Patricia's Dominican national identity is critical in her perceptions of race relations. Influenced by Dominican nationalist narratives, Patricia very much detaches race, racism, and colorism as aspects that influenced her understandings growing up in the Dominican Republic, and to an extent in New York City. Even in New York, Patricia did not necessarily agree with other Dominicans' tendencies to identify more with black Americans and in turn their disdain for white Americans. This underlines theories that hold that processes of racialization in countries of origin that are portrayed as more 
benign than those in the U.S. make other black immigrants candidates for better assimilation, particularly as it concerns a more warm perception of white Americans than black Americans (Waters 1999). To an extent, we could argue that Patricia engages in practices that may be labeled as assimilationist. On the other hand, in the opening of this section I present an account from Daniel, who is also Dominican but who more strongly identifies as Afro-Latino as opposed to Patricia. In comparison to Patricia's light brown complexion, Daniel is probably a shade lighter but unlike Patricia, Daniel identifies more with black Americans and could not find any sense of belonging among whites but instead experienced outright hatred in his interactions with these populations. Daniel also saw the Dominican-Haitian relationship as one rooted in race and anti-blackness, which he uses to compare to the black-white racial binary of the U.S. South. Critical here is also gender. It could be that Daniel as essentially a light skin black man in the U.S. South confronts additional challenges than Patricia as a light skin black woman, who chooses to assert her national identity rather than her racial identity. Still, the limited but at times arbitrary spectrum of which Afro-Latinos select varying identities ranges from asserting national identity, racial identity, or simply the inability to find belonging anywhere.

\section{"With Nobody"; Unbelonging in Charlotte}

On a summer day, I met MaReyni, a young Dominican hairstylist in her and her mother's beauty salon located in a small run-down shopping center, lodged in the back of a parking lot behind a Mexican/El Salvadorian restaurant, and neighboring a Guinean owned grocer, a Liberian owned convenience store, and an African American owned barber shop in East Charlotte. MaReyni previously lived in Brooklyn before relocating to 
Charlotte with her mother. I interviewed both MaReyni and her mother in their salon, speaking to MaReyni in English and her mother in Spanish. In fact, most of my interviews and conversations with older Latino women took place in Spanish while those with younger participants were held in English. This linguistic boundary and generational difference deeply impacts the options of group identity and membership among Afro-Latinos. MaReyni and her mother both acknowledge their African ancestry and both interact a great deal with black Americans each day as this is the primary clientele at their salon, which greatly differs from their previous salon in New York City. However, MaReyni's mother identifies more with the dominant Latino population while MaReyni appears to identify with no one. She revealed that despite identifying as black, she could not identify as Latino, with the greater Black American community nor with white Americans.

I am interested in the validity of MaReyni's non-identity, what informs this nonidentity, and how does her non-identity speak to the liminal space that Afro-Latinos occupy. It is as if MaReyni claims an identity of nobodiness, nowhereness and ultimately unbelongingness. This sense of nobodiness and nowhere coincides with Bhaba's notion of the "unhomely." The unhomely are not homeless but instead feel the "estranging sense of the relocation of the home and the world"-a "condition of extra-territorial and cross cultural initiations" (Bhabha 1994, 9). As such the "unhomely" are not easily accommodated within the familiar divisions of society (Bhabha 1994, 9). When asked how she identifies in terms of race or ethnicity MaReyni responded, "with nobody." She elaborated on this stating, "I do not identify with the Latinos, I do not identify with the African Americans, I do not identify with the white people, I'm my own person.” 
MaReyni clarified that she does not identify with Latinos because they are "too superficial" relaying that perhaps Latinos come to occupy the stereotypes that portray them as "too much about how they look and very family centered" and "out-going partygoers." MaReyni on the other hand sees herself as an introvert.

MaReyni stressed a refusal to adhere to the stereotypical representation of the festive and family-oriented Latino/a. These are images widely displayed in the U.S. media as well as the tourism industry, most notably in marketing places like Miami and the Caribbean, and even holidays such as Cinco de Mayo as well as the portrayals of actresses like Sofia Vergara, Shakira, Salma Hayek and of course, Jennifer Lopez. Further, Latino/as are often associated with flavorful adjectives like spicy, sexy and hot, signifying an exotification and generalization of Latino culture. In fact, it seems that the stranger as Latino/a reflects a binary stipulation underlying what Ahmed (2000) reveals to be the dominant groups decision to welcome the stranger or exclude the stranger. For Latino/as, within this binary stipulation the festive and exotic Latino/a gains acceptance while the illegal immigrant is rejected and excluded; all of which are more than often gendered perceptions and representations. However, each of these representations, within popular imagination, ignores the positionality of black Latino/as, if they fit in at all.

We can place these stereotypes of Latinos/as within what Bhaba (1994) as well as Hall (1997) sees as particular cultural signs, signifiers and symbols, or particular symbolic orderings that establish representations and become constitutive of our subjectivity and construct identities. MaReyni's assertion that she identifies with no one, and definitely not the general representations of Latinos, direct us toward what Bhaba 
(1994) suggests as a "reinscription and negotiation" of subjectivity—a sort of intersubjectivity, in which the "sign is deprived of the subject" — underlying "new agencies and articulations" (Bhabha 1994, 275). Like the accounts of other Afro-Latinos in this chapter, MaReyni must negotiate her identity within existing symbolic orderings. However, MaReyni's stands out, appearing to resist the social ordering and refusing to seek membership within any group. This is further revealed as our conversation continued.

MB: Ok, so why don't you identify with African Americans? Do you feel like you have that option here, to be either or [African American or Latino/a]? MaReyni: Because I think African Americans are very confused MB: In what way? MaReyni: In what way? I think that they're very cut throat, instead of helping one another, they put one another down and they're all over the place. I don't identify with white people because I think that...you never know who they are... and they're not to be trusted [laughs]...they're very fake, they'll smile at you with the knife about to stab you...at least African Americans don't do that...they do that to their own people but they won't do that to you.

MB: Okay, so what has been your experience living in Charlotte...I guess, it may not matter to you what people [think], but how do other people classify you?

MaReyni; Actually, it matters what people think because I'm very perceptive, I'm all about information so I observe...

MB: Okay... 
MaReyni: What do people think about me?

MB: Or, how do they classify you?

MaReyni: They classify me as a mixed girl if I don't open up my mouth, if I open up my mouth they always ask me, "what are you?"... "You look like you're black but you're not black"...that's more of the people that have lived here [in N.C] their whole lives and, "you have an accent like where are you from"...so, most people think that I'm black like African American. My Own people [Latino] because we live in a place that is [predominantly] Latinos, they think that I'm African American as well. That would be a different experience if I was in New York City but here they think that I'm African American... what [do] white people think about me? I don't know because...I don't behave like a black person, I don't behave like a Latino... and I know they pick that up when I go into a place like a Starbucks or something...I know that they're thinking "what is she"

MB: So your circle of friends...what ethnicity are they?

MaReyni: I have a friend that is black Japanese, I have another friend that is Dominican, I have another Dominican friend, I have omm...two African American friends..

MB: So not a lot of Latino friends?

MaReyni: I don't like Latino people

MB: Why not? Well you kind of explained it earlier..

MaReyni: I don't like people that lack perception. If you're fake and all about your shoes and things, we're not going to get anywhere, you [have to] come at me with something.. MB: So have you had any experiences of discrimination since living in Charlotte? 
MaReyni: Let me see...have I been discriminated against? Probably yes. Did I stop and think about it? No. I have gone into stores where I know they don't want me there because I'm black, I can feel it. You know you go into a place and all the white people [are] looking at you like you shouldn't be there. I have noticed that more in the Matthews [neighborhood] because you know those white people, they're comfortable living there...yea I don't really care. I realize that if they're racist, that's their problem, as long as I have the cash to go in a place and I want to go in there, I'll go in there, but its very uncomfortable...you go into a place and you feel like you know, like you're in a box...

As MaReyni elaborates on her personal identification, the intricacies of subjectivity and identity are further complicated. First, it becomes somewhat problematic to suggest MaReyni's refusal to accept or identify with Latino culture, or here, African American culture is a form of resistance as this refusal continues to underscore stereotypes associated with both groups. At the same time, self-identifying as black, MaReyni shares a staunch distrust of white people insomuch that it constitutes/supports an Us versus Them binary, a feeling that was communicated by other Latino participants. This is supported by her later admission that the comfort of white people in certain places in Matthews, a southeastern suburb, comes at the expense of her own comfort. Therefore, MaReyni may distance herself, at least rhetorically, from Latinos in general and African Americans but she remains within the "order of symbols" in the social imaginary (Bhabha 1994). We are then compelled to return to conversations of performativity, as MaReyni suggests that Latinos or African American behave a certain 
way. Of course, this is an essentialized perception of black American and/or Latino/a behavior and performance. Nevertheless, as Butler (1990) contends that while performativity is constituted by forms of anticipation existing outside of the body, performativity is also no singular act, but ritual and repetition that come to be naturalized within the context of the body (xv). In turn, performances of blackness and racial/ethnic identities function in "shifting myriad ways" along with subjects' relations with one another as well as the broader society that they inhabit and construct (Stovall 2005, 221). In accordance with Stovall (2005), black subjects "create not only themselves, but also their white interlocutors" through conscious and unconscious performative strategies (221).

Thus, while MaReyni may not behave or perform like broader essentialized representations of Latino/as or African Americans, according to her own stereotypical views, as a black subject, she still consciously and unconsciously relies upon strategies of performance to establish her own identity, which is shaped by her aversion to projected stereotypes and normalizations as well as her distrust of white people. Ultimately, MaReyni uncovers layers of identity that do not conform to membership within the Black American community, the Latin American community, and especially not the white community yet she continues to enact performative strategies and ideologies that reify the social ordering. Still, the black American community provides belonging for other black immigrant subjects like Daniel while the broader Latino community provides belonging for Afro-Latinos like Kurma. I reiterate the significance of Tiffany Joseph's (2015) "transnational racial optic" in informing self-understanding, identity and subjectformation among my participants. For those like Patricia, national identity preferably 
supersedes that of her racial and ethnic identity, for others, a collective transnational blackness informs their racial ideologies even before coming to the U.S. In these instances, acceptance and denials of membership into the black American community are even more critical to one's identity and subjectivity.

\section{Gente! Afro-Brazilians in Charlotte}

"So, I think, Black Americans they are--I have two kinds of relationships with them.

There are some that are open, I think it's the same to what I said earlier, people, if they're open to new cultures and new ways of life, it's alright. There are some AfricanAmericans, [who are] close-minded. [They say], "this is America, we don't do this, what's that? That's weird." [And] I'm like, hey, that's my food, dude, chill [laughs] so they're like that. I feel like--I don't feel part of it at all, although I wish--at the beginning I was like oh we're all brothers and sisters! We're all Black! Then it was [from African Americans], “you're not Black, you're Brazilian!” It's not easy to find people who don't see beyond race relations here, so they [say], "you're Brazilian”, but in Brazil, I'm Black! But here, I'm just Brazilian [laughs]. This kind of etiquette, I don't appreciate it, so I try to stay away from it. But these collectives and things I go to, there're a lot of other Black people, I can go to, like hip hop artists and I make peace with the African American community because of them [laughs]. They show me a different side because at first, I was just getting the other side, like, you're not part of us, you're Latina...you're not part of us, you're Latina”-Carolina, Brazilian, 8 April 2017 
Earlier in the chapter, I disclose Carolina's fear of being racially profiled, persecuted and/or attacked as a result of her skin color and immigrant status. Despite this reality, Carolina's relationship with the black American community is still decided by either those who are receptive to the multiple aspects of her identity or those who seemingly operate within a one-dimensional Middle Passage Epistemology. For the latter, Carolina's Brazilian identity negates her claims to blackness in the U.S. South, which apparently includes rejecting aspects of her culture like food and music. Before arriving in Charlotte, her first destination in the U.S., Carolina's "transnational racial optic" entertained a belief that as another black person who happens to be from Brazil, "we were all brothers and sisters." For Carolina, her nationality does not preclude her blackness, they exist simultaneously. However, her nationality oftentimes denies her membership into the black American community. As a result, in one instance, Carolina finds similarities, acceptance and love among the dominant Latino population. Selfidentifying as Afro-LatinX and part of the LGBTQ community, Carolina also finds belonging within the multi-cultural brown and black alternative community in Charlotte, and it is here in these spaces where she "makes peace" with black Americans.

I met Carolina as well as her cousin at a cookout hosted by my participants Tamara (black American) and her husband Luciano (Afro-Brazilian). Carolina and her cousin are from the same department of Minas Gerais as another Afro-Brazilian participant, Contra Mestre Zumbi (Capoeira Master), a state that according to Tiffany Joseph's work (2015) hosts one of the largest immigrant sending cities in Brazil. While Carolina and I had great conversation over barbecued chicken hearts (which I did not eat), we decided to extend our discussion on another day at a small black-American 
owned ice cream café, that Carolina selected in University City, right across from UNCC. Carolina identifies as "Black Latina, Afro-Brazilian, Afro-Latina, and LatinX." Her identity as a queer Black Latina and Afro-Brazilian significantly influences the places and spaces that she chooses to hang out as well as the people she chooses to hang out with.

After a recorded interview at the café, that evening Carolina invited me to a performance/party at studio Area 15 located in NoDa, a gentrified portion of East Charlotte. I expand upon my time at Area 15 and other venues that Carolina introduces me to in Chapters Five and Six. It was during my time with Carolina that I began to process the central arguments of this dissertation. Even though there is a very visible Brazilian population in Charlotte, it is predominantly white Brazilian. Carolina suggests that Brazilian populations in Charlotte tend to cling onto similar notions of race and politics held in Brazil, carried with them to the States. In our interview and en route to the party, Carolina expressed that she avoids engaging with the larger Brazilian community in Charlotte which is predominantly white and conservative. Carolina's accounts allow us to see another spectrum of the transnational racial optic, in that it sways and disassociates from a Brazilian national identity rooted in myths of racial harmony.

Carolina: So, the people that I mentioned earlier [Tamara and Luciano], it's all good. But I don't hang out with the Brazilian community here. MB: Why not? Carolina: Because they're mainly conservative, right wing...and last semester I interviewed some of them, and they have a very elitist view of life and Brazilian society. 
And I keep thinking, I know that the U. S. is good, I'm here, I came here to get something, too. I think everybody comes with a dream or a goal or something, I came here to reach that, but I'm aware of the flaws the country has, I'm aware of the value that my country has, too. And sometimes they're like, "The U. S. is so great" and they will call it America and I'm like "America”, shut up! Say Estados Unidos! [Laughs]. So, I feel like they sort of incorporate this speech of meritocracy. You just need to work harder, you can get it. And as they are mainly white, sometimes I feel that they just don't get it. They're not the group I like to hang out with all the time. If I see them, I'll be nice-we can go do samba woohoo-- but It's not like people [that] I'll be friends with. I'm talking generally, not specifically. I have some good Brazilian friends. Especially when I got here, they were the only ones I knew so I mean like the community in general. So, for example, the biggest party they have here

\section{MB: Carnaval?}

Carolina: Uh, huh, yeah, The Night in Rio. On the same day, we had a house party from Queens Collective. To me it was very clear that I would go to Queens Collective and not the Brazilian party because--Oh! these people that I hang out with they are also LGBT friendly and Queer and Lesbians and I feel way more comfortable, in those environments than the festivals, you know, um so, there's a great divide in Brazil now because of politics, it's a very educated political moment, so I get very--people are angry with the left government we have, they impeached the President. But the government [in Brazil], the government is messed up, lots of corruption scandals and stuff, but they made access to the university easier for the poor, the Blacks, and many other things concerning the 
less privileged part of the society, and some people from the elite, they are angry at the government for that, for supporting the poor, the Black people...

MB: Similar to what's going on in America?

Carolina: Yeah, yeah, [laughs] it's very similar. So when people have this kind of speech, it's not like I can't have friends with different views, I can but there are things, I think it's better if we be around people who have the same kind of energy. Of course we can disagree, [but] why am I going to be friends with someone who sees my cousin walking on the street, they're going to cross the street because they will be afraid of him? Yeah...like what's the point?

MB: I was going to ask what about the broader Latino community?

Oliveira: I love them...I love them more than Brazilians.

MB: Why is that?

Carolina: I don't know. For example, I have a friend, she's Mexican and tomorrow I'm going to her brother's place. We always do this and every time we get together, she always invites me to go. I met her in 2012, and every time I'm around a Latino family, I feel like it's my own, like the way we--the way they interact with each other, playful and interact, drink Mexican beer, and churrasco cookouts...so I feel better, like my heart is warm...and when I go to clubs, I go to Latino clubs.

For Carolina, there exists an immutable relationship between blacks and whites in Brazil that inform her negotiations with race, ethnicity, and nationality in Charlotte. As a queer black Latina and Afro-Brazilian woman, Carolina connects racial profiling, "why am I going to be friends with someone who sees my cousin walking on the street, they're 
going to cross the street because they will be afraid of him?," with the greater political happenings among conservative, mostly white Brazilians and white American conservatives in the U.S. Despite the large population of Brazilians in the Charlotte area, which may provide a home and sense of belonging for some, even with the major event "A Night in Rio", which introduces Carolinians to a night of Brazilian food, song, and dance, as a queer black Latina woman, Carolina elects LGBTQ friendly events like Queens Collective and smaller diverse house parties. It is also important to mention here that Luciano, an Afro-Brazilian from Salvador also opts out of the annual "A Night in Rio" because he feels it is a convenient appropriation and exploitation of an exotic AfroBrazilian culture mostly through Samba and popularized images of the over-sexualized mulata. Luciano angrily stated in Portuguese, that, "everybody wants to be black now!" Luciano also felt that "A Night in Rio" presents a myopic and stereotypical image that suggests the entirety of Brazil is nothing more than Carnaval in Rio de Janeiro.

Carolina's perception and interaction with the general Brazilian community in Charlotte is therefore not isolated.

Both Carolina and Luciano grapple with representations of Brazilians as well as Brazilian race relations in Brazil and in the U.S. South in different ways. Still, their experiences differ from that of Contra Mestre Zumbi, who identifies as black/AfroBrazilian and whose identification and self-understanding is guided by the principles of Capoeira. According to Zumbi, the purpose of Capoeira is to "bond people, forget about color, forget about religion, and to be friends and be helpful to each other." This point of view appeared to underscore Zumbi's reaction to police brutality and race relations in the U.S., in which Zumbi contended that if the cops approach you, one should "be nice" and 
"be calm" holding that, "they won't repay to you bad, if you don't start the bad." Of course, this is unfortunately not the reality as it has been proven that innocent black men and women are killed at an alarmingly higher rate than whites, and we have seen the videos for additional "proof." However, while we could simply brush this off by attributing this point of view to Zumbi's immigrant status, accent, etc., through my observations, it is Zumbi's actual work and space that allows him to hold such views. His understanding could perhaps also be informed by an ideal of racial harmony in Brazil. Yet, the Brazilian Arts Center in East Charlotte is indeed perhaps one of the most diverse multicultural spaces in Charlotte. As such, I believe that is not only the art and philosophy of Capoeira, but the actual space that provides a nucleus to foster such selfunderstanding and subjectivity. Zumbi has also had the opportunity to instruct Capoeira around the world, in countries like Germany and Israel, which have undoubtedly been critical to his subject-formation and identity. This stands in contrast to both Carolina and Luciano, who have only lived in Brazil and Charlotte. Therefore, again I argue that there is no one way to project or define Afro-Latino identity and subjectivity in the South as it is often shifting and revolving around one's individual transnational racial optic in addition to the spaces and places they inhabit and traverse each day.

\section{Conclusion: We're All Brothers and Sisters}

I argue that Afro-Latinos occupy a liminal space both within the black-white binary and an expanding racial/ethnic categorization, black-white-Mexican, the latter of which generalizes the dominant Latino population. Initially, I proposed that Afro-Latinos are compelled to seek membership into the Black American community, and that it is here where they find belonging. For some subjects like Daniel, this proved true. 
However, I found that for others who may initially seek membership into this community, their diverse black subjectivities and identities are confined by a Middle Passage Epistemology that denies their membership into the black American community. Cultural and linguistic differences as well as black Americans' unfamiliarity with the realities and histories of Afro-descendents in Latin America and the Caribbean are the primary causes for this denial of membership into the black American community. At the same time, the constant inquiry of, "what are you" often alienates Afro-Latinos from the broader Mexican and Central American community just as much as it does from the black American community.

Many Afro-Latinos contend that cultural and linguistic differences distinguish them from Mexican and Central American immigrants. Another critical factor that distinguishes many Afro-Latinos from South America and the Hispanic Caribbean is legal citizenship. Therefore, at times their struggles and trajectories also differ from Mexican and Central American populations. I argue that the "transnational racial optic" informs a great deal of Afro-Latinos/as' perceptions and understandings of race in the U.S. South. The transnational racial optic yields varying forms of identification and outcomes among these individuals. For instance, Carolina's original perception that "we're all brothers and sisters" quickly changed upon seeing that she could be at times denied membership into the black community. However, this optic also informed her disdain for white Brazilians. Joe and Mayra as well as Patricia also reveal the malleability of blackness that is not only made possible by U.S. Census and Immigration racial and ethnic classifications but also by black Americans and white Americans who either label these populations as simply "Mexican" and non-black or offer a form of admission into 
cultural whiteness that opposes the pathology associated with black Americans. This is unacceptable for Joe and Mayra as well as Patricia. Yet, which Joe and Mayra strongly assert the simultaneity of being black and Dominican, it appears that Patricia would prefer her national identity and the ideals attached to that identity to precede. The alternative to un-become black does not shield Afro-Latinos/as from the double-dealing fears accompanies being black and immigrant. Therefore, Afro-Latinos must negotiate and confront popular representations and stereotypes associated with blackness and Latinos. The internalization and projection of such representations lead some AfroLatinos to identify and perform as a "no one", another indication of liminality. This chapter puts forth the ways in which Afro-Latino identity and subjectivity in the South is complicated by processes of racialization and understandings of race in the host country and other cities they reside in prior to Charlotte. Comparing and contrasting where/how and when they "fit in" in Charlotte is a critical factor in their self-understanding. Ultimately, Afro-Latinos disrupt the social ordering of the South. The intersections of Afro-Latinos, Africans, Caribbean immigrants and black Americans represent the myriad of ways in which identities and subjectivities are confronted and negotiated in the South. As the dissertation unfolds, these intersections prove vital in the construction of space and place in the New South. 


\section{CHAPTER FOUR}

\section{CHITTERLINGS, FUFU, AND CURRY: DIASPORA WARS AND THE}

IMPLICATIONS OF AFFECT

"They [African Americans] don't come here cause they say it stinks or smells funny, but I say, you eat chit'lins don't you? And that stinks too!'-Mrs. Tina, Sierra Leonian, owner of Sierra International Market

Nestled in an East Charlotte shopping center between a Mexican-owned Botanica and a Central American-owned restaurant serving \$1 dollar pupusas on Saturday and \$2 tacos on Friday is the Sierra International Mart where I found myself at around 7pm on a Friday in February knocking on the locked door. Although the store is open at this hour, Mrs. Tina, the owner and a native of Sierra Leone, revealed that she found herself and her shop safer with the doors locked after sundown on this side of town. As I entered, I perhaps like many other outsiders or Black Americans was struck by the strong pungent smell of what Mrs. Tina would later tell me is dried fish that she brings back to Charlotte, along with other goods, directly from Africa. Along with palm oil and cassava flour, dried fish is among her top sellers at the market. Mrs. Tina's customers are not confined to just those from Sierra Leone, but on my many occasions in the store, I encountered Nigerians and Liberians (among the dominant African populations in the city) as well as Congolese, Senegalese and Guineans. Sierra International Mart represents what I see as a transethnic and transnational West African space, that is also often a gendered space either dominated by women or men depending on whether Mrs. Tina is running the shop, or her husband, which is the case when Mrs. Tina is travelling to Africa, India, or the Middle East to make purchases. Mrs. Tina often pauses to recall where individual 
customers are from, having built both a personal and economic relationship with each. In our initial encounter, we walked through the narrow aisles of her store; each aisle colored by stacks of cans, huge gallon jars of palm oil, large sacks of cassava flour, and the walls surrounding the aisles, lined with a variety a brightly colored and intricately patterned African fabrics. Mrs. Tina also sells hijabs, abayas, shoes, and curtains; she would later joke that she is a "jack of all trades." As Mrs. Tina points out and describes the products significant to her and her clientele, she says, "you're different, you come in and ask what the foods are, what the smells are." Mrs. Tina expanded upon this by stating that to her, black Americans tended to "look down" on her and other Africans as well as their culture, or view African culture not only as homogenous but also as inferior. Mrs. Tina has sensed these moments through both verbal and facial expressions from Black Americans, recalling one time she sat eating a fish stew and a black American woman walked by squinching her face, saying, "Oh that stinks, how can you eat that?" to which Mrs. Tina responded to the woman by again noting the horrid odor of hog chitterlings, a traditional southern black American dish.

At the same time, based upon my research, many black Americans also feel that African and Caribbean immigrants see them as inferior. In fact, many of my immigrant participants did indeed share their opinion that black Americans do not take advantage of the many opportunities afforded them in the United States whereas according to black immigrants, they felt they had a greater appreciation of the "American Dream", a stronger work ethic and a higher value for education. Mrs. Tina also posed the question of "why should I have to fear people who look like me" after her shop was broken into by a young black American, and the reason she now keeps her doors locked after a certain 
time. Mrs. Tina's position reveals a simultaneous black solidarity that exists alongside an assertion that black Americans are prone to criminality, an idea and/or fear that was shared among many African and Caribbean subjects who live and work in the area. Yet, for Black Americans in my research as well as in other studies, this perception is an unfair judgment of their success in the U.S. and a generalization and pathologization of black American culture when the argument stands that black immigrants would not be able to take advantage of such opportunities if Black Americans had not fought for civil rights (C. W. Smith 2014; Pierre 2004). As discussed in the previous chapter, for black immigrants, these sentiments often reflect subconscious deployments of the "myth of the model minority." Sociological works such as those of Waters (1999), Portes, Rogers (2004), Vickerman (2001), and Foner (2001) that explore the experiences of West Indian immigrants in New York City have fueled these false cultural narratives of a pathologized Black America (Pierre 2004). However, these studies fail to capture the reality that all black subjects are misrecognized within the context of global white supremacy.

Candis Watts Smith's (2014) study of the "politics of black pan-ethnic diversity" argues that despite previous scholars' emphasis on the ideological differences that at times constitutes existing conflicts among black immigrants and black Americans, all black subjects must navigate the racial hierarchy in the U.S., a collective feat central to Smith's idea of "diasporic consciousness" (C. W. Smith 2014, 7). Within this situational and contextual diasporic consciousness, certain strategies utilized to navigate U.S. racial hierarchies establish unity among black subjects while at other times, particular strategies further conflict between black ethnic groups (C. W. Smith 2014, 7). In accordance with 
Hintzen and Rahier (2010), "white supremacy naturalizes black inferiority, inhumanity, and abjection" (P. C. Hintzen and Rahier 2010, xi). Hintzen and Rahier (2010) put forth DuBois' conceptualization of "double consciousness", in which black subjects find themselves "always looking at one's self through the eyes of others" as one of the most fundamental analysis of misrecognition and the construction of diaspora as politics (DuBois 1953; Hintzen and Rahier 2010:xi). Despite being a contradictory characteristic of black subject formation as it "simultaneously challenges and reinscribes the racial hierarchy and black marginality", respectability is a critical strategy in gaining recognition among black subjects (Queeley 2015b, 5; Greenbaum 2002; M. M. Wright 2004; P. C. Hintzen 2001).

To combat the stereotypes of the "tribal savage" and "poor malnourished" African, the marijuana consumed dirty dread-locked Rastafarian, the poor dead-beat Black American thug and "welfare queen", "the terrorist" or the "illegal alien", black subjects globally find themselves enacting narratives of respectability to distinguish themselves from the various iterations of pathological blackness in a quest for acceptance from the dominant group and to avoid the negative consequences of being pathologized (Greenbaum 2002; Wilson, n.d.; Frazier 1957; Queeley 2015b). Respectability is also deployed in order to have a stake in citizenship and belonging in the host country. In E. Franklin Frazier's classic and controversial work Black Bourgeousie (1957), he defines respectability within the context of what are now Historically Black Colleges and Universities. According to Frazier, black teachers and students were charged with the duty and expectation of differentiating themselves in "their morals as well as in their manners from the Negro masses" (Frazier 1957, 77). By this, they were taught to "speak 
English correctly", to "avoid the ungrammatical speech and dialect", and to "speak soft and never exhibit the spontaneous boisterousness of ordinary Negroes"(Frazier 1957, 77). Franklin goes on to state that the values of the black teachers and students began to often align more with the prejudiced white middle class and in their "struggle to attain American middle-class ideals, they gave the impression of being super-Americans" (Frazier 1957, 83). I see Frazier's idea of "Super-Americans" as analogous with the deployment of the "model minority" by West Indian and African immigrants as they both demonstrate the same quest for full citizenship and recognition. I contend that respectability exemplified through attempts to be Super-American function interethnically and intra-racially as each group seeks to gain citizenship, acceptance, recognition and belonging in the U.S.

In this chapter, I argue that respectability and attempts at being Super-Americans function to establish boundaries between black immigrants and black Americans in East Charlotte. I specifically explore the role of food and material culture as particular tastes, sights and smells trigger affects such as disgust and fear that construct sociocultural and ethnic boundaries. I argue that for Black Americans, certain foods and their accompanying smells construct a sense of certain places as not only foreign, but unAmerican. On the other hand, fear and disgust establishes boundaries between those black and brown bodies deemed unsafe, illegal and foreign and those perceived of as respectable, esteemed, and safe. I also explore the ways in which the exchanges of food and other commodities serve to establish transethnic and gendered spaces of belonging and familiarity while also establishing intra-racial and inter-ethnic socioeconomic hierarchies among black subjects. Lastly, in focusing on material culture, food, cultural 
expressions, and affect, I explain what I call Diaspora Wars; on-going cultural wars between black subjects from Africa and the Diaspora over appropriation, respectability, behavior and performance. While the overall argument of this dissertation holds that material culture and affect play a critical role in the task of constructing alternative spaces of belonging for black subjects, this task is not without contention. Therefore, understanding how black subjects in Charlotte negotiate and wrestle through the many battles of Diaspora Wars is critical to uncovering shifting subjectivities and identities as well as the attainment of situational solidarity or "Diaspora Love" within the context of the U.S. South.

\section{Engaging in Diaspora Wars}

A friend and I initially began to use the term Diaspora Wars to semi-jokingly and cynically refer to the multiple on-going arguments we saw unfold on social media outlets such as Facebook and Twitter between those in Africa and the African Diaspora. It appeared that almost weekly black Facebookers and Tweeters took to comment sections and furious tweets to squabble over everything from what Africans saw as Black American's "convenient appropriation" of African garb and Yoruba ritual face-paintings, perceived denials of blackness by Afro-Latinos, black Americans not being accepted by their supposed brothers and sisters abroad, the infamous "jollof rice wars" between West Africans, how black Americans should or should not protest, who black Americans were willing to defend in protests, recollections of being called the abominable "African booty-scratcher", and black Americans awaiting the results of their African DNA tests to find their "true identity" and "true culture" somehow suggesting that black Americans are lacking of a true culture and identity. The list goes on. The debates are extensive, 
painful and exhausting and yet perhaps sometimes necessary. These exchanges are indicative of what Jemima Pierre (2013) describes as "the predicament of blackness" which entails shifting confrontations with and understandings of blackness within the context of global white supremacy. The same friend Janae, with whom I coined the term Diaspora Wars is a black American with shared roots in rural North Carolina and New York City, and spent much of her adolescence in Saudi Arabia before returning to North Carolina for college. We met nearly seven years ago without words, simply running up to one another and embracing on a humid evening at a crowded concert in Barranquilla, Colombia after spotting each other's hair and fashion in a sea of people, Janae then with a short close haircut and myself at the time, with a large blonde Afro. We did not see each other or speak until once again, we looked up to see each other's brown faces staring at one another while sitting on a concrete bench at the Festival de Tambores in San Basilio de Palenque, Colombia. Since that moment on, we have served as each other's Diaspora Therapists, counseling, consoling, and listening to the other's anguish, sadness, happiness and excitement as two black women with differing diasporic experiences and opinions traverse the daily roller-coasters of Diaspora War and Diaspora Love.

Ironically, as Janae and I sat discussing the intricacies of Diaspora Wars one day in my Miami apartment, I shared with her Pierre's work. She later posted a photo of the book on SnapChat, which sparked a heated debate between a Ghanaian friend in London, who was vehement in stressing that Jemima Pierre as a Haitian-American essentially had no right to address intra-racial and inter-ethnic issues in Ghana as an outsider. Janae and this friend have not spoken since this SnapChat debate almost two years ago. These cultural disputes are often highly triggering, both mentally and emotionally, and 
demonstrate the complexities of black subject formation and diaspora. More specifically, diaspora is itself a theorization of the on-going formation of black subjectivity. These intricacies are compiled in what Edwards (2001) sees as black internationalism in practice, quoting Francophone journals like La Dépêche Africaine, Edwards highlights the intent to "create among Negroes of the entire world, regardless of nationality, an intellectual, and moral tie, which will permit to better know each other [,] to love one another, to defend more effectively their collective interests and to glorify their race" (Edward 2003, 48). The moral ties and collective interests of those of African descent and the disputes that arise from attaining such collective perspectives are embedded in my discussion of black subjectivities and identities in the U.S. South, and central to my conceptualizations of Diaspora War and Diaspora Love. Diaspora War and Diaspora Love evoke the multiple manifestations and iterations of Diaspora, as identity/subjectivity, as politics, as geography, as geneology, as culture, and as people. As such, oftentimes, the intra-racial social media debates described above were points of reference in my interlocutors and I's conversations.

It was for the sake of our mental health that Janae and I decided to disengage from extensive social media Diaspora Wars. At the same time, I was beginning to realize that Diaspora Wars were becoming very much part of local life here in Charlotte outside of social media. Many of the conversations and sentiments illustrative of Diaspora Wars often took place with participants over the buying, selling, and eating of food, most notably at Queen Sheba Ethiopian Restaurant and Sierra International Mart, among others in East Charlotte. In this chapter, I extend my concept of Diaspora Wars beyond global social media conversations to put forth a discussion of the implications of affect, 
respectability and the construction of boundaries as black subjects interact within the local context of the New South.

\section{The Battlefields of East Charlotte}

As discussed in Chapter One, East Charlotte exhibits a demographic diversity indicative of the city's potential for multiculturalism and cosmopolitanism. One of Charlotte's two key "immigrant corridors" and noted to be the more diverse of the two due to its "plurality of African Americans" (O. Furuseth, Smith, and McDaniel 2015), East Charlotte embodies Appadurai's (1996) concept of an ethno-scape. In accordance with Appadurai (1996) within an ever-globalizing context, ethno-scapes represent landscapes of group identity(ies) constructed as deterritorialized groups of people, whether immigrants, refugees, tourists, etc. find themselves intersecting and interacting with one another through transnational and translocal exchanges (Appadurai 1996, 33). Expanding upon Benedict Anderson's concept of “imagined communities”, Appadurai asserts that the multiple acts and outlets of reterritorialization occur "when tourists and locals imagine places and long for meaning, creating place as a destination and a site of collective imagination" or "imagined worlds" (Setha M. Low and Lawrence-Zuniga 2003, 29; Appadurai 1996, 33). We can then understand reterritorialization as a critical form of "place-making", which Fettes and Judson (2010) refer to as the "active engagement of humans with the places they inhabit” (Schuch and Wang 2015, 216).

Place itself is constructed not only by the physical setting or location, but by the "sociocultural relations that occur" in the space or locale. From this, subjects gain a "sense of place" through the social and physical constructions of place, thus reflecting the "social dynamics of the population" while in exchange, places acquire their 
characteristics from those who inhabit the space (Schuch and Wang 2015, 216; Miller et al. 1998; Lefebvre 1974). While places are often created out of subjects' quest for belonging, recognition, and legitimization, they are often contested. For East Charlotte, this contestation has been most exemplified through local community organizations such as the Eastside Political Action Committee's (E-PAC) endeavors to advocate against Latino place-making, specifically targeting loncheras, or Mexican food trucks (O. Furuseth, Smith, and McDaniel 2015).

Throughout this dissertation, I argue that as a "pre-emerging gateway city," on the surface, New South rhetoric in Charlotte fosters an image of receptivity. However, local controversy in conjunction with local, state, and national policies present challenges to immigrant receptivity. On a state level, House Bill 786, also known as "RECLAIM NC" and the fight to "remove terrorists and criminals from the community" presented the opportunity to local law enforcement to interrogate anyone who appeared Latino (O. Furuseth, Smith, and McDaniel 2015, 9). On a local level, immigrants' attempts at placemaking have often been met with disdain, mostly by the few white residents left in East Charlotte and South Boulevard. Neighborhood activists formed the Eastside Political Action Committee (E-PAC) whose goal to protect and improve the quality of life for Eastside residents translated into local actions to "stop or minimize the Latinization of the Eastside," which was played out in a zoning fight over loncheras or food trucks that members of E-PAC saw as a risk to neighborhood safety and a decline in the quality of life, as food trucks selling tacos, taquitos, quesadillas and other Mexican or Central American delicacies seemingly proposed a threat to the well-being and image of the neighborhood. This resulted in the City Council establishing strict regulations that placed 
the food trucks in "exclusionary zones" (O. Furuseth, Smith, and McDaniel 2015, 13$14)$.

Further, national institutions such as Immigration and Customs Enforcement (ICE) have been documented as terrorizing East Side residents with the threat of deportation (O. Furuseth, Smith, and McDaniel 2015). After the recent election of Donald Trump, a subsequent surge of deportations began to take place in East Charlotte. Unpredictable ICE roadblocks and raids provided an air congested by a thick palpable fear. This shared sense of fear by both the documented and undocumented Latino population led to many of the sites I had identified for observations during preliminary research, to be noticeably empty, with the exception of late evening hours in which immigrants could so-called hide under the radar. Therefore, fear enacted through both local and national rhetoric along with heightened surveillance has furthered attempts to contest place-making and maintain the "safety" of mainly white middle class citizens who still remain in East Charlotte.

At the same time, the diverse population of East Charlotte has resulted in an array of immigrant-owned businesses ranging from restaurants to small markets, representing what Duruz, Luckman and Bishop (2011) call "cosmopolitanism in a microcosm." Within these microcosms, the buying, selling and eating of food is the essential method of cultural exchange, and a hallmark of hybridity. While fear and persecution of strangers and foreigners are played out in moments such as the attack on Mexican food trucks, in other moments in which the city-New South rhetoric in this case — chooses to celebrate its cosmopolitanism, food is the central factor that makes diversity both fashionable and acceptable (Duruz, Luckman, and Bishop 2011). Enter "Charlotte East." 
I happened to stumble across this new name/image for East Charlotte while sitting at a stoplight after meeting with a Togolese participant in an old apartment complex turned predominantly immigrant office spaces and next door to my favorite Honduran restaurant that serves the best baleadas and enchiladas Hondureñas in the city. It was post-baleada and jugo de maracuya that I sat at the intersection of Central Avenue and Sharon Amity, where the famous Eastland Mall once stood. There, in front of the recently built QT gas station where the backdrop of the demolished mall's ruins and empty parking lot are still visible, a brick sign had been erected, stating, "Welcome to Charlotte East." In contrast to "East Charlotte" what the area has been historically called, and what locals, residents of the area, and WSOCTV Channel 9 News calls the area whenever a crime occurs, the Eastland Area Strategies Team (E.A.S.T.), a volunteer board dedicated to fulfilling the goals of the Charlotte-Mecklenburg's Planning Department Eastland Area Plan established "Charlotte East." The area's website states:

"As Charlotte rapidly grows and changes, the city's east side is quickly becoming an area of excitement and progress. With its location close to downtown, beautiful established neighborhoods, and international and cosmopolitan flair, Charlotte East welcomes newcomers while maintaining the loyalty of longtime residents" ("Discover Charlotte East," n.d.)

In this attempt to market East Charlotte to the white middle class, what stands out in this description is its emphasis on the East Side "becoming" an area of "progress" suggests that it has not always been so. This provides a counter-image to the negative portrayals of the area, attempting to establish the area as welcoming to outsiders, who are mostly middle and upper class whites as well as young white hipsters. It is important to note that 
areas of East Charlotte are undergoing significant gentrification. Further, by highlighting the area's "cosmopolitan flair" alongside the organization's goals to "maintaining the loyalty of longtime residents" we gain a sense of the ways in which the city and neighborhood wrestle with the transition of East Charlotte from predominantly white middle class or "long time residents" to predominantly black and immigrant; both descriptive phrases carry racial and socioeconomic undertones. The description is also indicative of the layers of negotiations that take place in the New South that are realized politically, socially and spatially.

For the last 15 years, E.A.S.T. has sponsored the annual "Taste of the World" that takes place in what is described on the organization's website as the "Charlotte East International District" and "East Charlotte's Cosmopolitan International District." According to CharlotteEast.com, "Taste of the World is a food tour of more than 25 restaurants representing cuisine from across the globe all right here in beautiful east Charlotte. Let us be your guide for the 15th consecutive Taste of the World event and take your taste buds on a culinary expedition to three of these local treasures!” For $\$ 49$, guests meet at the Charlotte Museum of History (also in East Charlotte) for a registration reception where they are treated with one complimentary beverage before boarding "tourguided buses" that take them to 3 of the 25 international restaurants for tasting.

I was one of the last to board our shuttle bus at Taste of the World. On a small bus of about 10 participants out of about 200 people who also attended the event and boarded shuttle busses, I was one of three black people on our bus. This number reflected the general demographics of those present at the event. I later discovered that about three of us actually lived in East Charlotte; this included a middle-aged white 
woman, who was a long-time resident of my current neighborhood (a transitioning neighborhood that has historically been shared by working class whites and blacks, but where gentrification is in full throttle with property values rising at a startling rate, new homes in the area are beginning at $\$ 600,000$ while renovations begin at $\$ 300,000$ ), Darrell, a young black man who later revealed that he was the City Council representative for District 5 (East Charlotte) and was our tour guide, and myself. The other mostly white individuals were from other parts of the city.

Upon departing from the museum, our tour guide, Darrell, enthusiastically detailed the history of East Charlotte, noting some of the area's landmarks, it's transition and facts about it's current demographics. In many ways, Darrell was marketing the cosmopolitan value and diversity of East Charlotte and later revealed to me that he was passionate about changing the image of the area. At one point on the tour, as we loaded the bus from our first restaurant, a small family-owned Bosnian café, Darrell asked tourists what they knew or remembered about East Charlotte. Mostly everyone recalled the famous Eastland Mall while an older white man who works with a retirement community in the area, mentioned how the area was once the city's Ballantyne, referencing the upper middle class Southeast neighborhood. At the end of our tour, Darrell and I spoke of how the demolition of Eastland Mall signaled what has been seen as a decline in the image of the area. Darrell owned an "urban-wear" men's boutique in the mall after it transitioned from well-known department stores to predominantly black and immigrant-owned businesses. After the mall closed, Darrell struggled to find investors or spaces that would allow him to re-open his business because they did not want to attract a "particular clientele." Darrell mentioned that with the mall's demolition, 
the city failed to embrace the growing diversity and ultimately allowed the area to be subsumed by an image of crime associated with black Americans and immigrants. The older white gentleman also noted the difficulty in convincing the daughters of predominantly elderly white individuals to select his retirement village because of the area's association with crime. In turn, he aimed to portray the neighborhood as "exciting" "eclectic" and "diverse" that contrasted with "boring" (more expensive and white) Southeast Charlotte. The fact is that crime in East Charlotte is a reality, however, this is arguably a great deal due to the city that, in actuality abandoned the area evidenced through a lack of road maintenance, public services, accessibility and investment once black American and immigrant populations began to move in and whites began to move out, choosing to invest in the growth of the wealthier and whiter southeast neighborhoods like Ballantyne and Southpark.

On the surface, the use of "tour-guided buses" could be seen as an act of convenience. However, the setup of Taste of the World significantly differs from Taste of Charlotte, which is organized as a street festival Uptown, and Restaurant Week, in which individuals visit restaurants mostly Uptown on their own and are offered tastings or small meals at a discounted price. Bussing, here, appears to signal an attempt to keep guests safe while venturing through those ungentrified areas, where the majority of international restaurants are located; areas with "international and cosmopolitan flair" that are not the "beautiful established neighborhoods" of older and/or gentrifying parts of East Charlotte. The city must then negotiate a desire to market cosmopolitanism and diversity with its fear of the stranger. Zukin (1995) notes, while the city may aestheticize diversity, fear is also equally aestheticized. While this is exemplified through heightened 
forms of surveillance and gated or barred communities that find their way into aesthetic design, in Zukin's (2010) work, she also discusses the transformation of the term "gritty" (Zukin 1995a, 2; Zukin 2010, 51). Mid-century American portrayals of the "gritty" city depicted the city's "tragic loss of power" with "crowded streets, rising crime-rates, and blue-collar lives" along with aesthetic blight (Zukin 2010, 52). However, over the years, mainly through American pop culture movements, "gritty" came to signify an authenticity often defined by adventure and difference as hipsters, or what I see as chiccolonizers "discover" old warehouses, local bars, pubs, restaurants and historic buildings (Zukin 2010, 52,53).

Stoller's (2002) ethnography of the $125^{\text {th }}$ Street African Market in Harlem offers another example of aestheticized fear, noting the festive environment of the market attracted tour busses that allowed European tourists to snap shots and enjoy the market from a safe distance (Stoller 2002a, 14). In turn, a celebration of cosmopolitanism and diversity as seen with events such as Taste of the World demonstrate Charlotte's assumed "hospitality towards the stranger", particularly critical to an upcoming gateway city such as Charlotte and its New South image (Duruz, Luckman, and Bishop 2011, 600). Taste of the World offers outsiders (upper middle class whites) an opportunity to see that perhaps strangers "aren't so bad" after all. Once shuttled into the depths of East Charlotte, the mainly white participants become the guests on an adventure seeking authenticity of foreign food and nostalgia of old Charlotte. Memories and recollections of what buildings used to be and what stores used to be in the place of the current restaurants were very much part of our conversations as our randomly assorted group of people clustered together in tight restaurant booths. Taste of the World is then a complex 
encounter through which food is the essential way both critical and cosmopolitan interactions take place. More importantly, being shuttled into these New South culinary sites, which have been approved by the committee, is a safe way to experience the stranger along with memories attached to old Charlotte. In addition to marketing East Charlotte on the guided bus tour, the coupon booklet enclosed in the included gift bag incentivizes guests to come back. Darrell later clarified that one of the central goals of Taste of the World is to get outsiders and residents alike to "come back", patronize and invest in the many immigrant-owned restaurants dotting the shopping centers of East Charlotte. At the end of our tour, small survey questionnaires posed the question of "how likely are you to visit East Charlotte", providing a scale of one (least likely) to ten (most likely), in an attempt to gauge both perceptions and comfort levels of guests in East Charlotte.

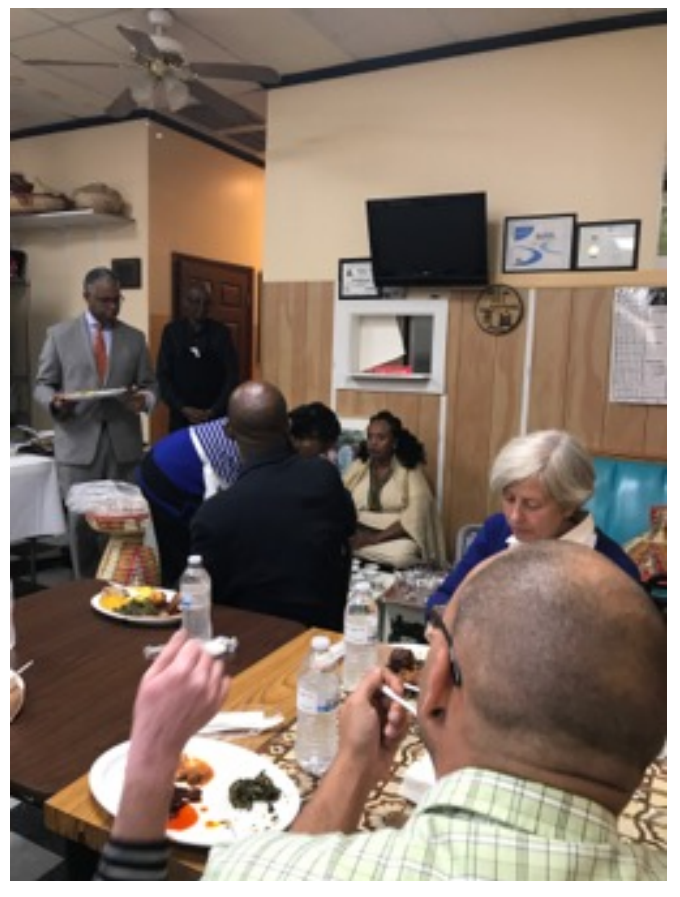


Figure 4.1. Ned, Ethiopian-born and long-time Charlotte resident, graduate of Johnson C. Smith University explaining the process of Ethiopian coffee preparation as the women prepare in the traditional manner. Photograph by Author.

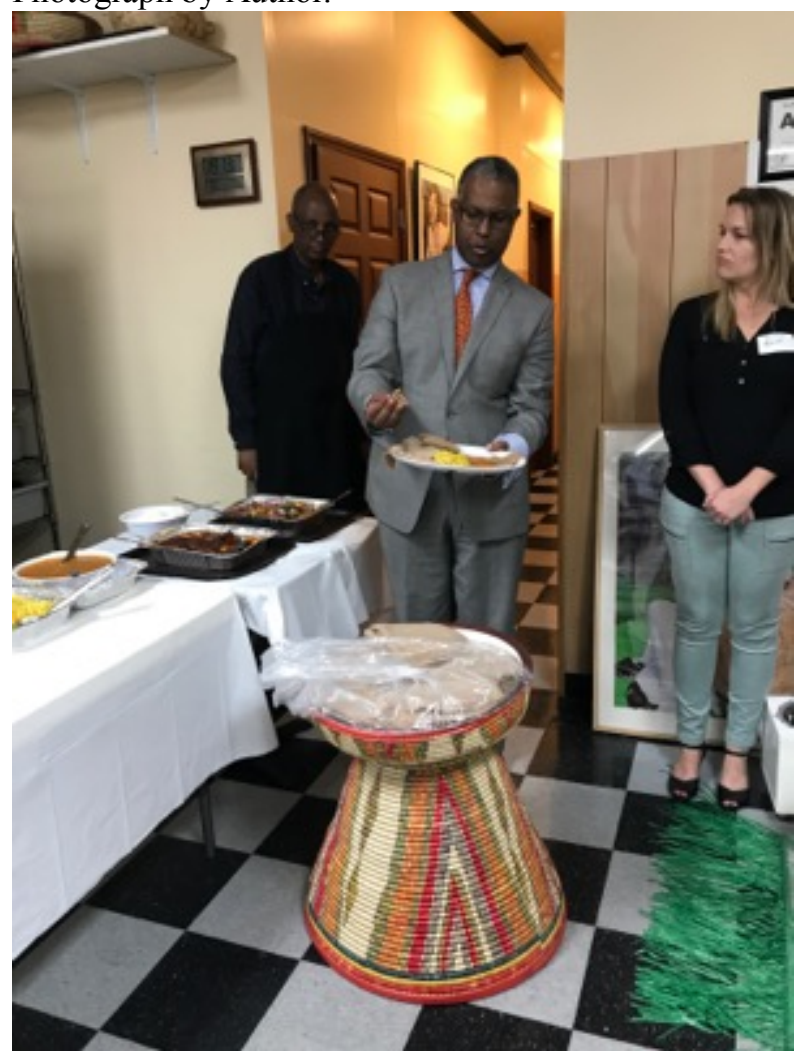

Figure 4.2. Ned explains how to use hands to eat with Ethiopian Injera bread at Nile Grocery, our second stop on Taste of the World. It is important to note that Nate does not own Nile Grocery but he is "wellversed," corporate and trusted among guests. Photograph by Author.

The implications of fear, control, surveillance and the city's marketing/design of place with these principles in mind as well as general fear associated with foreigners, or more explicitly with strangers and the Other has been central to a great deal of scholarship (Ahmed 2005; Ahmed 2000; McClintock 1995; K. . Appiah 2006; Zukin 1995b; Urry and Larsen 2011). For Ahmed (2000) while the discourse of multiculturalism may operate to welcome the stranger as the "origin of difference", or to "assimilate the stranger as a figure of the unassimilable", the discourse of "stranger danger" simultaneously establishes the stranger as the "origin of danger" (Ahmed 2000, 
4). It is through processes of either expelling or welcoming those recognized as strangers that determine the figure of the stranger (Ahmed 2000, 4). Further, the uneven and shared interpretation of who is constructed as host and who welcomes the stranger is a reflection of dominant power structures. For "Charlotte East", organizations such as EPAC and E.A.S.T serve to simultaneously welcome the stranger with events such as Taste of the World while expelling or controlling the stranger by attempting to maintain the "loyalty of longtime residents", who are mostly white middle class individuals, through national entities such as ICE and the local fight against the loncheras that seek to literally expel the stranger. At the same time, as Furuseth, Smith, and McDaniel (2015) reveal, there is a relatively strong presence of African Americans in the neighborhood. In fact, the population of African Americans (unspecified by ethnicity or nationality) outnumbers that of white Americans by about a quarter (Charlotte-Mecklenburg Quality of Life Explorer District 5 2015). Therefore, it is equally critical to consider Ahmed's notion of the "host" as it pertains to not only the dominant white population in Charlotte but the prominent African American community as well.

bell hooks contends that encounters with the Other by the dominant culture are both exciting and intense while also quelling white fears of being deemed racist. At the same time, these encounters still provoke fear and threat (hooks 1992, 26). Building upon past scholarship that considers the ways fear and surveillance are often simultaneous with notions of authenticity and aesthetic as mostly upper middle class whites encounter and re-encounter neighborhoods like East Charlotte, intersections of race, affect, gender, space, and place are critical (Ahmed 2000; Ahmed 2005; Zukin 1995a; Zukin 2010; Urry and Larsen 2011; C. M. Hall 1997). hooks presents an 
understanding of the simultaneity of fear and excitement more clearly anchored in the intersections of gender and race. In "Eating the Other", hooks offers a literal entrée into how experiencing the Other through sex, eating and venturing through a particular neighborhood or country are rooted in racialized fetish (hooks 1992). Whether we are walking, looking, eating or having sex, the excitement of the journey into the dangerous, unknown and exotic through bodies, space, place, and food triggers affects central to our being, especially for white Americans. One example of this can be seen in the Trip Advisor description of Queen Sheba Ethiopian restaurant, one of the 25 restaurants featured on Taste of the World, and a main site for participant-observation over the course of the last 16 months. According to a Trip Advisor review, Queen Sheba, "is hidden on a strip mall among Latino shops, in a not very nice area of town - however one can argue that this adds to the whole experience as usually these are the most authentic places you can find. So yes, if you're adventurous enough to go off the beaten path, you are in for a treat with this restaurant" (Trip Advisor 2016). This statement reveals the fear that the East Charlotte landscape- beyond the line of gentrification - evokes. It also represents a "gritty authenticity" that contrasts to the "bland homogeneity" of corporate Uptown and suburban Southpark (Zukin 2010, 37). It produces a sense of adventure for those who dare venture into this area of East Charlotte in their search for "authenticity." Zukin (2010) argues that the kind of subjectivity that emerges from really living in a neighborhood contrasts with what we inhibit in venturing "off the beaten path," as the latter romanticizes inequalities through asserting authenticity and also establishes difference in how we see ourselves and others (20). Further, to briefly return to hooks' point, situating her arguments within a Foucaultian perspective, she contends 
that it is through a "longing for the pleasure" that sustains the white west's "romantic fantasy of the "primitive", it is the danger, the adventure that makes it a real "treat" (hooks 1992, 27). Yet, the idea and longing for the primitive and exotic Other is not necessarily exclusive to whites. Based on personal experience, Black American men and women alike often seek pleasure in Latin America and the Caribbean from other exoticized black and brown subjects. Further, "Mandingo", the name of a West African people, popularized by the 1975 film of the same title, became a slang term in black American popular culture that referred to the size of black men's genitals, reifying the fantasies and myths of primitive black male sexual prowess both inter- and intra-racially. However, in this chapter, I argue that Black American respectability evidences an ongoing crusade against falsely theorized and popularized images and notions of the primitive. The struggle against stereotypes and in turn, the quest to attain civility within a hegemonic capitalist patriarchy also serves to construct intra-racial boundaries.

It is in many black Americans' quest to counter "the primitive" that they often subconsciously endeavor to be what Frazier calls "Super-Americans." As argued above, this condition however is not unique to Black Americans, neither is the deployment of the “model minority" by West Indians or Africans, but instead a condition shared among most marginalized subjects living within post-colonial societies. McClintock (1995) as well as others have highlighted Homi Bhaba's concept of mimicry, which Bhaba sees as a "flawed identity imposed on colonized people who are obliged to mirror back an image of the colonials but in imperfect form: 'almost the same, but not white"' (McClintock 1995, 62). In his discussion of “mimicry,” Bhaba (1994) draws from Fanon (1952) noting that subjects' mimicry can at times be ambivalent while at other times it fulfills 
the fetishized conceptualizations of the Other as the subject develops a fixation with colonialism (Bhabha 1994, 129).

Fanon's (1952) Black Skin, White Masks presents language as a primary form through which the colonized subject enacts or embodies such mimicry. Similar to DuBois' "double consciousness", Fanon asserts that the black man "possesses two dimensions: one with his fellow Blacks, the other with Whites" (Fanon 1952, 1). Considering "proper" language as a form of mimicry, "to speak means being able to use a certain syntax and possessing the morphology of such language, but it means above all assuming a culture and bearing the weight of civilization"(Fanon 1952, 22). Mastering such skill exudes an overwhelming power as well as the possibility to become white, or at least as close to the colonizer as possible (Fanon 1952, 1, 2-21). Fanon refers to the use of French versus Creole in Martinique, however, much of the same could be gathered from the emphasis upon speaking "proper English" for Anglo-black subjects. Within what appears to be less of an ambivalent zone, Fanon offers the image of a black man holding the breasts of a white woman as a metaphor for the black subject subconsciously grasping the unattainable secrets of white colonialism. Somewhere between the accessibility of learning to speak a language properly and the realization of forbidden sexual conquests underlies other fluctuating and unassuming performances of the postcolonial subject including how one dresses, styles hair, decides where to go, and what to eat. In this ambivalent occupation so-called "mimic men" imitate "an image they cannot fully assume" (McClintock 1995, 63). At the same time, mimicry can pose an opportunity for both resistance and fidelity. As a form of resistance, mimicry can serve as a counter-narrative to dominant stereotypes associated with the primitive; loudness, 
boisterousness, criminality, sexuality and other forms of perceived deviance. In terms of food, we could consider the act of avoiding tastes and smells that are spicy, hot, exotic, brightly colored, or odorous that become ultimately representative of the Other.

Taste in itself leads one to consider Bourdieu's (1984) concept of habitus, or the "structured set of classificatory schema which is inculcated in the child as its sense of cultural propriety and normative order" (Miller 1987, 103; Bourdieu 1984). This established cultural ordering becomes a critical factor in subjects' sense of identity whereby habitus is shared among certain groups, revealing class, gender etc. As a product of interactive processes and learned familiarity, habitus allows us to understand subjects' relationship with the material world as it is through expressions of "disgust, distaste and discomfort" as one interacts with the object world in which subjects determine whether some thing is acceptable or not (Miller 1987, 105, 106).

If we consider Fanon's conceptualization of language in conjunction with DuBois' "double consciousness", for black subjects habitus is both a relative and definitive accomplice of mimicry among black-subjects in post-colonial societies. Bourdieu's (1984) habitus allows an analysis of lifestyle choices as they conjoin with aspects of agency, and/or a "class of agency" that can be "hidden under the diversity and multiplicity of the set of practices performed" (Bourdieu 1984, 101). In further defining habitus, class is "identified through an indices of occupation, income, or even educational level course", these elements and the materializations of such, gain hierarchal cultural and social significance that can be performed if lacking in actual material manifestations. Although Bourdieu's central example of mimicry lies in the pretentions and/or conspicuous consumption among the petit bourgeois in France, if we reference Fanon's 
presentation of language, sex, dress, these materializations/performances signify the postcolonial subject's endeavors to become the colonizer. In accordance with Bourdieu, taste is not simply gastronomy but a "natural gift" of recognition and loving perfection (Bourdieu 1984, 68). Concerning food, being knowledgeable of spices, textures and perhaps how to eat are markers of cultural capital i.e. travel, education, etc. Therefore, it is one thing as a black subject, to sit at a table among white individuals, select a cracker, unknowingly spread it with foie gras, and become immediately nauseous as the host poses the question, "you've never had foie gras?" On the other hand, a black subject sitting among other black subjects at an Ethiopian restaurant deciding to eat with hands in the traditional Ethiopian way or to eat properly in the American way represents performance and respectability that distinguishes one between the civilized and the primitive. Understanding the politics of respectability and the deployment of the model minority as instruments of mimicry, as well as reflections of an adopted habitus, we begin to unravel the ways in which affective boundaries are established intra-racially and interethnically and the ways in which subjectivities are shaped/reshaped as black subjects' interact with one another in the making of these boundaries.

\section{Hanging Out in the Trenches; (Un)Respectable and (Un)Safe Bodies as Boundary-Markers in East Charlotte}

"Krystle and Keisha [black American and Trinidadian-American respectively] both expressed that they had concerns about the area upon pulling into the sketchy looking parking lot [at Queen Sheba Ethiopian Restaurant] as the doors of the actual restaurant aren't clearly marked. As we walked in, there appeared to be a dispute between a Black American man standing on the corner, and an African woman standing in the door of a 
neighboring business in the shopping center, perhaps her business. From what I could gather, the woman had asked the man to move [from loitering in front], and in response the man yelled that he did not have to move because he had been coming to hang out in that location for years, asserting, "I been here all of my life!" He went on angrily yelling, "I don't know nothing about Africa!" While the man was clearly in the wrong, the situation evidenced that contestations over space and place in East Charlotte are just as prominent in everyday interactions intra-racially as they are by larger organized forces. I quickly ushered my friends into the restaurant, hoping they were not alarmed or discouraged from the upcoming eating experience by this mini-altercation. "-Field Notes, Queen Sheba Restaurant, June 2017

Simone, Keisha and I arrived to dinner about five minutes behind Krystle and Kester, who is from Guyana. Krystle and Kester, who both work at TIA insinuated that they were slightly weary of getting out of the car and were unsure if I had given them the correct address, as the shopping center appeared "sketchy." Simone, another black American, and I reassured them that the food is good and that they were safe, recalling our night hanging both inside and outside of the location with some of the Ethiopian, Eritrean and Latino locals. Hoping that Krystle was not alarmed by the mini-altercation or the "sketchy" location, I ushered everyone inside and we were seated at a table in the center of the small restaurant. This was Kester's first time meeting Simone and Keisha, and his sister's first time meeting everyone. I was excited to meet Kester's sister, Andrea, as he mentioned her several times on our participatory GIS adventures shopping at Compare Foods. I recall standing in the crowded fruit aisle of Compare, when Kester 
with a small plastic bag in one hand and gathering plantains with the other, expressed that Andrea, who lives in the same Charlotte neighborhood as him, often prepared his Guyanese meals in the way his mother who lives in New York does, and brings them to him. As do most introductory conversations begin, Kester started by asking Simone and Keisha what profession they were in. It was somewhere in this very basic entrée that the conversation began to take an odd turn. After Simone and Keisha responded that they are psychologists, Kester noted that his sister was also studying to become a psychologist. Andrea in turn, responded very cynically that she was instead a psychiatrist, and then began to laugh. This made it unclear whether she was actually a psychiatrist, psychologist or any of the above. Simone and Keisha later revealed that for them, this was the first of many offenses that in their eyes, sought to minimize not only their credibility as black women psychologists, but as accomplished black American women in general.

Once the menus were handed out, we conveniently shifted our conversation to the Ethiopian food we were about to eat and from there, our conversations ventured to Washington, D.C. Simone and Keisha recalled the accessibility of Ethiopian food while living in D.C. and began to reflect on other memories, expressing their longing to return to the city. On the contrary, Andrea chimed in that she did not like D.C., after living and attending school in the area, she stated matter-of-factly that she was "too Bourgie" for D.C. Here, "bourgie" signifies a colloquial term used to describe the oftentimespretentious behavior of the black American bourgeoisie, much like Bourdieu's petit bourgeoisie. The term represents a sort of backhanded compliment that connotes one is snobbish but also has expensive taste. Andrea's assertion left us somewhat puzzled as 
many black Americans envision D.C as the black Bourgeoisie capital of the U.S., not only because D.C is commonly referred to as "Chocolate City", but also because the city has historically been home to a significant successful black middle class, beginning in the 50s and 60s. Simone, Keisha and Simone seemingly jeered in response, looking at one another from the corner of their eyes, perhaps even more so since an actual member of the D.C. black bourgeoisie, Keisha, was sitting at the table with us. It was almost as if it were common knowledge that one cannot be "too bourgie" for D.C. To whatever extent, Andrea designating herself as "too bourgie" was the beginning of a quickly unraveling performance of socioeconomic status that seemingly attempted to distinguish herself from others at the table. Kester also seemed to sense this, as he nervously redirected the conversation.

The conversation returned to the actual food. Since this was Kester's first time having Ethiopian, I recommended the Yah-beg tibs, the stewed lamb. Kester ended up not liking the lamb due to it's "gamey" taste. Andrea went in for a taste and lauded that while she does not normally prefer lamb, she had "been all around the world" and had the opportunity to taste lamb from "all around the world" and was shocked to taste exceptionally good lamb in Charlotte. Andrea's approval of the lamb signaled her presumed knowledge of food that she gained through her travels, all of which illustrated another attempt to reference her cultural capital and class. Still recovering from Andrea's comments on D.C., Keisha questioned Andrea on the places she had visited "all around the world." Andrea jestingly responded, Pineville and Shelby, both of which are local towns in North Carolina. At this point, it became clear that Andrea assumed others at the table, with the exception of her brother, had not been out of North Carolina, or at least the 
East Coast. Simone, Keisha, Krystle and myself were in this instance, uncultured and unknowledgeable southern black Americans presumably without distinguishable taste. Taken as such, Keisha responded that she had in fact not been to any of those local places. Seemingly overwhelmed with embarrassment, Kester asked his sister to clarify where "all around the world" actually meant. She then boasted that she had travelled to every continent with the exception of Australia and Antarctica. Again, attempting to shift the conversation to a less-awkward state, Keisha mentioned the excitement she gets from getting a new stamp in her passport, suggesting that she had indeed travelled outside of the country. Andrea then arrogantly reveled that she was now "over" the excitement after having travelled so much. At this point, the underlying competition and pretention was beyond palpable. In one last notable exchange, Simone was adamant about eating our food with our hands, as is Ethiopian custom and as Noah, the owner had instructed us to do on our last visit together. We then briefly discussed the varying cultural customs of eating with hands around the world, all in trying to lighten the mood. Andrea abruptly interrupted to mockingly ask, what hand does your [black American] culture eat with?

Whether Andrea's comments were meant to facetiously suggest that black Americans lacked a culture or simply a poor effort at sarcasm was unclear. However, it did become evident that in each of the triggering exchanges described above, boundaries were constructed through particular performances of respectability, class, culture, and education. The other black women did not falsely perceive these exchanges at the dinner; Kester later apologized for his sister's behavior, although no one directly mentioned the post-dinner sentiments to him. Andrea's performance of respectability, superiority and class could be situated as a deployment of the "model minority" or just as easily within 
the dynamics that have historically enacted sociocultural boundaries between Northern and Southern black Americans since the Great Migration. The relationship between northern and southern black subjects has been underlined with a sense of respectability derived from a perceived closer proximity to progression, civilization, and certain attainment of cultural capital versus the backwards, rural, poor, segregated south. My parents often half-jokingly recall when friends or family would visit up north for the summer as children, and return home feigning "New York accents," or "speaking properly" as opposed to their deep southern accents laden with improper English grammar. Distinctions between Northern and Southern black Americans often play out in greater political and cultural quarrels as black Americans return to live in the U.S South through return migration. Based upon my own coming of age in the South and spending summers with family in D.C., these quarrels are most times an exchange of whose education, way of life, or experience is superior. Further, Andrea's performance of respectability was not necessarily one-sided as it evoked defensive and corresponding assertions of respectability and cultural capital by the black Americans present. Therefore, performances of respectability by black immigrant subjects can be just as much underlined by subconscious deployments of the model minority as they are by assumptions of behavior, language, etc., associated with regional distinctions between black American subjects.

Another distinction made both between Northern and Southern black subjects as well as urban and rural black subjects is the notion of "street smarts" or "street wise." Just as it is presumed that southern and/or rural black subjects allegedly do not possess this street smarts, West Indians and black immigrants are assumed to have attained a 
heightened and/or ruthless street wise, or "hustle." According to Anderson (1990) street wisdom is "largely a state of mind" demonstrated through one's behavior and representing a perspective gained through public interaction that allows one to " "see through' public situations to anticipate what is about to happen" (E. Anderson 1990, 6). Further, street wisdom is often initiated by what Anderson sees as a "certain uptightness" regarding the urban environment that often stems from decisions based upon stereotypes. However, with time and experience "nervousness and fear" leads to a realization that "street life involves situations that require selective and individualized responses" in a complicated environment where simply applying stereotypes will not due (E. Anderson 1990, 6). A great deal of Anderson's ethnography focuses primarily on the inter-racial relationship between whites and blacks in a changing urban environment. Yet, Anderson's work fails to fully capture the underlying implications of respectability within intra-racial relations in an urban environment. Upon entering Queen Sheba, Kester, a black Guyanese via Brooklyn, Krystle, a black-American from Rocky Mount, North Carolina, and Keisha, a black-Trinidadian American from D.C. expressed concern before entering. Coming of age in Guyana, and an adolescent in working class Brooklyn undoubtedly rendered Kester's street wisdom different from Krystle's. Whether in the nascent or more progressive stages of street wisdom, stereotypes of black subjects shared by other black subjects despite nationality inform both fear and a conscious distancing from black subjects of a certain class. This active distinction involves performance through dress, behavior, hairstyles, etc. Fear and the decision to distance oneself indicates a level of attained bourgeoisie that may be threatened or tainted based upon one's entrance and involvement in the area. The practice and expression of the idea that 
"I am not like them", or the masses, reiterates Frazier's conceptualization of respectability while also establishing physical boundaries between Us (bourgeoisie) Black Americans/immigrants and Them, working class black subjects despite ethnicity or nationality.

In Chapter Two, I introduced Kester as what Sara Ahmed calls the "wise subject." Ahmed (2000) presents the "wise subject" as one who knows where to go, where to walk, where to hang out, and simultaneously as one knowing who not to talk to, where not to walk, and how to or not to move, talk, or dress. In turn, the wise subject is one that possesses "an expertise that can be understood as both bodily and cultural capital" (Ahmed 2000, 34). With the notion of "stranger danger" Ahmed holds that, "the discourse of stranger danger involves techniques of knowledge that allow wise subjects to prevail: to arrive at their destination, to leave and return home and still maintain a safe distance between themselves and dangerous strangers" (Ahmed 2000, 34). For many of my participants, this has meant staying away from "unsafe" or aggressive situations and people and for black subjects in particular, this can mean either staying away from predominantly white spaces or disassociating themselves from lower working class "hood" black spaces, revealing an underlying fear black subjects have of one another.

Kester was born and raised in Guyana until the age of 16, when he moved to Brooklyn, New York. He holds a degree in mechanical engineering from a Historically Black College/University in Atlanta, and after working in several high-ranking engineer positions for corporations like Electrolux and Harley Davidson, Kester received an M.B.A and now works at TIA, an investment and financial services corporation in Charlotte. I previously interviewed Kester at his home in a gentrifying Northeast 
Charlotte neighborhood, where I was intrigued by the baby grand piano in his meticulously decorated living room. He does not play the piano. So impressed was I by his furniture and décor I inquired about certain pieces, which he purchased from high-end retailers like West Elm. Kester also drives a Porsche Panamera, which while common in cities such as Miami with costs starting at around $\$ 78 \mathrm{~K}$, is not so common in Charlotte, at least in this particular neighborhood. In other words, it is quite flashy. Other acquaintances of Kester often commented on the irony of his seemingly debonair dress, high-end house decor, and his lavish car while living "around the corner from the hood." Their criticism of Kester's neighborhood choice discloses a common sentiment and reality among upper middle class black subjects, which holds that once one is able to "leave the hood", they should. This common sentiment furthers the conversation of taste and distinction among respectable black subjects.

According to Wilson (1969), "money is but a means to the procurement of the signs of accomplishment" (Wilson, n.d., 76). It is in the way that money is spent, in which we gather differences between goals of reputation and those of respectability (Wilson, n.d., 83). Extravagant expenditures like a Porshe Panamera in Charlotte reveal the basic complex of values black subjects internalize that underline reputation. In a similar manner, many black subjects in Charlotte feel that a home in a newer "safe" development is more consistent with the reputation of owning a Porshe versus purchasing a more economical home in an older predominantly black neighborhood, or one in the beginning stages of gentrification. Both understandings are underscored by a lack of concern with economizing that constitutes the seemingly larger need to uphold a reputation. Kester, however, sees his home purchase and future desire to purchase a 
home in gentrifying East Charlotte, which he also expressed, as an investment with greater return. Indeed, the reality in Charlotte is that as whites move back into areas like East Charlotte, the land/home values rise at a significant rate while in newer suburban areas like University City where a large black middle class reside, and where working class blacks will most likely find themselves after being pushed out of East Charlotte, home values are falling. Kester's decision then to live in the "hood" is perhaps more economically promising, as has been the case with whites. Therefore, Kester's lifestyle and economic values are revealing of the entwinement of reputation and respectability.

In accordance with Wilson, reputation is more so derived from face to face interactions within one's own personal social group i.e. the way one views himself and his peers and while reputation greatly contributes to respectability, the latter is linked to more external systems and institutions such as a respectable occupation, marriage, and investment (Wilson, n.d., 79). Kester's manner of conscious investment along with his emphasis on working extra hard, aspects he felt to be a point of conflict that led to the demise of his marriage to a black American woman, teeters on a respectability that more clearly aligns with a deployment of the model minority myth. This is based on Kester's assertion that his black American wife, who he used as an example for the "mentality" of other black Americans, did not understand the value of working extra hard in order to reap the benefits later. I discuss this in more detail in Chapter Two.

Outside of our interview, Kester also participated in a photo-voice focus group, participatory GIS and we often hung out as a group at research sites with Krystle, who introduced me to Kester as well as several other participants in the study. The evening after our focus group meeting, Kester, Chantel, a participant from Grenada, Krystle and I 
went to a local black American-owned hookah bar and lounge where we further discussed some of the topics that emerged in the focus group. Kester, Chantel and Krystle all work at TIA. At one point in our conversation, the significance of appearance and dress came about. Krystle, who had been wearing her hair curly, in its natural form during the summer months, expressed that she did not like nor feel comfortable wearing her hair in its natural state, particularly at work, where she believed it was unprofessional, in contrast to straightened hair. Chantel seemingly agreed with this notion while Kester added that he felt it absolutely necessary to dress and behave in a certain manner, alluding that certain attire and attitude made him more acceptable and presentable among white colleagues and within the panorama of corporate America. In Chapter 2, I expand more upon Kester's behavior, specifically moments in which he feels the need to turn down the stereo in his car when pulling up next to white people or police officers in Charlotte. In this case, appearance, dress, and a certain level of performed respectability serve as methods of resistance while also reifying social hierarchies as black subjects attempt to gain acceptance and recognition from the dominant group (Bourdieu 1984; Frazier 1957; Greenbaum 2002).

Acceptable or respectable dress and behavior are not always conscious. Instead these performances are a conditioned necessity used to distance oneself from particular sites or events associated with "unsafe", "ghetto" or "hood" blacks as it could mean possibly sacrificing one's time, money, job, or life. Greenbaum's (2002) exploration of Afro-Cubans in Tampa reveals a critical aspect of respectability in which black subjects were encouraged to regard one another as a threat, or to stay away from those who were perceived of as "unskilled", "unpropertied", and "uncouth" as they could be dangerous to 
black progress (Greenbaum 2002, 87). The divisive perception of one another as a threat further underlines Frazier's (1957) concept of Super-Americans as well as DuBois' notion of the "Talented Tenth" which called upon the small group of black bourgeoisie intellectuals, entrepreneurs and artists to lead blacks away from what DuBois saw as the menial existence and complacency of the masses. At the same time, some black subjects may distance themselves from "dangerous blackness" due to fear of confronting the police, being wrongly accused, and/or being somehow involved in a violent act. However, the ability to firmly state that "I don't hang with that group" or "I don't go to those places" serves as methods to gain respect and acceptance among white upper class co-workers and friends as well as other respectable black subjects (Wilson, n.d.; Greenbaum 2002; Queeley 2015b). Here, I am concerned with the implications of such on intra-racial and inter-ethnic boundary making among black subjects. I asked participants about places they avoided and places they felt at home. While I did find the black-white binary to significantly impact the choices of my participants, I also found intra-racial fear and disdain of one another to be a poignant boundary-marker as well. When I asked Kester about places in Charlotte that he avoids, in contrast to other participants' responses that included Uptown, Park Road/Montford, and the Epicenter, all of which are mostly white spaces that in Chapter 1, I suggest use modern forms of racial discrimination and segregation through strict dress codes, Kester mentioned Crystals Reggae Club as the one place he purposely avoids. He expanded upon this stating that, "I just feel like we [black people] can go from 0 to 100 in a minute and I don't really want to be someone that was in the wrong place at the wrong time. Ifeel like it's a dangerous vibe. And that's just not me. I think there were shootings there. I just avoid 
places that have conflict, known conflict. I prefer to go to Jamaica to get the realness (Laughs). Even my sister, she'll tell you, [I tell her] do your thing but don't tell me you went there because I get paranoid and even worried, but she would take my cousin but you won't catch me there. I don't want to be caught up in nothing."

While explaining his reasons for avoiding Crystals, Kester often shook his head disapprovingly and motioned his hands as if to signal rejection, reiterating his fear and disdain. I see this fear and disdain as a form of intra-racial boundary making implicated by respectability as well as affect.

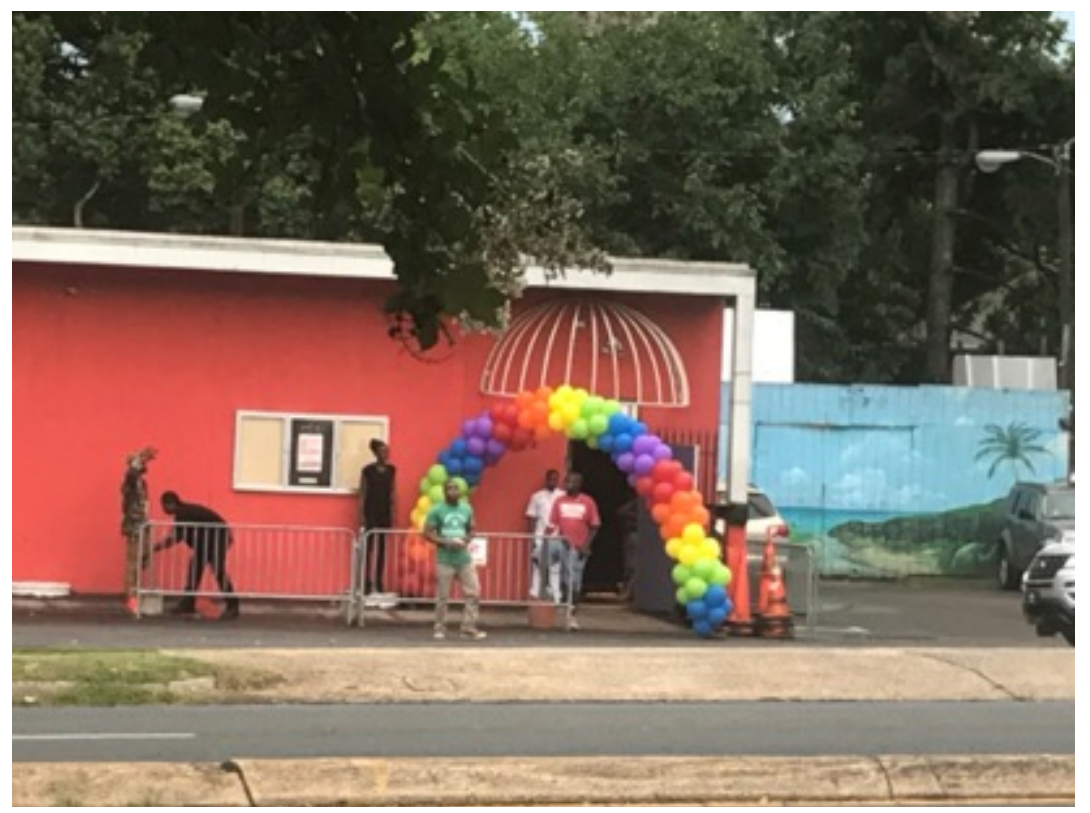

Figure 4.3. Crystals Reggae Club on The Plaza in the heart of East Charlotte. Pictured is the entrance during a daytime festival. To the right is a painting of an island with palm trees, ocean and beach suggesting it's "Caribbean vibe." To the far left, a security guard pats someone down. Photo by author.

Nigel Thrift (2008) invites us to consider the multiple theorizations of affect. One of the most popular definitions of affect holds it as "a set of embodied practices that produce visible conduct as an outer lining" wherein the central concern is to describe 
"how emotions occur in the everyday life, understood as richly expressive/aesthetic feeling-cum-behaviour of continual becoming that is chiefly provided by bodily states and processes" (Thrift 2008, 175). In this instance, Thrift suggests that context is the most vital element in the "constitution of affect" as the source of emotion appears to come from "outside of the body", or from the setting itself (Thrift 2008, 176). Thrift applies Katz in arguing that, "the problem is that emotions are largely nonrepresentational: they are 'formal evidence of what, in one's relations with others, speech cannot congeal" (Thrift 2008, 176). Therefore, Thrift seems to argue that first, affect is not necessarily blatantly nor easily captured through outward emotion or expression and second, affect is not always contingent upon context. Instead, he holds that there is "no time out from expressive being" as the "perception of situation and response" are intertwined and call upon a particular "response-ability" (Thrift 2008, 176). This then suggests an on-going exchange in which affect is triggered from outside of the body just as much as the body (or bodies) actively project affect onto the context.

Jane Bennett (2010) provides a more specific discussion of bodies and affect by putting Spinoza's concept of "affective bodies" in conversation with Delueze and Guattari's idea of "assemblage." For Bennett, the very nature of the body holds the power to affect other bodies or a "corresponding and inseparable capacity to be affected" (Bennett 2010,21). Within these affective exchanges, there exists the power to act as well as a consequential suffering of action. In turn, Bennett sees the intersecting traffic of bodies, non-human actants and affect as assemblages, or "living, throbbing confederations that are able to function despite the persistent presence of energies that confound them from within" (Bennett 2010, 24). Assemblages exist within uneven 
topographies and are not specifically governed by one sole entity (Bennett 2010, 24). If I were to create an "urban dictionary" definition of assemblage, I would define it as the colloquial term, "vibe." The "vibe" serves as a way to verbally capture particular inexplicable or non-representational emotions presented by the diverse elements within a context and the affective bodies that occupy the particular space. Just as an assemblage is an "ad hoc grouping" of vibrant materializations of affect, the vibe then is constituted by elements such as thundering dancehall music, the clash of bodies rhythmically grinding against one another in response, hands raised in the hair simulating gun fire as the DJ yells "More Fiyah" and the mixed aroma of curry and marijuana smoke that can enact a sense of fun and happiness for some, but for others can cause disdain and fear, all of which as an assemblage, can be understood as energies that coexist and persist without governance. Kester's perceptions of Crystal's Reggae Club, offer a window into what constitutes a bad or "dangerous" vibe.

Crystals Reggae Club has been a staple in the black American and Caribbean community in Charlotte for more than 15 years. I have personally been going to Crystals since around 2005 and I currently live about three blocks away from the club. Even now, it remains one of the only late nightspots in Charlotte, open (sometimes) until 4am, and serving according to many, the best Jamaican jerk chicken in the city. It has in many ways become a landmark, not only because it is a Caribbean go-to, but because it has managed to stay open through various shooting incidents and liquor license violations that the club received due to selling liquor in Charlotte after 2am, which is illegal. Despite this unpredictability, Crystals has kept it going. However, for Kester, Crystals' precariousness is the source of its dangerous vibe. Using another colloquial phrase, 
"from 0 to 100 ", Kester implies that the vibe or mood of Crystals can quickly escalate from a calm and jovial "Caribbean vibe" to a violent and dangerous one. The situational vibe of Crystals and the fear and disdain it produces for some designate a boundarymarker between "unsafe" and "unrespectable" black subjects and "wise" respectable black subjects. Still, Crystals was one of the first places that Kester mentioned he avoids even though it does perhaps possess the "realness" of the Caribbean vibe, which denotes the club's significance in both the black American and black immigrant communities. The local nightspot was also a point of reference for several other participants, although not always recognized for its dangerous vibe.

On a chilly March evening, I sat with Ndelo, a second-generation Congolese immigrant and creator of the monthly Afropop event that I later argue is a Pan-African site of "Diaspora Love" in contrast with those of Diaspora Wars. In the exchange below, Ndelo and I share our thoughts on Crystals, other African clubs and why/how he and friends decided to start Afropop.

Ndelo: You know you've got places like Bakadi Lounge ${ }^{i} .$. [have] you been there before? Interviewer: No, I've just heard of it.

Ndelo: Okay...so you'll see a difference if you go to Bakadi Lounge...you'll notice a difference in the cultural vibe there than at Afropop

MB: In what way?

Ndelo: If you go to Bakadi Lounge, you're going to get more of a raw African pop vibe...you know what I'm saying? [It has a different] nightlife vibe; you would experience how Africans treat Africans in Africa. You're going to experience that 
rudeness at the door, [there aren't] really any "Thank You's"...it's like, "Who are you?" "It's ten dollars!" If you want to negotiate, forget about it. That's normal in the culture, its not being offensive. Here, [in the South] customer service is a big thing, you're used to the "Thank yous" and the "Heys!" and people being a certain type of way, taking your money in a certain way, someone handing you money in a certain type of way, [but there] you feel like, "hold up, you're disrespecting me." There, its a whole other ball game, but then you come to Afropop--because even like Kato--he was born here too as well... Interviewer: Where is Kato [the other Afropop creator] from? Ndelo: Nigeria [Kato's parents are from Nigeria, but he identifies as being from Nigeria]. He has the same type of experience as I do, but we've both been back home multiple times and getting our culture back home, because he is [a] Nigerian born here, and I'm Congolese born here. Our other partner, April, she's an African American born [in Charlotte]. We make sure that we mesh the goodness of all the cultures into one, that is what allowed us to bring the true Pan-African/Diaspora into one place because some of those people [customers] said, I can't really fuck with Bakadi like that because it's not as inviting in there if you're not really speaking the language, or know the dances, you know what I'm saying or-- it might be too raw for them--especially if you never been to Africa to know how Africans really act in Africa--have you been to Crystals?

MB: Yea [laughs]

Ndelo: Yea, so you know that's a real like--the realest authentic Jamaican experience you will find here

MB: Yea, I've been going to Crystals for like- 
Ndelo: Since way back right? That's always been the spot...word! Nice! So, you know it's been around, and it's going to stay around because they do [it] best. You know what you're going to get there and the ladies say--you know some women can't take it-because, [they say] "oh they grabbin' me here" "they doing this right here" you know its like [laughs]

Interviewer: Yes that what my friend said when she came here from Detroit. I told her that we had to go to Crystals - but there were a lot of New York dudes there. She said she couldn't take the New York aggression...but maybe [there were] a lot of New York Jamaicans too--because they go there--and she was like, "they're just too aggressive"

While Ndelo and I's conversation offers a different perspective than Kester's, both uncover intra-racial and inter-ethnic boundaries foregrounded in a particular "vibe." These vibes or affects are inclusive of cultural, behavioral and gendered boundaries between groups of black subjects. For my friend, who I brought to Crystals, the club gave a vibe of aggression. Bria was taken aback and threatened by the aggressiveness of touching, invasion of private space and cat-calling by men. Referring to "New York dudes" as perhaps more aggressive is also suggestive of a perceived regional difference in behavior and performance among black subjects from the U.S. South and other regions. Historically, black male bodies in the south, and the U.S in general, have been marked as over-sexualized, violent and unsafe, a purported stereotype that resulted in thousands of lynchings and deaths of those who were innocent and an image that I do not want to further perpetuate. However, it is necessary to address how this narrative underlies the distinctions made by "respectable" black subjects and others as they 
internalize these narratives and/or reject them. At the same time, male sexual and physical transgressions against women transcend race and ethnicity, so this is also not to undermine the prevalence of sexual assault and invasion. Still, the usage of "New York dudes" and "New York Jamaicans" imply a layering of the black body as being even more aggressive and threatening based upon ethnicity and regional association. This coincides with what Ndelo highlights as the particular "cultural vibe" of Crystals and Bakadi wherein behaviors and bodily movements, like dances or handling money, may be taken as "rudeness" or simply "too much" for black American clientele, particularly black American women. On the other hand, respectable Caribbean and African subjects also attempt to disassociate with particular threatening behaviors attached to foreignness and blackness as seen through the debonair wise Caribbean subject Kester. In Chapter 2, I also introduce Rossano, a self-identified Black American-Greek-Ethiopian, as a "different" black subject, which I argue often runs parallel with the "wise" subject.

Rossano's account focused more so on avoiding predominantly white spaces in Uptown, however he was often torn as segregation based upon a black-white binary often forces black subjects to choose. With this in mind, Rossano stated that he avoided allblack parties Uptown because he feared "something happening or breaking out [because] black people be acting up, and I don't want to be associated with that, or involved with that, so I try not to deal with it." Instead, Rossano elects to hang out at mostly Salsa events hosted by the dance community he has immersed himself in. Although Rossano noted that he opts for his dance community and their events because they offer a diverse multicultural environment, for the wise subject, they are also considered safe both from the potential criminal or unpredictable behavior of the masses, and from the possibility of 
discrimination in predominantly white spaces. The search and need for diversity in Charlotte, especially diverse populations of black and brown subjects, is perhaps one of the most critical aspects in creating and locating safe spaces of belonging, a safety not only necessary for respectable black subjects, but also for women and LGBTQ communities who happen to be black or brown.

The relaxed vibe of Afropop provides this safety and diversity. Upon entering before 10pm there is a discount for those dressed in African or African inspired attire, there is no strict dress code like Uptown. Usually, I was the only one to receive the discount as Kester and Krystle often accompanied me, and needless to say, African inspired attire is not really their thing. The event starts out relatively slow allowing space to move around and socialize as people dance to salsa, merengue and bachata or reggaeton blasting on the inside while Kompa and Kizomba lessons are offered outside. Throughout the club and outside, vendors sell everything from African printed clothing to handmade jewelry to natural oils and creams. More than anything, the diversity of Afropop is visible. I gauged diversity mostly through observing who could dance salsa and bachata the best, who took over the dance floor with excitement, reciting and singing the lyrics to Spanish songs, and then taking a seat to let others take over the dance floor with equal excitement when a Jay-Z, Fela Kuti, or Afrobeat song came on. I talked to and patronized the vendors, meeting Hope, a black American and her husband/business partner from Haiti. I also came to understand the diversity of Afropop through the group of people who chose to attend Afropop with me, or those that I encountered while there, Kester being among this group along with other black American and immigrant participants such as Chantal from Grenada and additional friends like Eric, the self- 
identified "Blasian" (Black American and Korean) also part of the TIA corporate group. It is a stark contrast from the crowded, ruggedness and aggressiveness of Crystals and as such Afropop received Kester's stamp of approval and returned with me on several other occasions. Ndelo and his friends' desire to create an inclusive setting for Afropop in contrast to Crystals or Bakadi, accentuates the need to accommodate not only southern black Americans but also respectable middle and upper middle class black subjects in general, which may not necessarily be required in cities accustomed to a black immigrant presence. It is important to note Ndelo's own self-identification, a literal journey that is reflected in the creation of Afropop and his clothing line.

Born in Charlotte to Congolese parents, Ndelo was often denied membership into the Black American community because of his Africanness. He, like Kato, further honed their African identities through frequent trips back to Congo and Nigeria respectively. On these trips "home" Ndelo connected with his Congolese roots, perfecting his Lingala language fluency and becoming intrigued by the LeSap fashion movement in Congo. At the same time, frequent trips to Congo also reminded Ndelo of his Americanness and as an adult he came to process the Diaspora Wars that ultimately came to constitute his identity and career. In many ways Afropop is a manifestation of Ndelo and Kato's African-American identity. As such Ndelo and friends seemed to discover a niche to maneuver the trenches of hanging out in black Charlotte; one that accommodates black fears, disdain, and ultimately respectability while simultaneously offering the Caribbean and African vibes in a safe place. Still, fear and disdain often triggered through other mediums such as food and smell and are expressed through disgust. Foods and smells 
move beyond the "vibe" and in turn, are not so easily containable, as Mrs. Tina discloses in the opening vignette.

\section{Eating Behind Enemy Lines; Food and Disgust as Boundary-Markers}

Mrs. Tina goes on to tell the story of another lady's kid who is half Black American and half African. Tina recalls telling the lady (African American) that her daughter was fat. A friend present [at the moment] tapped her and told her that she couldn't talk to African Americans like that, and Tina questioned why not? Reasserting that the girl was fat, asking what did she eat? The other Sierra Leonean woman sitting in the store laughs, and responds "it's the macaroni and cheese, it's not good for you." They then both agree, going on about how the African Americans here are "so fat" because they eat food with "layers and layers of fat." They both let out an accented, "Oooh!" reflecting on the layers of fat, they laugh and continue to briefly talk about African American food preparation.-- Field Notes, Sierra International Mart, May 2017

The above account reveals the ways in which food consumption becomes indicative of disdain for particular bodies; it is because of the layers of fat used in Black American food preparation that makes their bodies not only fat but unhealthy in comparison to African bodies. At the same time, as Mrs. Tina reflected upon this exchange she recounted that she was apprehended by her friend who warned that Mrs. Tina could not talk to African Americans "like that", referencing her telling the girl that she was fat. Mrs. Tina could not understand why she could not simply state the obvious, the girl was fat, and Mrs. Tina proceeded to ask what the girl ate that contributed to her 
fatness. In this instance, Mrs. Tina's matter-of-factly statement signaled what could be taken as rude and inappropriate to African Americans. The fact that Mrs. Tina as well as other Africans are either aware or must be warned that they "cannot talk to African Americans like that" suggests certain cultural differences that are not only rooted in what is deemed respectable behavior for African Americans but also further underscores boundaries that are established between groups based upon performance and behavior. Still, what is most intriguing about Mrs. Tina's account is that the exchange stemmed from two very basic materializations, food and bodies that represent an equal disdain and disgust for African American food that the latter often shares of African food.

Highlighting the scholarship of Kristeva, Ahmed's (2005) work, "The Skin of the Community: Affect and Boundary Formation," contends that it is how bodies come into contact with one another that allows the collective body to emerge (Ahmed 2005, 95). It is also our contact with other bodies that allows us to dissect one another, to cut away and extract the entrails of our being and belonging. Here, Ahmed draws particular attention to skin. It is our skin that not only separates us individually, providing a literal protective boundary as an organ, but collectively and symbolically through varying ethnic, social, cultural, and political boundaries (Ahmed 2005, 100). Ahmed's work portrays skin as one of the most visible materializations of abjection. Ahmed's interpretation of skin particularly addresses the relationship between the dominant white majority and those deemed as Other. Yet, among those deemed as abject, who are of the same skin, while there are boundaries of color, culture, language, ethnicity and most notably class, I am interested in other materialized forms of intra-racial boundary markers of which respectability and claims to citizenship underline. While food is indeed an indicator of 
culture and ethnicity, as such, I have found food to be a critical boundary marker in East Charlotte.

Based upon my participant-observation, most notably at Queen Sheba Ethiopian, Motherland Cuisine, and Sierra International Mart, I argue that food and smell often materialize intra-racial and inter-ethnic boundaries between black subjects. This argument stems from my initial interview with Mrs. Tina, the owner of Sierra Leone International Mart, who recalled instances of black American disgust geared towards the sight and smell of African food, which I discuss at the beginning of the chapter. When I began sitting in at Sierra International, I was warned by another black American to be careful that the smell of dried/smoked fish could "seep into my skin." In this instance, my actual skin could potentially become contaminated with the smell of the abject. I want to assert that affects triggered by varying behaviors/attitudes like rudeness as well as smells, tastes, and sights of certain foods of the Other are based upon Brennan's (2004) employment of Bion's theory of "basic assumptions" (Brennan 2004, 63). In her analysis of group psychology, Brennan holds that affects stemming from "basic assumptions" serve to sustain group membership even when the group is physically dispersed. According to Brennan, these "basic assumptions" revolve around essential affects such as "anxiety, fear, hate, love" and are enacted when the group leader(s) are in "fight or flight" mode. As a psychological phenomena "fight of flight" is often grounded in basic assumptions that preserves the group by identifying a particular threat or danger that the collective must fight or retreat from (Bion 1961). If we apply this group mentality to black subjects fighting the so-called pathology of the masses, "fight or flight" then coincides with Frazier's conception of the "Super-American" as black subjects strive for 
recognition and citizenship. Respectability is among all things, about survival. In contrast to Bion, Brennan (2004) holds the individual accountable and contends that while the collective group can bring about political effectiveness, the "basic-assumption mode" can lead to feelings birthed in an aggressive envy and hatred with persecution as consequence (Brennan 2004, 64). As such, it is difficult for the group to break apart from its general assumptions of the Other. Thus, while one may venture outside of the group, being warned that the smells of the abject may seep into one's skin, reveals that the group's assumptions and attachments are always looming.

Stepick, Grenier, Castro and Dunn's (2003) examination of interactions among Haitian and African American adolescents in Miami reveals the implications of basic assumptions rooted in establishing cultural and ethnic boundaries. In one instance, a young Haitian girl asserts that being called, "You Haitian!" connotes "you are stupid, smelly, and dirty!"(Stepick et al. 2003, 124). At the same time, another Haitian adolescent described black Americans with the terms/phrases, “Don't give a shit. Dirty. Rude. Less Class" and "they don't wash enough" (Stepick et al. 2003, 126). Therefore, it seems that the most trivial of basic assumptions stem from preconceived stereotypes attached to skin and smell i.e. cleanliness versus dirty and smelliness that transmit affects such as disgust, disdain and hatred intra-racially.

Brennan (2004) gives equal attention to the transmission of affect through smell. According to Brennan, smell is critical in "communicating responses ranging from the aggressive to the soothing," which can establish a shared alikeness. I relied upon this claim while forming my initial research questions. However, I did not immediately consider the ways in which smells could communicate a shared disdain for other black 
subjects. McClintock (1995) defines the abject as "everything the subject seeks to expunge in order to become social" or "a compromise between a "condemnation and yearning" marking the "borders of self" as "it [the abject] threatens the self with perpetual danger" (McClintock 1995, 71). There is a simultaneous condemning and yearning within the constructions of a "border of self" along with "basic assumptions" that exist within the fears of Kester as a Caribbean black subject in the South, Bria and I's usage of New York aggression and "New York Jamaican", and the idea that the smells of African food may "seep into my skin." In turn, as abjection is materialized in the skin, it is also materialized through food, spices, and other commodities.

Disgust as an affect requires us to once again reflect upon Bourdieu's concept of taste as well as Frazier's Super-American. Food, particularly ethnic food, as abjection materialized, is a sign of "something else" from "somewhere else" (Ahmed 2005, 103). For Ahmed and Kristeva, it is the "somewhere else" or "the not" threatening the identity of the subject or the "who I am" and "who we are", which signifies the process of the materialization of the abject and the becoming of what is disgusting (Ahmed 2005, 103). The object is not inherently disgusting, but instead comes to be disgusting through proximity and contact with other objects that have been designated as disgusting through prior social encounters (Ahmed 2005, 103). As such, Ahmed argues that affects work to align the subject and community in "specific and determinate ways", they serve as "the skin of the community", an "effect of the alignment of the subject with some others and against other others" (Ahmed 2005, 104).

If we consider that the disgusting object comes to being through contact and proximity with some thing previously designated as disgusting, we can recall perhaps one 
of the most popular derogatory terms of the late 80 s to early 90 s directed toward Africans mostly by black Americans, the "African booty scratcher"; a term that Ndelo remembered being taunted with as a child. I can even recall in my early adulthood hearing the phrase, "lookin' like Biafra" referencing the widespread images of malnourished children from the Biafran War. Even though the Biafran War took place between 1967 and 1970, the images circulated in the media were some of the first and longest lasting portrayals of modern "Africa" that seemed to permeate the minds of black Americans as they were shared through generations. The usage of these offensive terms by African Americans is reflective of a deeper collective self-hatred of Africa instilled through global white supremacy.

While none of my black American participants explicitly expressed hatred of Africa, the sentiment is more subtly communicated or captured in moments of discussing simple things like travel and food. For instance, in one conversation with a black American on travel, they expressed a very noticeable exciting desire to travel to Europe but stated that they had no desire to travel to Africa, with the exception of South Africa. As I sought deeper reasoning behind this by asking why, since they had not travelled to Europe in the past, and experienced only minor travel outside of the U.S. in general, they could only respond with "just because." I took "just because" to imply that it was "just because" of the popularized myths and stereotypes revolving around Africa, with the exception of South Africa that has been portrayed as more modern and progressive than other African countries. I have found that self-hatred of Africa is not necessarily something that is always outwardly or explicitly expressed, it exists most often as a subconscious inheritance and/or within the ambiguous nature of "just because." 
Irele (2005) seems to capture this deep-rooted rejection of Africa by referencing Toni Morrison's The Bluest Eye, which encapsulates a generational hatred of Africa, blackness and self in which the narrator indicates that one must separate "in body, mind, and spirit from all that suggested Africa" (Irele 2005, 26). Of course, in the case of young Pecola, the main character of Morrison's pivotal work, rejection of Africa and of blackness manifests into a harrowing story of hatred and disgust. Although the depths of The Bluest Eye does not fully play out in this study, the story remains relevant as we discuss not only black, but black immigrant bodies. The attachment of disgust by the media and popular imagination upon black bodies is also notably exemplified through the persistent characterizations of Haitian refugees as dirty, AIDS-infested, "evil" voodoo practitioners and "barbaric" (Marcelin 2005, 213). In conjunction with Grenier, Stepick, Castro and Dunn's (2009) study of Haitian adolescents in Miami, Msia Kibona Clark (2009), a Tanzanian immigrant, contends that black immigrants are often forced to perform black American identities to avoid further marginalization and torment from mainly black Americans. With this, I return to Mrs. Tina who, during our initial interview, goes more in depth in her discussion of black American disgust. As she walked me through her store describing products, she explained the following:

Tina: Okay. This is corn beef

MB: Oh black Americans eat a lot of this same stuff Tina: They do...but they don't come in my storeMB: You think because they don't know- 
Tina: No, no. Let me tell you the difference. You see when a black American comes to the store, they say "oh What's that?" [scrunches face] they have this face, this attitude, [like] "what's that?" You see how you come in here and ask me questions, you want to learn, you ask a question. I like how you come here, you are very professional, you ask me. You see I was doing something, but I stopped because you are coming in. But if you come to my store like "what's that" and you have that attitude [with] me, I don't want you to come here. You have the choice to come or not to come, I'm not upset [either] way. So even though they know...they don't [come in] because you see this peanut [picks up bag of peanuts], it says, "peanut." You go to Wal-Mart, they sell peanut. But African Americans come here, they won't buy this peanut. Even if you show them "peanut" they won't buy it. They will not.

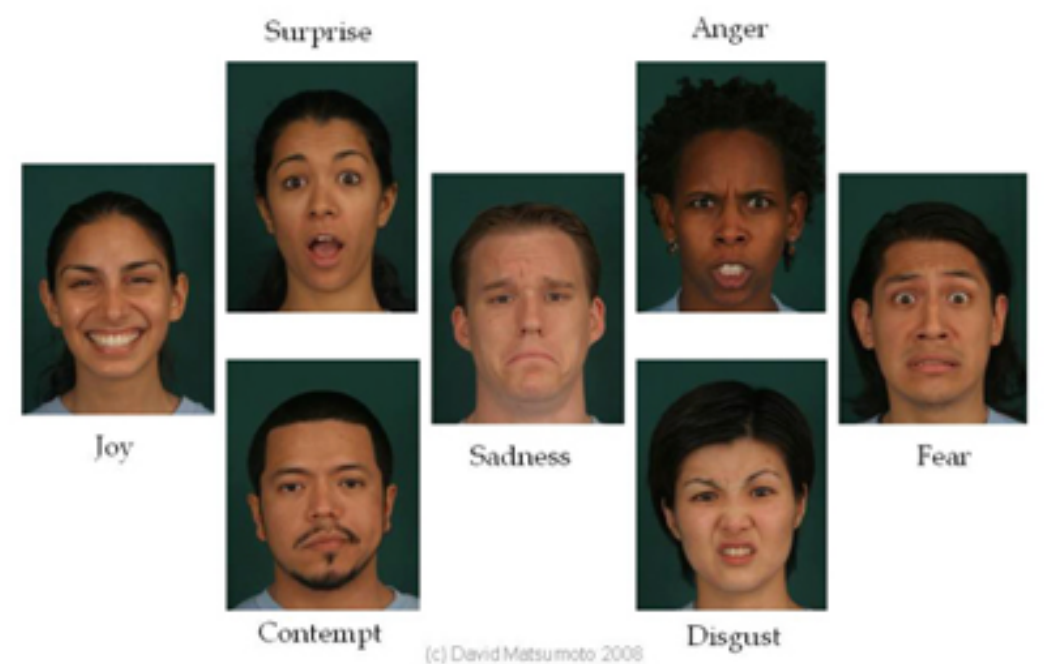

Figure 4.4. "Reading Facial Expressions of Emotion" (Matsumoto and Hwang 2011) 
Several aspects of Mrs. Tina's account expose how disgust is both gauged and further established in the construction of intra-racial and inter-ethnic boundaries. Mrs. Tina notes her ability to read disgust through the facial expressions of black Americans, which she mimics by scrunching up her own face to demonstrate. It appears that these facial expressions and accompanying attitude, suggestive of revulsion, in conjunction with the question of "what's that" signals Ahmed and Kristeva's assertion of the abject as constituted by some thing from "somewhere else." Yet, perhaps a more striking example of this is Mrs. Tina's explanation using the bag of peanuts. Emphasizing that, "it says peanut" recognizes that it is not in another language, and further, that peanuts are one of the most common universal commodities. However, again, because these peanuts are from "somewhere else" and not from Wal-Mart, which is also (sadly) one of the most prominent symbols of America and American identity, they become foreign abject peanuts, and essentially un-American for those subconsciously attempting to be SuperAmericans.

Miller's (1998) A Theory of Shopping frames the act of shopping as various complicated acts of love. Citing Weiner's argument of gender as objectification, Miller contends that through devotion to certain objects, people objectify an "ideal of stable identity" and as such, objects "constitute the materiality of social identity" (Miller 1998, 129). This process often constitutes a sacrificial self for the love of objects that are symbolic of larger social groups (Miller 1998, 130). Accordingly, Miller holds that, "memorials, as with land, or nation, or other forms of inalienable object become the objectification of what are purported to be permanent values" (Miller 1998, 130). For Super-Americans, loyalty to Americana encompasses values that underline a respectable 
American identity. To be fair, I suppose we shall consider brand-loyalty and trust.

However, aligning with Miller, purchasing for brand-loyalty signals a love for the owner or manufacturer of said brand. Therefore, it seems as if Mrs. Tina was also suggesting that many black Americans would rather be loyal to major exploitative corporations, such as Wal-Mart, than to support other black-owned businesses, consequentially sacrificing their black identity for their love of America. This is not just an argument that Mrs. Tina made, but several other participants as well. In addition to Mrs. Tina, Dolawi, another woman and business-owner of Motherland Cuisine from Nigeria, reflected on similar notions when asked both about East Charlotte as well as experiences with discrimination in Charlotte. These sentiments also revolved around food and smell. While Dolawi's account signifies boundary-making, her account also muddies the divisive line that exists between here and "somewhere else" and in turn leads us to consider boundary-crossing.

MB: How do you feel about East Charlotte? And how do you feel about the relationship with black Americans in the area?

Dolawi: Hmm...East Charlotte is growing, [it] can be better and I know that there's been a lot of community involvement like the Taste of the World. I've been in the programI've been featured in the program now since 2010 and I know that they've been helping out ethnic restaurants around this area...so that has been helpful because it brings people that are not from East Charlotte to East Charlotte to see nice restaurants and ethnic restaurants around here. Concerning the black community, we're still not getting [as] much business as I think we're supposed to [from them]. And I think its just because... black communities can be divided in this area, the East Side of Charlotte. The East Side 
can be divided into two: those that have been exposed to other food, other cuisine or cultures, and that means they've visited other big cities like L.A and New York, and Atlanta. You can see they are more open to try other cuisine, other cultures, other food. Those that are local, it's tough to break through to them. But at the same time, I think they are now kind of welcoming to try ethnic food and gradually...its been dragging for a while but we'll get there.

MB: While in Charlotte have you experienced any discrimination?

Dolawi: Omm...not that I haven't, but I'll say an aspect of being a business person, you have to be open to a lot of criticism and at the same time, I believe education helps because a lot of people they criticize your business and you don't know who is judging you. So what I do when people-- I have had some people pass by and say what smells like that? [she squinches her face to mimic disgust] I say, "well that's me cooking goat, it's just like beef! You want to try some?" And fortunately for that person, or customer, they now always come here to get fried plantains and it dawned on me that if somebody that doesn't know about you complains [about] and criticizes you, its just because they don't know better. If they're educated about where you come from maybe they see another part of you. At the same time, being criticized or judged in this community to me is not as much as when you're on the other side of the community, which is a major Caucasian community but to tell you the truth I've had a lot of Caucasian Americans that come in here it's not that bad

In her responses to both questions, it seems that Dolawi has come to process aversion in a slightly different way than Mrs. Tina. However, both women reveal that as business-owners, one of the most present boundaries they encounter is that between their 
culture and food and black Americans. Both also seem to suggest that education and open-mindedness are critical to traversing these boundaries. Dolawi's account is even more telling of how these distinctions exist in the U.S. South by suggesting that the East Side can be divided into two, those that have been "exposed" by having had the opportunities to travel outside of Charlotte and those that have not. Even while events such as Taste of the World allows one to gain such exposure, the majority of the participants are white. The notion of exposure coincides with Bourdieu's idea of possessing cultural capital in which one has both the means and desire to travel along with education that in turn broadens one's taste and distinction. It is then cultural capital that gains particular black subjects respect in the eyes of other black subjects as in this instance, the willingness to try foods from other cultures are markers of respectability. At the same time, avoiding certain places like Sierra International Mart and Motherland Cuisine as well as the associated foods and smells may constitute black American's respectability and claims to citizenship. Therefore, education and distinction may not necessarily serve to traverse boundaries. Dynamics such as these are illustrative of the intricate continuous wrangling of ideals among black subjects and are the heart of what I see as Diaspora Wars. It deserves to be noted that Mrs. Tina's and Dolawi's experiences as African business owners contrasts to that of Caribbean, most notably Jamaican business-owners and restaurants. I would contend that this is most likely due to a longerstanding familiarity with the Caribbean community and culture as well as a rejection of the purely African. In Chapter two, I highlight the proximity of the Caribbean community with the black American community in contrast to the Caribbean-African relationship in Charlotte. Crystals Reggae Club, Jamaican restaurants such as Mama's 
Caribbean, and black American-owned boutiques like Reggae Central as well as the accounts of both Caribbean and African participants attest to the closer relationship between black Caribbean and black American subjects in Charlotte. These sentiments are situational and dependent upon each other's previous and on-going interactions and exchanges in Charlotte and other cities.

\section{A Conclusion: Washing the Wounds}

One of the central goals of this chapter has been to illustrate the ways in which Diaspora Wars are battled out within the local context of East Charlotte. Performances and notions of respectability rooted in attempts to be Super-Americans underscore many of these disputes that take place over food and space/place. Aversion to particular bodies, places, smells and food cause affective triggers of fear, disdain, and disgust that construct boundaries between black subjects in the U.S South. This materialization of boundaries are part of a larger conversation regarding socioeconomic hierarchies among black subjects. Distinguishing oneself from the masses by either refusing to go to certain places and spaces, performing, dressing, and speaking a certain way acceptable to white Americans, or distancing oneself from foreign or un-American bodies and commodities serve as a apparatuses to gain recognition and full citizenship. At the same time, these divisive actions reify social, economic and racial hierarchies.

As an ethno-scape, East Charlotte presents opportunities for black American and immigrant place-making through the numerous establishments of restaurants, small grocery stores, bars and boutiques. While these places represent the growing diversity and cosmopolitanism of the city, this diversity often poses a threat to the safety of loyal long-time white residents as well as the aesthetic of the "beautiful established 
neighborhoods" that have withstood the ethnic transitions of East Charlotte. As such, local, state, and national forces often contest immigrant place-making in the city by seeking to expunge the stranger through enforcing harsh policies. Therefore, the simultaneous and situational embrace of diversity, or situational "welcoming of the stranger" with events like Taste of the World run alongside a permeable fear of the Other that reveals the contradictions of the New South rhetoric and image. Taste of the World also allows mainly long-term white residents to safely remember what East Charlotte used to be and encourages the willingness to "come back", an irony in that much of East Charlotte is currently under-going rapid gentrification. Further, Taste of the World represents one way that primarily white Charlotteans interact with East Charlotte in their own quest for the exotic and the adventure, while black subjects on the other hand, attempt to steer away from these associations in their endeavor to be Super-Americans.

Places such as Crystals Reggae Club have managed to withstand the wave of gentrification, for now. Yet, the unpredictability of violence, aggression, and local law violations often evoke fear among black subjects who are given this option in their search for an authentic Caribbean vibe. For many black subjects, this authenticity comes with the looming possibility of a danger. For respectable black subjects who are encouraged to stay away from "unsafe" black subjects, Crystals is not a respectable place. For some, the intertwinement of "unsafe", "unpredictable" and "aggressive" black bodies elicit fear and/or discomfort. Events such as Afropop quell these fears by offering a Caribbean, African, or Diasporic vibe that is not only safe but welcoming and inclusive for middle and upper middle class black American and black immigrant subjects. While black Americans and black immigrants of a certain class come together in spaces such as 
Afropop, the tastes, sights, and smells of food are not so easily negotiated, at least in the case of Sierra International Mart and Motherland Cuisine. As I discuss in other chapters, these places are often sites of trans-ethnic interaction among Africans as well as intersections between African and Latino populations, however black Americans are less likely to be found in Sierra or Motherland. These restricted boundaries established by food shift as the dissertation unfolds. Nevertheless, it is significant that many of the underlying battles of Diaspora Wars emerged over the eating, the actual buying and selling of food, or the conversations had about food.

Food and smell often become cultural markers for both bodies and boundaries, with bodies themselves again being representing materializations of boundaries. Particular foods and smells and the affinity for or aversion to certain foods and smells are just as much indicative of attained cultural capital as they are pretentious performances of respectability and class. In other words, for some individuals, spicy ethnic foods offer an entrée into the exotic while their knowledge of certain foods or willingness to try new foods are revealing of an attained cultural capital i.e. education, travel, etc. Yet, for others the same foods cause disgust and disdain that wreak of a cultural and consumer nationalism devoted to Americana. The stirring of affects caused by food, smell, and interaction with black bodies are critical to black subject-formation as they are telling of the ways in which these groups establish identities and construct places of belonging. Further, fear, disdain and disgust are often ironically accompanied with love, collectivity and solidarity. The simultaneity of affects are suggestive of the ways in which black subjects navigate the racial and economic hierarchies of the U.S. South and while conflict 
may be inevitable, opportunities for collectivity are just as critical even if they are situational. 


\section{CHAPTER FIVE}

DIASPORA LOVE: INTERSECTIONS, INTERACTIONS, SOLIDARITY, AND THE MAKINGS OF AN ALTERNATIVE NEW SOUTH

A great deal of my research took place during the blazing humid months of Carolina's summer. Lacking the ocean breeze accosted by the Atlantic Ocean and the cool aridness of its western Appalachian sisters, Charlotte's interior location provides for an extremely stifling summer. Carolinas' temperate climate is indeed what brings many of its newcomers, particularly from the North, to the region. Still, neither newcomers nor long-term Charlotteans are ever prepared for the intense motionless heat of Carolina. On one of Charlotte's muggier summer nights, I revisited "SuCasa" at Petra's Piano Bar off Central Avenue in East Charlotte. Repudiating the "white washed" spaces of Uptown and Southeast for their lack of diversity, culture and intellect, Maf, a young black American man, recommended I visit SuCasa at Petra's, one of his favorite monthly events at one of his favorite bars. I met Maf, an advanced Capoeirista, through Capoeira, an AfroBrazilian martial arts form, at the Brazilian Arts Center on Central Avenue, another critical field site. Moving from Miami back to Charlotte, upon discovery, SuCasa immediately filled the void of cosmopolitan diversity and representative "diaspora" that the city seemed to lack. The majority of those enraptured by SuCasa's atmosphere, individuals from around the Diaspora, all attested to the idea that the monthly event provides a sense of diversity, inclusivity, and cosmopolitanism that "feels" like "home." SuCasa emerged as one of the most significant spaces of belonging for young black American and immigrant subjects in Charlotte, designating it as what I see as a "diasporic space." 
Upon entering Petra's, which on this night was even hotter than outdoors, the 2014 Brazilian film, "Ventos de Agosto" played on a large screen adjacent to the front stage. Much of the film's striking cinematography depicts the main Afro-Brazilian characters making love atop a bed of coconuts and/or their semi-nude brown bodies baking in the sun while floating on fisherman boats, offering a profound visual treatise on the relationship between physical landscapes, aquatic space and black bodies in coastal northeastern Brazil. It is a fitting backdrop that speaks to the role of SuCasa and Petra's in establishing connections between black subjects, space and place in East Charlotte. Even with the actual dialogue and sound muted, in order to maintain an emphasis on the music, the images provided by this film as well as others ranging from the iconic imagery of Julie Dash's "Daughters of the Dust" to the documentary "Black Power Mixtape" characterize the visual space of SuCasa. The visual context of SuCasa intentionally sparks inquiry as well as emotion from those who may not be as focused on the music or the dance floor. Meanwhile, artists, performers, vendors and "cultural workers" are busy further constructing the multidimensional aspects culminating the SuCasa experience. Once inside, one may encounter local artist Dammit Wesley live painting on canvas to the right of the door. Dammit Wesley is part of the League of Creative Interventionists in Charlotte, a larger social arts activist network dedicated to creating and preserving black cultural spaces in the city. Of a handful of events in the city, at SuCasa one will most likely spot contemporary dancer Isaiah Derricks prancing around, creating his own individual clearing on the dance floor. I can almost guarantee that I will run into a couple of friends and associates from the Capoeira community, including Maf as well as Janelle, also with the League of Creative Interventionists. In fact, the Capoeira community 
unleashed a broad social network of artists, friends, Afro-Brazilian/other immigrants, and cultural workers dedicated to the establishment, construction and seeking out of meaningful spaces and places of belonging for black and brown subjects. Then, there is Jasiatic, the mastermind behind SuCasa. Oftentimes, she can be recognized by her elaborately tattooed arms, hair color and style that seemingly changes monthly from pink afros, blue bouffants to turquoise corn rows that surf from behind the front door counter to the main stage and through the crowd greeting friends and patrons. I knew right away that Jasiatic, a black-American woman, and her perspectives on diaspora and placemaking would be central to this dissertation. In this chapter and the following, I discuss the ways in which Jasiatic as well as a broader sociocultural network of "cultural workers" like Dammit Wesley, Isaiah Derricks, Maf, Janelle, and others work daily to produce and protect spaces of belonging for black subjects in Charlotte.

We ventured to Petra's outside courtyard area, where another DJ "spins on the ones and twos"; the inside of SuCasa at Petra's normally blasts a range of Hip Hop, Dirty South, new and old school Rhythm and Blues as well as more smooth Afro-Latin Caribbean genres like Bachata, while outside plays a livened variation of Afropop, Afrobeat, Soca, Zouk, Reggaeton, and Dancehall. The majority of people there on this night found themselves moving toward the courtyard in search of any inkling of a night breeze that could deliver them from the airlessness inside. Outdoors, we continued to sweat, dance, and converse in heavy out-of-breath shouts over the music, the humidity arresting our words before they could emerge. Sweating in a red, yellow, and green tricolored net shirt and sneakers, I met a young Jamaican man from Texas attending SuCasa for his first time and his Nigerian friend. While we briefly engaged in conversations 
about Igbo-Yoruba-Nigerian relations, it was difficult to dismiss the invasive heat disrupting our conversation. It began to feel as if we were actually in the Caribbean. The heat did not go unnoticed as the DJ yelled through the microphone that at SuCasa, "you gotta sweat it out!" The Latinas were in "full effect" responding to tunes with quick cut footwork, Caribbean women shifted a mean "dutty wine", West African women grinded to Fela Kuti and searched for "Johny" in the manner of Yemi Alade's hit song their right legs uncontrollably tapping to the beat and their shoulders jumping at attention, while Southern ladies "dropped it like its hot." The handful of white people in the crowd attempting to mimic the latest dance moves were met with strong "side-eyes" by the majority black crowd, one black woman passing by letting out a lamenting sigh before saying, "why are they even here?" As a space that specifically caters to a diverse black crowd, SuCasa represents one of the only spaces in Charlotte in which white people are outsiders, intruders and in turn, do not necessarily belong. During the brief musical intervals, while maneuvering through the extra sweaty crowd, we struggled to catch a breath despite the smothering heat, complimented one another on fashion, glanced at and purchased African printed fashions, artwork, sunglasses, and hand-made jewelry from black American, Caribbean and African vendors. In addition to the mentioned visual and sonic tools already at play in the construction and presentation of this diasporic space, SuCasa provides an arena in which black artists and entrepreneurs can showcase and sell merchandise to other black subjects, another aspect of its material setting. Through these multiple exchanges and exposés, SuCasa embodies Diaspora Love.

Like any relationship, Diaspora Love is both complicated and contingent. Midway through the night, a good friend accompanied by her hometown crew from 
Rocky Mount, North Carolina were discomforted by the overwhelming Reggaeton, Afrobeat, and Dancehall playing outside. They were unaccustomed to this music and dance, and elected to leave, opting for a late-night Uptown eatery. To me, their disdain for, or refusal to embrace a moment of diasporic collectivity signaled one of the many dissimilarities constituting what I call Diaspora Wars. In the previous chapter, I define Diaspora Wars as historical and contemporary sociocultural debates and contestation between black subjects throughout Africa and the diaspora that manifest in the form of cultural boundaries. In Chapter 2, I discern these contestations by presenting cultural differences versus "cultural differences", the latter born through superficial distinctions between those that may be the same racially, but who are racialized and rendered Other in different ways (Queeley 2015a; S. Hall 1990; M. M. Wright 2004). In these previous chapters, I contend that more than often, intra-racial and inter-ethnic quarrels pivot upon notions of respectability and/or the myth of the model minority, both evidenced by affective displays of fear, apprehension, disdain and disgust as well as performances of difference evoked by particular cultural spaces and places in East Charlotte. Respectability, the myth of the model minority and the subsequent composition of "cultural differences" based upon the two are part of a larger schema to gain recognition and visibility in the face of global white supremacy. As such, in accordance with Queeley (2015) these strategies "simultaneously challenge and reinscribe the racial hierarchy and black marginality" (Queeley 2015,6). In this chapter, I argue that in very much the same way that strategies such as respectability and the deployment of the myth of the model minority (re)produce black marginalization and exclusion through on-going 
Diaspora Wars, marginalization and the quest for recognition also produces Diaspora Love.

It is easy to mistake my argument here for suggesting that Diaspora Love signifies an acquiescence to a spatial and temporal sameness and/or homogeneity, in which differences are momentarily released. Instead, I am referencing the ways in which the political framework of blackness, or a collective Black identity has functioned within the U.S. vis-à-vis white supremacy and systemic racism (S. Hall 1997a, 56). Again, I return to Hall (1997) who asserts that the political construction of Black in the U.S. served to dismiss ethnicity in order to combat a common enemy, yet through this dismissal of ethnicity, there emerged an essentialist articulation of a Black identity that silences those other dimensions of black subjectivity and identity (S. Hall 1997a, 56). In accordance with Hall, these are both the "costs" and "strengths" of conceptualizing the notion of Black as essentialist; the "strengths" being the political and sociocultural gains of an essentialist framework of blackness in the U.S. albeit at the expense of those that do not adhere to this framework (S. Hall 1997a, 56). Recognizing and relenting to the "costs" and "strengths" of an essentialist framework is very much part of the Diaspora Love I speak of.

At the same time, Diaspora Love speaks to Hall's question of, "what is it like to live, by attempting to valorize and defeat the marginalization of the variety of Black subjects and to really begin to recover the lost histories of a variety of Black experiences, while at the same time recognizing the end of any essential Black subject?" (S. Hall 1997a, 57). Thus, while Diaspora Love often manifests itself in spaces, places and times rooted in an essentialist Black identity, it is simultaneously "the politics of living identity 
through difference" or "the politics of recognizing that all of us are composed of multiple social identities, not of one" (Hall 1997:57). This chapter is dedicated to examining those spaces, places and times in which these two paradigms of blackness and diaspora serve the construction of meaningful spaces and places of belonging for black subjects in Charlotte.

Emphasizing the notion of Diaspora Love in contrast to Diaspora War calls upon an analysis of the multiple translations and interpretations of diaspora, that of which Brent Edwards (2003) asserts as a "practice of diaspora" in which "diaspora is forged through exchanges across diverse subjects"(Queeley 2015, 6). Having interrogated and demonstrated the social, cultural, and spatial contradictions of the New South, in this chapter I build upon this discussion by examining the ways in which sociocultural and spatial marginalization of black and brown subjects in Charlotte yield spaces and places of mutual recognition and belonging particularly in East Charlotte. I contend that varying practices of diaspora manifest in space, place, and forms of material culture and material setting that are critical to forging a black American and black immigrant collective identity. Those scholars, theories and interpretations of diaspora within the polar schools of thought deemed either essentialist or anti-essentialist are central to my argument.

Like Jacqueline Copeland-Carson (2004), whose ethnography explores African and African American subject formation at the Central Wellness Center in Minneapolis, instead of dismissing essentialist perspectives, I endeavor to "proceed from the assumption that any act of human cultural creativity is a legitimate area of academic study" (Copeland-Carson 2004, 22). By introducing and discussing spaces and places of Diaspora Love more in depth, I explore the role of what I see as an affective kinship 
based upon Alaì Reyes-Santos' (2015) notion of a transcolonial kinship model informed by an affective matrix of "sympathy, empathy, harmony, compatibility" as well as notions of "brotherhood, friendship, national family and extended family" in the Antilles (Reyes-Santos 2015, 5). Reyes-Santos (2015) utilizes the term transcolonial instead of transnational to delineate nineteenth-century "alter-native community formations that contested the racialized violence endemic to European imperialism and creole nationbuilding projects" (Reyes-Santos 2015, 7). Further, the usage of transcolonial versus transnational returns agency to those black and brown subjects as it establishes a horizontal relationship between these groups in place of a vertical power structure of European colonial nations and their colonies, implied by the usage of transnational (Reyes-Santos 2015). I see particular East Charlotte spaces and places as evocative of and erected through an affective kinship among black and brown subjects that in turn, fosters an alternative New South that responds to the regions sociocultural and racial contradictions.

In a similar manner that Reyes-Santos presents the transcolonial-alter-native community established through kinship, I would like to assert an East Charlotte transethnic-alternative New South established through affective kinship. This assertion (re)places the agency of constructing an image of the New South in the hands of its diverse black and brown populations, not necessarily within the hands of policy-makers nor corporate entities. In other words, an Alternative New South represents a horizontal happening and making in constant process that contrasts to the vertical power relationships of corporate culture and neoliberalism to black and brown people that have historically defined the city. Whereas much of the transcolonial kinship model that 
Reyes-Santos presents centers primarily on an intersection of Antillean culture and political economy, [culture and political economy are equal factors in this study], I consider material culture and setting as triggers of affective kinship among black subjects.

Miles Richardson (2003) utilizes the theories of George Herbert Mead to note that "people respond to objects on the basis of what those objects mean and that the meaning of those objects arises out of the negotiated experience of social interaction" (Richardson 2003:75). In turn, material items are used to "recall, reconstitute, and communicate our experience" (Richardson 2003, 75). For black immigrants and black Americans in Charlotte, material items as well as the act of shopping and experience of being in particular places are critical signifiers and producers of black subjectivities and identities. Further, material items are equally significant in constructing spaces and places of belonging as well as establishing and designating particular place-identities (Miller et al. 1998:19). I continue to build upon these central theories in the following chapter with more consideration given to embodiment and alterity. This chapter focuses primarily on two of East Charlotte's longest standing black-owned businesses and the ways in which Diaspora Love is fostered and manifested through space, place, and material culture based upon diverging articulations, interpretations, and epistemologies of Diaspora that nonetheless place agency in the hands of black subjects in the constructions of an Alternative New South. 


\section{Essential Love: The Annual Juneteenth Festival of the Carolinas, an Afrocentric Family Affair in the House of Africa}

Pap, a Senegalese immigrant has been in Charlotte for more than twenty years. For much of that time, he has owned the House of Africa located on Thomas Avenue right off of Central Avenue. In fact, House of Africa is among one of the longest standing businesses on this principal stretch of Central Avenue that has undergone significant gentrification in the last ten years. Just around the corner, among the string of relatively new hipster restaurants and bars on Central, is also Reggae Central, another long-standing black-American woman owned boutique and Mama's Caribbean Grill and Bar, a Jamaican-owned restaurant. Reggae Central opened in May of 1996, followed by House of Africa in June of the same year, with Mama's Caribbean opening about six years later. Thomas Avenue and this small corridor of businesses was also the site of the first Annual Juneteenth Festival of the Carolinas initiated by Pap more than twenty years ago.

While Juneteenth emerged as a critical field site early on in my research, the summer of 2017 marked the festival's twentieth anniversary in Charlotte, and I was able to sit in on several of the planning meetings held inside of the House of Africa as well as participate and volunteer in the festival and its preceding events over the week. The Annual Juneteenth Festival of the Carolinas celebrates the African American holiday Juneteenth also known as Emancipation Day, which commemorates the June $19^{\text {th }} 1865$ announcement of emancipation made to slaves in Texas. Pap informed me that he was 
motivated to begin the festival in Charlotte after living and travelling throughout the U.S. and noticing that other cities held Juneteenth Festivals but Charlotte at the time did not. As the Festival grew over the years, it moved from Thomas Avenue, in front of House of Africa to Independence Park in the Elizabeth neighborhood of East Charlotte, not far from the House of Africa location. However, for the $20^{\text {th }}$ Anniversary, the Festival returned to its roots in front of House of Africa, but now expanding from Thomas Avenue into the perpendicular cross street of Commonwealth that runs parallel with Central. The Festival is compiled of about four days worth of activities, including one final planning meeting that Wednesday, an opening banquet held on that Thursday evening, a summer day camp at a local elementary school on Friday, and then the actual festival on Saturday and Sunday. Yet, as Pap and the House of Africa essentially bore the Juneteenth Festival of the Carolinas, it is necessary to begin with a discussion of the role that these two actors play in fostering Diaspora Love primarily between the black American and African community.

In Chapter Two, I discuss Pap's and I's exchange regarding his identification. There, he asserts that while he does not have actual family members in Charlotte, he has his "African American family." When asked if he could confirm African Americans as meaning "black Americans" he corrected me by firmly stating, "do not call them black, they are Africans born in America, that's the only difference between you and me." I suggest that Pap's identification underlines an interchangeability of "Blackness" with "Africanness" in that anyone who is Black is African, making "Blackness" a "sense of cultural principles and memory which happened to be manifested, in part, through skin color" in conjunction with Jacqueline Copeland-Carson's participants in her ethnography 
of the Cultural Wellness Center in Minneapolis (Copeland-Carson 2004, 37). This principle understanding of blackness as interchangeable with Africanness characterizes the place identity of House of Africa as well as the familial relationships that derive from the space as they are centered in both actual and mythological ideations of Africa. Upon entering the House of Africa, one is immediately overwhelmed by the numerous large wooden statues and intricately carved wooden furniture covering all but the small path leading one into the interior of the boutique. In many ways, it is more like an art gallery than a home décor store and apparel boutique. Although I had visited House of Africa several times prior to my research, I recall one of my first visits during preliminary research walking around the store when a young black family with a small baby entered the store. The baby obviously startled by the size and array of statues began to cry with fear. At this moment, I began to ponder the very basic and immediate affects that the store's material setting evokes. With the exception of a few extremely large furniture pieces and statues, all of the small to large wooden hand-carved statues in House of Africa are for sale in addition to jewelry, herbs/teas, clothing, music, books, and other accessories oftentimes at relatively steep prices. Or as Pap would have me say, there is something in every price range. As with other East Charlotte shops and boutiques, the majority of Pap's goods come directly from Africa, and most times are goods that he personally brings after weeks-long trips to the continent back to sell in either Charlotte or his other shops in New York City. Thus, House of Africa is just as much of a transnational space as the other spaces and places discussed throughout this dissertation. It is arguably just as much a production of neoliberalism and globalization that epitomizes Uptown's corporate culture. However, in contrast to Sierra Leone 
International Mart or Motherland Cuisine, House of Africa caters predominantly to a middle and upper middle class African American sector and given its location, some young white hipsters who want to feel the "authenticity" of Africa. This connection is equally embodied through Pap's own social network.

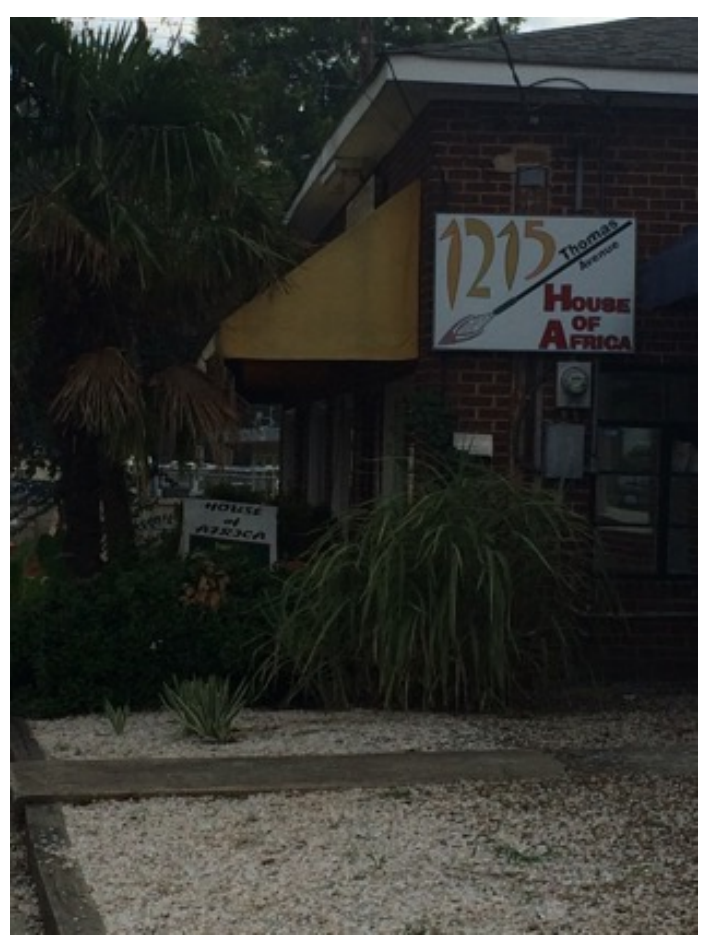

Figure 5.1. Outside of House of Africa, on Thomas Avenue. Photograph by Author. 


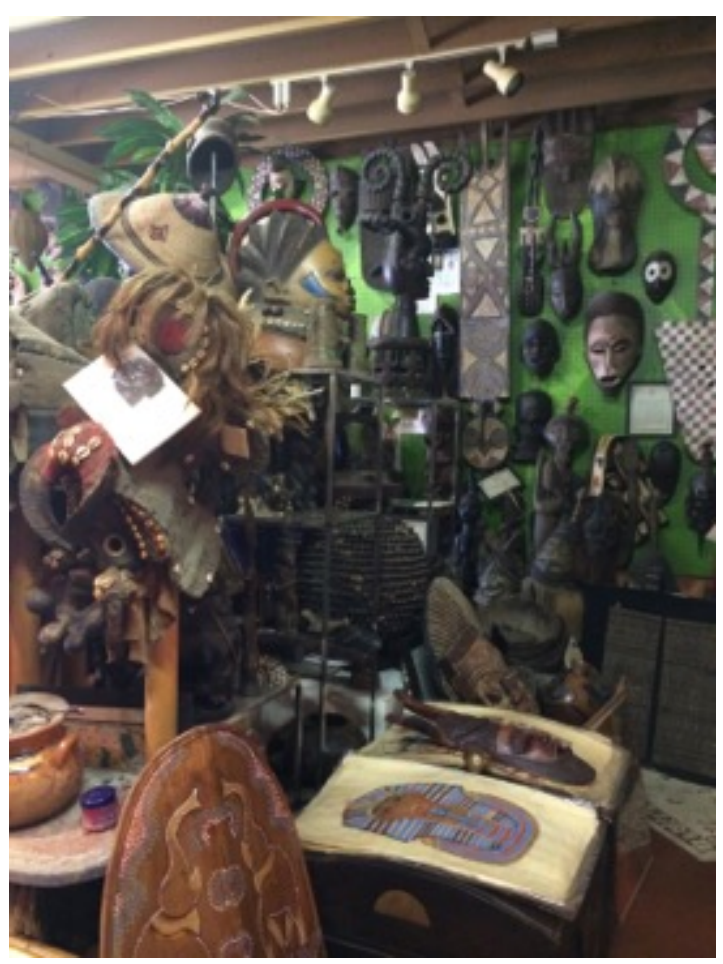

Figure 5.2. Inside the first portion of House of Africa. Photograph by Author.

At the beginning of one Juneteenth planning meeting, as we all seated into the

small living area of the House of Africa, occupied by a large couch, loveseat, and two large African carven leather chairs with a large animal horned chandelier hovering over, I met Sankofa. Sankofa is an older black American woman, who according to Deedra, another older black American woman, is "very knowledgeable about Africa." Indeed, when I first met Sankofa in April at one of the first planning meetings, she informed me that she has lived in Charlotte over the last twenty years after moving from New York City. In the last few years, she initiated the Harambee Cultural Center located on North Tryon in East Charlotte. Sankofa established the center in order to share her own knowledge derived while visiting and studying the continent of Africa with young black youth as well as adults. Among the historic and sociocultural lessons offered at the Harambee Cultural Center, Sankofa shares the teachings of Ifa, a Yoruba based religion, and also informed me that she studied astrology in Egypt under Haile Sellasie's 
astrologist, which she also shares at the Center. In our first meeting, while taking a seat on the loveseat adjacent to my small spot on the larger couch, Sankofa looked mesmerizingly around at the living area and all of the artisanal work surrounding, in conjunction with the African music playing in the background, she commented that House of Africa is a "sensory overload." In another instance, Sankofa remarked that it is “a literal House of Africa." As I unravel my time at HOA and Juneteenth, it becomes clear that Sankofa and the other predominantly black American women are just as equally critical to the planning of Juneteenth as they are to constructing the multiple tapestries of House of Africa. Providing "sensory overload" as a "literal House of Africa", the boutique in many ways becomes an African home-away-from-Africa for Black Americans in Charlotte. This represents one way in which particular epistemologies and imaginations of the African Diaspora, Afrocentrism in this case, are mapped onto certain locales (Nassy Brown 2005; Nassy Brown 2006:73,75). Black scholars in the late 80s and early 90s, most notably Molefi Asante and Maulena Karenga attempted to construct an epistemology centered within principles of African philosophy in order to decentralize Eurocentric thought, epistemic practices and categorizations (Stoller 2002, 67). According to Asante (1993), “Afrocentricity is a perspective which allows Africans to be subjects of historical experience rather than objects on the fringes of Europe" (Stoller 2002, 68). I argue that the central principles of Afrocentrism are mapped onto HOA and the Juneteenth Festival.

In addition to the clientele I witnessed enter House of Africa intermittently over the last 18 months, which was at times sprinkled with some white and ethnically ambiguous customers, the majority of clients were black as were the women that planned 
Juneteenth. Keeping in mind the price of merchandise, as well as the particular affluence and notoriety House of Africa and Juneteenth has gained, these were mainly middle and upper middle-class black Americans. Even if we speak solely of Sankofa, the economic capacity it took for her to gain knowledge of Africa, Ifa, and East African astrology through travel and to later open a center dedicated to sharing this knowledge, speaks to her socioeconomic status. Oftentimes attaining the desire and socioeconomic status to travel and to learn becomes the task of the survivor. A product of parents and grandparents that endured Jim Crow and the Civil Rights Movement, and even slavery as my great aunt was born a slave and lived long enough to deliver her testament to my mother, I undoubtedly considered the notion of myself a survivor. However, I cannot say that I ever processed the notion beyond my parents' "what we had to go through" lessons or the popular Destiny's Child song. The theme of survivor emerged several times during my observations at House of Africa, mostly during the planning of Juneteenth. Yet, in these instances, survivor did not just signal surviving slavery, Jim Crow, and the Civil Rights Movement. Underlining the usage of this notion at House of Africa was the idea that black Americans in particular were among the strongest of black subjects that persevered the Trans-Atlantic Slave trade evidenced through black Americans position as purveyors and influencers of a global black popular and political culture. Indeed, this notion of survivor does signify surviving the Middle Passage and slavery, however, I am drawn to the emphasis on survivor that equates it with black American cultural dominance. Yet, these ideations of our collective survivorship as African Americans fail to mention the significance of U.S. hegemony, in which black Americans "incorporate and refashion" Western practices as their own making even our most "traditionalist" 
practices part of a proliferation of and acquiescence to the same economic systems that ripped us from Africa in the first place (Clarke 2006). Now, searching for our roots through DNA testing is among an array of ironic souvenirs including keepsakes, statues, bracelets, garments, tourism, and even actual people that serve to solidify our connection to a distant past and place, Africa.

Venturing into and being apart of the House of Africa in many ways presents the opportunity to travel to the "motherland" locally and feel Africanness away from Africa. This is the privilege of the Black American survivor. The Black American privilege I speak of in no way coincides with nor reflects that of white privilege. Instead, Black American privilege embodies the paradox in which the U.S. has "shaped the relationship of African Americans to people of African descent elsewhere" allowing us to define how other Black subjects should identify and/or shape their histories (Thomas and Clarke 2006, 13). Simultaneously, there exists what Henry Louis Gates Jr. suggests as a middle class African American sentiment of "the guilt of the survivor" that emerges as black Americans' feelings of alienation inflicted by white society compel them to seek and maintain a "cultural fidelity" to blackness through the purchase of Afrocentric goods (Stoller 2002a, 70).

Further, Kwame Appiah asserts, "African American culture is strongly identified with a culture of poverty and degradation... you have a greater investment, as it were, more to prove [if you are middle class], so Kwanzaa and kente cloth are part of proving you're not running away from being black, which is what you're likely to be accused of by other blacks" (Stoller 2002a, 70). In turn, middle and upper middle class black Americans imagine themselves through objects that "co-produce" a reality, that makes 
the act of shopping an integral part of place and identity" wherein "particular parameters of identity such as the family, class, ethnicity, and gender" are reconstitutued by shopping sites "through the addition of particular distinctions which emerge from the experience of these spaces" (Miller et al. 1998, 19). The interaction between black Americans and even white Americans between the objects, or merchandise in House of Africa affirms and alleviates for black Americans, their longing and fidelity, while affirming white Americans acceptance of Africans...and more importantly of "blacks."

While an Afrocentric lifestyle provides a sense of ethnic pride for black Americans, the marketability and commodification of culture often dilutes the cultural distinction of goods as the distinction of goods then lies in them and us being “'African'-a monolithic whole in the Afrocentric imaginary" (Stoller 2002a, 82). According to Paul Stoller's (2002) ethnography of African markets in Harlem, marketing Afrocentric goods establishes a link between Africa and African Americans in their search for cultural meaning and personal meaningfulness that centers upon a reduplication and simulation of a monolithic Africa. In this simulation, distinction between real and unreal becomes superfluous, and when "the real is no longer what it used to be, nostalgia assumes its full meaning" (Stoller 2002a, 84). Therefore, nostalgia becomes "energized" as an ideal Africa is articulated through Afrocentric signs where in "myths of origin and signs of reality" rooted in a distant past are proliferated. In addition, entrepreneurs and traders within Afrocentric markets, often create a selling environment that "reminds clients of Africa." This involves trade-marking goods, burning African incense to "evoke the motherland", addressing shoppers as "brother" or "sister" to simulate African/African American kinship and solidarity, and contextualizing 
themselves as African among African Americans, all of which are "good for business" while also reifying African American links to Africa (Stoller 2002a, 87). Positioning House of Africa as a place of business that is also an "African home" away from Africa for African American clients and friends/ "family" of Pap, I consider the role of "cultural fidelity", marketability, simulation/reduplication, the notion of survivor and affective dimensions like nostalgia and kinship on the construction of House of Africa and the Juneteenth Festival as Afrocentric spaces and places of belonging and the implications of this space on black subjectivity and identity.

The notion of survivor and the conjoining quest for identity, fidelity, and ancestral roots through the simulation/reduplication of Africa underscore "two of the most powerful ideological narratives of U.S. black imaginaries" (Clarke 2006). The "slavery narrative" and the "African nobility narrative" were crystalized in the mid-1960s among black nationalists and black Americans that have sought to "reinvent" themselves as both Africans (through descent) and U.S. Americans (through lived experience) (Clarke 2006, 133). Based on notions of ancestral and biological commonalities, the slavery narrative recounts how Africans were torn from Africa, enslaved in the New World where they continued to endure racial oppression yet despite these conditions they persisted, created diverse cultures and maintained fundamental connections to an African past (Clarke 2006, 134). Underlining this narrative is "the symbolics of blood and diasporic displacement and suffering" or in other words, the survivor (Clarke 2006, 134). The African nobility narrative on the other hand, prioritizes pride of black heritage and while recognizing slavery, this narrative emphasizes that "African Americans are not merely victims of slavery but descendants of an African noble and religious elite who are, at the 
present time, culturally imprisoned in the racist United States" (Clarke 2006, 134). Both the "slavery narrative" and the "African nobility narrative" are active components in the planning of Juneteenth Festivities.

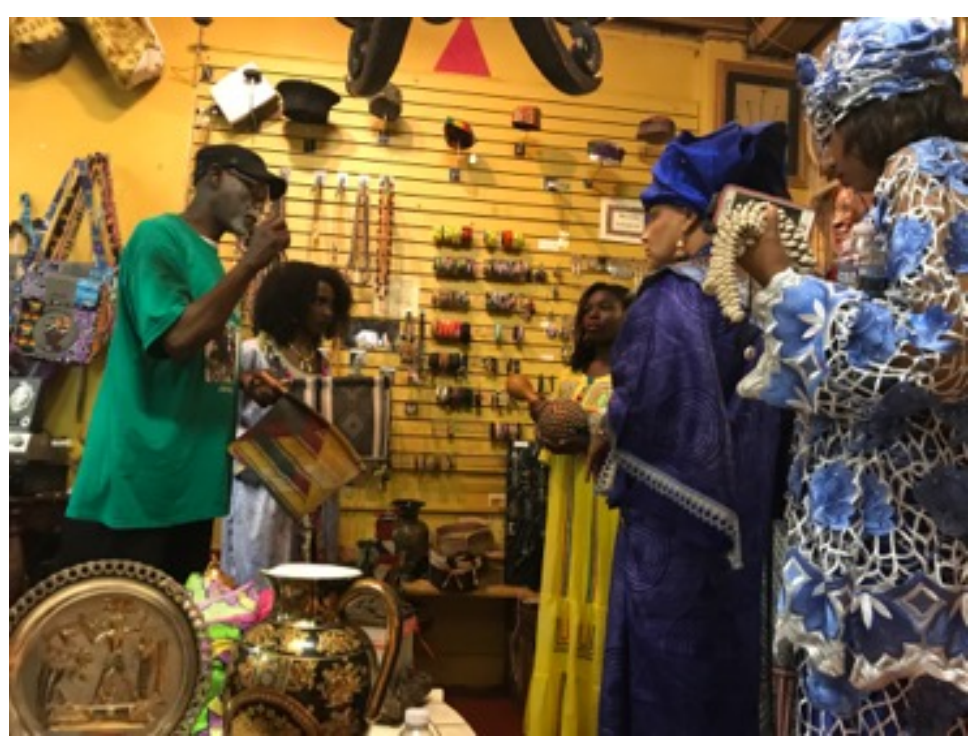

Figure 5.3. Mrs. Olita (African American) and Waly (Pap's brother, Senegalese) briefly debate the usage of fans and chew sticks in the Juneteenth Fashion Show. Waly suggests that in order to be truly representative of African women, we (I participated in fashion show) should carry the fans, Mrs. Olita disagrees. All of the models were African American. Inside House of Africa. Photograph by author.

Since this was the $20^{\text {th }}$ Anniversary of the Juneteenth Festival of the Carolinas, the committee added new celebratory rituals and details to the list of events. One was that they wanted to emphasize and showcase the "Juneteenth Babies", millenials that have grown up under the umbrella of Juneteenth, or whose parents were heavily involved in establishing and planning the original festival. I return to the significance of "Juneteenth Babies" later in the discussion. It is also worth mentioning here that Juneteenth 2017 took place on the last weekend of Ramadan, which also factored into the planning as the Nation of Islam holds a notable presence in Charlotte and at the Festival. 
Note that I specify the presence of the Nation of Islam but not necessarily the larger Muslim African community, although Pap himself is a practicing Muslim. The second was a special extravagant opening night banquet, which Sankofa was in charge of planning. Sankofa is an artist and was also in charge of the stage design at the actual festival. Unfortunately, the evening of the banquet coincided with another yearly LatinCaribbean Festival that I would not have another opportunity to attend. However, I was still treated with the unveiling of Sankofa's master lay out of the evening, which according to the final meeting went beautifully as planned.

For the unveiling, we all sat around in the small living space in House of Africa ready to be captivated as Sankofa painted an intricately detailed story of "A Cruise to Nubia," the banquets theme. Sitting on the couch, her long legs crossed, and with long wooden Ankh carved earrings dangling right beneath her African printed headwrap that matched her cape-like African printed dress, reading from a legal pad, Sankofa began with, "imagine that we are about to board a ship" that will take us on a voyage to Nubia. Sankofa envisioned that upon entering the banquet, guests would receive an "African" passport, a name change, currency, and most important, acceptance and blessing by the Kings and Queens of Nubia and Egypt as we return to claim our throne. The ship would stop along the way to pick up our "Caribbean Brothers and Sisters" as the Kings and Queens, performed by members of the planning committee, would then share history with the passengers as they embark on this journey to Nubia.

Upon arrival, the Kings and Queens would show the passengers their homeland. Sankofa then interrupted her story in order to clarify some parts of her thematic idea. According to Sankofa, in the U.S, black Americans have reestablished/realized 
themselves as Kings and Queens, and they are now returning to see how their homeland has changed from when they left. For Sankofa, it was important that the event is "historically sound" yet equally important that the passengers realized that "we are already African royalty here [in the U.S]." Affirming our royalty, Sankofa asserted that when the colonists selected African slaves, they chose the "best stock" and "the best of the best" to be brought to America. According to Sankofa, THIS is why African American culture is so powerful and so dominant globally, reiterating that the BEST landed here in the U.S. She reminded the women of the committee that they will still stop along the way to pick up their brothers and sisters in the Caribbean. Once the passengers realize their royal heritage, there would be a collective response of, "now we know who we are."

Deedra interjected to recommend that as they all travel on this imagined journey, that the music and food shift along the way, slightly joking, they could "move from Fried Chicken to Caribbean food." Rose, another woman on the committee, spoke up to confirm that the banquet would indeed be catered, serving Caribbean and African food. Sankofa continued describing the planned visuals of the event. She noted that on a large screen, images of the Middle Passage would be displayed while those in attendance were required to dress as "Kings and Queens." Following the journey, there would be a procession in which the designated Kings and Queens of Nubia and Egypt would ask, "will the kings and queens of the African American experience stand and come forward?" They would go on to ask, "how does it feel to know where you come from" to which the black American kings and queens would respond, "I feel liberated" a statement that coincided with the end of slavery and thus significance of Juneteenth, yet as Kings 
and Queens, slavery is decentered from the narrative which for Sankofa made "Juneteenth all the more powerful." According to Sankofa, they would have Caribbean Kings and Queens as well, these Caribbean kings and queens would be seated in a designated area since it was important to "honor them as well." The Caribbean kings and queens would join the African Americans, and "now they too will know that they all come from the same stock." This would be the journey to Nubia. As the women reflected on the ending of the thematic events of the evening, one of the women let out in a longing voice, "that is beautiful." Shortly after Sankofa finished her description of the itinerary for the banquet, Mrs. Olita, a fair complexioned black American woman who exuded an old school Charlotte black middle class and respectability that commanded attention and obedience as she referred to herself as an "educator", reminded the women that they needed to practice James Weldon Johnson's "Lift Every Voice and Sing" otherwise known as the Black/Negro National Anthem in preparation for the opening of Saturday's festival. She brought copies of the lyrics to hand out to everyone, one of the younger women boasted she did not need a copy because she attended an HBCU. We sang the anthem one time while sitting before Deedra instructed us to stand and sing. So we stood and sang together. Pap came out of the office to join, his tall lanky body towering over the women, he raised his voice to emphasize the last line of the song, "true to our God, true to our native land."

Truth to our native land; our longing and desire for Africa; our trip to Nubia; our royalty; it is beautiful, isn't it? Our imagined trip to Nubia while sitting in our Africaaway-from-Africa-in Charlotte seemed to trigger the affective dimensions of a nostalgic and romantic past of "when we were kings." Yet, to say it is a false imaginary is an 
understatement. Both the "slavery narrative" and the "African nobility narrative" emerged throughout Sankofa's tale of proposed events for the opening night banquet. Here, the "slavery narrative" coincides with the notion of the "survivor" as suggested through Sankofa's emphasis on the "best stock" and the "best of the best" being brought to the Americas, specifically to the United States, with the global promulgation of Black American culture being both evidence of survival and proof of "stock." Our Caribbean "brothers and sisters" appear to be a mere side note and there is no mention of the majority of Africans that were brought to South America. In many ways, this sort of parenthesizing of Caribbean blacks and outright exclusion of Latin American blacks underpins Michelle Wright's (2015) Middle Passage Epistemology, which again is the linear trajectory of surviving the Middle Passage, slavery, etc. that has and continues to define blackness in the U.S. With Wright in mind as well as my arguments in Chapters Two and Three, I wondered if Afro-Latin populations were excluded from Sankofa's narrative because they are not considered black; is Latin American blackness equally interchangeable with Africanness in the same way as that of black Americans and Caribbeans, based upon Sankofa's narrative? In turn, blackness was not questioned pertaining to Caribbean populations, although the gravity of their survivorhood seemed to be.

It then seems to be only under the guidance of their big African American brothers and sisters that our Caribbean brothers and sisters can realize their ascendance to nobility thus reestablishing a direct link between African Americans and Africa that excludes the histories and experiences of other black subjects. Moving along on our journey to Nubia we somehow bypassed the ocean, seas, and many rivers of Western and 
Central Africa, where the majority of our ancestors most likely derived and where longterm sub-Saharan African civilizations reigned even before or at least alongside Egypt and Nubia. It seems then, our "cruise" detoured Ghana, Mali, Congo etc. in order to avoid positing or revisiting slavery as the beginning of African American history. This is furthered by Sankofa highlighting the collective statement of "I feel liberated" not just as a representation of liberation from slavery, but being liberated through knowledge of a royal African heritage, and in turn, a noble history. Just like the usage of "survivor" and "slavery narrative" in this context, the African nobility narrative still reifies Western imperialist ideations, one of which being a romanticized imagery and ideological conquest over Egypt in particular. Black Americans subscribed longing for and instillation of Egypt as our history versus Sub-Saharan African civilizations symbolize black Americans' quest for acceptance by white society as Egypt has been whitened and detached from continental Africa in Eurocentric thought. Nevertheless, Sankofa's "Cruise to Nubia" echoes and ascribes to the very fundamentals of Afrocentrism; the kente clothed thread stitching together the House of Africa, Juneteenth, and an affective kinship. Again, Afrocentric epistemology recenters Africa and African culture within a black nationalist framework, which was in many ways conceptualized in opposition to what had historically been a Eurocentric thought and way of life. Central to Afrocentrism are the principles of Kemet, or those ideals derived of ancient Egyptian civilization (Stoller 2002a, 68). Yet, as I have attempted to display, one of the primary criticisms, among many, is that in its ideological attempt to oppose Eurocentrism, Afrocentrism oftentimes reinforces Eurocentric conceptualizations (Gilroy 1993). Still, keeping in mind the arguments of Copeland-Carson as well as Hall's assessment of the 
"costs" and "strengths" of a Black political identity in the U.S., here I emphasize the strengths of Afrocentrism as an instrument in place-making and grounding "family values" in the House of Africa.

In our quest for Africa, an identity, dignity, and an ancient past, African immigrants and our patronage of their businesses serve to solidify an interchangeable Blackness and Africanness. In accordance with Stoller's (2002) ethnography of African markets and Copeland-Carson's (2004) ethnography of the Cultural Wellness Center, African leaders and merchants help solidify an identity of "Africans born in America" in a similar manner as Pap identified himself and I. At the same time, we must keep in mind that these businesses are catered to fulfilling this void for black Americans and garnering black American patronage. Nevertheless, the relationship between black Americans and certain African immigrants and African spaces serves affirmations of Blackness, Africanness, and cultural fidelity. This must be taken alongside the fact that the presence of African immigrants can also ignite Diaspora Wars by foregrounding black Americans' claims to respectability and superiority as I discuss in Chapter Four.

Further, for a certain class and status of black Americans, African Americans like Sankofa with an attained knowledge of Africa can also attest to black Americans' Africanness. Even if Sankofa's knowledge contributes to myths of a romantic past, myths do eventually become factual within the imaginary (Heffernan 2001). Sankofa's Africanness is confirmed by Pap's presence, approval, and acclamation of her banquet plans and stage design, her own construction of space that confirms these narratives. Pap then emerges as an African paternal figure while the mainly black American women of the planning committee become maternal figures that together construct the familial 
space and identity of House of Africa and the Juneteenth Festival. Pap, as an African immigrant, Sankofa, "knowledgeable of Africa" and those objects composing the space of House of Africa and Juneteenth certify "narrative identities", "constituted by a person's temporally and spatially variable place in culturally constructed stories composed of (breakable) rules, (variable) practices, binding (and unbinding) institutions, and the emultiple plots of family, nation, or economic life" albeit that "narratives are not incorporated into the self in any direct way; rather, they are mediated through the enormous spectrum of social and political institutions and practices that constitute our social world" (Miller et al. 1998, 20).

In Charlotte, narrative identities among black immigrants and black Americans are mediated through those political institutions and economic factors that marginalize groups, but also through social and cultural organizations and business that bring them together. Like past Juneteenth Festivals in Charlotte, notable African Americans are sure to attend, including local pastors, political leaders including those runnng for office, and other African American organizations like the Nation of Islam, the Nuwabian Nation and Five Percent Nations. It is also a space in which black American and black immigrantowned businesses from around the region can showcase and sell their services and products. Together, they construct an American American community of "creative nostalgia" just as much as they establish a reality of black economic and political subsistance, power, and recognition. Another critical moment in the $20^{\text {th }}$ Anniversary was a special ceremony in which former Mayor Jennifer Roberts, who lost much respect from the African American community after her mishandling of the September protests and failure to fulfill many of her initial political promises to the community took the 
stage. See Figures 5.7 and 5.8 below. Met with boos from the black American crowd as she approached the stage, interrupting a black youth African dance performance, the crowd eventually calmed down for Mayor Roberts to give Pap a "key to the city" and to commemorate Juneteenth Festival of the Carolinas as a city holiday. This certified Pap as a leader in the African American community as well as the significance of House of Africa. Through this recognition of the black community as a whole, the moment revealed the agency and power of the black American community. 


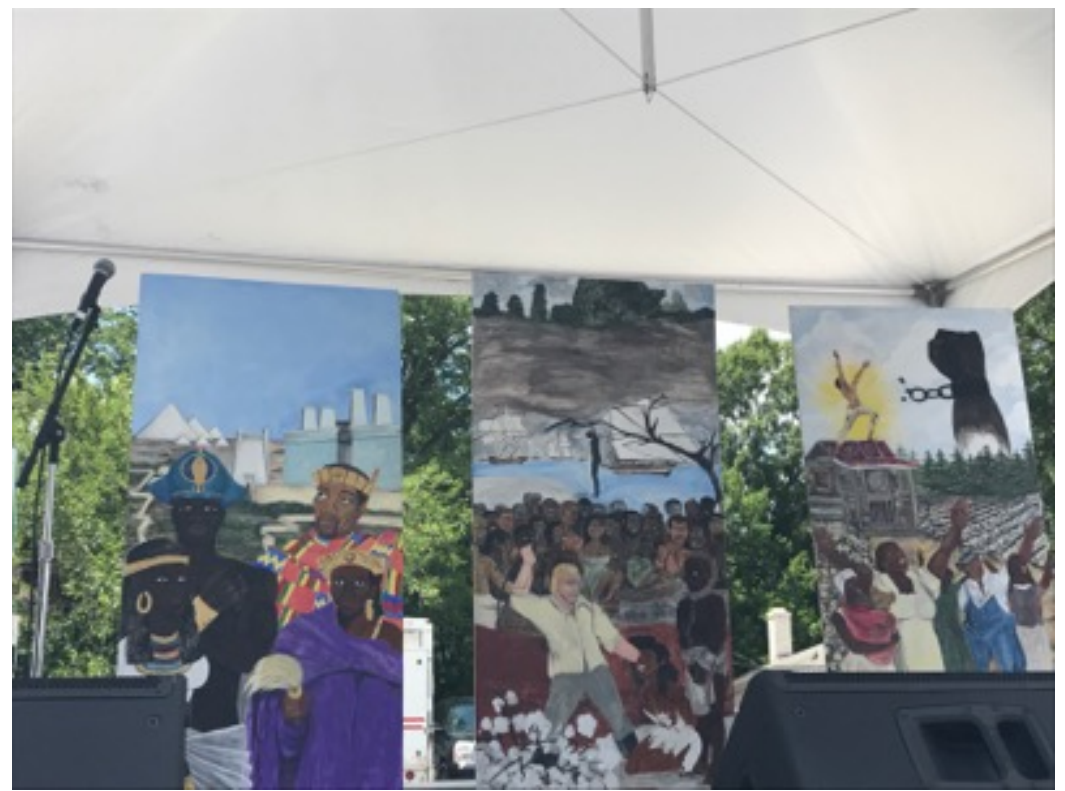

Figure 5.4. Sankofa's stage design and artwork on Juneteenth's main stage. To the far left are depictions of African nobility in Africa. In the middle, a scene from slavery. To the far right are depictions of liberation from slavery. Photograph by author.

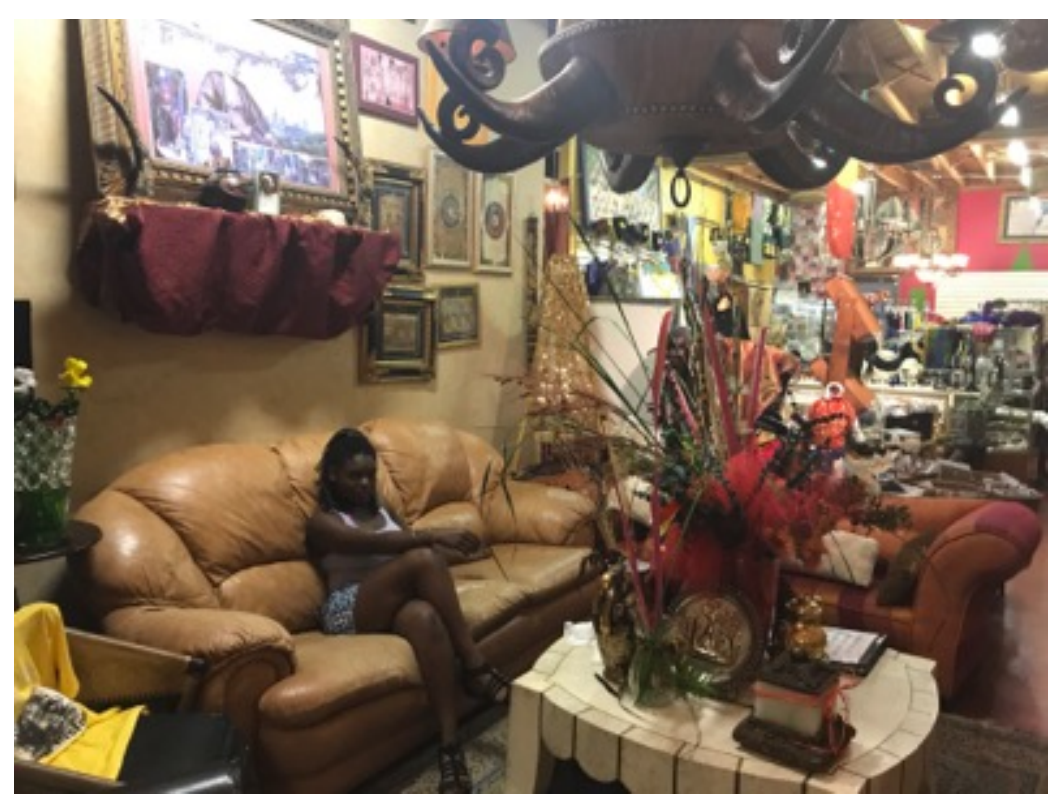

Figure 5.5. One of the "Juneteenth Babies" and now, employees of HOA poses in the Living Room of the House. On the mantle above the living area is a photograph of Pap, the paternal figure reigning over the boutique and shop. Photograph by author. 


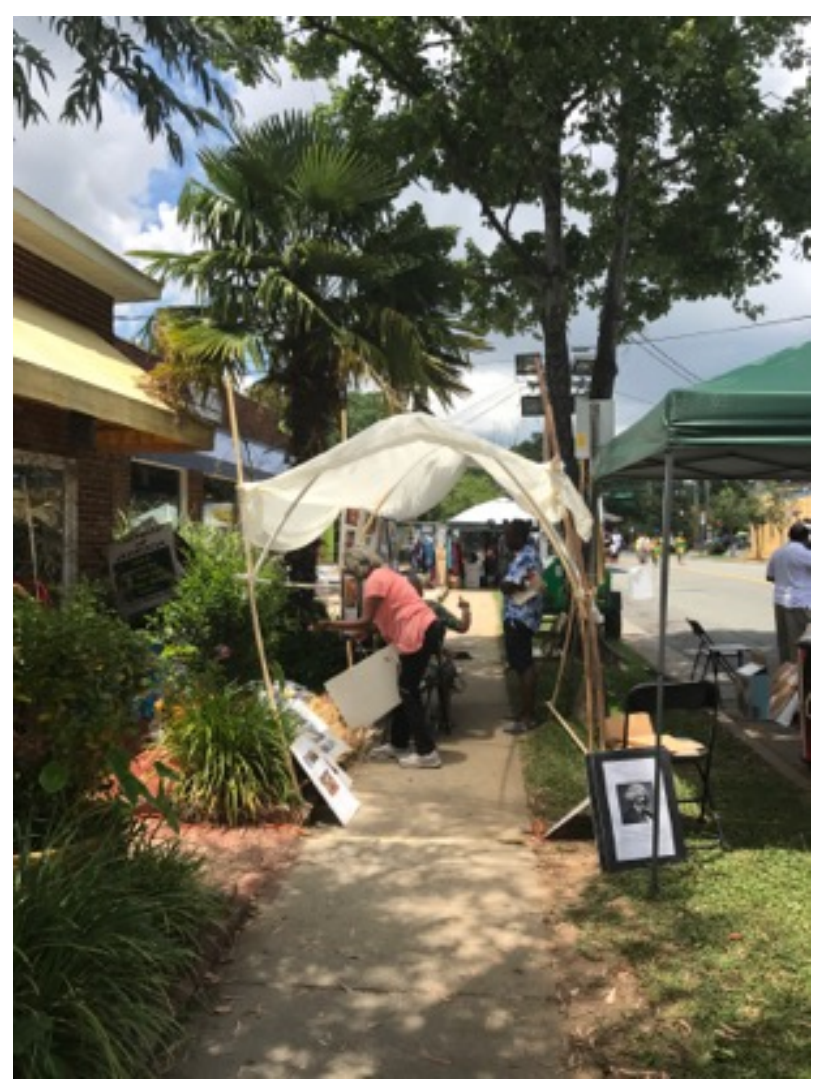

Figure 5.6. "Women at Work." The women of the planning committee build the "African History Tunnel" among many things at Juneteenth. Photograph by Author. 


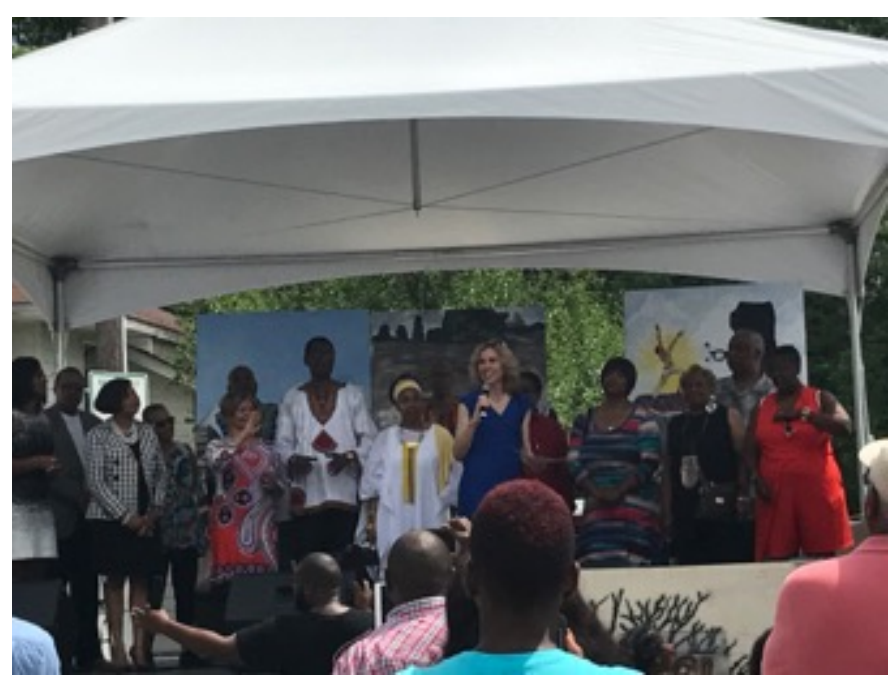

Figure 5.7. Former Mayor Jennifer Roberts grants Pap, the Key to the City, and recognizes Juneteenth Festival of the Carolinas as a city holiday. Standing alongside to the left of Pap is previous mayoral candidate Vi Lyles, now the city's current African American mayor. Surrounding the stage are other prominent African American leaders in the city. Photograph by Author.

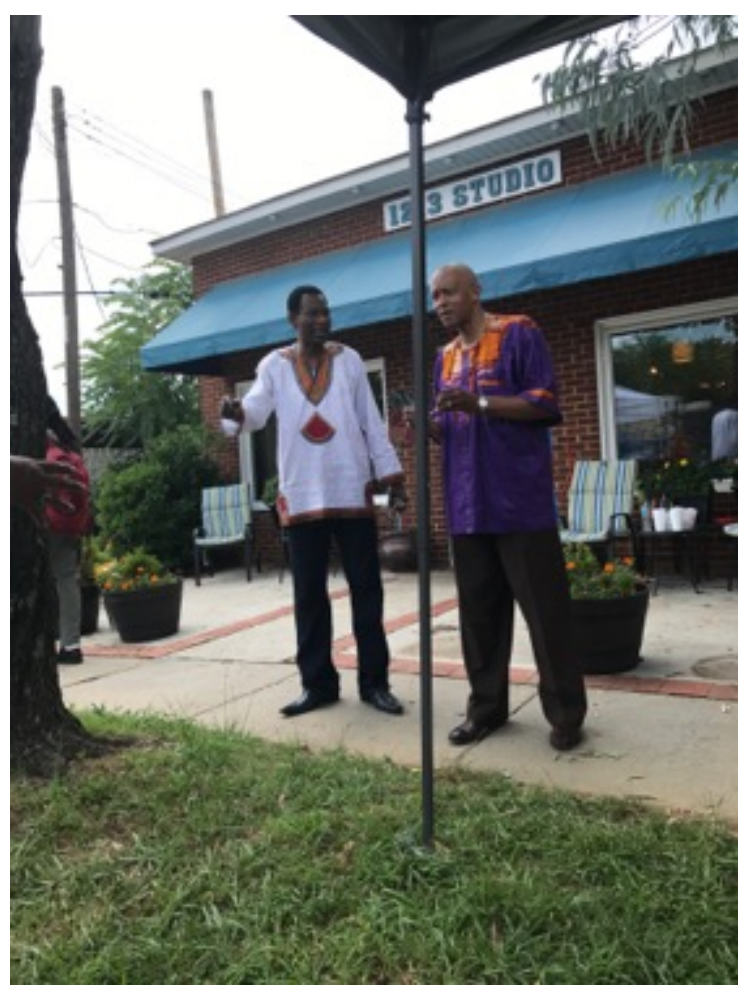

Figure 5.8. Pap converses with a local well-known African American pastor (in purple dashiki) of megachurch in front of a business next door to House of Africa during Juneteenth. Photograph by Author. 
Long before our voyage to Nubia, on a routine visit to the store after much inquiry into the Juneteenth Festival, Pap invited me to attend the Juneteenth Planning meetings held at House of Africa. The first meeting I attended ended up an informal meeting where I met some of those involved in the planning — some African—most black American, we all mainly just talked, I introduced myself to as many people as possible, but the actual meeting never transpired. In a later official meeting, there were different individuals present, only a few that I had previously met. With the exception of Mr. Gary, an older black American leader and teacher of local African drum classes, and sometimes Waly, Pap's “blood" Senegalese brother, the planning committee consisted of all black American women, some originally from Charlotte, others return migrants from the North, all of which had lived in Charlotte for at least the last ten years. As we settled for the meeting in what I like to call the "living room" of House of Africa, some of the women held small children while adolescents sat or walked around the store doing their own thing apart from the meeting. Pap for the most part remained in his office. During this official meeting, I took a seat on a small wooden stool in the living space before one woman questioned why I was there. I explained to the women that I had not previously met that I was conducting research and presented paperwork. This did not suffice. Amidst the confusion, another black woman committee member recommended that I petition the committee secretary separately for a one-on-one meeting, archival photographs and information regarding the festival. I then informed the women that Pap invited me to the meeting. The secretary got up to enter Pap's office to confirm this. After the woman's query, Pap emerged from the office to approve my presence, jokingly assuring that, "she is not working for Trump." At the next meeting, the secretary 
apologized, reassuring me that the women only wanted to confirm "who I was working for." I was not offended by the exchange, instead my introduction to the women of the planning committee was among the many moments over the course of planning and festivities that signified the role of the women as gatekeepers, mothers, builders, and protectors of the Juneteenth Festival. The Festival is indeed a gem in the black American community that the women had cultivated into a large-scale event over the last twenty years. It required protection. At the end of that initial meeting, Pap charged me to volunteer and be present in the activities in order to prove my dedication to Juneteenth and House of Africa.... and to also bring in customers.

In Chapter Two, I mention that Pap is well-known among the upper middle class Black American community, ranging from affluent pastors to doctors to educators. To say that he is simply "well-known" is an understatement. Pap is affiliated not only with the prominence of House of Africa and Juneteenth, but also multiple community organizations including mosques, black American churches regardless of denomination, and other critical city polities. Without a doubt, Pap is wholly embraced and accepted in the Charlotte black American community, if he is not at most "one of them." Pap's inclusion and acceptance within the Black American community stands as one aspect of Pap's assertion of "his African American family" here in Charlotte and comes to be embodied within the actual boutique. Pap's far-reaching social network, the women of the planning committee and the families that come and hang out in the shop while awaiting their adolescent children to get off from what is for many their first jobs, or to just hang out and converse with Pap further exemplifies his African American family and the familial environment. 
The everyday interactions of House of Africa is a family affair in itself; adolescent girls and boys work the front register, attending to customers while Pap mainly remains in his office handling the real business of the shop. As I sat inside of the office with a young black American family waiting to pick up their teenage child from a day's work, the father went to the small fridge located outside in the living room, bringing in a bottle of white wine to pour for those of us sitting, waiting to talk, to see Pap. While pouring a small glass of wine for the small group of us waiting in the small office, the young black American father noted that this was a regular occurance; them sitting, waiting, "chillin" in Pap's office, noting that they were all like a family, with their kids also knowing Pap since birth. The waiting father reminded me, that House of Africa "was a family" in turn, they do family things, like taking it upon themselves to pour a glass of wine while they wait for Pap, or for their children to complete work duties for the day. Therefore, it is not surprising that at the Juneteenth Festival, the women planned to hold a "rights of passage" for the "Juneteenth Babies" in order to pass the torch of what would soon become their responsibility to carry on the legacy of Juneteenth...of the family. Juneteenth then becomes an extended family, for all of black Charlotte to convene in a sort of large-scale family reunion. Usually at black American family reunions, aunts, uncles, cousins, mothers, and fathers wear T-shirts oftentimes emblazoned with a family tree recognizing the ancestors or multiple branches that make up the greater family. In my mind, I hear the lyrics of the O'Jays' classic tune, "Family Reunion" that recalls "its been so long since we all got together" and "its so nice to come together and to get together" playing in the background as the the aroma of burning charcoal from the grill mixes with the popping sound of hot grease from fried fish 
bopping at the top of a the caldron float along with the music. At Juneteenth, there is indeed either old school R\&B or gospel blasting, a large grill running, my favorite fried croaker and also jerk chicken and rice and peas and every now and again a Nigerian food truck. You are bound to run into long time friends and acquaintances, reunite with college friends, church members, former co-workers and their children "that have gotten so big since I last saw you" and "I remember when they were just a baby." These are the social relations, material and non-human actors that feed the family reunion, while in the place of family legacy T-shirts, kente cloth, other African inspired fashion and shirts emblazoned with black leaders/ancestors, and the red black and green of the black nationalist flag are all representations of the family. Thus, as Mary Douglass (1996) contends, "modern identities are constituted through a direct relationship with the material world" in which we must see consumption as a choice not just between “different kinds of goods" but between "kinds of relationships"(Miller et al. 1998, 23). Keeping in mind that identities are social processes that shift based upon context, the symbolic material culture constructing House of Africa and Juneteenth reflects the functioning of imagined narratives that evoke nostalgia and other affects that underscore kinship bonds. House of Africa and The Annual Juneteenth Festival of the Carolinas stand as "distinctive articulations of social relations" in which black immigrants and black Americans hold agency in fostering and maintaining an Alternative New South, even if it leans on an essential Afrocentric love. 


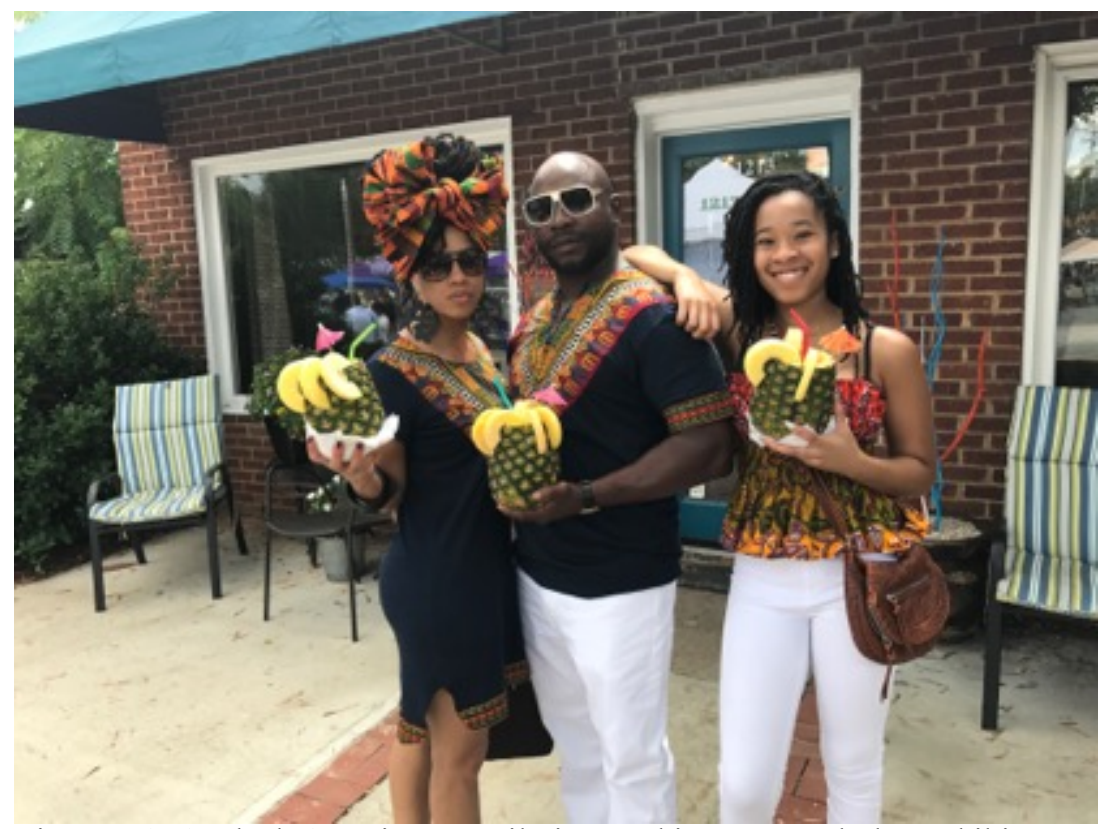

Figure 5.9. A Black American Family in matching Kente-cloth-Dashiki patterned-African Inspired outfits poses with their tropical fruit drinks at Juneteenth Festival. Photograph by Author.

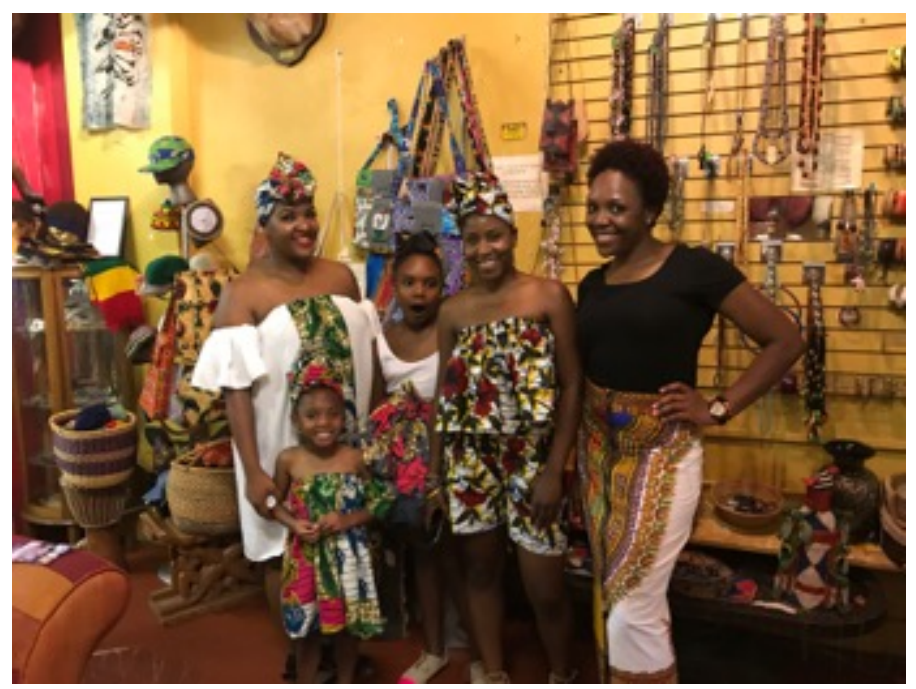

Figure 5.10. Another family shows off their designs modeled on the front stage at Juneteenth Festival. The black American mother is the designer and hopes to also publicize her custom-made garments at the festival. Photograph by Author.

\section{One Love: Reggae Central and the transnational Black Atlantic Family}

Paul Gilroy (1993) emerged as one of the leading critics of Afrocentrism,

deeming it as essentialist. Inferring an "anti-anti-essentialist" perspective, according to Gordon and Anderson (1999), Gilroy "addresses the question of unity and commonality 
of the African Diaspora", or the Black Atlantic, "as a theoretical and political problem rather than as an ontological given rooted in a presumed racial essence or mythological origin" (Gordon and Anderson 1999, 287). Gilroy’s ground-breaking work, Black Atlantic, had a tremendous impact on the field of African and African Diaspora Studies. The work envisions the "formation and transformation of New World Black cultures" beyond the centrality of African cultural continuities (Gordon and Anderson 1999, 287). Instead, retaining the image of the ship as a "living, micro-cultural, micro-political system in motion" moving across "the spaces between Europe, America, Africa and the Caribbean as a central organising symbol" Gilroy proposes his most fundamental concept of "roots versus routes" (Gilroy 1993, 4; Gordon and Anderson 1999, 287). Gilroy argues that it is not just "roots", or those direct connections and vestiges of Africa but "routes", the "movement of people, practices, ideas, and commodities across national boundaries - as a constitutive component of Black thought, culture, and politics within and beyond particular nations" (Gordon and Anderson 1999, 288).

In his ground-breaking work The Black Atlantic; Modernity and Double Consciousness, Gilroy delivers an epistemology and articulation of Diaspora premised on black modernity rooted in global shared understandings, expressions, and embodiments of DuBois' undying notion of double consciousness. For Gilroy, this global quest for recognition and the transnational circuits of exchange of Black popular cultures of the Atlantic as those ships circulating ideas, activists, and "the movement of key cultural and political artifacts" constitutes black modernity (Gilroy 1993, 4; Edwards 2001). Among these circulating "key cultural and political artifacts", Gilroy emphasizes the "symbolic use" in which music comprises "a central and even foundational element" in articulating 
the self-understanding of black musicians and their listeners, noting that this artistic and aesthetic component is how we first emerged from the plantation (Gilroy 1993, 75). Although Reggae was once a "supposedly stable and authentic category" emerging as a Caribbean hybrid of rhythm and blues, in accordance with Gilroy, in Britain, the genre ceased to "signify an exclusively ethnic, Jamaican style" deriving a "different kind of cultural legitimacy both from a new global status and from its expression of what might be termed a pan-Caribbean culture" in a similar manner as "the style, rhetoric, and moral authority of the Civil Rights and Black Power movements", also "detached from their original ethnic markers and historical origins" (Gilroy 1993, 82). While Gilroy contends that these cultural and political expressions may have been detached from their critical political, historical and cultural origins, "exported and adapted", with "no evident respect but little sentimentality to local needs and political climates" I argue against a supposed intra-racial and inter-ethnic appropriation. Despite the fact that there are no identical forms of racial oppression and segregation, the "memory of slavery", the "legacy of Africanisms", and the "stock of religious experiences" are "funded" by common experiences of blackness and strivings for Diaspora (Gilroy 1993, 83). Reggae Central, owned by a black American woman, is rooted in Reggae and Rastafarianism, decentering Africa, and caters to a diverse Pan-African and Pan-Caribbean clientele.

One immediately knows Reggae Central on Central Avenue first by the green, yellow, and red vertical sign announcing the store to those passing by and second by the looming aromas of nag champa, lavender, or frankincense that wanders through string of smoke seeping from a stick of hundreds stuffed in a small plant pot, and lastly the low base of reggae riddims from the likes of Sizzla, Bares Hammond, Peter Tosh, I-Wayne, 
and of course, Bob Marley and the Wailers playing outside in the entryway. The string of smoke from incense follows customers into a small entryway encased by an array of palmetto shrubs on one side, and a small living area with a wall-painting of the beach, indoor palm plants, and straw furniture on the other side. Bewildered by the tiny encased jungle, children peak inside the window, their curiosity aiming to catch a glimpse of a potential snake of alligator. In the store always is either Nikki or her mother, both with long-flowing dread locks and smooth dark skin tightening the physical generational marks dividing mother and daughter. If the store isn't too busy, one may find one of the women laid out on the straw couch reading a book, resting, talking with a friend seated in another straw chair, or focusing their hands on tiny pliers operating coils of copper around small stones into jewelry while quietly monitoring the foot traffic along Central. Nikki and her mother are two black American women from the neighboring city of Rock Hill, South Carolina. I have personally been patronizing Reggae Central since I was a young college undergraduate. Other than the small stores in Eastland Mall, we were guaranteed to find our black militant college student's survival pack at Reggae Central: T-shirts printed with iconic images of Marcus Garvey, Angela Davis and Che Guevara, black nationalist and Rasta tri-colored flags to hang on our dorm room walls and bulk sacks of incense to chase out any other smells that would require the residence assistants to bang on our doors. In those early days, Nikki's mother ran the shop and was sure to engage in a conversation about politics, history, whatever Reggae artists were coming to perform at Crystals, upcoming festivals and the annual Reggae on the Lake. Offering similar conversation, Nikki is the main one you will find now, becoming a central interlocutor entertaining and engaging in wide-ranging conversations during my time 
spent at the shop. Just like her mother, her love of people and ease of conversation is both absorbing and welcoming. It is in fact Nikki and her mother's ease of conversation that begins those threads of affective kinship and creates a sense of home and belonging. Also like her mother, Nikki takes her role, the shop, and the shop's legacy as one of the longest standing black American woman owned businesses, and the first and only on the most popular and most expensive stretch of Central seriously. Being a mother, a daughter, a black woman unsuspectingly in her early 40s, and heiress to a store her mother has owned for more than twenty years, the store, its legacy, and its merchandise, much of the jewelry she hand makes are all critical layers of Nikki's identity and how she defines herself. Since childhood, Nikki has grown up in the store and travelling with her mother to different festivals to vend and market the store's merchandise as well as she and her mother's hand-crafted jewelry. Therefore, material culture is very much part of Nikki's being.

On this one particular day again sitting with Nikki in the window setting, intrigued by her attire, I asked Nikki to explain to me what her outfit that day represented. She reflected for a minute, noting, "God that's a hard question", first recognizing her jewelry I inquired if this contributed to her style and the other elements that possibly influenced how she dressed. The attention to her jewelry prompted the following:

“Yep, I made the jewelry. So...it shouldn't be hard, but I guess its hard to explain because when people see me, they say things like, "you like Erykah Badu don't you?" [laughs] and I'm like, omm yea but if you go back and look at probably...let me see where I can think back to- 
omm...definitely, [since] high school...[I've] been dressing like this--I guess I've been dressing like this since-I've been wearing African print and African garb and African clothes and Ankhs since...Okay. Remember when Salt-n-Pepper and Spinderella came out and they had their whole [look]? That's when I started. And yea because I got in trouble in school for--the teacher tried to kick me out so many times--that was when the Title 7 laws came in when boys couldn't wear hats in schools and girls couldn't wear hats, and I had that hat on and my stepdad had to come to school and say this is her cultural garb you will not make her take it off. So, that's then. So when I worked in corporate America, you kind of have to [fit in]--but I would always throw on some amethyst, always throw in some red, black and green, always throw in an Ethiopian Coptic cross, ALWAYS have on an Ankh, the Ankh is tattooed, never covered it up and dared anybody to say anything to me about covering it up. I left one job because they were starting to, they were about to start to say something to me about locking my hair-remember I said, "about to start" I knew they were about to start. N'n'n'n No. No. No. No. Because my stepfather was an attorney with locks, when I was in the 7th grade, so ain't no way in hell nobody paying me to do a job for them is going to tell me how to do my hair. Period. Point blank.

Never."

Here, Nikki expresses her early years of fashion as a sort of venture of finding and establishing a diasporic identity, whether it stemmed from Hip Hop or symbols like the Ankh or Ethiopian Coptic cross. This account also reveals Nikki's encounters with corporate entities attempting to control her black body, style and fashion. In response, Nikki used her dress and style to subvert this control. Now free from the control of 
corporate culture, running her mother's business, Nikki went on to describe the evolution of her style in a way that encompassed her own agency and alterity as well as the significance of her relationship with her mother and the shop.

"A lot of times I wake up and I look at my calendar, I have a witch's calendar because it tells me about the planning and the growing, and the color of the day, and which days the moon is in, and that's how I do. If its yellow, and I'm feeling blue, I'm going to put on--a lot of times I'll put on either my jewelry or my clothing will align with whatever the color of the day is...that's how I match all of that up. But as far as like clothing and stuff--I like to be comfortable, I'm a girl, I like to be pretty. I like to make statements but I'm not one that will go--like tomorrow is Woman's Day--not--I don't--I'm coming to work. Because this is my momma's store, and she's a woman, and I'm coming to work. And that I can be an example--my mom is an example--I think she is more of an example than she realizes for women, especially entrepreneurs who are trying to do their own thing. For the ones that are doing their own thing, she gets a lot offlack from a lot of-I think new people in Charlotte--because she's married to a white guy--they think that "they" did this [the store]. No, THEY did not do this! She did this. She started this when she was married to a black guy, SHE did this--you know ALL of this is her--you know, like none of this is nobody else's, none of it at all. I'm VERY defensive when it comes to Reggae Central and this store... VERY VERY defensive. And I think a lot of my style comes from her. Cause the wrap that I had my hair in yesterday omm that's one of the first wraps that she ever had you know, and I think a Liberian lady made a whole outfit for her... and I can wear it now! [laughs] It's too big for her now! But its the right size for 
me, its from--from like a young child, it was one of my favorite outfits to even see her in. And so...she only gave me the head wrap, she won't let me have the whole thing yet [laughs] because she thinks she's going to be able to get back in it".

Revisiting the concept of narrative identities, Nikki here appears to narrate her identity through her style. Very much connected to the shifting affects evoked by certain colors, her style is also reflective of her relationship with her mother and the store. Further, in the way that Nikki attempted to use her style and dress as subversive acts to declare her agency, culture, and blackness in her youth and while working in corporate America, she also uses it to defend and reflect her mother's legacy. Like most diasporic spaces of belonging in Charlotte, Reggae Central requires protection, mainly from the hipster spots opening up around the store that attempt to model their business after Reggae Central, although for a different market. Protecting the store's legacy and space is then also intertwined in the women's identity. Highlife smoke shop just across the street is an East Indian owned shop ran by young white hipsters. Discussing the owners of Highlife and the store itself, Nikki stated, "They came in here! Looked at all our stuff, checked our prices, stupidly asked me where I get my stuff from. I'm not stupid." So, when East Indian customers in particular enter, who rarely enter the shop, Nikki's "antennas go up." On the other hand, if an East Indian customer is accompanied by a black person this signals that they are indeed there "to shop legitimately." Nikki recognizes that this is part of competition, recalling that some customers have admitted that they go across the street when Reggae Central is out of something. However, these customers also confessed to Nikki that while at Highlife "they tried to sell me this shirt, I 
was only in there for a brand of incense they sell, and they tried to sell me a Bob Marley shirt, and I said hmmm I get my shirts at Reggae Central!” Other times, young white workers come across to Reggae Central and ask if they can leave flyers to which Nikki responds, “ 'Hell No, You cannot.' And I don't know what would make them think that that would be okay. You basically set up shop based on our model, and you want to put your shit here? No, No, No. Because one thing about my mom, at-13-bout 10 or 11, I was out vending with her. I'm 43 now, so this — we been here for 20 years but she was doing this 20 years before them so there's no way I'm going to market your stuff in my mom's life. Are you crazy? It's not going to happen." In this instance, kinship is first displayed through the loyalty of the store's customers by informing Nikki that while they did go to the competition for something that Reggae Central was out of in the moment, they also warned her that they were attempting to sway Reggae's customer base, who then affirmed their loyalty to Reggae Central to the competitor. Her competitors, apparently sneaky, are for Nikki, identifiable by groups or pairs of East Indians who stand as enemies to the family's legacy. On the other hand, an East Indian accompanied by another black person, we can look at this accompanying black person as a cousin of sorts, reassures a sense of trust or acceptance into the family. Lastly, by referring to the store as her "mother's life" Nikki is not just protecting a space, or a home, but her mother who embodies the store. The bonds of kinship and loyalty undergird the on-going success of Reggae Central. 


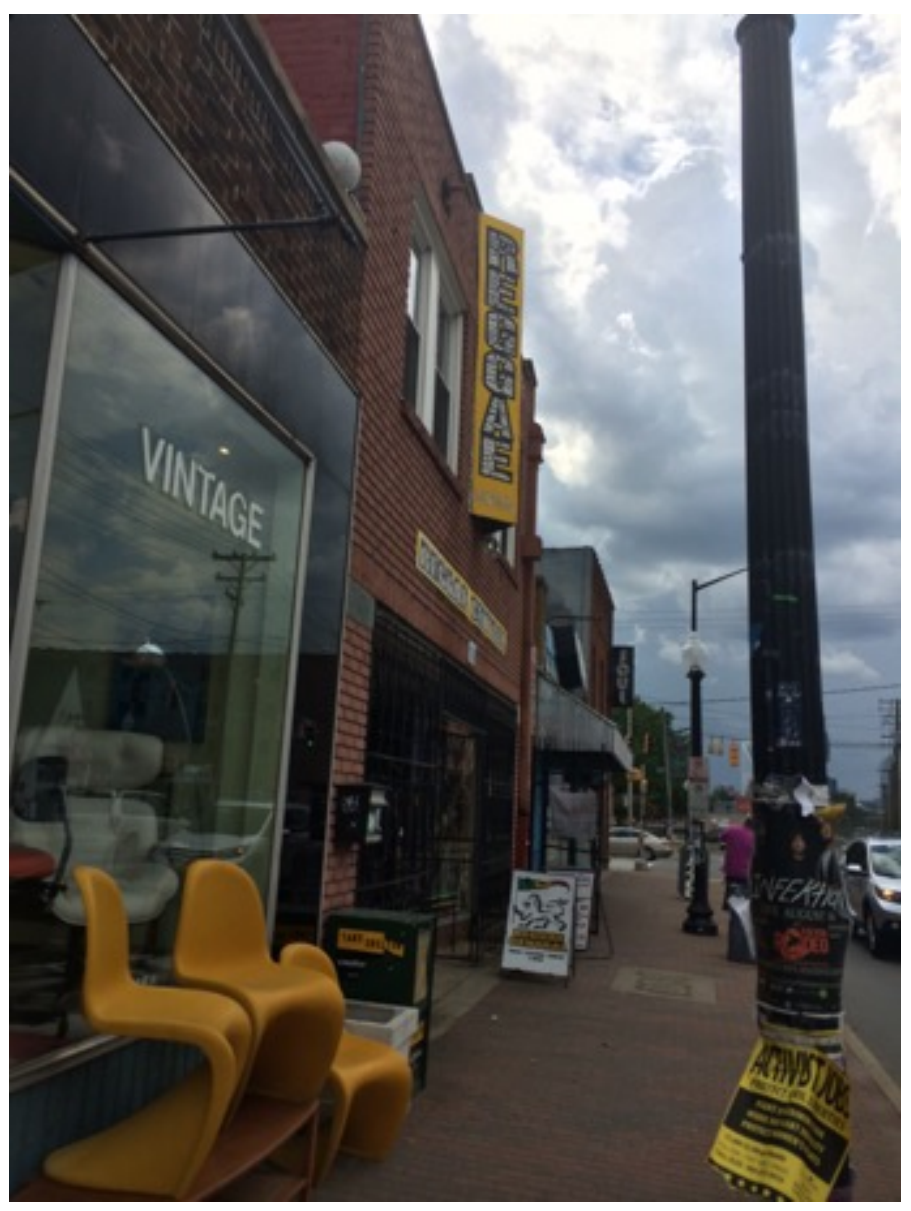

Figure 5.11. Reggae Central on Central Avenue. Photograph by Author. 


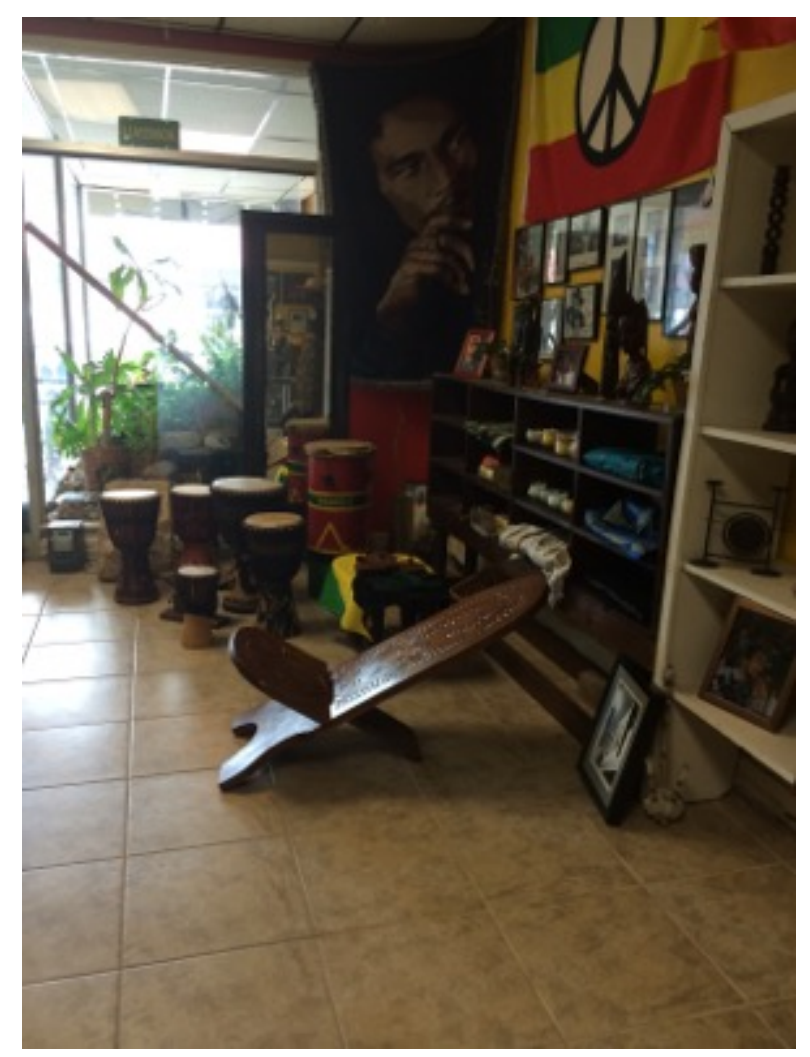

Figure 5.12. Inside of Reggae Central. Photograph by Author.

Unlike the House of Africa's predominantly black American upper middle-class clientele, Reggae Central's customers, lured in by that seething string of incense are still composed of black Americans, but the store also brings in array of people from around the world, particularly the Caribbean in search of that one love. It was Nikki who during preliminary research, assured me that there was indeed a larger Afro-Latino presence (outside of Dominicans) because they regularly come into the store and Nikki usually surveys where her customers are from through sparking conversation with almost everyone. Once past the window dressing of an island living room to the right and a potential jungle to the left, one finds an array of T-Shirts printed with black leaders, and 
quotes, the majority of which are of Bob Marley printed atop tri-colored "Lion of Zion" designs. However, venturing counter clockwise through the store, after stopping first to pull out and examine T-Shirts to your right, customers continue on to the center where they neatly extract hangers to examine and consider purchasing the several stitched, crocheted, and hand-sewn garments and accessories that come from all over Africa and the Diaspora. Maneuvering to the front of the shop there is an old school television box playing music videos, Caribbean films like the classic Shottas or Bob Marley concerts. Surrounding the TV stand/shelf is a vast array of Reggae CDs, Caribbean and African DVDs. Just in front of the TV, a small coffee table displays a collection of patches of national flags, images of revolutionaries and activists like Che Guevara and of course Haile Selassie, and revolutionary fists for stitching onto cloth. Shifting around the coffee table, there are small dressing room areas, a large tub of raw shea butter sitting in front, which Nikki scoops out and jars portions for purchase. Flying just above the tub of shea butter and dressing areas is an array of flags representing countries of Africa and the Diaspora, also for purchase. After exploring the collection of flags, perhaps looking for one's own country, there is a small assortment of small statues, drums and art pieces from around the Diaspora as well as Nikki's handmade candles. In the back of the store one can step down into a dimly lit area with wooden shelves and woven baskets filled with incense, soaps, cones, oils and herbs for burning; hidden behind a beaded curtain, it is almost a sacred space of the store. As it is the aroma of the incense that brings customers in, Nikki mentioned that indeed incense, oils, shea butter and flags are her main sellers. During my time in the store, several return customers came in describing the scent of a particular oil that they had previously purchased and needed a refill. Further, with flags 
as another main selling product, I see Nikki as a supplier for the construction of identities as well as a space of belonging through the (re)production of cultural expression.

Arjun Appadurai (1986) describes commodities as things "with a particular type of social potential" that reach beyond the possibility of products, objects, goods and artifacts (Appadurai 1986: 6). This contrasts with Marx's definition of commodity, which are "special kinds of manufactured goods (or services), which are associated only with capitalist modes of production (Appadurai 1986: 7)." Appadurai suggests that, "the commodity situation in the social life of any 'thing' be defined as the situation in which its exchangeability (past, present, or future) for some other thing is its socially relevant feature (13)." The products purchased in Reggae Central often epitomize constructions of identity in a new country/city. Nikki mentioned one customer who was born in the Virgin Islands, whose mother was from Trinidad and Tobago, but whose father was from Puerto Rico, had difficulty deciding which flag to purchase while Nikki suggested they buy the South Carolina flag since he currently lived in the state. He ended up purchasing all three flags. Nikki noted that anytime there was a particular ethnic festival or celebration in town, including the viewing of soccer matches, whether Jamaican, Ivory Coast, Colombian or Mexican, they immediately sold out of flags. During the Charlotte September 2016 protests, Nikki says that the store quickly sold out of black nationalist flags and during the Day Without Immigrants, she specially ordered several flags from Central America. The American flag is the least purchased. Of course, in their most obvious productions, flags are mere representations of a national identity, yet in Charlotte, national flags, including the red, black and green of the black nationalist flag, 
or the red, green and gold of the Rastafarian flag become seemingly symbolic of family crests that signify a collective group/ethnic identity.

In addition to flags, immigrants from cities such as New York come to the store and mention that they feel like they are "back in New York" where everything is located in one shop. When asked what kept the store alive, Nikki mentioned the broad customer base, and the location. At the same time, people also come in to "just talk" with Nikki's mother when she is there. Nikki and her mother may be from South Carolina, however her mother graduating from Johnson C. Smith University as well as her business has endowed a great deal of community connections. In conjunction with this important aspect of black status in Charlotte, Nikki shares her mother with customers, reflecting another aspect of affective kinship. The sense of kinship is heightened as other customers come back after 15 years, and according to Nikki, have the taxi driver bring them directly to Reggae Central only to arrive and smile and say "I got my bearings again", delivering a sense of home with maternal and/or sibling-like figures remaining. Nikki revealed this as "the sense of yea, your culture is here too...with a sense of belonging and they know...we're from South Carolina, they're shocked by that, but still [they] get that vibe...that this is theirs." In the previous chapter, I discuss "the vibe" as a feel of environment or atmosphere that can be potentially dangerous, an urban dialectical term for affect, yet here the vibe is love. Other than flags, oils, clothing, and decorum, Nikki notes that it is the "Rasta vibe...the oneness of it all, that's that Bob Marley, that one love...that thing...that spans all races and cultures" that brings customers to Reggae Central and keeps the place alive. 


\section{A Conclusion: Unconditional Love}

I preface this chapter with my adventures at SuCasa, a monthly event started by a black American woman, held in East Charlotte in order to assert the functioning of multiple articulations, interpretations, epistemologies and ultimately practices of diaspora working to construct, maintain, and protect an Alternative New South. In contrast to Chapter Four, centered upon Diaspora Wars, this chapter highlights those moments of Diaspora Love that attempt to adhere to Stuart Hall's call to realize "the politics of living identity through difference" or "the politics of recognizing that all of us are composed of multiple social identities, not of one" requiring scholars of the Diaspora to recognize, consider and embrace the multiple histories, memories, trajectories and lived experiences of those from the across the Diaspora. Like Gilroy (1993), Wright (2015), Hintzen and Rahier (2010), Rahier (2003, 2010), Hall's (1997) assertion foregrounds an antiessentialist school of thought concerning Diaspora. At the same time, recognizing the sociopolitical and cultural power of Afrocentrism in the U.S., Hall also contends that we must recognize the "costs and strengths" of a Black essentialist identity. By directing my focus to two long-standing black-owned businesses in East Charlotte's main corridor, House of Africa and Reggae Central I attempt to reveal the dynamic ways in which articulations, interpretations, and epistemologies stemming from these two polar schools

of thought, essentialist and anti-essentialist, are manifested in different ways to construct spaces and places of belonging in East Charlotte that produce black identities and subjectivities reflective of these manifestations. Further, relying upon Alai ReyesSantos' transcolonial kinship model informed by an affective matrix of love, empathy, 
sympathy, etc., I argue that these spaces, places, material culture/setting, as well as the individuals that inhabit and construct these spaces and places produce an affective kinship that underscores the bonds of Diaspora Love.

In turn, through this affective kinship, black subjects become agents in creating an Alternative New South, representative of a horizontal relationship with the city that replaces the vertical power relations between corporate entities and policy-makers and marginalized groups of people in Charlotte. At House of Africa and The Annual Juneteenth Festival of the Carolinas, initiated by Pap, a Senegalese immigrant, affective kinship is rooted in an Afrocentric ideology and material setting that reproduces narrative identities of the survivor and African nobility. Despite these narratives being oftentimes based upon essentialist and false imaginaries of a monolithic Africa, they nevertheless foster a familial relationship between the African and African American community that demands recognition, visibility and agency. Reggae Central, on the other hand, owned by a black-American woman decenters Africa, reproducing and reflecting the on-going circulation of music, goods, fashion, and other cultural expressions across the Black Atlantic, highlighting Gilroy's notion of "routes versus roots." The role of women is critical in the construction of both House of Africa, Juneteenth in particular, and Reggae Central. These mainly black American women establish themselves as protectors and mothers of these spaces and places and oftentimes come to embody the spaces and places as Nikki does. For Nikki, Reggae Central is one very critical layer of her identity if not the essence of her identity. Affective kinship in Reggae Central revolves around the universal Rastafarian and Bob Marley idea of "one love." One love represents the voices, needs, and wants of those throughout the Diaspora, which is reflected in Reggae 
Central's broad customer base and the store's top-selling goods; flags, that could be seen to connect and produce visibility of black and brown subjects in Charlotte. The House of Africa, the Annual Juneteenth Festival of the Carolinas and Reggae Central provide a window into the most fundamental "practices of diaspora." Through this chapter's discussion of these main places and events as evocative of varying formations of Diaspora Love, the goal has been to provide a theoretical foundation for the concluding chapter which directs more extensive attention to the ways space, place and material culture become embodied in the on-going construction of an Alternative New South that I begin to envision as a Borderland in the production and celebration of alternative/collective black and brown subjectivities and identities. 


\section{CHAPTER SIX}

EMBODIED BORDERS: FOOD, MUSIC, DANCE, AND THE MAKING OF DIASPORA IN THE “BORDERLANDS” OF THE TRANS-ETHNIC ALTERNATIVE NEW SOUTH

"The entire aim of SuCasa is the intersectionality of us-it's for us--and it's for--I'll say whoever comes is welcomed but make no mistakes about it, like, it's built in the soul of black music and black--diasporic black--from Kenya to Honduras to Spanish Harlem to wherever so yea that was always the goal. And I actually started eight years ago as MiCasa at my house, and I did it for about a year, then took it to [another] space where it was MiCasa for about a year, and then we had some disputes around the name, and so then it became SuCasa."-Jasiatic, Black American, Charlotte native, 13 July 2017

I met Jasiatic one-on-one for the first time at a new small artsy café that serves draft teas and coffees as well as craft beer and wine in the NoDa (North Davidson) neighborhood of East Charlotte. After ordering a draft black tea and opting for the turkey wrap amongst several vegan menu options, I recognized Jasiatic approaching with long flowing cotton candy pink cornrows. I never asked nor could I ever quite gauge the exact age of the golden-brown woman approaching me. Still, from her presence, I gathered the sense of a travelling black woman, the embodiment of diaspora, and the "Taste-maker. Baby-maker. Fire starter. Picture taker" she describes herself as on social media. There, in her, I somehow saw my future self at an age apparently old enough to have adult children but still able to thwart the phases of time, her high glowing cheekbones and playful light pink hair maintaining a certain mystery, youth, curiosity, and adventure. 
Perhaps her femininity, body language and warmth simply exuded the words of Chaka Khan's famous song, "I'm Every Woman, It's All in Me.” After noticing one another in the open-spaced café, we took a seat in a small nook, cushioned by pillows woven with what appeared to be South American indigenous designs and colors. We wasted little time. After briefly establishing that Jasiatic was born and raised in Charlotte preferring to live and be in East Charlotte amongst people and things of color, I eagerly commenced with, "So, tell me about SuCasa." Jasiatic immediately responded with the following:

"I really think it [SuCasa] means different things for different people. It's definitely a space for artists, for art, where people can bring and show their art, where people can sell their crafts you know-sometimes there [are] drummers-it's definitely a space where no matter who you are, you come there, you feel good about being there and dancing. Like, you can't not dance if you're there. I've always seen it as this diasporic meeting space, [a] sort or melting pot, a space where all of us from--you know, whoever we are from the diaspora can be there to kind of unite and move. So that's why the DJS are encouraged to play lots of different music from throughout the diaspora... and its been interesting because it has definitely grown into what I wanted to see out of it. I mean it's still continuing to grow but I think initially, you go to some of these bigger cities, the diasporic community is very blended because, I guess just that space of--when people come to this country and Charlotte is kind of a fairly new space for new immigrants, you know what I mean? So whereas people would usually default to Boston or New York or Miami, people are starting to come to Charlotte. I meet so many people there [at SuCasa] and Charlotte's their first stop, and I'm like, 'really? You weren't in New York 
before?' I think Charlotte is a new space for that. What happens in Charlotte very often is that people get pulled into their own little communities based on church, or based on the people in your family so my hope [for] SuCasa was to have it be this meeting space of people from you know all parts of Africa, all parts of Latin America, all you know--all of us that share these very similar dances, whether they're American or you know--whether they're--I mean just everyone--its amazing how much we have in common in terms of just the drum you know."

There are several aspects of Jasiatic's description of the purpose and intention behind the construction and maintenance of SuCasa that furthers the central arguments of Chapter 5, which posits the existence of an East Charlotte trans-ethnic-alternative New South established through affective kinship. This designation stems from Reyes-Santos (2015) transcolonial kinship model informed by an affective matrix of "sympathy, empathy, harmony, compatibility" as well as notions of "brotherhood, friendship, national family and extended family" that contests the racialized violence endemic to European imperialism and creole nation-building projects in the Antilles (Reyes-Santos 2015, 7). Utilizing this notion I contend that in East Charlotte, affective kinship (re)places the agency of constructing the New South in the hands of its diverse black and brown populations not corporate entities or policy-makers (Reyes-Santos 2015, 7). With this in mind, Chapter Five foregrounds my concept of Diaspora Love in contrast to that of Diaspora Wars by illustrating the stirring sounds, visuals, material culture, and affects emanating from the social, cultural, and warm intra-racial and inter-ethnic interactions of spaces such as SuCasa, House of Africa, the Annual Juneteenth Festival of the Carolinas, 
and Reggae Central. By focusing primarily on House of Africa, Juneteenth, and Reggae Central, Chapter Five presents some of the most fundamental ways in which articulations, interpretations, and in turn, practices of diaspora rooted in either essentialist or antiessentialist schools of thought are manifested in particular spaces and foster forms of kinship. In the case of House of Africa and Juneteenth, this kinship often stemmed from affects such as nostalgia triggered by narratives of African nobility as well as a sense of pride underlining notions of collective black American survival. These notions reflect the central principles of Afrocentrism. On the other hand, Reggae Central is demonstrative of Gilroy's emphasis on "routes versus roots" that maintains the notion of ships, or goods, media, thought, and popular culture that circulate the Black Atlantic. This chapter continues this discussion by weaving together the complex practices of diaspora and the role of affect and material culture in fostering collective identities and subjectivities.

With this, I aim to build upon the role of affective kinship in the formation of a trans-ethnic alternative New South. This chapter considers several critical theories that contribute not only to understanding the construction of a trans-ethnic alternative New South, but also to conceptualizing this trans-ethnic alternative New South as a borderland that comes to be embodied by the black American and black immigrant subjects that construct it, inhabit it, imagine it, and traverse it. In order to lay a foundation for this chapter's arguments, we can return to Jasiatic who I envision as a cultural worker, an agent and a mediator of social, cultural and inter-ethnic/intra-racial relations as well as place-making in East Charlotte (Nassey Brown 2005, 37). The fact that SuCasa originated in Jasiatic's home as "MiCasa" eight years prior advances my inquiry into the significance of ritual and kinship in the formation of a trans-ethnic alternative New 
South. Presenting the notion of kinship as a fundamental component in establishing an alternative New South compels us to first consider Nassy Brown's (2005) assertion that kinship acts as a "vehicle of racially trangressive practice" wherein race exists as politic that constitutes "racialized geographies of imagination" or those social spaces that emanate through processes of racialization (Nassy Brown 2006, 34, 76). In arguing that kinship acts as a form of racial transgression in response to the marginalization of black and brown bodies in the city of Charlotte, I am drawn to Gaye Theresa Johnson's (2013) conceptualization of "spatial entitlement." In accordance with Johnson, spatial entitlement "entails occupying, inhabiting, and transforming physical places but also imagining, envisioning, and enacting discursive places that 'make room' for new affiliations and identifications" (Johnson 2013:1). Spatial entitlement allows for the transformation of "ordinary residential and commercial sites into creative centers of mutuality, solidarity, and collectivity" precisely because upon experiencing "race as place" subjects change "the racial realities of their society" requiring them to change the spatial order as well (Johnson 2013:1). Nassy-Brown's presentation of kinship as a "vehicle of racial transgressive practice" and Johnson's "spatial entitlement" are equally constitutive of both ritual and borders.

In its most raw and basic form, kinship is a product of ritual, if it is not ritual itself. We need look no further than anthropology's most revered scholars and theorists, Clifford Geertz (1973) among those, to understand that ritual is composed of symbolic repetitions, inscriptions, and solidification of practices or "structures of signification" that come to symbolize and define a culture, a religion, a thing, a life, a person (Geertz 1973). It is from the beginnings of MiCasa in Jasiatic's actual home that in eight years 
transformed into SuCasa, literally from My House to Your House, that a ritual was established. For those individuals that attended MiCasa and continued over the years, bringing along others to join in the broader collective of SuCusa, forms of kinship were established through this "diasporic meeting space" giving way to a symbolic diasporic community. With this, I move toward an argument of the trans-ethnic alternative New South as a borderland. According to Michel Agier (2016), ritual enables both the "line of border" to exist in a "sacred form" or symbolic community (Agier 2016, 21). Positing this trans-ethnic alternative New South as a borderland calls upon a reconceptualization of borderlands that moves beyond the geopolitical designation that it has held in our minds e.g. Mexico/United States, Palestine/Israel, Europe/Africa, etc. while discussions and politics concerning these borders are often wrought with conflict and turmoil. When I speak of the physical, social, and cultural boundaries that are manifested through both Diaspora War and Diaspora Love, I aim to conjure Agier's (2016) explanation of an "anthropology of/in the border" wherein he contends:

"Border of places (here and over there), border of time (before and after), and border of the social world of experience, that is, of everything that comes to exist socially by delimiting within a defined environment an 'own' and a 'different': these are the elementary forms of the border, but also the contexts of its uncertainty, its incompletion in space, in duration, and vis-à-vis others. The social and non-natural character of the border ends up creating a particular situation: the uncertainty of its drawing is expressed in time-of waiting, reflection, conflict-and in space-vague, as if the border was the place where uncertainty had found its most exact recognition. This consubstantial uncertainty explains the necessary repetitions and reconfigurations assumed by ritual, 
whose fundamental role is not to freeze the border, but rather to make it live in order for self and other to live at the same time"(Agier 2016, 23).

By expanding upon SuCasa and other spaces and places mentioned throughout this dissertation and introducing others, this chapter progresses the idea of a trans-ethnic alternative New South. As such, I am drawn to Agier's conceptualization of the "social and non-natural character" of borders that posit them as situations that exist temporally and summon the vagueness and uncertainty of "waiting, reflection, conflict." Further, if we reckon that ritual does not "freeze borders" but instead creates a space "for self and other to live at the same time" and where uncertainty finds "its most exact recognition" we can begin to shift our notions of borders from those that staunchly divide to then rethink borders as "good for living" at least in the "production of locality" (Agier 2016, 15). Conceiving borders and particular "border situations" as "good for living", leads us to consider what Agier calls "border dwellers", those of whom I would align with cultural workers, agents, and mediators; those individuals and groups caught in a "border trap" oftentimes burdened with the inability to "completely cross", "find a place, a status recognition, or citizenship" (Agier 2016, 58). In accordance with Agier, these "border dwellers" occupy a space of uncertainty and a state of alterity as a foreigner (Agier 2016, 58). I contend that the uncertainty and alterity of the "border dweller" applies to both black immigrants as well as black Americans, especially considering those black and brown American and immigrant subjects that represent diverging experiences, histories, and trajectories that contest heteronormative, homogenous and monolithic understandings and epistemologies of blackness in the U.S (M. M. Wright 2015; M. M. Wright 2004; Rahier 2003; Crenshaw 1991). If the border signifies uncertainty finding its recognition, 
this must stand for those border dwellers as well in that at least temporally, they can find recognition within those border situations that are "good for living." Recognizing the active work of ritual, kinship, spatial entitlement and consequentially borders that are "good for living" I argue that many black subjects come to embody and embrace these border situations and in turn, their alterity.

Adhering to Agier's anthropological approach to borders, I also utilize NassyBrown's phenomenological approach to interpreting the relationships between black subjects, place, and material culture, in which the view of place is that "its being dynamically affects human being and experience" (Nassy Brown 2006, 11). Thus, I contend that the borderland, or "border situations", specifically those places that constitute the trans-ethnic alternative New South, are just as much a reflection/producer of the alter-native identities that inhabit and imagine them as they are identities in themselves (Nassey Brown 2005, 131). This interchangeable relationship between the objective world that constitutes place, and those humans who inhabit place, is what I put forth as an embodiment of borders (Csordas 1990; Thrift 2008; Nassey Brown 2005; Agier 2016). This embodiment is reflected in the conversations, observations, and experiences of my black American and black immigrant participants and their placemaking within the trans-ethnic alternative New South.

Lastly, this chapter argues that the spaces, places and identities that designate East Charlotte as a trans-ethnic alternative New South borderland produce a “cosmopolitan condition." Agier (2016) argues this "condition” of cosmopolitanism "is the experience of those men and women who experience the concreteness and roughness of the world", the "ordinary experience" of "crossing borders", and those border 
situations in which "the relationship with the other is put to the test, with an unknown who is also the embodiment of what the world is for those who find themselves there, arriving at the border" (Agier 2016, 76). Agier's "cosmopolitan condition" greatly differs from the generic notion of 'cosmopolitan', that of a "globalized" way of life, international business, multi-culturalism, Ang's (2001) idea of "together-in-difference" and even Gilroy’s (2004) “cosmopolitan conviviality” that highlights "processes of cohabitation and interaction" that endeavors toward multi-culture as an ordinary aspect of life. I am not dismissing these arguments, I am however compelled to see these definitions as simple regurgitations of New South rhetoric that markets Charlotte as place despite deeper and more complex histories and realities (Agier 2016, 74; Duruz, Luckman, and Bishop 2011, 601). I hold to Agier's "cosmopolitan condition" because like Reyes-Santos trans-colonial kinship model, this concept allocates the agency of the city, the city's being, and its cosmopolitanism to those black and brown subjects that occupy and create the borderlands of the alternative New South. This chapter is an exploration of the trans-ethnic Alternative New South borderland(s) and its alter-native border-dwellers illustrating the ways in which black and brown subjects practice diaspora in their construction of borders that are "good for living."

\section{Intersectional Kinship: SuCasa, Queens Collective, and Snug Harbor as Safe Spaces for Alter-Native Black Subjects}

I begin Chapter Five with a description of one of many visits to SuCasa at Petra's Piano Bar in East Charlotte. Yet, it was my first visit to the monthly event and a live performance by the local band "Blame the Youth" that convinced me of the significance 
this site would hold in my research. I later discuss an instance in which I accompany one of my central interlocutors to another Blame the Youth performance at Snug Harbor. Through my time "hanging out" in the alternative New South, I came to recognize many of the members of the band as part of a small multi-cultural local social network of artists, activists and performers: those I deem as "cultural workers" in the city. Upon entering SuCasa at Petra's on my first visit, I was greeted with the stunning cinematography of Göran Olsson's 2011 historical documentary, “The Black Power Mixtape 1967-1975." Although silenced in order to simultaneously draw attention to the old school Hip Hop and R\&B playing on the inside, the bold images of the Black Panther Party and footage of unseen interviews with Stokely Carmichael, Kathleen Cleaver, and Angela Davis emblazoned on the large screen inside seemed to make an immediate public announcement that this is not just a black space, it is a radical and revolutionary one. After exploring the inside and outside of Petra's Piano Bar, gaining a feel of what SuCasa was all about, the interesting petite black woman with blown out pink hair in a little black dress and ripped fishnet stockings, Jasiatic, stepped on stage to announce on the microphone that the band would soon be taking the inside stage.

Blame the Youth is a group of self-identified non-binary/gender non-conforming individuals of color. The lead singer at the time was a young early twenties Mexican transgender man, while the other members who also sing as well as play the drums and guitar are all black. The band commenced with a few of their own songs and then proceeded to "bring the house down" with their upbeat cover of Jill Scott's Go-Go inspired classic "It's Love." The lead singer belted out the lyrics, "Do you want it on your collard greens? Do you want it on your candy sweets? Do you want it on your 
pickled beets? Give it to Me, Give it to Me, Give It! Do you want it on your rice and gravy? Do You Want it on your biscuits baby? Do you want it on your black eyed peas? Feed it to me, feed it to me, feed it!" before smoothing out his voice in the sweet reprise of "its love OOOOweeOOO." The crowd responded with uncontrollable "Yeas!" while swaying their hips, bouncing shoulders, strongly nodding heads, and hands waving and pumping in the air to the pronounced drums and snares of the Go-Go beat as this young mustached man perfectly hit all of Jill's notes. Taking a moment from my own Jill Scott/Go-Go trance, I looked up and around the crowd and realized there in that time and space, an assortment of black and brown men and women, of all sexualities, genders, and ethnicities were jamming to a gender non-conforming band with a Mexican trans lead singer...in North Carolina. You see, at SuCasa, the beauty of Diaspora Love is that the event attracts those that attend the all black American clubs in Charlotte, the "trappers" and "hood dudes" i.e. those associated with working class neighborhoods, just as much as it attracts alternative black American and black immigrant artists, performers, intellectuals of varying socioeconomic backgrounds and those of us in between. If we recall Diaspora Wars, there is a clear necessity to raise those inter-ethnic and intra-racial quarrels concerning gender and sexuality, or on-going issues of homophobia throughout black communities in the Diaspora. Yet, in that Jill Scott/Go-Go/gender non-conforming moment these spats were seemingly released, even if temporarily. What I am saying is that when I lifted my eyes from my Jill Scott/Go-Go trance, I was captivated by the sight of presumably heterosexual black men, of course among other black men that may/may not identify as part of the LGBTQ community, in polos, baggy jeans, gold chains, fitted caps, and fresh Jordans and Timberlands raising their hands in the air and bopping their 
heads - and with no other way to say this in order to emphasize my point — not giving a damn about the sexuality or gender of this band and the mustached lead singer and his soprano voice that hit all of Jill's notes. I knew then that the mysterious pink-haired woman who took the stage to introduce the band had successfully created, established, and maintained a riveting and powerful place of inclusion and belonging, a sacred diasporic community.

The LGBTQ community is ostensibly visible at SuCasa. In addition to Blame the Youth, several of my self-identified queer and black immigrant subjects suggested both SuCasa and Petra's in general as go-to spaces for those apart of the community. When I revealed my observations to Jasiatic and inquired about this presence and most notably the significance of the space for this community and belonging, she responded with the following:

“Absolutely, oh absolutely yea, that's always a number one personal aim: to be completely inclusive of all aspects of everyone. And SuCasa is a very safe space and even like-- breaking up the monotony [of Charlotte], anyone can come and feel comfortable. I've had-there's been some dialogue-there have been people before that have said, 'ahh I came but there's...you know?' And I have to be very clear with them and say, you know, SuCasa is for everyone, and I have zero tolerance for any of your -isms so you know if you don't want to- this is what we do--this is very inclusive of every single person no matter how they identify whether they identify as trans, identify as - this is a safe space for them to dance and be themselves and be home. So [at] SuCasa, that's always a goal, an aim, yea so I'm happy that people feel that way. And it's interesting 
because when you really sit down and listen to Reggae, you know a lot of times, there's stuff [homophobic lyrics] that's just outrageous essentially, and the shit has to stop here, and we have to draw lines that say this is not to be tolerated."

Keeping with Reyes-Santos' transcolonial kinship model, which she posits as a transcolonial kinship fostered through political, social and cultural ties among those in the Antilles, she argues that it is necessary to explore the ways in which antillanistas imagined, or reimagined Antillean brotherhoods, communities, and families that had historically been interpreted through "filial" relations with European nations (ReyesSantos 2015,30 ). It was the work of those "revolutionary anticolonial thinkers" to combat slavery, colonialism, and racial subordination in order to build regional brotherhood and political communities that "mobilized particular imaginations of interracial and interethnic relationships and narratives" (Reyes-Santos 2015, 30). Therefore, at certain points in the varied histories of the Antilles, it became necessary to acknowledge and address those "family secrets" before embracing notions of transcolonial kinship. In the Antilles, among those inconvenient truths were racism, slavery, and colonialism as well as transnational hierarchies among nations that ultimately positioned the Dominican Republic, and Haiti especially, at the bottom. In order to further build upon Reyes-Santos' presentation of "imagined communities" (Benedict Anderson 1983) and kinship, by reattaching these theories to the local, I want to first suggest that homophobia remains one of the inconvenient truths of the Diaspora, which Jasiatic highlights in her mentioning of Reggae and Dancehall lyrics, many of which are extremely violent toward those in the LGBTQ community. Even if we look to 
the some of the critical thoughts underlying Afrocentrism, there is an outright denouncement of queer black identities. Completely overlooking the contributions of queer black activism Molefi Asante contends that, "homosexuality cannot be condoned or accepted as good for the national development of a strong people" (Ransby 2000, 220). Again, Afrocentrism is implicated in reinforcing Eurocentric heteronormative structures and ideals. In turn, Jasiatic seeks to acknowledge and rebuke this "family secret" by creating a safe space that speaks to the intersectionality of black subjectivities.

Attaching a transcolonial narrative to the local, I move toward what Rodman (2003) puts forth as "multilocality" and "multivocality" in the effort to "empower place." Concerning multilocality and "multi-locale ethnography", Rodman (2003) cites George Marcus's goal to "eliminate distinctions between the macro and micro levels" and to instead seek an ethnography that "encompasses local conditions" that aims to represent "system or pieces of system" (Rodman 2003, 210). The multilocal and in turn, multivocal space provides a meaning that is "comparative", "contingent" and "reflexive", or in other words, expresses "polysemic meanings" for those that come to inhabit it (Rodman 2003, 213). Considering the multilocality and multivocality of space guides us to Giddens "environment of trust" that forms the basis of kin relations, local communities, cosmology and tradition, all of which are not only place-based, but reflect an imagery critical to reclaiming place (Rodman 2003, 209, 213). By bringing to the forefront Reyes-Santos' arguments from a regional and global perspective to those I present as local manifestations, I contend that in a similar fashion that Antillean "founding fathers" sought to reestablish various forms of kinship ties that challenged those of their Europoean colonizers, similar operations take place among black 
Americans and immigrant cultural workers and agents in Charlotte who seek to establish, "empower", and protect places that not only challenge the status quo of Charlotte but also those "family secrets" that underscore Diaspora Wars.

Considering her desire to provide not only a safe space that actively constructs and empowers a place for artists, performers and vendors to display and sell their work as well as patrons that resemble the diversity of the Diaspora, I am compelled to envision Jasiatic as a mother. However, I present Jasiatic as a mother, not in the matter-of-fact sense as the self-proclaimed "baby maker" she defines herself as, nor necessarily in the sense of the black women architects of Juneteenth discussed in Chapter Five. Instead, there is a desire to align Jasiatic with, or should I say envision Jasiatic as a mother for what it signifies in the clandestine Ballroom Culture of the LGBTQ community most notably displayed to the public in Jenny Livingston's (1990) documentary Paris is Burning. Within this arena of the LGBTQ culture and community, transgender women and sometimes men serve as mothers in order to recruit, foster and nurture other young mainly black/brown/LatinX performers of the community in the ballroom scene (Bailey 2013). To avoid conflicting or deflecting the significance and agency of "mothers" or "muthas/muvas" in the ballroom scene/LGBTQ community to that of cis gender women and heteronormative familial structures that many queer individuals are often vehemently ousted from, I aim to make this alignment in a way that likens Jasiatic with those who foster and nurture alternative kinship formations, and in turn alternative communities. These alternative kinship formations and communities offer spaces where those who are marginalized, not simply based upon race or ethnicity, but sexuality and gender can find belonging, and a family. In addition, mothers in the Ballroom scene serve not only to 
nurture their oftentimes displaced and/or marginalized "children", they also serve to hone their performative and artistic expressions and realizations. Their work as cultivators of family, art, and expression underscore what Marlon Bailey's (2013) ethnography Butch Queens Up in Pumps presents as another dimension of the "Labor of Diaspora." Considering Jasiatic as among the few in Charlotte that acknowledge and provide safe spaces that embrace the intersectionality of black/brown patrons, artists, and vendors, I pose the juncture of mother, cultural worker and agent in the "labor of diaspora"; labor signifying birth as well as the molding that ensues afterwards. I use the metaphor of birth and nurture to signify the construction and fostering of an Alternative New South for those black and brown subjects who may exist on the fringes of society.

Jasiatic's "labor of diaspora" leads us to those thoughts and theories that specifically address the complexities of queer black immigrant identity and subjectivity. I align this "labor of diaspora" with what Rinaldo Walcott's (2016) Queer Returns calls the creation of contexts of "diasporic sensibility and consciousness" (Walcott 2016, 13). Walcott centers his arguments within the realm of Canadian theatre and performance, what he holds to be representative of "diasporic aesthetics" (Walcott 2016:13). In accordance, "diasporic sensibility and consciousness", and in turn "diasporic aesthetics" concern "the piecing together of all the ways in which diasporic expressions of blackness can fashion a commentary on its nationally-local and global conditions" in an “uncompromising” manner (Walcott 2016, 13-15). For Walcott, black Canadian theatre stirs "dramatic instabilities" that are not negative in consequence but are instead instabilities "dramatic in their demands for a more ethical constitution of the nationallylocal scene and condition for making a life that is Black and livable both national and 
international" (Walcott 2016, 15). Jasiatic, then as "mother" and cultural worker in the labor of diaspora endeavors to practice the "ethics of diaspora" (Walcott 2016, 15, 133). While I am again referencing Edwards' $(2001 ; 2003)$ concept of "practices of diaspora" that in which "diaspora is forged through exchanges across diverse subjects," I am equally emphasizing Walcott's argument that "when the ethical is inserted into the conversation as a form of concern, some different manner of outcome may be expected" (Edwards 2001; Edward 2003; Queeley 2015a; Walcott 2016, 14). By constructing and reassuring a "safe space" for black queer subjects, Jasiatic inserts an "ethics of diaspora" resulting in a scene, a condition, a situation, an aesthetic that speaks to/demands a "life that is Black" and fashions a commentary on national-local and global conditions in an "uncompromising" manner. Walcott's exploration of black Canadian theatre offers another articulation of diaspora that more explicitly involves a consideration of queer black/brown immigrant experience, identity and subjectivity. Positing Walcott's analysis as an articulation, I am conjuring Stuart Hall who puts forth articulation as a complex structure and/or discourse that allows for "difference within unity" (Edwards 2001, 59). With this, I seek to demonstrate the ways in which structures of kinship and performance premised on ethics, sensibility and consciousness are manifest within the space of SuCasa. SuCasa then is a particular articulation of diaspora that recognizes "a necessary heterogeneity and diversity; by a conception of 'identity' which lives with and through, not despite, difference" (S. Hall 1990; Edwards 2001, 60). Spaces and places like SuCasa allow black/brown subjects to embrace their alterity and/or alter-native identities. Operating as an articulation of diaspora, the core social network of those black/brown 
subjects that inhabit SuCasa are another elemental structure that emerges in and constructs other spaces and places throughout this trans-ethnic alternative New South.

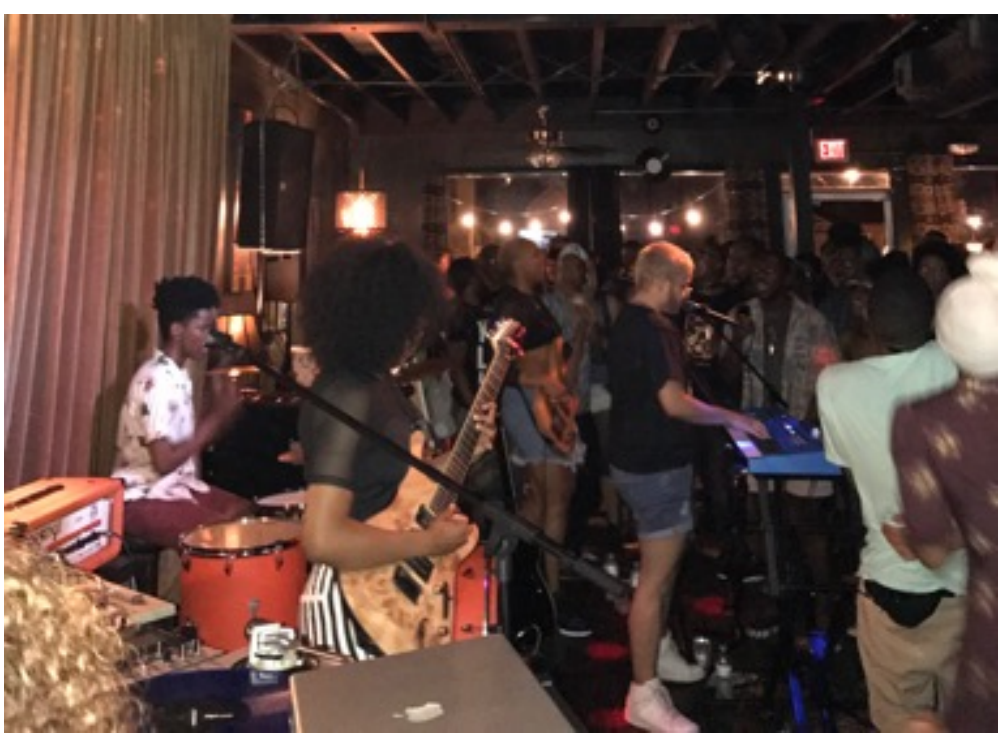

Figure 6.1. Blame the Youth performs at SuCasa at Petra's Piano Bar in East Charlotte. Photograph by Author.

I introduce Carolina in Chapter Three, a 26 year old self-identified "Black Latina, Afro-Brazilian, Afro-Latina, LatinX all those things" from Minas Gerais Brazil who at the time was completing a Master's in Latin American Studies at UNC-Charlotte. Following our official interview, we continued our conversation in the car as we headed out to my first venture at a Queens Collective event. In addition to Petra's and SuCasa's, Carolina stated that Queen's was an important space that made her feel "at home" in Charlotte. It was during this outing with Carolina that I began to process the central arguments of this dissertation. Queen's Collective is a community organization that supports "local culture" and maneuvers itself throughout the city hosting events at various East and West Charlotte venues, which this night was held at Area 15. Area 15 is a co-operative studio that hosts a series of other community organizations/events 
including those that branch out from the Brazilian Arts Center. We entered the small studio door and later they let up the adjacent garage door in order to offer the April night air into the small space decked with paintings from local artists and the small makeshift stage placed in the center of the room. Carolina was excited to introduce me to her friend Quisol, who was performing that night. Quisol identifies as queer LatinX/ Puerto Rican/Phillipino. I would get to see Quisol perform at other Queen's Collective events during the spring and summer of 2017. After a couple of different performances, Quisol took the stage and almost immediately, I was captured by his smooth voice, the soothing chords of his guitar that accompanied him and his calming stage presence. Yet, aside from his neo-soul-Latin Caribbean inspired set, I was most taken aback by the ways in which Quisol incorporated activism into his songs and intervals between. During one interval, with African/Caribbean drums in the background, Quisol pulled out his phone to read a poem he had written speaking against on-going and recent anti-immigrant legislation both nationally and locally, recognizing the fact that he was born to immigrant parents. He went on to speak against the oppression of black and brown peoples and police brutality, specifically addressing the Keith Lemont Scott killing in the city. As I held up my phone to record, I recall a young black woman who I discovered had recently graduated from Johnson C. Smith University and wanted me to send her a copy of my recording of the poem. It was a powerful moment.

Prior to my initial visit to SuCasa, in an excerpt from my field notes, I began to lay the foundations for the central arguments of this dissertation based upon this experience at Queen's Collective: 
"In combination with the actual diversity of the space as well as the LGBTQ friendly environment, the eclectic mix of music, [it] was perhaps one of the most eclectic, unconventional and diverse spaces I've seen in Charlotte. I see it as the construction of an alternative space; alternative to other spaces in the city in terms of race, nationality, sexuality, gender etc... In addition, the actual vibe through a range of alternative music, through both modern and traditional instruments and the people there served to construct a space of belonging." -Field Notes, 7 April 2017

That evening as I recorded these notes, I began to nickname this collective of individuals as the "cool kids of Charlotte"; a group of black and brown immigrant and American young adults mainly in their twenties who are active in the intellectual, arts, immigrant, and queer communities. The overwhelming sense of acceptance, consciousness and freedom the space evoked led me to envision it as a "Zona Libre" or Free Zone. My usage of the term is not to be confused with the name given to those free trade zones and sites of economic exploitation in Latin America. Instead, in my attempt to (re)place agency, I use the term to suggest a strong contrast between spaces such as Queen's and SuCasa that (dis)place the confining clean, neat and racialized spaces of Uptown and Southeast Charlotte.

About a month after our time at Area 15, in which Carolina and I developed our friendship/ethnographic relationship, she invited me to another one of her favorite places, Snug Harbor, where one of her favorite bands, Blame the Youth was performing. I was excited and notified her that I was familiar with the band. Snug Harbor is a cozy little bar/club/venue located off of Central Avenue's main stretch, around the block from Petra's Piano Bar, Reggae Central and House of Africa. This night, I was granted not 
only the opportunity to see and enjoy another Blame the Youth performance, I was also able to mix and mingle with some of the band members as well as Carolina's other friends and acquaintances, all of whom roam within the same alternative cultural and social network. Like Mrs. Tina in Chapter Four, Carolina jokingly introduced me as "the researcher" before presenting my actual name to her friends. Carolina's friends like the space itself were a multicultural group of individuals of color and were either black American or first or second-generation immigrants born to parents from across the globe; Palestine, Colombia, and Mexico were among those countries represented that evening. Despite being a long-standing spot on this stretch of Central, this was my first time at Snug Harbor. On this Tuesday evening, there was a handful of white individuals, while the majority were black/brown, who in terms of fashion and creative expression displayed their alternative self-representations through varying hair colors and styles, piercings, tattoos, shaved heads, natural hair, etc. This representation of an "Afropunk" Charlotte stood as a blatant and intentional embrace of alterity, or a diasporic aesthetic that transgresses not only the "normalcy" of Uptown but also definitions of blackness and particular articulations of diaspora. Therefore, similar to my discussion of Juneteenth and Reggae Central in Chapter Five, fashion and creative expression as aesthetic operates as politic within the makings of alternative New South spaces and places. These are the moments and expressions that temporally align Charlotte to traditional gateway cities like New York City, Los Angeles, and Miami. In these times and spaces, alterity and the Other are actually normal. The temporal and spatial normalcy of the Other reiterates that the heart of Charlotte's cosmopolitanism lies not in the corporate air of Uptown, but the 
colorful, expressive, artistic individuals I saw at events and places like Queen's Collective, Snug Harbor and SuCasa.

Once the crowd began to dwindle following the live performances, the DJ continued to spin a range of Afrobeats and Hip Hop that moved into popular Brazilian songs. Carolina pranced and danced around the outdoor patio singing lyrics to the songs and belting out Portuguese expressions of joy and happiness. In between trances of dance and singing, Carolina took breaks, coming over to confide those specific moments that thrilled her. One of these moments came at the end of the night, as Carolina relished in the range of Brazilian music, from pop music to samba. With breathless excitement in her voice she expressed that as a "Black Brazilian" listening to Black Brazilian music at an American bar was an "incomprehensible" feeling. As I reflected on her reaction to the music that night, I recorded in my field notes that 'I'm not sure if I could even fully describe the sense of what it must feel like to be her and to hear her music in this random spot in Charlotte." Conjuring my own memories of being black American abroad, even as black American music is extremely popular abroad, to hear the particular songs you thought only black Americans knew, and to hear those songs play in some random steamy hot Colombian nightclub among people who look like you or relate to you but perhaps are not of your particular background is what I imagined Carolina's immeasurable excitement to feel like. Atop of her sense of ease and comfort in being in this open, free and familiar environment where she knew the people, the band etc., Carolina elaborated on her identity as a queer Afro-Brazilian in Charlotte and mentioned that she was awaiting her Brazilian partner to receive the correct paperwork that would bring them both together here in Charlotte. Carolina was looking forward to sharing 
these moments with her partner. This moment evidenced that those affects of love, enjoyment, joy, nostalgia triggered by certain music, people, and things established an affective kinship that crossed transnational boundaries. In turn, affective kinship formations do not only build and sustain an alternative trans-ethnic community in the local but globally. Further, through my time with Carolina at Queen's Collective events and at Snug Harbor, I began to see these spaces and places as moments of black and brown solidarity.

There were two central inquiries that inspired this dissertation. Initially focusing on Afro-Latinos in the South, I noticed that, with the exception of Bobby Vaughn's (2005) (2007) study of Afro-Mexicans in Winston Salem, North Carolina and Hannah Gill's (2010) sociological study of Latino immigrants in rural eastern North Carolina, scholars of Latino immigrants in the South rarely engaged the experiences of, or even acknowledged Afro-Latinos or indigenous populations for that matter. When scholars of Latino immigration in the U.S. South such as Stuesse (2016) and Marrow (2011) do mention distinctions in race, color, ethnicity, they seem to focus on either Latino-White American relations and/or Latino-Black American relations, the latter of which is almost always contentious while relations with white Americans appeared to be more amicable and negotiable. I recognized that oftentimes these scholars failed to consider how processes of racialization in countries of origin in addition to the specific color/caste of an individual impacts one's perception and experience of racial and ethnic belonging in the U.S. South. As a result, I was drawn to John D. Marquez' (2013) study of black/brown solidarity in the New Gulf South. Marquez contends that the ways blackness and latinidad have been produced as racial and ethnoracial signifiers of 
"deficiency and criminality within the assemblage, organization, and governing bodies that constitute the South as a racial/colonial formation" have yielded conditions for the amalgamation of black and brown subjectivities that result in a "shared consciousness" (Marquez 2013, 32). With this, Marquez presents the concept of a "foundational blackness" which he defines as "the ways collective memories of black antiracism...that is, an oppositional culture derived from African American history and responsiveness to expendability" undergirds how Latinos/as have formed their own methods of survival and resistance (Marquez 2013, 33). Black popular culture and black art forms are often those central mediums through which black and brown subjects make symbolic connections rooted in collective memories of displacement and oppression that produce "hybrid cultures" (Marquez 2013, 49, 50, 51). The production of "hybrid cultures", rooted in a "foundational blackness" that is exchanged and processed through mediums of black popular culture and art forms offers another lens through which we can view an affective kinship between black and brown subjects in the South.

At the very end of summer, I received an invite from Carolina to attend a Queen's Collective event at Bennu Gardens in Camp North End. It was one of my last and perhaps one of the most critical events I attended during my span of ethnographic research, even though the venue was located outside of East Charlotte. Camp North End was first a Ford Factory that produced Model Ts in the mid 1920s and later became a U.S. Army Missile Plant in 1941 and as such is comprised of several large warehouses and bunker like buildings. The space has been transformed into a range of small art studios, co-opt and non-profit business spaces and a variety of other multi-use indoor and outdoor spaces located in the Seversville neighborhood at the entrance of West Charlotte, 
just one-mile from Uptown. Similar to portions of East Charlotte, the historically allblack neighborhood of Seversville is undergoing dramatic demographic and economic shifts due to gentrification. Bennu Gardens located behind the large warehouse-like structures, is a black/brown managed community garden that endeavors to provide fresh farmed food, youth activities, and to teach black and brown peoples healthy sustainable living. Bennu Gardens is part of several other efforts to reclaim space and place for black and brown people living in Charlotte, some of which I discuss in Chapter 1. Still, Bennu aligns with the goal of Queen's Collective by demanding the visibility of marginalized groups of people through arts, activism and sustainability. There were several significant happenings on this evening. First, headlining the event was Quisol, this was his last performance before leaving for graduate school at Harvard University. Next, there were samba and capoeira performances by those in the Brazilian Arts Community. Finally, Carolina's partner had finally arrived in Charlotte and this was her first outing in the city. Upon arriving by myself as Carolina had not yet arrived, I was greeted by familiar faces, all of whom I had met while researching i.e. hanging out at SuCasa and/or with Carolina at other spots, or through the Brazilian Arts Community. I even saw one of the planners and vendors of the Juneteenth Festival who was there selling her famous pineapple fruit drinks. Among this crowd of new and familiar black and brown faces, a young black man maneuvered through the outdoor space with a burning stalk of sage and in the front, just below the main stage, Josiah Derricks danced, waiving his arms and legs almost in sync with the looming smolder of the sage that seemingly glided to the rhythms floating above in the summer evening air. The saging of the outside former factory and bunker seemed to clean and clear the space, providing an energetic and almost spiritual aura. 
Upon walking in or down the hill to the outdoor space, Celeste was in the middle of giving a shout out to the very present "family vibe" defining the space that evening. Attesting to this vibe, I began to process a sense of affective kinship through the ways individuals spoke to one another, sparking conversations with strangers, and offering compliments; indeed, this mode of communicating with others in itself, is how I met and came to know many of those in this trans-ethnic alternative community. When I finally conceded to use the outside Port-a-John in spite of wearing a romper (a one-piece jumper) that buttoned in the back, I relied first on a stranger, a young black woman to unbutton the back. Apparently, witnessing my struggle to reach my arms to the buttons on the upper back of my romper, the young woman interjected with, "girl, let me help you, you know I know how it is." I then ran into Janelle, who I knew from Capoeira and the League of Creative Interventionists who immediately assisted my re-buttoning. Though this was a particularly comical predicament, these were the sorts of interactions that provided comfort and familiarity in the space of Queen's Collective.

Shortly thereafter, Carolina arrived and we quickly met up in the midst of what had turned into quite a small crowd. As the night ensued, Carolina mentioned that the outside industrial space of Camp North End reminded her of Brazil, where there may not be actual space to hold events, especially for Afro-Brazilians, so instead they oftentimes hold them in random spaces, or parking lots. In addition, the concreteness and industrial buildings of the former factory and military bunker offered a sense of home for Carolina. As mentioned, I finally had the opportunity to meet Carolina's girlfriend. With them, was Carolina's other friend Maria, who was also Brazilian and currently lived in Charlotte. Briefly after meeting up with Carolina, Maf, a black American and Juan, a 
mestizo from Venezuela (both of whom I met during Capoeira classes at the Brazilian Arts Center) took the stage to perform or "play" Capoeira for the audience. Afterwards, Adriana, a member of both Capoeira and Samba groups and another young black woman (ethnicity unknown) took the lower center concrete paved stage to perform Samba. At the end of their performance they called upon the crowd to join. Carolina and her friends ran to the center expressing extreme delight while dancing along and yelling what I have come to believe to be Carolina's favorite Portuguese term, "Gente!" Similar to our time at Snug Harbor, she ran over to me to confide that dancing to and hearing Samba in Charlotte is "the heat in her heart, a heat she feels in Brazil." Carolina further revealed that having her girlfriend here from Brazil, and the ability to now connect and introduce her to the community of friends, the family she's made here, brought her great happiness. 


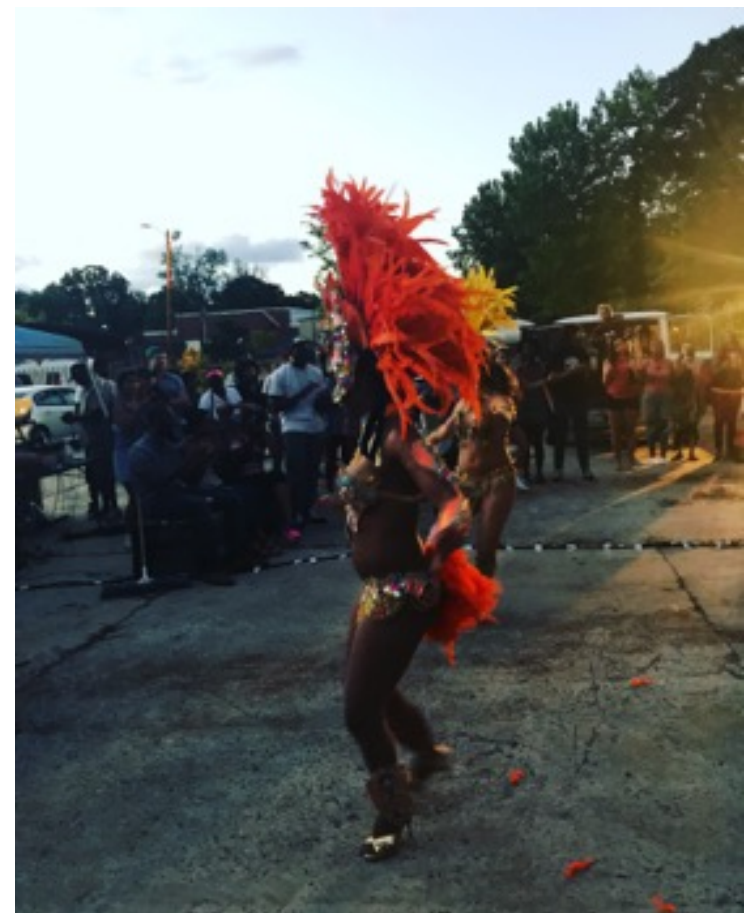

Figure 6.2. Adriana, a Latina (in background) and a young Black Woman, ethnicity unknown (at the forefront), members of the NC Brazilian Arts Project perform Samba for the Queen's Collective crowd at Camp North End. Photograph by Author.

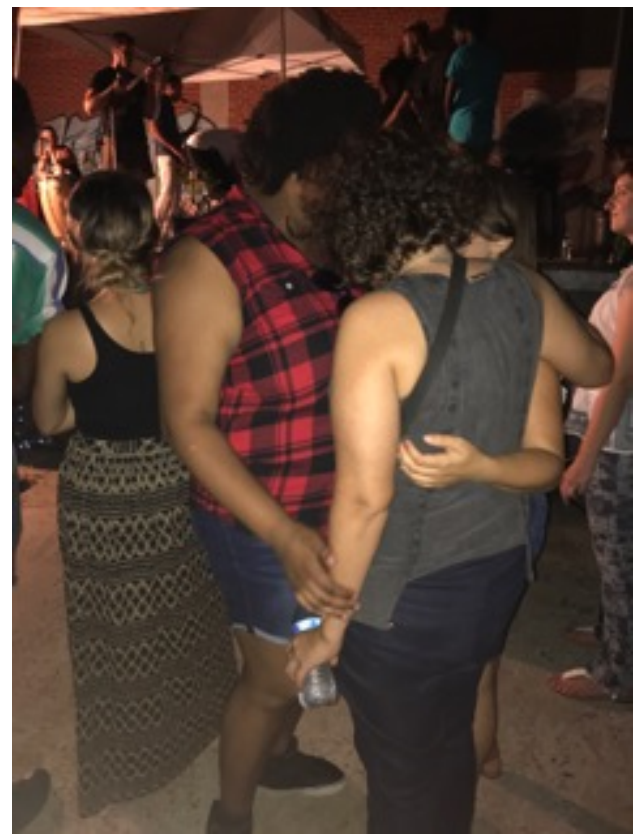

Figure 6.3. "Heat in her Heart." Carolina, her Brazilian partner, and Brazilian friend embrace in a moment of love triggered by the music and Carolina's reunification with her girlfriend. Photograph by Author. 


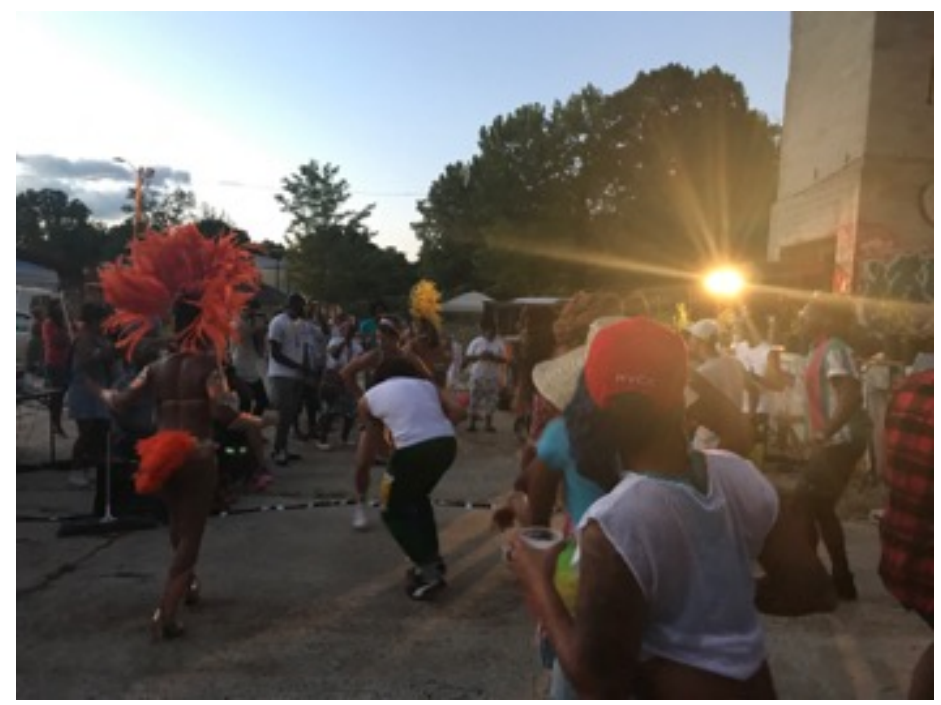

Figure 6.4. After both Samba and Capoeira performances by the NC Brazilian Arts Project, they signal for the crowd to join in on the dance floor, the outdoor concrete dance floor is flooded with footprints of Samba. Photograph by Author.

Queens Collective, Snug Harbor and SuCasa are all indicative of alternative spaces in that they are welcoming to all people, particularly people of color, LGBTQ friendly, and establish spaces and places of belonging based upon sensibility, consciousness, and alterity. This is revealed through the performances, the music and the actual people, a community of sorts that culminates a social network of artists, activists, performers, and vendors. In all of these spaces, there is a familial "vibe", an affective kinship constructed through music, performance, other forms of material setting, and the intersection of black/brown identities/subjectivities that may or may not share similar experiences of oppression, invisibility and marginalization. Therefore, I reiterate the consequence of an aesthetic, a diasporic aesthetic that operates as politic for black and brown peoples in Charlotte. I could have perhaps evaded the latter description of Queen's Collective at Camp North End as it is not located in East Charlotte, which is the primary area of this dissertation's focus. Yet, I found Queen's at North End fascinating 
first in the fact that the Seversville neighborhood is undergoing similar transitions as portions of East Charlotte, and second and most importantly because of the symbolism that lie in transforming a former Ford Factory and U.S. Army Missile plant, both of which epitomize U.S. imperialism/capitalism into a space of belonging for marginalized groups of people. Finally, I was drawn to the nostalgia for home as well as the love, the "heat in her heart, a heat she feels in Brazil" that the outdoors concrete paved dance floor and the beats of Samba bouncing against those tall bricked prison-like structures glazed by fragile window-panes evoked from Carolina and her friends.

I return to the colloquial usage of "vibe", which I link to an expression of affect in Chapter 4 and throughout this chapter as well. Tompkins conceptualizes affect "as an entire vital and modulating field of myriad becomings between human and nonhuman", a "transformative force" that is intimately involved with but also distinct from feeling and emotion suggesting that while affects play a role in feeling and emotion, they are discreet and innate although not necessarily private and obscure. These private and obscure moments are expressed primarily in the face and I would contend other bodily behaviors/movements (Thompson and Biddle 2013, 7). In accordance with Thompson and Biddle, Tompkins puts forth nine central affects; “enjoyment-joy, interestexcitement, surprise-startle, anger-rage, distress-anguish, fear-terror, shame-humiliation, disgust-and 'dis-smell'” (Thompson and Biddle 2013, 7). In Chapter 4, I focus on the "vibes" and affect evoked from particular places and people that display "fear-terror, shame-humiliation, disgust and dis-smell" primarily through facial expressions and additional active displays of avoidance, disdain, and disgust. However, continuing with the theme of Diaspora Love underlining these last two chapters, while I aim to emphasize 
those moments of enjoyment, joy, interest/excitement, it is still necessary to divulge the significance of anger-rage, distress-anguish, and fear-terror in their service of a Diaspora Love. The latter affects of anger, distress, fear etc., are signified through Quisol's poem speaking against anti-immigrant legislation, black/brown oppression, and police brutality including the Keith Lamont Scott killing at my first Queen's sponsored event as well as a protest song (performed at Camp Northend) dedicated specifically to the Scott killing. Therefore, I argue that the collision of affects such as excitement, enjoyment, anger, fear, terror, or what Gaye Theresa Johnson (2013) puts forth as "constellations of struggle" among marginalized groups of color can in particular border situations, establish a collective empathy and solidarity. This dramatic collection of affects in the places, spaces, moments I have described above are represented through a particular diasporic aesthetic that enables sensibility and consciousness and operate as politic.

According to Thompson and Biddle (2013) music and sound can be used to "create a particular ambiance or atmosphere, via the induction, modulation and circulation of moods, feelings and intensities" that can be felt but "at the same time belong to nobody in particular" (Thompson and Biddle 2013, 17). Further, music and sound permit a (re)thinking of "authenticity, affiliation, and identity" allowing us to move beyond "true/false binarisms" as affect arises in the midst of "in-betweeness" but also "may stick" onto the subject (Thompson and Biddle 2013, 6). For those black and brown subjects I have deemed as border-dwellers, through their shared sense of "in-betweeness" within those border situations, music and sound are central in forging solidarity. To expand upon this notion, I return to Johnson's conceptualization of "spatial entitlement" or "a way in which marginalized communities have created new collectivities based not 
just on eviction and exclusion from physical places, but also on new imaginative uses of technology, creativity, and spaces" (Johnson 2013:x). In accordance with Johnson, spatial entitlement creates "new articulations, new sensibilities, and new visions about the place of Black, Brown, and working-class people on the local and national landscape" (Johnson 2013: x). Johnson advances her arguments through an exploration of the role of music in fostering black and brown solidarity, place-making and activism among working class Black and Mexican Americans during the social, cultural, and political movements of the late 1960s to 80s in Los Angeles. For Johnson, spatial entitlement encompasses the sonic realm, which is "not merely a matter of frequency and vibrations" but also entails the construction of social "soundscapes" (Johnson 2013: 2). Here, Johnson builds upon Appadurai's (1990) concept of -scapes, which I also do in chapter 4 in my discussion of ethno-scapes. Appadurai uses the particular terms such as ethno-, media-, techno-, ideo- with the "common suffix -scape to indicate first of all that there are not objectively given relations which look the same from every angle of vision, but rather that they are deeply perspectival constructs, inflected very much by the historical, linguistical and political situatedness of different sorts of actors", diasporic communities being among those (Appadurai 1990:296). With this, like other scholars of blues, salsa, banda, etc., within the social soundscape, music provides and constructs a home for which dispossessed and displaced populations can never be evicted (Johnson 2013:2). In Johnson's analysis of Black and Mexican Americans in Los Angeles, these populations were able to not only become visible to one another through physical space, but audible to one another through sonic spaces (Johnson 2013:2). Thus, efforts towards spatial entitlement and in turn visibility and recognition, require more than just physical 
space in order to survive. As spaces possess social meanings, they serve to maintain memories and preserve practices that "reinforce community knowledge and cohesiveness" aspects that realign this discussion with ritual and kinship (Johnson 2013:48). In turn, "aggrieved" subjects seek to enact their claims by whatever means are available, and in the cases discussed above, this has been the production and consumption of music. In the following sections I discuss this aspect as it concerns other forms of material culture and cultural expression. These forms of expression, especially sound, transform the configurations of urban space, as I have attempted to demonstrate with Camp Northend, Snug Harbor and SuCasa. For the artists, devoted patrons, and cultural workers in the trans-ethnic alternative New South, the challenge is not to "simply acquire new spaces for settlement, but to challenge the logic of racialized space itself - to transform spaces of surveillance, exploitation, and marginalization into sites of solidarity and self-activity"(Johnson 2013:58). Music remains a central factor, however it is not the sole contributor to building the many -scapes constitutive of the trans-ethnic alternative New South.

\section{Cultural Expression, Kinship and Commodity: The Brazilian Arts Center and the Multi-Cultural Familial Bonds of Capoeira and Samba in Charlotte}

"I love that my Black children have this outlet to enhance their physical abilities and connect with another diasporic African culture at the same time. The camaraderie, songs, beauty of movement, fun and grace that they experience is unparallel [sic]. We have practiced capoeira in Brooklyn and Harlem NY, Connecticut and now Charlotte NC"-Anonymous, Brazilian Arts Center participant, Brooklyn NY, USA 
The Brazilian Arts Center, located on Central Avenue across from an Ethiopian/Eritrean shopping center, emerged as a critical field site over the course of my research. I originally met Contra-Mestre Zumbi, an Afro-Brazilian immigrant from Minas Gerais, Brazil in the summer of 2015 during preliminary research. At the Brazilian Arts Center, Zumbi instructs Capoeira, an Afro-Brazilian martial arts most likely derived in Angola and brought to Brazil by African slaves from that country (Obi 2008). Zumbi's name pays homage to Zumbi dos Palmares who was the leader of a quilombo (runaway slave) community established in Palmares, Brazil. While Zumbi's small athletic frame is initially unassuming of such powerful name, I soon realized the many layers of force this quiet dark skin man embodied. Our initial interview took place long before I'd find myself pushing the physical, mental and spiritual limits of my mind, body and soul under his instruction in weekly Capoeira classes. This interview was also well before I possessed the ability to contour my body into a meia lua de compasso, a basic Capoeira move that rotates in the form of a half-moon through a reverse roundhouse kick as well as other strenuous movements and drills with Zumbi yelling in the background, "Vamos Masonyaaaaaa!!!”

I decided to enroll in Capoeira classes at the Brazilian Arts Center simply for the sake of ethnographic research and a Groupon special that offered ten classes for \$30. My ten courses extended into eight months of Capoeira and a monthly student membership fee of $\$ 60$ per month, non-student membership begins at $\$ 90$ and can go as high as $\$ 180$ for family plans. Capoeira transformed from "just" research into a hobby, taking precedence as a personal pursuit to prove to myself what I could achieve mentally and physically. Classes also offered 3-4 weekly hours of peace and mediation through 
physical endurance and the Afro-Brazilian songs and rhythms that accompany Capoeira. My assessment was that it was one of the most difficult and yet most fulfilling activities I have done to date. In addition, during my time at the Brazilian Arts Center, I met, "played" Capoeira with, and relied upon a multi-cultural group of individuals to assist me as I advanced to higher levels. My own beginners' group consisted of Barbara, a young black Haitian woman from France whose boyfriend is a black American at an advanced level of Capoeira and who is also part of the Samba group operating from the same studio; Diane, a slightly older black American woman whose children participate in the Capoeira kids classes and whose black American husband was at one of the highest levels; Juan, a young Colombian mestizo college student from Bogota, with whom I often translated the words of songs and terms for movement/combinations together from Portuguese to Spanish to better understand; Luna, a middle school aged Brazilian girl who I always envied for her youthful flexibility, she'd quickly advanced from the childrens' classes into adult; Jerome who was from India but who I honestly thought was a black American when he told me his name; and Mark, a tall Chinese-Swedish guy from New York City. Outside of our beginner's level group, there were others from Brazil (white and black), from a long list of other countries including Mexico, Puerto Rico, Chile, the Philippines, Kenya, and Nigeria and black and white Americans from across the U.S. At the end of the eight months, my beginner's group earned our green-belt advancing to the intermediate level while others advanced to even higher levels.

Belts were granted at a ceremony held in a large studio space at Camp Northend. In order to receive our green-belts, we underwent three basic fields of examination; learning three Capoeira songs in Portuguese; learning to play three of the central 
instruments, the pandeiro (tambourine), the atabaque (a particular drum of African origin), and the agogô (a wooden cow-bell like instrument), the berimbau (a singlestringed with a gourd base instrument of African origin) is reserved for only advanced Capoeiristas and Mestresii ${ }^{\mathrm{ii}}$ finally, learning three different Capoeira martial art combinations, which we would ultimately display in front of the broader regional, national and international Capoeira community. I excelled in the playing of the instruments and the singing and clapping along, on-beat, to the Capoeira songs. Growing up in the black church, A.M.E. Zion specifically (and Black Baptist or Pentecostal depending on which side of the family I was with at the time), tambourines, drums, clapping and call and response seemed to come naturally to me. Our final test came as we "played" in the roda (pronounced joda) with Mestres from Brazil, California and New York City who came in to Charlotte specifically to observe, approve and belt us.

At the end of this long venture, our beginners' group all hugged one another as well as those from the advanced and intermediate levels. Yet even before this ceremony, almost immediately following the end of my initial ten-class trial, I realized that I had become part of some sort of family grounded in Afro-Brazilian martial arts, language and cultural expression. It was another reason I decided to stay beyond my trial. Therefore, the peace and meditation I gained at the Brazilian Arts Center was equally due to my own sense of home and family provided by the movements, songs, and instruments our African ancestors used to secretly and actively resist slavery even if they were in this other region of the Americas. At the same time, within the space of the Brazilian Arts Center, I relied upon other black, brown and white individuals of diverse backgrounds for encouragement, to assist with my progression and to assure my safety. There were times 
when I literally feared breaking my neck midway through some difficult movement or attempting some jump or flip. It was Zumbi's unrelenting words of motivation and encouragement and belief in me, a belief I did not even possess, that pushed me to endure my struggles, my physical pain, my fears, and even my flailing confidence in performing and playing Capoeira with more advanced students that led me to view Zumbi as a sort of coach/big brother/father figure. There was a small living room space where these children often waited if they were not sitting in the outside studio space. Therefore, there existed a visible level of trust and sense of family between Zumbi and these parents. When I was compelled to end my time at Capoeira because of physical and financial reasons, I felt deep sadness and remorse as it seemed I was giving up on myself, my budding Capoeira family, and most of all, Zumbi. I was also leaving a space of peace and meditation, a space that I had built a personal relationship with, a space that I could walk into and feel immediate relief and lightness albeit never light enough to do ten cartwheels in a row.

Based upon my own subjective experiences and alterations during Capoeira at the Brazilian Arts Center, amidst my time there, I decided to place a "box of feelings" at the front desk. I used this as a stand-in free-list method in order to gauge affects and other aspects of subject-formation evoked by the classes, the bright green painted floors of the space, the music, and the constant twizzles, kicks, twirls, running and jumping that constituted the place. This method proved most effective given that there was little time in between classes. I knew some of the physical effects; twice I witnessed individuals vomit either inside or outside of the studio in between drills while the pain in my left hip remains as one of my own battle scars. Yet, I wondered what participants in either 
Capoeira or Samba felt, why and how they progressed/continued along this journey, their relationship to the space, and ultimately, if we all share similar connections and transformations. On this "box of feelings" I placed a label asking participants to list three to five words or thoughts that immediately came to mind when they think of or participate in Capoeira and/or Samba at the Brazilian Arts Center, and to also include their countries, cities, states of origin, and any additional information they felt comfortable providing. They were not required to include their names. I have kept the majority of participants' responses in their initial format regarding citation. Responses were collected in the box over the course of about two weeks from July 25, 2017 until August 4, 2017. Among the responses I collected, the following (in addition to the abovementioned account) stood out:

"Capoeira is my life philosophy, I am Contramestre Zumbi." From: Brazil. State: Minas Gerais. City: Sete Lagoas"

"My kids take Capoeira. I'm hoping to start soon. I LOVE coming here, watching, and soaking up all the beautiful energy. This space is a magnet for love, unity, happiness, diversity, yummy feelings" -Country of Origin: Kenya, City: Nairobi, Planet: Earth

"It makes me feel happy, athletic, and capable."- North America, United States of America, Charlotte N.C, 10 years old 
"From Colombia: Cultural, Fiesta, Union, Familia, Defensa Personal [personal defense]"-

Anonymous

"Super Exercise, Accomplished, Nice to Meet Other People"-Anonymous

"Less Suicidal Thoughts, Less Loneliness"-Anonymous

"Awesome, Energized, Confident"-Anonymous

"NYC, USA: INCLUDED, APPRECIATED, FIT, FINESSING, Active"-Anonymous

"India, Tamil/Nadu, Tsichy; It is a great experience and good camaraderie"Anonymous

"I feel Alive"-Anonymous 


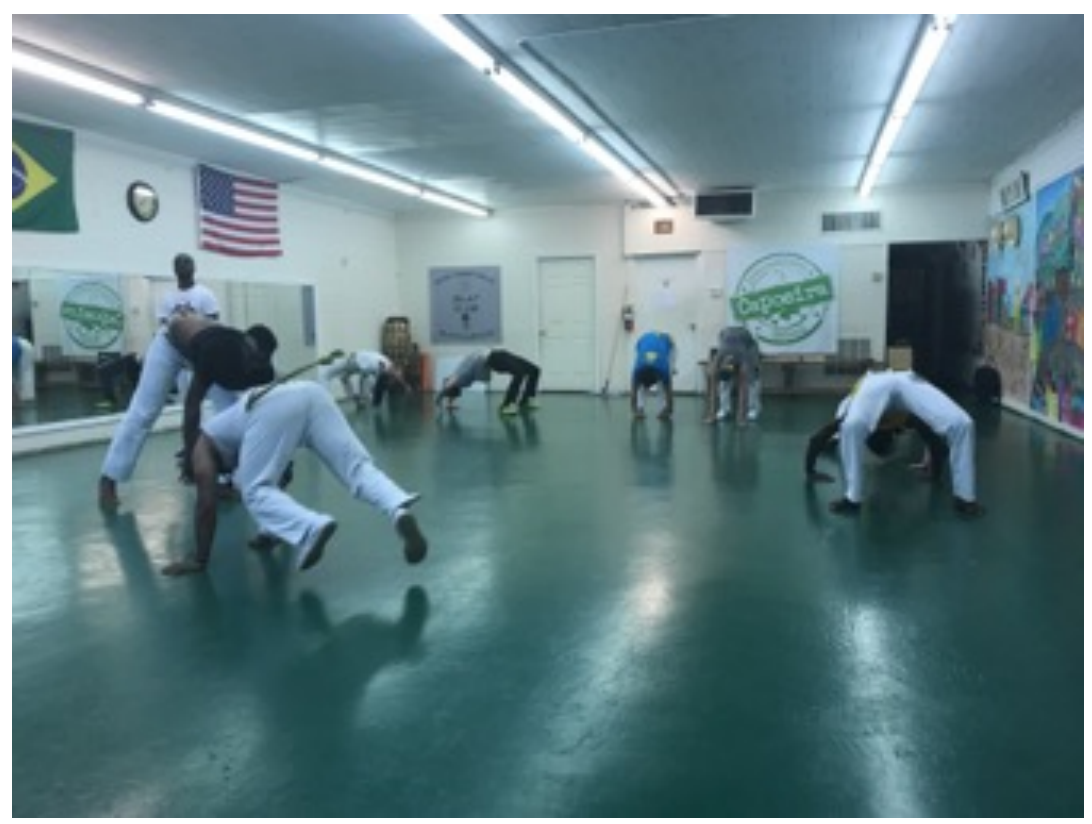

Figure 6.5. Warming Up. The Intermediate class warms up for Capoeira class at the Brazilian Arts Center in East Charlotte. Contramestre Zumbi observes movements (standing far left center). Photograph by Author.

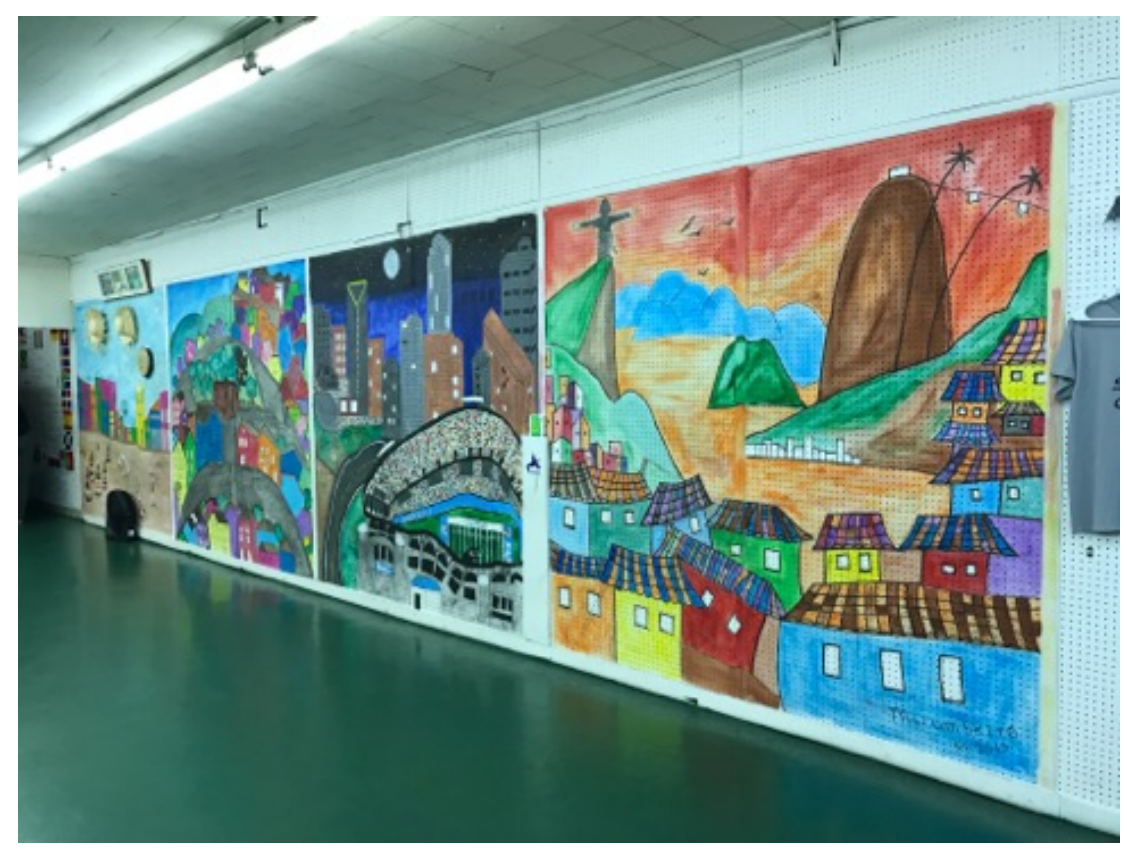

Figure 6.6. A "Life Philosophy." Mural inside of the Brazilian Arts Center depicts images of Rio de Janeiro alongside Uptown Charlotte as well as Capoeira being played in villages/communities in Brazil. The mural speaks to the transnational connections Capoeira has fostered globally and locally. Photograph by Author. 
The most prominent themes that emerged from the words/accounts of participants as well as my own experiences at the Brazilian Arts Center were those of unity, family, love, happiness, inclusion, and energy. In addition to these responses, in a separate interview with Maf, a black American, he described what Capoeira meant to him:

"Capoeira is something that provides all of those challenges and things like that, the physical aspect. But then also, the culture-like the group here is unique in that they have a very strong culture that you get into when you join and that part-you get friends and you get things to do--we take trips together--we party together--we help each other out, you know...so you get a community and a family. I find for a lot of people in our group, that's what keeps them there because you know a lot of people move to Charlotte, they're not from here--and they may not have any family, or know people so that's what kind of draws them, and keeps people--gives them people that care for them, that help them, and look out, things like that. People find husbands and wives, you know, through Capoeira."

Maf's account reiterates those collective themes discussed above and implies even stronger bonds fostered through this community, among those are marriage as well as structures of family support systems. Further, there were three main responses that encompass the profundity of the space and activity, the first two were, "I feel alive" and "Less Suicidal Thoughts, Less Loneliness." What does it mean to "feel alive"? Or perhaps I should pose, what are those affects that constitute aliveness. If here, we posit aliveness in opposition to death, suicide and depression, without delving deeply into the many reasons, conditions and debates that underscore suicide, we can contend that 
loneliness, depression, anxiety, fear, and unbelonging are among those affects that may contribute to suicidal thoughts. In contrast, within the space of the Brazilian Arts Center and through the practice of Capoeira and/or Samba, the transmission of joy, purpose, unity, camaraderie, and belonging critically impact/shape the identities/subjectivities of those who participate. The transmission of these affects within the space of the Center and those affects that "stick" to subjects outside are indicative of an affective kinship. The most obvious affective triggers within the Center is the actual physical movements and music of Capoeira and Samba. In accordance with Teresa Brennan (2004) rhythm provides a tool in "the expression of agency" in a similar manner as words (70). Brennan contends that rhythm holds a "unifying, regulating role in affective exchanges between two or more people" as such, "the rhythmic aspects of behavior at a gathering are critical in both establishing and enhancing a sense of collective purpose and common understanding" (Brennan 2004, 70). At the same time, the rhythms that emanate from the Brazilian Arts Center are distinctive in that they are rooted in Afro-Brazilian culture, which for black subjects may signal similar affects of joy, unity, happiness that function through the sharing of transnational blackness and ancestral links. This is highlighted in the opening statement of this section in which a black parent, who participated in the free-list activity submitted the idea that, "I love that my Black children have this outlet to enhance their physical abilities and connect with another diasporic African culture at the same time." In turn, culture, specifically Afro-Brazilian culture, and a diasporic aesthetic provides additional affective triggers for black and brown subjects.

It is important to remember that while Capoeira and Samba classes at the Brazilian Arts Center function in multiple ways to impact, build and transform identities, 
subjectivities, and relationships, they also function as commodities within this context. Or, if we return to Appadurai's (1986) notion of a "commodity situation" that again, suggests that we look at the "commodity potential of all things rather than searching fruitlessly for the magic distinction between commodities and other sorts of things" within the space of the Brazilian Arts Center, Capoeira and Samba become commodities (Appadurai 1986a, 13). However, outside of the Center they may not operate as such. Still, operating as a commodity does not necessarily divorce Capoeira from its cultural significance (Appadurai 1986a; Miller 1987, 120). This factor did emerge while discussing the Samba community with other Afro-Brazilians due to what they perceived as cultural appropriation that continued stereotypes of the over-sexualization of the mulata and only emphasized Rio de Janeiro samba, not that of Salvador (Appadurai 1986a; Miller 1987, 120). They did not share these feelings regarding Zumbi and Capoeira holding that Zumbi made history and culture an important aspect of his instruction; in fact, they conducted drumming circles/classes alongside Zumbi at the Center. Nevertheless, I want to briefly explore the possible implications of the material world of Capoeira and Samba on identity and subjectivity among black and brown participants in Charlotte.

Above, I identified the musical instruments used in Capoeira, in addition to these tools of music, usually after one has committed to Capoeira, or the Samba group, they are required to purchase uniforms; for Capoeira these are white pants and matching T-shirts, which at least must be purchased before the belting ceremony. In total, I spent about $\$ 150$ on my pants, T-shirt, and registration for the ceremony. For those in Samba, they must purchase the necessary sequined costumes and/or matching T-shirts for their 
performances. Keep in mind that some participate in both activities. For those that are extremely advanced, or can afford it, they usually take a group pilgrimage to Salvador, Bahia, Brazil. Moreover, the use of instruments, clothing, the singing of songs, and movements etc., in Capoeira are rooted in centuries of Afro-Brazilian as well as broader Black Atlantic cultural exchanges. Considering those deeply involved with the Capoeira community in Charlotte and those progressing through the ranks of Capoeira, I look to Daniel Miller's (1987) analysis of material culture and consumption. Miller contends that in some societies, "the clothing, ornaments and tools belonging to an individual may be considered so integral to him or her that to touch or do harm to these inanimate objects is considered indistinguishable from taking the same action against the person. Such property is identical to the person and may stand for that person in his or her absence" (Miller 1987, 119). This assertion first recognizes that certain objects are not only representative of but sacred to an individual and/or group, therefore, the objects that compose the space of the Brazilian Arts Center and the practice of Capoeira furthers an argument of a sacred diasporic community within this trans-ethnic alternative community.

Miller holds that, "by embodying ancestral links, objects may be the basis of an individual's present social identity such that loss of the object would itself constitute a danger to the legitimacy and viability of the personage and the group he or she leads" (Miller 1987, 119). With this notion, I pose the following arguments. The objects, the music, the movements, the practice...the material world of Capoeira and the Brazilian Arts Center offer ancestral links that legitimize an affective kinship and a transnational diasporic identity/subjectivity especially among black and brown subjects that participate. 
Lastly, I return to Zumbi's contribution to the "box of feelings", which firmly stated, "Capoeira is my life philosophy, I am Contramestre Zumbi." Thus, the art and material world of Capoeira is Zumbi, and Zumbi is the art and material world of Capoeira. Within the space of the Brazilian Arts Center, these things are "indistinguishable" from him; Zumbi embodies the art and material world of Capoeira as well as the Brazilian Arts Center, added that it is also how he makes a living. In addition, we must then ask, well, what is the philosophy of Capoeira?

Our first time meeting at the Brazilian Arts Center in the summer of 2015 during preliminary research, Zumbi reflected that:

“Again, it's not just martial arts because it's about our philosophy which is to bond people; forget about color, forget about religion, and be friends and be helpful to each other. I think places like that we need more of because again our religion is love. We don't say, "oh you have to do this this and this. No, it's, "guys, let's help, let's work together." It's teamwork and it's working. I remember my Master who was teaching here before, he said when he started here, he had some type of problem between races and colors, so the blacks didn't mix with the whites too much and he was talking to me, and he would say, "let's mix, let's mix.” And today, we don't see any problem. They're all friends, they hang out with each other, they go to each other's house... and Capoeira helped to break this down so...you see in Israel, Palestinians playing Capoeira with Jewish [people]...what else--tell me another thing [that] puts people together like Capoeira you know what I'm saying? They cross the war, and I think Capoeira is a very powerful tool for that... So this group, in Capoeira, we are a family. We are not just 
sports people, we are helping each other, not only within the same group, but everywhere in the world, we are bonded."

Zumbi's explanation returns us to Agier's (2016) idea of borders that are "good for living" where uncertainty finds recognition, and where uncertainty may temporally and spatially find some form of stabilization and/or completion where once incomplete. Zumbi's philosophy also propositions the Brazilian Arts Center and Capoeira as fitting of Agier's "cosmopolitan condition" where specifically in Charlotte, the relationship with the Other was "put to the test." Eventually overcoming these "tests" by emphasizing the need to "mix" and help one another yielded a family, that may indeed still undergo additional tests outside of Capoeira, or may close-in to form solid boundaries, all of which are processes of establishing kinship.

\section{Embodied Borders: Sustainable Transnational Black Families in the Borderlands}

"So, like I said I grew up so much being hated because I was African. I'm talking about hated! Then I didn't want to be African. I really wanted to be American. So, then I flipped it to now, I wanted to be all African, and not American at all but then the more times I went to Africa, the more I saw the benefits of being American. Then, I had to realize that I'm both of these. I grew up in the fusion. I grew up with a father telling me that you're not American, you're not 'those guys' to having 'those guys' embrace me as I grew up later, to being my best buds more than any Congolese would. So really being in touch with who I am as an individual and seeing that it was okay--you know what I'm saying?-That I am both. But that's the beauty - seeing how it was an advantage or a 
good thing because now-I became kind of like a spokesperson in a sense for the African community to the American community and then for the Americans to the African community. So, it's even crazier now, because as I progress in life, and I find out the true meaning of my last name, which is Ndelo, it means border. So, I am that border between all of these different worlds. So now the fusion—and what I feel is my purpose-makes so much more sense now."-Ndelo, Congolese-American, 16 May 2017

I introduce Ndelo, a second-generation immigrant born to Congolese parents in Charlotte, in Chapter 4. There, I discuss Ndelo's desire to construct a diasporic space and place that equally caters to black Americans as well as the African, Caribbean, and AfroLatino population. From this desire Ndelo and another second-generation Nigerian DJ established Afropop, a monthly party mostly held at Morehead Tavern near Uptown and more recently at Camp Northend as a block party during the summer months. Ndelo also owns a print company called "DRC Ape-Parel" that operates out of his studio in East Charlotte. The DRC title first pays homage to Ndelo's country of origin, the Democratic Republic of Congo, "Ape-arel" signifying Apes, a play on what has become the global mascot of the country. The second denotation of the acronym is Divine Righteous Children, the official name of the company. The success of his print company in Charlotte is evidenced in transnational sourcing of T-shirts to companies and organizations in Africa as well as the proceeds of certain T-shirts going towards the assistance of fostering entrepreneurship in apparel production in Goma, DRC. This collaboration with artists and entrepreneurs between Charlotte and the DRC is part of a "Back to Africa" campaign developed by Ndelo and friends. While in Chapter 4, I focus 
on Ndelo and Afropop as an attempt to placate the fear and disdain of respectable black American and black immigrant subjects, here I want to emphasize how Afropop is the embodiment of Ndelo's own identity and subjectivity. Via subjects such as Ndelo, Jasiatic, and other "border-dwellers" and the spaces, places, and material culture that emerges from them, other black and brown subjects are able to cross borders, inhabit and perhaps realize their own identities and subjectivities. While I have discussed affect substantially in this chapter, I want to more concretely align affective kinship with a black/brown economic sustainability critical to the existence of a transethnic alternative New South and the ways in which this is reflective of an embodiment of borders. An exploration of the local and global exchanges of goods also furthers an understanding of how diverging debates and articulations of diaspora are manifested in space and place. In Chapter Four, I briefly paint a picture of the Afropop experience that is similar but also different from SuCasa. Similar to SuCasa, Afropop plays a variety of music from the African diaspora. The outside area of the venue usually directs focus on music from Francophone Africa and the Caribbean like Haitian Kompa, Zouk, and Kizomba. Before the event officially begins there are sometimes Kizomba dance classes taught outside. Meanwhile, the inside plays a variety of Afrobeat, Hip Hop, Reggaeton, Salsa, Merengue, Bachata and Dancehall. There is also a discounted cover fee for those who come dressed in some form of African or African-inspired attire. Like SuCasa, there are also vendors. However, what I have noticed is that there are usually more vendors at Afropop than SuCasa, which provides a sort of monthly festival environment. At Afropop, I met an assortment of vendors, all of whom were black subjects from across the U.S and the Diaspora; there was a young black American woman from Detroit selling 
African-printed fabrics that her friends send her from countries like Ghana; there was a black couple, a middle-aged Haitian black man and his black American wife who sold creams, oils, and butters; a young black American couple who travels from Columbia, S.C. to sell their T-shirts and African printed materials inspired by their time studying abroad in Nairobi, Kenya, when the young man realized, "we're all the same"; a young second-generation Caribbean woman selling hand-made jewelry; a young black American woman actively painting and selling images of the diaspora; and a black American man doing Yoruba body-paintings. Some of the vendors, such as the young black American woman from Detroit, intersect with SuCasa. I have purchased materials from her in both spaces on different occasions. Ndelo also sells his own "freshly printed goods", T-shirts that either advertise Afropop in brightly colored words, or statement Tshirts that read "The People Have the Power." Depending on the site of Afropop, Ndelo brings his printing equipment so that customers can select patterns and T-shirt colors onsite fulfilling his slogan of "freshly printed goods." I am proud to say that I now own a healthy collection of Ndelo's T-shirts and had the opportunity to observe his printing process. In fact, during my times at Afropop and SuCasa, I began to realize that this research venture presented constant occasions to support local black-owned businesses The diverse backgrounds of the vendors, and the borders they cross through the buying and selling of their goods as well as their own personal relationships in many ways reflects Ndelo and the multiple meanings attached to the space through the objects sold. 


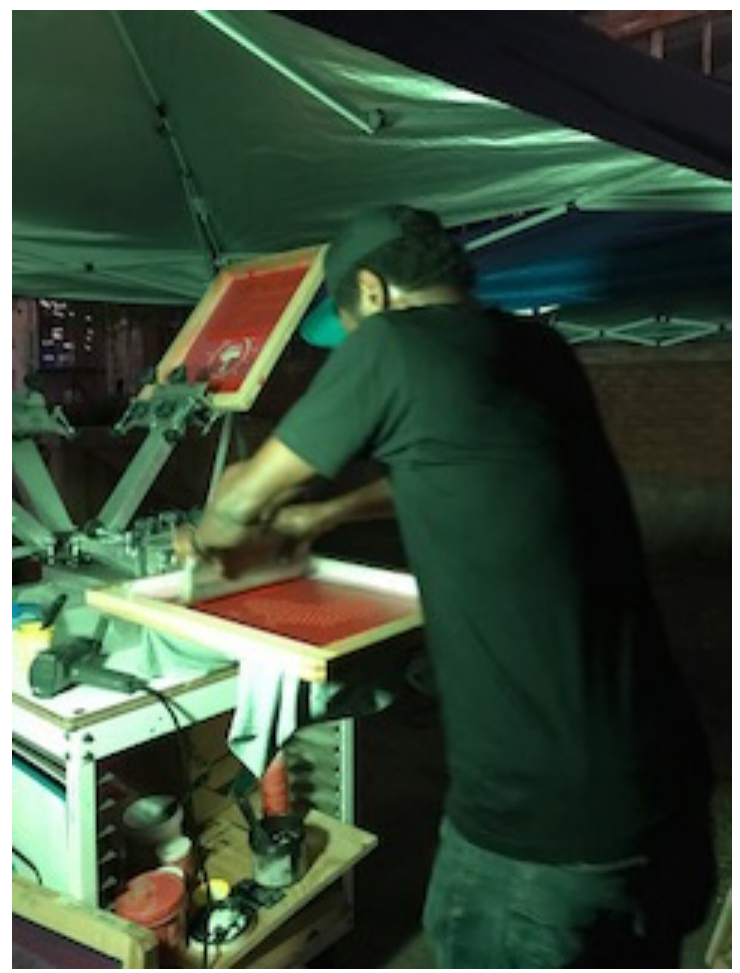

Figure 6.7. "Fresh Printed Goods." Ndelo hand prints an African graphic pattern on a T-shirt for me at an Afropop Block Part at Camp Northend. Photograph by Author.

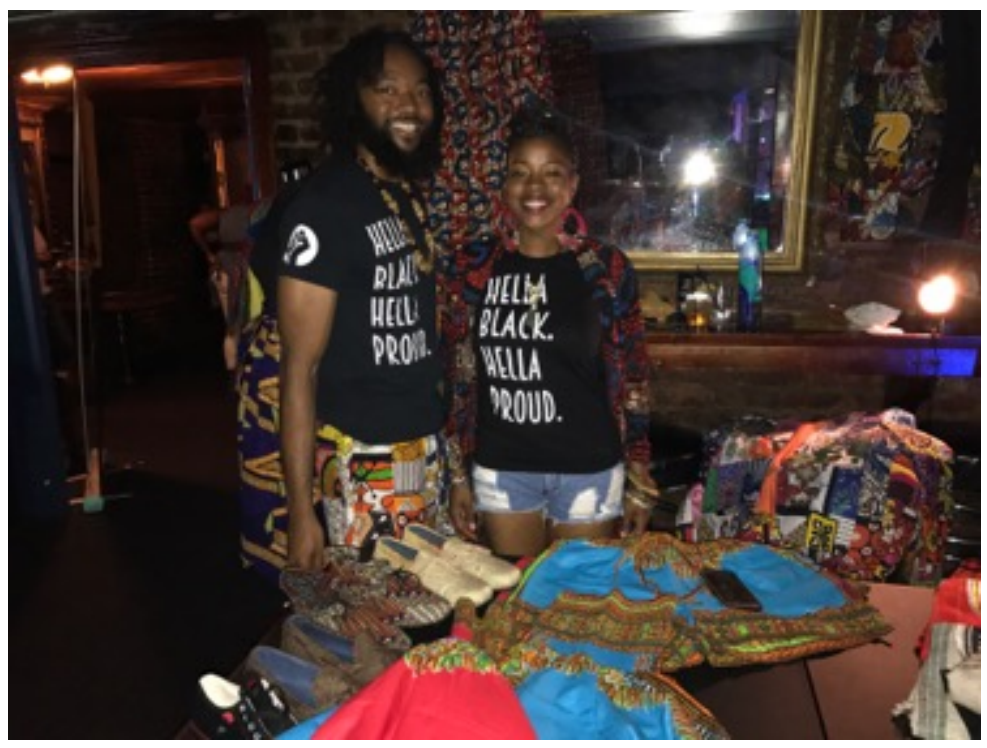

Figure 6.8. "Hella Black. Hella Proud." A Young Black American Couple, travels from Columbia, S.C to sell their goods, inspired by their study abroad time in Nairobi, Kenya, at Afropop at Morehead Tavern. Photograph by Author. 
Miles Richardson's (2003) exploration of market places in Central America illuminates the idea that people respond to objects based upon what those objects mean (75). Deciphering an embodied space, Richardson holds that material items serve to "recall, reconstitute, and communicate" experience and just as words, becomes a "scene" or an "opened text" (Richardson 2003, 75). The exchange of specific material objects then allows subjects to write a particular aesthetic onto a space, to create place that are indicative of their own identities as well as those who purchase them. The meaningfulness of objects arises through our interaction with the objects as well as the people we exchange goods with. Our behaviors, and as a result, our identities become meaningful through the presence of and exchange of objects and within the material world (Richardson 2003, 75, 76). It is in the act of shopping, amidst the multiple layer of affects that sites like Afropop and SuCasa evoke, in which particular "parameters of identity such as the family, class, ethnicity, and gender" are shaped and reshaped (Miller et al. 1998, 19). Moreover, the act of shopping at Afropop raises questions concerning authenticity and appropriation in what are essentially transnational and global exchanges of mainly African and African-inspired goods. For the reader, similar questions may have risen in Chapter 5 while reflecting upon House of Africa and Reggae Central. While I spoke with a great deal of vendors who receive their goods directly from Africa, many times they are only presumably "Made in Africa." The rebirth of the Dashiki and Ankara prints in the last few years that arguably aligns with a reawakening of black activism (I pinpoint this renaissance with the emergence of the \#BlackLivesMatter movement) has resulted in a current global proliferation of these materials, some "authentic" and others easily made in China or India. Beyond fabrics, jewelry, shoes, etc., these arguments are 
easily attachable to a black American providing Yoruba face-paintings. Yet, if we look to Appiah (2006), there is perhaps no true authenticity that can exist within a globalized world; heterogeneity is both a benefit and fault of globalization, while globalization can also produce homogeneity. Further, as black/brown subjects, those who occupy the Global South, we often view globalization, the intrusion of modernity and cultural imperialism as hindrances to our authentic selves and cultures without considering the cultural context of certain cultural imports nor realizing that people can respond to the "onslaught" of Western ideas and practices by turning them against their originators ( $\mathrm{K}$. A. Appiah 2006, 4). In the case of Afropop vendors, this is evidenced through providing a space for black economic sustainability; I can elect to purchase my graphic African print T-shirts and shorts from a young black woman in contrast to say, Urban Outfitters, and my essential oils from a Haitian man who produces them in his home in contrast to mass-produced diluted ones from Shea Moisture that are part of larger multinational skincare and beauty conglomerates. In addition, holding that the global "hybridization of culture" through travel, trade, conquest is not a new development, but historical and ongoing, Appiah inquires if there has ever been a true "cultural purity" (K. A. Appiah 2006, 7). Based upon this inquiry, he makes a "case for contamination" that suggests that while an "ideal of contamination" for the cosmopolitan celebrates a utopia of mixture, "impurity", cultural hybridity, and the "transformation that comes of new and unexpected combination of human beings", the other side of contamination requires a "global ethics" that respects difference and makes it possible to learn from the "stranger"(K. A. Appiah 2006, 8). Therefore, if the act of shopping and the realm of the material world at Afropop operates as a social process of interaction that is indicative of our identities and 
subjectivities, then black subjects can move beyond the disjunctures that emerge concerning authenticity, and foster collectivities, solidarity and economic sustainability through difference.

With this, I return to Ndelo, his DRC Ape-Parel printing company, and the development of a "Back to Africa" campaign that fosters artist entrepreneurship in the DRC. These ventures undoubtedly present for a discussion of Clarke's (2010) conceptualization of a humanitarian diaspora that decenters the trans-Atlantic slave trade as the premise for articulations of Diaspora and propositions instead new humanitarian economic linkages (48). Although I am tempted to divulge this notion based upon Clarke's emphasis on transnational economic linkages that foster a new diaspora, positing a separate ontology, I reckon this possibility with Rahier's (2010) response (Clarke 2010; Rahier 2010). Arguing against Clarke's notion of a separate and new ontology rooted in transnational and humanitarian exchanges and linkages between Africa and the U.S., Rahier summons Nassy-Brown $(2005,2006)$ study of black servicemen in Liverpool to contend that despite moments of "friction" and processes of "hierarchization," encounters between black Americans and black Liverpudlians "revealed a global connection while making possible a set of more or less painful creative interactive performances of negotiation during which blackness and diaspora are in fact reinvented, reimagines, and experienced anew, transforming history and memory along the way, and pointing to novel futures" (Rahier 2010, 50). The single "universal space" of Diaspora allows for the "mutual recognition" of blackness and consciousness across difference as well as "new revelations" in the production of "new forms of consciousness"(Rahier 2010, 50). As these debates regarding the possibility of new articulations of diaspora are seemingly 
indistinguishable from Ndelo’s opening account as well as his businesses, I want to build upon Rahier's delivery of Nassy-Brown's study of Black Liverpool in order to recall the significance of embodiment. In reconsidering globalization in terms of authenticity as well as conceiving diaspora, Nassy-Brown (2005) argues that while those "scholarly stories" of globalization that transforms places by "mobile capital, commodities, people and cultural influences" Liverpool seemed to revert from its previous status as global port of goods, media and culture (Nassy Brown 2006, 137). Nevertheless, from a phenomenological perspective, these histories "stick" and remain with subjects. With Ndelo in mind, Nassy-Brown asserts place can embody "transcendental truths of the self (if only the clutter of preconception can be cleared away), and a place that acts" while place can produce "human consciousness, experience, and action both in the form of events long ago and the mournful recollection of them” (Nassy Brown 2006, 150). Accordingly, if place can accomplish these efforts, it must be place that sustains life itself (Nassy Brown 2006, 150). Ndelo is part of many places all of which are sites, whether physically, mentally, or phenomenologically crosses and embodies transnational/global and local borders through his multiple business ventures that also offers a space/place for other to realize a similar position whether American or immigrant... or both. Yet what enables Ndelo to embody and imbue these experiences, histories and trajectories upon others is his ability to travel, an essential aspect of borderlands not just for immigrants, but for black Americans who also simultaneously dwell in and traverse multiple borders as well.

Provided these multiple collisions of diaspora, affect, material culture, and authenticity, I revisit the self-identified "fire starter," Jasiatic. In addition to SuCasa, 
Jasiatic makes a living as a self-employed plant-based chef and host of "Satisfy," a running series of dinner and brunch parties as well as cooking classes in which she prepares and serves plant-based foods inspired by the tastes, flavors and cooking techniques of the diaspora. I reiterate Jasiatic's ability to mediate relationships between black American and black immigrant subjects by forging affective kinship through varying means of material culture and setting; food being the medium within the realm of Satisfy. While Jasiatic's interpretation of and intention behind SuCasa highlights several elements that trigger not only an affective kinship, but a symbolic diasporic kinship and community, Satisfy, as Jasiatic's other passion and venture solidifies a complete oscillation of affects by tending to the diverse tastes of food inspired by her travels throughout the Diaspora.

"I do diasporic foods, so I do tend to do a lot a lot of Afro-Latin food. I'm always really inspired by how Africa has sort of touched all of these cuisines. Even in travelling, like going to places in just kind of looking wherever the African influence is in the cuisine, and then you know like finding home in that. So I do plant-based dinner parties that are essentially there to create a space to share food that is both healthy and nourishing, but also inspiring and insightful to people that often don't really know what to eat as a vegetarian as a vegan."-Jasiatic, Black American, Charlotte-Native, 13 July 2017

Given this basic description of Satisfy, I indulge the classic phrase, "you are what you eat" in order to conjure Jane Bennett's (2010) discussion of "edible matter" that details the act of eating and the "material agency" of food. If we place Bennett's argument that 
the material agency of food and the assemblage of eating underscores an active power to affect and cause effects in conjunction with Miller's (1987) assertion that objects embody ancestral links, there are several interpretations of Satisfy that emerge (Bennett 2010, 49; Miller 1987). First, one aspect of Satisfy is to present newer, healthier and more sustainable ways of eating and preparing food within black/brown communities. Second, the food prepared and served at Satisfy is reflective of Jasiatic's travels throughout the Diaspora, in turn the food embodies Jasiatic and vice versa. In this sense, food holds the power to create a border situation. Third, the idea of "finding home" through cuisine poses another spectrum of belonging, diaspora, and the transmission of affects that foster kinship. The ritualistic process of preparing and sharing food anchors kinship in many societies and communities, especially among black and brown subjects. Before expanding upon these central ideas, let us consider Jasiatic's own elaboration of Satisfy and the significance of food to her identity.

"One of the spaces that I found with doing SuCasa for so long and being a plant-based chef and being just an extreme foodie is that like what a gregarious type of space it is to be an African American, which I don't even identify myself as right? So I don't identify myself as an African American but it's very real to be able to travel and be in these spaces and to realize that I'm in Africa, but I'm an American, but I'm African. So here's the thing, no matter where you go in the world, America still tends to be this meeting space. Not to say that there aren't others, there are others that have this same space of privilege, but [in the U.S.] you get to be in a space like Brooklyn and be able to go eat dumplings at the Trinidadian restaurant, and have like--I mean anything--where all these 
cultures kind of meet up and blend and it's just a beautiful space to be able to have all of those things in you--and to be able to--in a very neutral way--like I always laugh about the Jollof wars because I've always made my own Jollof, and what does that look like to someone else? It's amazing to me, that you get to like to study all of these things and be at a vantage point to be able to say like "ahh I like Callilou" but like you know, I will straight like mix that shit with some cactus on the side [laughs]. I don't know just like all of these different things that come from these different cultures and different places that we as African people, in all of these spaces where we fell you know... have just utilized like no matter where it is--and to just be in a space where you can say that's native to me, but that's not native to me, or that's not native to me it is native to me. You know, it's in my DNA, that's dope to me, that's dope. And it's really like you know the more and more I know, the more that particular point just magnifies, cause its dope! Its dope to like really--like the deepest sense of you and who you really are genetically, how that shows up in your taste buds and your desires and what you see in the world."

Here, Jasiatic seemingly invokes multiple articulations of Diaspora. While recognizing the diversity of black experiences that in this case is expressed through food and the act of eating and tasting, Jasiatic also suggests direct linkages to Africa evidenced by the idea that cooking and preparing African and/or African-inspired food is in her DNA (Copeland-Carson 2004). At the same time, in many ways Jasiatic's account, equally serving as a presentation of self via food is rooted in Gilroy's "roots vs. routes" and Rahier's authorization of Diaspora as a universal space allocating room for multiple interpretations and articulations. The notion of food preparation as something in her 
DNA is critical to understanding the ways in which articulations of the Diaspora are not just manifested in space but also embodied; an embodiment captured in Jasiatic's words, "it's just a beautiful space to be able to have all of those things in you." The "beautiful" universal space of diaspora exists in her and expressed and transmitted in her food. Food's ability to write, paint, and draw a diasporic aesthetic speaking to multiple subjectivities within this sort of open discursive space that oftentimes is Jasiatic's home, designates a border situation, an in-betweeness we can taste. Realizing Jasiatic as a border-dweller, and her food symbolic of a border situation, I thought of Ginetta E.B. Candelario's (2007) mention of Maria Lugones' "world traveler" in Candelario's ethnography of Dominicans in Washington, D.C. Citing Lugones, Candelario writes, "those of us who are 'world'-travelers have the distinct experience of being different in different 'worlds' and ourselves within them... The shift from being one person to being a different person is what I call travel"(Candelario 2007, 137). The multiple shifts required from the "world-traveler" may be either "conscious or willful", from a phenomenological approach, shifts are a matter of 'being in the world'(Candelario 2007, 137). Jasiatic as "world-traveler" and black American woman "shifts" the conceptualization of the borderdweller from definitive immigrant to one traversing the multiple understandings of diaspora and blackness despite country of origin. In other words, Jasiatic shifts us to a horizontal landing, permissive of multiple beings, definitions, and expressions of blackness at once (M. M. Wright 2015). Based upon the work of scholars such as Wright (2015), Hall (1990, 1997), Appiah (2006) and Agier (2016), horizontal conceptualizations of not just blackness and diaspora, but the Other, while reconceiving the cosmopolitan, provide new and different landings for borders "good for living." 
Borders "good for living" entrench upon the liminality that Bhaba (1994) speaks of. I am suggesting that spaces, places, and things are just as much "liminal" as they provide a liminality that constructs a space for collectivity grounded in affect, ritual and kinship that goes against the dominant group.

Resuming with a conversation concerning food, there is need for emphasis on the "artful consumption" of food, or "slow food" that celebrates "ecological sustainability, cultural specificity, nutritional economy, aesthetic pleasure, and the skills needed to make from scratch" and I would add, the skill to make certain foods of the diaspora vegan (Bennett 2010, 50). "Slow food" obliges a reflection on the "life-history" of food in a similar manner that Appadurai (1986) summons us to consider the "social life of things." The histories and lives of things offers space for "the links that connect people and places at different points along the chain" (Bennett 2010, 51). Therefore, food as an "ontologically real and active, lively presence" is a "self-altering, dissipative materiality" that is also a "player" possessing the power to "enter what we become" (Bennett 2010, 51). Transmitting affects through aesthetic, taste, eating and food "is one of many agencies operative in the moods, cognitive dispositions, and moral sensibilities that we bring to bear as we engage the questions of what to eat, how to get it, and when to stop" (Bennett 2010, 51). Part of Jasiatic's purpose with Satisfy is to respond to the latter of what, how, and when to eat. It is very much a simultaneous conscious and subconscious endeavor to communicate and share new practices of diaspora with diasporic subjects to reformulate their moods, identities and subjectivities whether rooted in the border between essentialist and anti-essentialist arguments and articulations of diaspora. At the same time, by proxy many of Jasiatic's practices of diaspora in food are anti-essentialist 
constructions since they are solely vegan. Many methods of preparing and cooking traditional African and African diasporic foods require meat while Jasiatic modifies these methods. At SuCasa we can listen, dance, and feel the Diaspora through music, visual and movement while at Satisfy, we can converse about and taste the Diaspora in a more intimate setting.

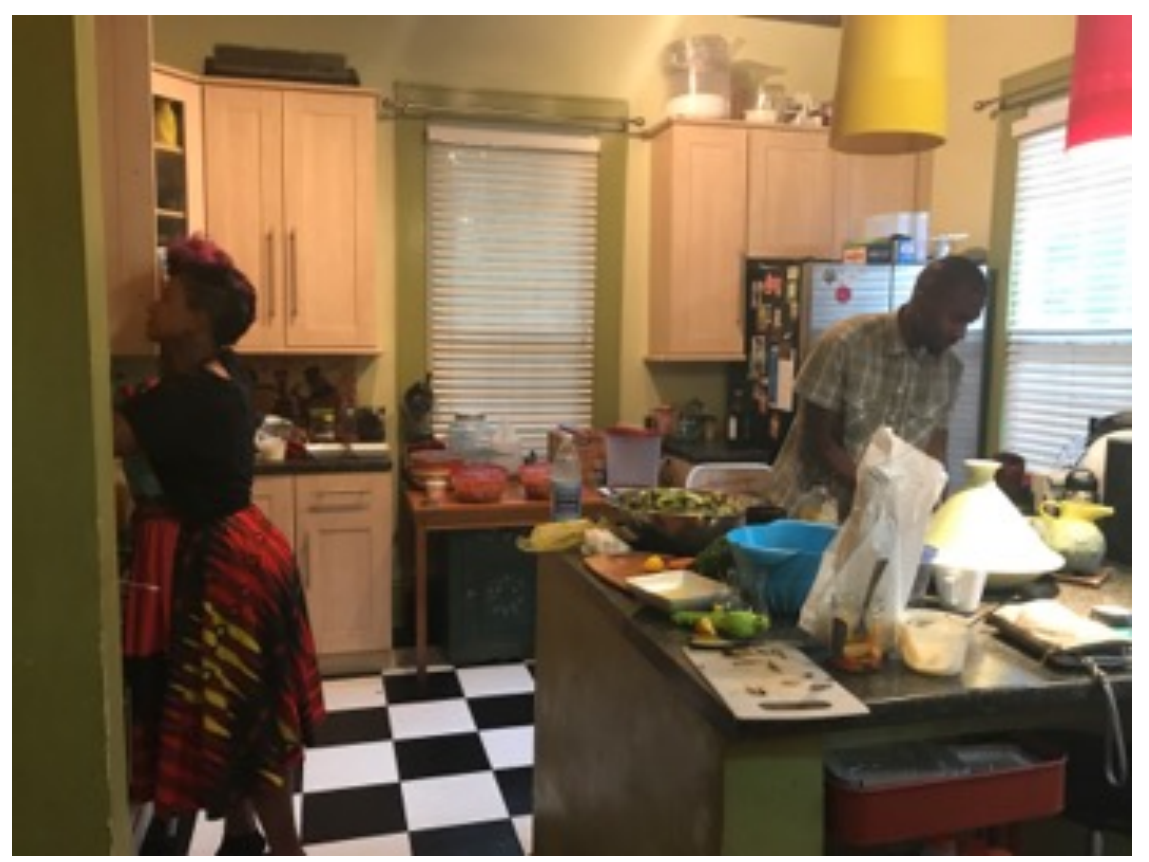

Figure 6.9. "Refashioning Food and the role of 'Mother'." Jasiatic prepares dinner for a Satisfy Dinner party alongside a sous-chef she'd just met that day at her home. Photograph by author. 


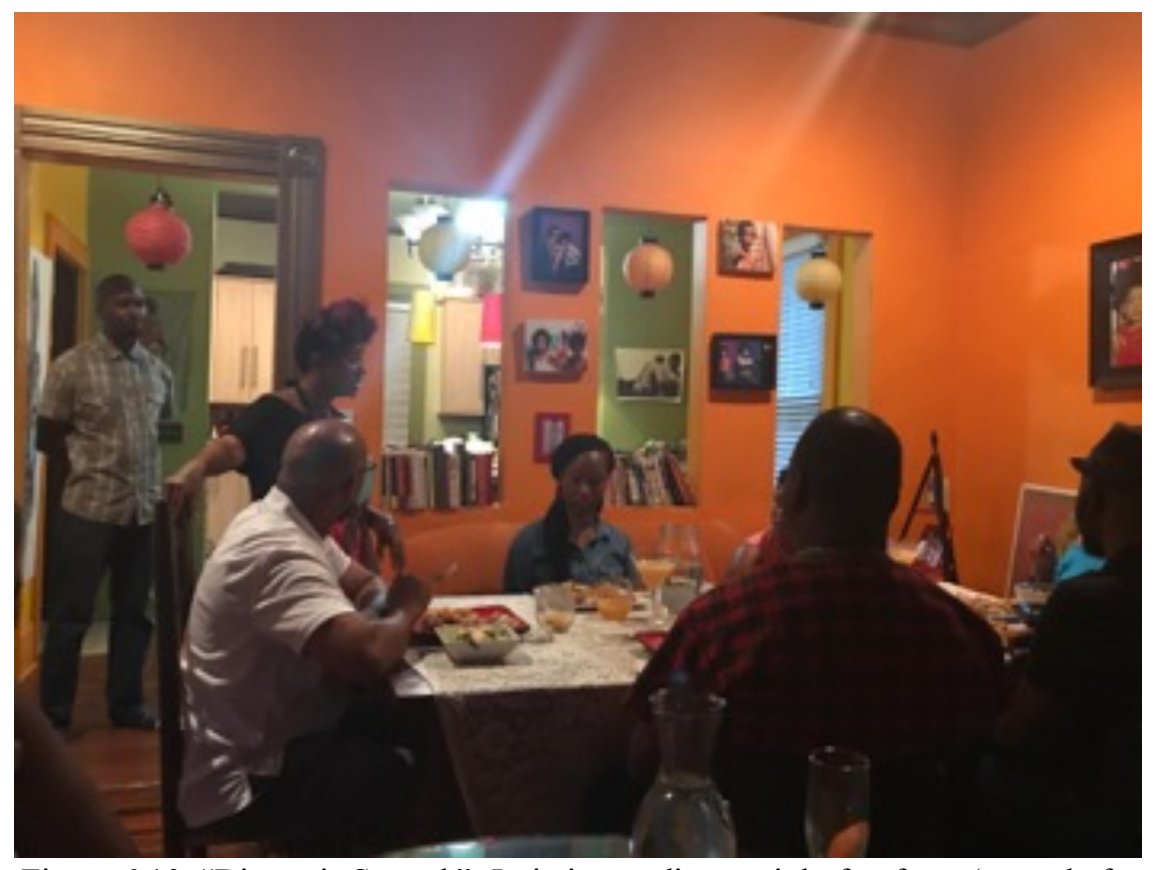

Figure 6.10. "Dinner is Served." Jasiatic standing to right forefront (sous chef to left back), explains the menu for the night to patrons of Satisfy in her East Charlotte dining room. Photograph by Author.

Most times, Jasiatic hosts Satisfy at her East Charlotte home, not far from my own, across The Plaza in the Villa Heights neighborhood. For some, the home is familiar as they are friends or acquaintances of Jasiatic. For others, this is their first time meeting Jasiatic and their first time pulling up to the mid-century craftsman style home where adolescent children, some of which are Jasiatic's own, others from around the neighborhood, sway lackadaisically on a wooden porch swing hanging from the outdoor ceiling. Upon entering the house, one is welcomed into the warmness of brightly colored walls, the aroma of well-seasoned food dashed with a hint of old hard-wood floors that creak beneath the shoes we are asked to remove before going further into the dining area. Despite the small distance from the doorway requiring one to quickly make a right into the dining area, one is struck by the collection of art on the walls, ranging from local artists' paintings and Jasiatic's own portraits of her children, and other people, places and 
things depicted in multiple collages hanging from a myriad of brightly colored walls. Jasiatic is also a local well-known photographer in the Charlotte area. Once in the orange painted dining area, one can see Jasiatic still busy prepping food, scurrying around black and white checkered linoleum floors, almost dancing to the pastel key lime colored walls of the kitchen. During this time, the all black/brown group of guests introduce themselves to one another and again with Jasiatic. With a $\$ 50$ contribution, Charlotte natives can connect and reconnect with newcomers from New York to Trinidad to Zimbabwe over a diaspora-inspired vegan meal. It is a means of sustainability as much as it is a reflection of Jasiatic's identity. Satisfy is usually advertised primarily through social media, which still makes for an intimate event given that the host, Jasiatic, chooses who comes and can also accept payment through now a variety of 'apps.' In our initial interview, she told me to keep a look out for a Satisfy event "coming soon."

On the Facebook invite, Jasiatic describes Satisfy as, "a swanky little dinner party with delish vegan goodies, fly beats, elevated conversation and the coolest people (hosted by yours truly)." The discussion prompt of the night was, "Non-injury, Compassion and Blackness." On the menu was, "peach infused spritzer (alcoholic and virgin), sun dried tomato mac and cheese, roasted herb fatoush batata harra with agave/spiced yogurt, buffalo cauliflower, a mystery dish" and for desert, "Cardamom Saffron Ice Cream Sandwiches." It was by far the most delicious vegan meal I have ever had in my life to date. That comes from a black southerner raised on bar-b-que pork and vegetables and beans stewed, boiled and cooked with some part of an animal. The sort of unruly combination of veganism with southern cooking coincided with the conversation that evening, which was again, "non-injury, compassion, and blackness." This was a 
participatory "family" conversation held while eating food. At one point as the conversation unfolded into one concerning the food-crisis within black American communities as a form violence to black bodies, I was taken aback by the usage of "slave food" by another black American man at the dinner, to describe what many black Americans call Soul Food. His connotation of "slave food" seemed to relegate an entire cultural genre of food as simply "slave" food instead of what should be deemed not just as soul food but as survivor food. Moreover, in that moment as we ate and conversed about our $\$ 50$ vegan meal, the connotation insinuated the same intra-ethnic socioeconomic hierarchies underlined by a sense of respectability that culminated the sorts of Diaspora Wars I discuss in Chapter 4. I was offended by this man's opinion. However, marinating on the idea of Satisfy and the rest of the discussion, I realized Satisfy provided a space to "hash out" disagreements and raise solutions for the issues confronting the trans-ethnic black family. More importantly, the space allowed us to connect, reconnect and share our love for one another and good food; it was a family dinner. The universal space of Diaspora that is embodied in black subjects like Ndelo and Jasiatic and the subsequent spaces and place they create reveal that Diaspora Wars are just as much part of Diaspora Love as we all navigate the many borderlands of blackness.

\section{A Conclusion: Ethics and Borders "Good for Living"}

In this chapter, I endeavor to build upon Reyes-Santos' transcolonial kinship model, that I introduce in Chapter 5. I aim to fortify my conceptualization of a transethnic alternative New South that exists within the places, people, and things that construct, inhabit, imagine, and traverse East Charlotte. Similar to Reyes-Santos, I argue 
that these people, places, and things trigger affects that found and sustain rituals that produce alternative forms of kinship, solidarity, and collectivity. By positing a transethnic alternative New South that (re)places the agency of corporate entities and policymakers into the hands of black/brown subjects who live on the fringes, I also seek to spatially (dis)place the dominant image and location of Uptown as the city's hub of cosmopolitanism.

Offering a more complex and intricate focus on the experiences of black/brown subjects, particularly those whom I deem as cultural workers and agents as well as the role of material culture and affect in fostering alternative forms of kinship, I contend that the trans-ethnic alternative New South operates as a borderland. Originally inspired by Nassy-Brown's assertion that kinship functions as a "vehicle" of racial transgression and Johnson's notion of spatial entitlement, I found anchor within Michel Agier's anthropological approach to borders. Agier's work allows us to process the temporality of "border situations," or those moments I explore at SuCasa, Snug Harbor, and Queen's Collective. These spaces evidence Agier's concept of borders that are "good for living" in that in a diasporic sense, they have been birthed, nurtured and established through ritual, symbolic and sacred diasporic communities of belonging. Borders "good for living" provide an array of aesthetics that communicate consciousness and sensibility that applies to the intersectionality of diaspora. As such, these spaces and places pose new considerations of the practices and articulations of Diaspora. Further, borders "good for living" and those who practice the "ethics of diaspora", even if they have arrived at this ethics through the multiple "tests" that the navigation of borders requires, indicate an embodiment of space, place, and material culture. This embodiment is displayed through 
Jasiatic, Ndelo, Zumbi, and even Carolina who as a patron and intellectual absorbed the affects and people that provided her a sense of home in Charlotte. These are the "borderdwellers" who may not necessarily find official recognition and belonging in the outside, but can embrace their alterity and alter-nativity within those borders and "border situations" that are "good for living" where the "ethics of diaspora" are respected and exercised. Expressions of these multiple forms of embodiment are most easily grasped through subjects' relationship with and responses to things ranging from music, sound, instruments, movement, clothes/fashion, and food. Culminated together in what would be some special Charlotte stew or brew, these people and things present new dynamics happening in the New South that counter the surface image of New South we have been served. 


\section{CONCLUSION}

\section{BLACK FUTURES IN THE NEW SOUTH}

When I returned to Charlotte in early November of 2016 to begin official ethnographic research following two previous summers of preliminary research in 2014 and 2015 , the city was still socially, culturally and politically reeling in the tumultuous racially-charged winds of protests and riots that erupted in response to the September 2016 death of Keith Lamont Scott. Scott, an unarmed black man, was shot and killed by an officer in the Charlotte-Mecklenburg Police Department. A week after I arrived back in Charlotte, I fulfilled my civic duties and voted in the November election. In addition to the Scott killing, Charlotte citizens were also grappling with the economic loss, political disarray and jab to sociocultural progression wrought by House Bill 2. The November election signaled two additional jolts locally in Charlotte; first, the presidential election of Donald J. Trump intensified fears among many in the immigrant community as well as black Americans; second, the gubernatorial election of democrat Roy Cooper, who ousted former Charlotte mayor and republican Pat McCrory after a week-long recount, indicated a potential repeal of House Bill 2. The repercussions of these events, which included fear and uncertainty, were extremely palpable during my observations, interactions and interviews with immigrants from Africa, the Caribbean, and Latin America and native black Americans in the field.

After on-going marches and protests contesting local, state, and national immigration policy, the city's atmosphere seemed to be rerouting back toward its' calm New South ideals. After all, one year later, in November 2017, Charlotte elected its first 
black woman mayor, Vi Lyles. Yet, just a few months after I completed Chapter One, in July 2018, news broke that Charlotte, the only city to place a bid, was set to host the 2020 Republican National Convention. Policy-makers and city leaders, including Vi Lyles, defended the decision by reminding the public that this was a necessary step in furthering the city's claims as a global city, bringing jobs, and building the city's economic growth. It was another necessary step in fortifying the "New" South. Yet, what did this decision say about the social, cultural, and political integrity of a city that promotes itself as an inclusive, diverse and multi-cultural city... as the New South? What does this political and economic move signal for the city's black and brown residents who also fortify the New South? Charlotte's social, cultural, political, and spatial inconsistencies and the ways in which they impact black immigrant and black American identity, subjectformation, and the potential for solidarity in response to shared marginalization is what inspired and guided this research endeavor.

Over the course of 18 months of ethnographic research in places of consumption in East Charlotte, I utilized a mixed method approach, including traditional ethnographic methods, mobile methods such as participatory GIS, focus groups, photo-elicitation, and free-list methods to explore the role of space, place, material culture, and affect in processes of identity and subject formation among black immigrant subjects. Living in the heart of East Charlotte made places and spaces of consumption as well as my participants easily accessible, with most places, people and things being within a 2-mile radius. I was also able to witness first-hand the many on-going transitions of the area and as a black subject, I was able to experience places, spaces, and the range of affects triggered by them, alongside many of my interlocutors. I also heavily patronized either 
my participants' places of business or the same places and spaces that my participants patronized. These experiences allowed me to further grasp the impact of space, place, material culture, and affect on black immigrant identity and subject-formation. Interested in how their interactions with black Americans in particular spaces and places shaped or reshaped black immigrant subjectivities and identities, as a black American interacting with black immigrants, my own positionality proved critical during my research. Several critical arguments and conclusions as well as a great deal of new insight emerged to culminate this dissertation.

I first arrived at a focus on black immigrants by noticing that, with the exception of Bobby Vaughn's $(2005,2007)$ work and Elizabeth Barnett's (2011) thesis, both concerning Afro-Mexican immigrants in Winston Salem, N.C. and Hannah Gill's (2010) research on Latino immigrants in rural eastern North Carolina, there was an absence of Afro-Latinos in studies on Latino immigration in the U.S. South. These studies were also heavily concentrated on rural North Carolina and not rapidly growing urban centers, like Charlotte. Surely, I thought, the growing population of immigrants from the Dominican Republic, their multiple business establishments, most notably, hair salons and restaurants, and conflicting ideologies concerning race in their country of origin, would warrant a vital area of study. I identified the growing Dominican immigrant population years prior to beginning studies toward a Ph.D. while working at an East Charlotte-based non-profit that assists immigrants from across the globe in legal, social, and cultural transitions to life in Charlotte. In addition, my time as an afterschool leader/mentor at an East Charlotte middle school offered another window into how immigrants were transforming the landscapes of the area. 
With these experiences, I began to inquire how other Latino/Afro-Latino immigrants may confront being perceived of simply as black in the South based upon their skin color, but who upon speaking Spanish or French posed an anomaly to southern perceptions of race, ethnicity, and nationality. Given the "one-drop rule" prevalent in the U.S South, what were their experiences being racialized as black within the context of the U.S South?; how did they identify within this context; what was their relationship with black Americans like?; did these interactions foster new collective black identities in the South?; and what was their relationship with the dominant Latino population? Searching for answers to these questions during preliminary research in the summer of 2014, I encountered my first challenge: Afro-Latinos outside of the Dominican population were difficult to locate despite numerous participants assuring me that they were here. By the summer of 2015, I realized that U.S. Census Data was unreliable in locating these populations. I recognized that the limited U.S. Census categorizations ultimately rendered these populations invisible. Yet, my observations at restaurants, beauty salons, boutiques, and bars/lounges, guided me to the fact that given the lack of cohesive ethnic enclaves one may encounter in a traditional gateway city, Afro-Latinos were present, but they were intersecting with black Americans, other black immigrant populations, and the greater Latino population in East Charlotte. More than often these intersections were taking place over the exchange of varying commodities from hair care to food to fashion.

With this information, I expanded my focus to black immigrants from Africa, Latin America, and the Caribbean, and their intersections and interactions with black Americans in places of consumption in East Charlotte. I also expanded and applied my initial questions regarding Afro-Latinos to this larger diverse population and became 
interested in the places and spaces in which these populations were intersecting and interacting. Moreover, I became interested in the significance of the goods that they were exchanging and what the material culture and material setting of these spaces and places communicated in terms of identity and subject-formation.

Over the course of my research, I encountered a range of intersections and interactions as well as disjunctures and boundaries among African, Caribbean, and AfroLatino immigrants and Black Americans in East Charlotte. These tensions and disconnections seemed to dramatically counter my proposed claims of an inter-ethnic collective black identity compelled by the stipulations of a stringent black-white racial binary in the U.S. South. In Chapter Four, I define these tensions as part of larger complex Diaspora Wars that are battled out locally and globally. At the same time, in Chapters Five and Six my findings indicate that East Charlotte places of consumption also foster what I call Diaspora Love, moments that cater to and embrace the simultaneity of sameness and difference that diasporic subjects embody. In order to understand how the dynamics of space, place, people and things became concentrated within East Charlotte, it was necessary to not only examine how East Charlotte emerged as a transethnic enclave, but also to explore how and why black/brown subjects' relationship with the greater city of Charlotte compelled them to convene in the East Side.

As a result of the social, cultural, and political inconsistencies of the New South narrative, in Chapter One, I contend that we must conceptualize the New South beyond the definitive and tangible "time, place, idea, reinvention, and people" that the Levine Museum of the New south puts forth. Positing the New South as an ontology, a discourse, an epistemology, and a way of life, allows a different understanding that 
presents the New South as a historical and contemporary paradox. The fact that the New South has and continues to undergo significant economic growth resulting in dramatic demographic shifts, primarily due to migration that has established Charlotte as a preemerging gateway city, qualifies the New South as an ontological fact, a separate entity from that of the Old South. However, this distinction is blurred due to abovementioned instances of discrimination, segregation, marginalization, and legislation. A history of temperate race relations that seemingly distinguish Charlotte from the violent racial past of other southern cities has constructed what I call a "dangerous discourse" of the "New" South that serves to either placate the everyday experiences and realities of black and brown subjects or to silence them. In turn, over time this dangerous discourse has become an epistemology; the New South is very much part of what Charlotte citizens predict and expect, so much so, that it was not until the second killing of an unarmed black man by the CMPD that Charlotte citizens had finally had enough, even then many Charlotte citizens, "didn't believe we had it in us." Still, the New South as a discourse operates in the imagining of city leaders and residents alike and helps to both market the city to corporate entities in a global neoliberal market and establish a corporate culture that simultaneously embraces "diversity" or multi-culturalism while also excluding those who do not fit the neat, clean, corporate imaginary.

In Chapter One, participants' accounts confirmed that Charlotte is extremely spatially, socially, and racially segregated, which includes separations among black subjects. Years of activating varying forms of segregation (both overt and subtle) in the past through real-estate covenants and now through music selection and strict dress codes are revealed in the city's many racialized landscapes. These landscapes are characterized 
by either predominantly white, clean, neat, and highly surveilled areas like Uptown and Southeast Charlotte that stand in contrast to working class black American areas like West Charlotte. There is also the middle and upper-middle class multicultural suburban expanse of University City, the city's other corporate hub. While University City offers another case for future study, as the city's second corporate hub built around the evergrowing University of North Carolina at Charlotte, the area's dynamics are noticeably different from those of the complex working-class/gentrifying trans-ethnic enclaves like East Charlotte and South Boulevard. The latter two areas have both transitioned from predominantly middle- and working- class white to the city's two main immigrant corridors, mainly due to more affordable apartment homes and cheaper commercial real estate. Yet, East Charlotte, in contrast to South Boulevard is geographically larger, and has always held substantial pockets of middle- and working- class black American neighborhoods. Therefore, many black and brown subjects find themselves avoiding Uptown and Southeast Charlotte, opting for more inclusive and multi-cultural spaces and places in areas like East Charlotte in their quest for belonging. The question still remained, did this shared marginalization and quest for belonging compel a shared identity rooted in collective blackness among subjects racialized as black in the U.S. South.

A great deal of studies within the field of sociology emphasize a contentious relationship between black immigrants, West Indians in particular, and black Americans. According to Jemima Pierre (2004) scholars such as Waters (1999, 2001), Vickerman (2001), Rogers (2001) and Portes and Rumbaut (1990) perpetuate an "ethnicity paradigm" that attempts to glorify ethnicity and cultural differences based upon a 
European "immigrant analogy" and ultimately, discounts the significance of race and racial inequalities that black immigrants may confront (Pierre 2004, 145). These scholars reify notions of a pathological black American culture and perpetuate the myth of the model minority. Through this, these scholars fail to display any comprehension of the ways in which respectability functions as a tool for black subjects throughout Africa and the Diaspora to distinguish themselves and gain recognition in the face of global white supremacy. Notions and performance of respectability as tools used to distinguish black subjects premise Chapters Two and Chapter Four. Chapter Two, which focuses on Caribbean and African immigrant identity begins to respond to one of the most critical inquiries underlying this research; how do immigrants racialized as black living in the U.S. South conceptualize, process, and/or perform blackness and how do these processes and conceptualizations influence the formation of their identities and subjectivities in the New South.

Chapter Two is grounded in the supposition that, "black is black", a popular phrase repeated by my interlocutors when asked the differences between blackness in their countries of origin and blackness in the U.S. At the outset, the phrase "black is black" appeared to signal potential intra-racial and inter-ethnic solidarity and collectivity. However, the phrase was more than often detracted with a "but" that would begin a disclaimer for participants' delivery of what Hintzen (2001) calls a discourse of difference. I build upon this notion by highlighting the existence of true cultural differences among black populations and "cultural differences," the latter being superficial distinctions suggestive of respectability and/or the myth of the model minority. Despite being almost completely enmeshed within the black American middle 
and upper middle- class community in Charlotte, Caribbean immigrants manage to maintain an air of "cultural difference" that is expressed amongst themselves. I found it interesting that many of my participants previously attended Historically Black Colleges and Universities, and despite being not only at an institution that was made possible by the activism of black Americans, but also being surrounded by other respectable black Americans, these individual still concocted "cultural difference" between themselves and black Americans. Therefore, this dissertation leaves room to further interrogate what informs and maintains these ideals among black immigrant HBCU alumni. What is clear is that, in conjunction with Hintzen, black immigrants can benefit from the sociopolitical power of black Americans when necessary while distinguishing themselves in other times and spaces. At the same time, in Chapter Two, I contend that a trope of difference has historically functioned to distinguish all respectable black subjects from the masses. While I root this idea within the early work and debates among scholars such as E. Franklin Frazier (1957), W.E.B DuBois (1903), Alain Locke (1925), and Booker T. Washington, the concept emerged through the interactions I had with many of my older black immigrant participants who held me as a prototype of the different black American. It is here in which my positionality became essential.

Confronted with the possibility of my own difference, I was compelled to reflect upon my own performances of blackness. In Chapter Two, I emphasize this aspect during my time in African hair braiding salons. What is more, African braiding salons and other African businesses revealed inter-ethnic socioeconomic hierarchies within the African immigrant community. Anglophone African immigrants from countries such as Nigeria, Liberia, and Sierra Leone are among the most visible African immigrant 
populations, consequentially they also occupy a higher socioeconomic status than many Francophone African immigrants. In salons, these distinctions are visible through who the actual braiders are versus who the owners are. In small African-owned grocery stores, socioeconomic hierarchies are evidenced through purchases and exchanges; working class hair-braiders often buy on credit. "Cultural difference" in these cases often center upon business exchanges within the African community as well as between Africans and working-class black Americans who make up the main clientele in many East Side braiding salons. Despite these differences, the reigning idea of Chapter Two, "black is black" prevailed as the blackness of Caribbean and African immigrants is never questioned in the manner that it is for Afro-Latino immigrants.

In Chapter Three, in conjunction with Homi Bhabha's notion of liminality, I argue that self-identified Afro-Latinos/as/X in the U.S. South find themselves in a perpetual liminal state. Afro-Latinos in Charlotte are not completely accepted by the dominant Latino population as a result of their blackness, yet they are also oftentimes denied membership into the black American community because they speak Spanish. The latter often results in Afro-Latinos from Dominican Republic, Puerto Rico, Colombia, etc. being dismissed and wrongly labelled as "Mexican." Still, acknowledging processes of racialization in their countries of origin, Afro-Latinos are unwilling to concede to whiteness, as many are presented the option to assert whiteness despite their complexion. Several Afro-Latinos in this study recall being asked if they identify as black or white since living in Charlotte. Chapter Three, relies a great deal on Michelle Wright's conception of a Middle Passage Epistemology, in which one's blackness in the U.S. is defined by a lineage of the trans-Atlantic slave trade and Civil Rights Movement, and 
subsequently excludes other histories, experiences, and trajectories (M. M. Wright 2015). Chapter Three also divulges Tiffany Joseph's (2015) concept of a “transnational racial optic", which posits that multiple processes of racialization in countries of origin as well as navigating other countries of residence, inform subjects' identity and subject formation (Joseph 2015). Joseph's assertion is very much part of the overall thread of this dissertation. While Chapter Two and Three explore the very complex layers of black immigrant identities, Chapters Four, Five and Six delve into the implications of where and how these identities and subjectivities intersect and interact and the affects triggered by the material culture and material settings of these spaces and places.

My interviews, observations, and mini-participatory GIS tours in which my interlocutors walked me through their places of business, led me to witness the construction of inter-ethnic boundaries between black immigrants and black Americans as well as inter- and intra- ethnic boundaries between black subjects in general. Chapter Four introduces the idea of Diaspora Wars. While this notion was inspired by my friend and I's observation of social media debates between black diasporic subjects globally, I saw these unfold locally in Charlotte as my interlocutors described the ways in which material culture and setting such as food, smell, other black bodies, and music triggered affects such as fear, disdain and disgust that ultimately established boundaries. As such, in Chapter Four, I argue that affects that lead to aversion and subsequently boundaries are rooted in performances and notions of respectability as black subjects (immigrants and native black) endeavor to be what Frazier (1957) calls, "Super-Americans." Like "cultural differences" discussed in Chapter Two, presenting oneself as Super-American reveals black subjects' attempt to gain recognition in the face of global (mis)recognition 
as all black subjects are attached to varying racialized stereotypes within a global white supremacist patriarchy. I argue that distinguishing oneself from the masses by either refusing to go to certain places and spaces, performing, dressing, and speaking a certain way acceptable to white Americans, or distancing oneself from foreign or un-American bodies and commodities serve as apparatuses to gain recognition and full citizenship. Nevertheless, because Diaspora Wars are an aspect of black diasporic life, in Chapter Five, I begin to argue that these battles are consequential and yet necessary in order for black subjects to maneuver and plunge through the wake of post-colonization in the journey of self-discovery. Rooted in the theories of Stuart Hall, both Chapters Five and Six argue that the path toward discovery and awareness calls upon the black subject to recognize the simultaneity of sameness and difference of black subjectivities as much as it summons us to recognize the significance of more essential conceptualizations of blackness. Therefore, Diaspora Wars is only a part of forging Diaspora Love. Rooted in multiple and oftentimes diverging articulations of blackness and Diaspora, Diaspora Love appeared to manifest in varying spaces and places, making Diaspora Wars a complex component of a (dis)functional black/brown family. Both Diaspora Wars and Diaspora Love are indicative of affective, spatial and temporal formations that underscore the construction and existence of an Alternative New South. In Chapter Five, I introduce Reyes-Santos' (2015) transcolonial kinship model and I contend that locally in East Charlotte, affective kinship rooted in either essentialist or anti-essentialist conceptualizations of blackness serve to construct spaces and places of belonging that foster collective black identities among black immigrants and black Americans. This is particularly evidenced at the House of Africa and the Annual 
Juneteenth Festival of the Carolinas, spaces and places that are grounded in Afrocentric ideals and conceptualizations. At the HOA and Juneteenth, there is exists a more direct and one-sided relationship between upper middle- class Africans and African Americans, the material culture and setting within this context also illustrates this relationship. On the other hand, Reggae Central is demonstrative of anti-essentialist arguments. In this case, I particularly emphasize the work of Gilroy (1993) in addressing the centeredness of the Caribbean and global exchanges exemplified through the flags, music, and clothing purchased. It is in Chapter Five, at each of the places I explore, that women emerge as central cultural workers in the construction and maintenance of an Alternative New South. Within the realm of affective kinship, I liken them to mothers. Women continue to play a vital role in Chapter Six.

In Chapter Six, I continue to build upon Reyes-Santos' theories and I apply them to argue towards the formation of a trans-ethnic alternative community that more truly represents the multicultural ideals and imaginations of New South rhetoric. I argue that this trans-ethnic alternative community, composed of spaces and places like SuCasa at Petra's Piano Bar, Queen City Collective, and Afropop, employ collective efforts, consciousness and sensibility that underline a practice of ethics (Walcott 2016) and presents the opportunity to enact and embrace the simultaneity of sameness and difference in the larger practice of diaspora (S. Hall 1997a; S. Hall 1990; Edwards 2001). With this, I posit East Charlotte as a trans-ethnic alternative community and ultimately as a borderland composed of spaces and places, or "border situations" that are "good for living" (Agier 2016). Ultimately, the "border situations" that emerge from East Charlotte spaces and places and exchanges of food, music, arts, fashion and other forms of material 
culture may be temporal, nevertheless they are indicative of black/brown solidarity. Further, the people who construct and inhabit these spaces and places, those who Agier (2016) define as "border-dwellers" embody not only the borders they occupy but their alterity as well, in turn East Charlotte's "border situations" are reflections of these alternative subjects. With this new visualization of an Alternative New South I reimagine and (re)place the agency of constructing the New South in the hands of its black and brown subjects not with policy-makers or corporate entities. These black and brown cultural workers and patrons establish a "cosmopolitan condition" (Agier 2016) in East Charlotte and other marginalized communities that (dis)places Uptown as the dominant image of New South progression. It is in Chapter Six that I also introduce another dimension of this research that I did not initially foresee or consider at the beginning of my research.

Gender and sexuality are aspects of the alternative New South that I only begin to explore in this dissertation. Black (mainly American) women and queer immigrant subjects emerged as central agents in constructing the transethnic alternative New South. In this conclusion, I propose the need for future more in-depth studies on the work of queer black and brown subjects in the U.S. South, and in Charlotte, given the aftermath of House Bill 2 and what on-going anti-immigrant legislation signals for black/brown queer immigrant subjects. In addition, black American and black immigrant women made up the majority of business owners included in this study. This was not by conscious selection, and it is an aspect that I only touch the surface of in Chapters Five and Six. I contend that there is a need to explore the significance of black immigrant and black American women business owners from a more direct black feminist and gender 
studies perspective. Lastly, University City is mentioned quite a bit throughout this dissertation. As the city's second corporate hub built around a major college campus, it is a multi-cultural middle- and upper middle- class neighborhood where several of my participants reside. With a visibly growing concentration of Caribbean immigrants living in the area, and a relatively large black American population, the area is worthy for more in-depth research pertaining to class, respectability, immigration, and blackness.

In conclusion, I argue for a reconceptualization of the New South, one that recognizes those existing on the margins as possessing the agency to imagine and construct meaningful spaces and places of belonging. They are the beacon of the Charlotte' cosmopolitanism, and therefore this is equally a call for Charlotte city leaders to reassess its identity as a city. As such, I maintain that the context of the U.S. South compels new dynamic interactions and intersections among black immigrants and black Americans that (re)shape black subjectivities and identities and foster new black and brown solidarities. This dissertation has sought to highlight how varying conceptualizations and performances of blackness and Diaspora serve in the navigation of race and space in the New South. Charlotte is still a pre-emerging gateway city and as these populations continue to grow, I am certain that the trans-ethnic alternative community will expand alongside the swelling and on-going inconsistencies of the New South. For these reasons, there is a continued need for research on the experiences of black and brown subjects in the Alternative New South. 


\section{BIBLIOGRAPHY}

Agier, Michel. 2016. Borderlands: Toward an Anthropology of the Cosmopolitan Condition. Malden: Polity Press.

Ahmed, Sara. 2000. Strange Encounters: Embodied Others in Post-Coloniality. New York: Routledge.

— 2005. "The Skin of the Community: Affect and Boundary Formation." In Revolt, Affect, Collectivity; The Unstable Boundaries of Kristeva's Polis, edited by Tina Chanter and Ewa Plonowska Ziarek, 95-111. Albany: State University of New York Press.

Alderman, Derek H., and E. Arnold Modlin Jr. 2013. "Southern Hospitality and the Politics of African American Belonging: An Analysis of North Carolina Tourism Brochure Photographs." Journal of Cultural Geography 30 (1): 6-31.

Alexander, Bryant Keith. 2006. Performing Black Masculinity; Race, Culture and Queer Identity. Lanham: Altamira.

Anderson, Ben, and Paul Harrison, eds. 2010. Taking-Place: Non-Representational Theories and Geography. Burlington: Ashgate Publishing Ltd.

Anderson, Benedict. 1983. Imagined Communities. London: Verso.

Anderson, Elijah. 1990. Street Wise: Race, Class, and Change in an Urban Community. Chicago: The University of Chicago Press.

Anderson, Mark. 2005. "Bad Boys and Peaceful Garifuna: Transnational Encounters Between Racial Stereotypes of Honduras and the United States (and Their Implications for the Study of Race in the Americas)." In Neither Enemies nor Friends; Latinos, Blacks, Afro-Latinos, edited by Anani Dzidzienyo and Suzanne Oboler, 101-17. New York: Palgrave MacMillan. 
Appadurai, Arjun. 1986a. The Social Life of Things; Commodities in Cultural Perspective. Cambridge: Cambridge University Press.

. , ed. 1986b. The Social Life of Things. Cambridge: Cambridge University Press.

- 1990. "Disjuncture and Difference in the Global Cultural Economy." Theory, Culture \& Society: Exploration in Critical Social Science 7 (2-3).

1996. Modernity at Large; Cultural Dimensions of Globalization. Minneapolis: University of Minnesota Press.

Appebaum, Nancy P., Anne S. Macpherson, and KArin Alejandra Rosemblatt. 2003. "Racial Nations." In Race and Nation in Modern Latin America, edited by Nancy P. Applebaum, Anne S. Macpherson, and Karin Alejandra Rosemblatt. Chapel Hill: University of North Carolina Press.

Appiah, K.W. 2006. Cosmopolitanism: Ethics in a World of Strangers. London: Allen Lane.

Appiah, Kwame Anthony. 2006. "The Case for Contamination.” New York Times.

Arthur, John A. 2009. "Immigrants and the American System of Justice: Perspectives of African and Caribbean Blacks." In The New African Diaspora, edited by Isidore Okpewho and Nkiru Nzegu. Bloomington: Indiana University Press.

Bailey, Marlon. 2013. Butch Queens Up in Pumps: Gender, Performance, and Ballroom Culture in Detroit. Ann Arbor: The University of Michigan Press.

Barber, Mark. 2017. “"NoDo Residents Getting Kicked from Low-Income Homes.'” Charlotte Observer, July 20.

Barot, Rohit, and John Bird. 2001. "Racialization : The Genealogy and Critique of a Concept Racialization : The Genealogy and Critique of a Concept." Ethnic and 
Racial Studies 24 (4): 601-18. doi:10.1080/01419870120049806.

Bennett, Jane. 2010. Vibrant Matter; A Political Ecology of Things. Durham: Duke University Press.

Bhabha, Homi K. 1994. The Location of Culture. New York: Routledge.

Bion, Wilfred. 1961. Experiences in Groups and Other Papers. New York: Tavistock Publications Limited.

Bourdieu, Pierre. 1984. Distinction; A Social Critique of the Judgement of Taste. Cambridge: Harvard University Press.

Brennan, Teresa. 2004. The Transmission of Affect. Ithaca: Cornell University Press.

Brettel, Caroline B. 2008. "Theorizing Migration in Anthropology; The Social Construction of Networks, Identities, Communities, and Globalscapes." In Migration Theory; Talking Across Disciplines. New York: Taylor \& Francis.

Brodkin, Karen. 1994. "How Jews Became White Folks and What That Says about Race in America." New Brunswick: Rutgers University Press.

Butler, Judith. 1990. Gender Trouble. New York: Routledge.

Candelario, Ginetta E.B. 2007. Black Behind the Ears; Dominican Racial Identity from Museums to Beauty Shops. Durham: Duke University Press.

Charles, Carolle. 2003. "Being Black Twice.” In Problemetizing Blackness; SelfEthnographies by Black Immigrants to the United States, edited by Percy Hintzen and Jean Muteba Rahier, 169-80. New York: Routledge.

Clarke, Kamari Maxine. 2006. "Mapping Transnationality: Roots Tourism and the Institutionalization of Ethnic Heritage." In Globalization and Race; Transformations in the Cultural Production of Blackness, edited by Kamari Maxine Clarke and Deborah A. Thomas. Durham: Duke University Press. 
- 2010. "New Spheres of Transnational Formations: Mobilizations of Humanitarian Diasporas." Transforming Anthropology 18 (1): 48-65.

Copeland-Carson, Jacqueline. 2004. Creating Africa in America; Translocal Identity in an Emerging World City. Philadelphia: University of Pennsylvania.

Crenshaw, Kimberle. 1991. "Mapping the Margins: Intersectionality, Identity Politics, and Violence Against Women of Color." Stanford Law Review 43: 1241.

Csordas, Thomas J. 1990. "Embodiment as a Paradigm for Anthropology." Ethos: Journal of the Society for Psychological Anthropology 18 (1): 5-47.

Degler, Carl. 1971. Neither Black nor White: Slavery and Race Relations in Brazil and the United States. Madison: The University of Wisconsin Press.

"Discover Charlotte East.” n.d. http://charlotteeast.com.

Doran, William. 2016. "How Much Money Has HB2 Cost North Carolina." Charlotte Observer, May.

DuBois, W.E.B. 1996. The Souls of Black Folk. Modern LIb. New York: Random House.

Duncan, James, and Nancy Duncan. 2006. "Aesthetics, Abjection, and White Privelege in Suburban New York." In Landscape and Race in the United States, edited by Richard H. Schein, 157-77. New York: Routledge.

Duruz, Jean, Susan Luckman, and Peter Bishop. 2011. "Bazaar Encounters : Food, Markets, Belonging and Citizenship in the Cosmopolitan City." Continuum: Journal of Media and Cultural Studies 25 (5): 599-604.

Dzidzienyo, Anani, and Suzanne Oboler, eds. 2005. Neither Enemies Nor Friends; Latinos, Blacks, Afro-Latinos. New York: Palgrave MacMillan. 
Edward, Brent Hayes. 2003. The Practice of Diaspora; Literature, Translation, and the Rise of Black Internationalism. Cambridge: Harvard University Press.

Edwards, Brent Hayes. 2001. “The Uses of Diaspora.” Social Text 19 (1): 45-74.

Ehrkamp, Patricia, and Caroline Nagel. 2012. "Immigration, Places of Worship and the Politics of Citizenship in the US South." Transactions of the Institute of British Geographers 37 (4): 624-38.

Ellen, Barbara, Jamie Winders, Barbara Ellen Smith, and Jamie Winders. 2008. "We're Here to Stay: Economic Restructuring, Latino Migration and Place-Making in the US South." Transactions of the Institute of British Geographers 33 (1): 60-72.

Fanon, Frantz. 1952. Black Skin, White Masks. New York: Grove Press.

Finney, Carolyn. 2014. Black Faces, White Spaces: Reimagining the Relationship of African Americans to the Great Outdoors. Chapel Hill: The University of North Carolina Press.

Foner, Nancy, ed. 2001. Islands in the City; West Indian Migration to New York. Berkeley: University of California Press.

Forman, Murray. 2002. The Hood Comes First; Race, Space, and Place in Rap and Hip Hop.

Frazier, E. Franklin. 1957. Black Bourgeoisie; The Book That Brought the Shock of SelfRevelation to Middle-Class Blacks in America. New York: Simon and Schuster.

Freyre, Gilberto. 1933. The Masters and The Slaves: A Study in the Development of Brazilian Civilization. Berkely: University of California Press.

1963. New World in the Tropics; The Culture of Modern Brazil. New York: Vintage Books. 
Furuseth, Owen. 2016. "Charlotte: Facing the Challenges of Economic Opportunity and Mobility." Charlotte.

http://mseap.uncc.edu/sites/mseap.uncc.edu/files/fields/presentations/field_file/Economic Opportunity and Mobility 6.9.16.pdf.

Furuseth, Owen J., and Heather A. Smith. 2006. "From Winn-Dixie to Tiendas: The Remaking of the New South." In Latinos in the New South; Transformations of Place, edited by Owen J. Furuseth and Heather A. Smith, 1-19. Hampshire: Ashgate Publishing Ltd.

Furuseth, Owen, Heather Smith, and Paul McDaniel. 2015. "Belonging in Charlotte: Multiscalar Differences in Local Immigration Political and Policies." Geographical Review 105 (1): 1-19.

Geertz, Clifford. 1973. The Interpretation of Cultures: Selected Essays by Clifford Geertz. New York: HarperCollinsPublishers.

Gill, Hannah. 2010. The Latino Migration Experience in North Carolina; New Roots in the Old North State. Chapel Hill: The University of North Carolina Press.

Gilroy, Paul. 1993. The Black Atlantic; Modernity and Double Consciousness. Cambridge: Harvard University Press.

Godwin, R. Kenneth, Suzanne M. Leland, Andrew D. Baxter, and Stephanie Southworth. 2006. "Sinking Swann: Public School Choice and the Resegregation of Charlotte's Public Schools." Review of Policy Research 23 (5): 983-97.

Goldfield, David. 2010. “A Place to Come." In Charlotte, NC; The Global Evolution of a New South City, edited by William Graves and Heather A. Smith. Athens: The University of Georgia Press.

Gordon, Edmund T., and Mark Anderson. 1999. "The African Diaspora: Toward an Ethnography of Diasporic Identification." The Journal of American Folklore 112 (445): 282-96. 
Graves, William, and Heather A. Smith, eds. 2010. Charlotte, NC; The Global Evolution of a New South City. Athens: The University of Georgia Press.

Greenbaum, Susan D. 2002. More Than Black; Afro-Cubans in Tampa. Gainesville: University Press of Florida.

Hall, C Michael. 1997. "Geography, Marketing and the Selling of Places Geography, Marketing and the Selling of Places." Journal of Travel and Tourism Marketing 6 (3-4): 61-84.

Hall, Stuart. 1990. "Cultural Identity and Diaspora." In Identity, Community, Culture, Difference, edited by Jonathen Rutherford, 222-37. London: Lawrence and Wishart.

. 1997a. "Old and New Identities, Old and New Ethnicities." In Culture, Globalization, and the World System; Contemporary Conditions for the Representation of Identity. Minneapolis: University of Minnesota Press.

- 1997b. "The Local and the Global; Globalization and Ethnicity." In Culture, Globalization, and the World System; Contemporary Conditions for the Representation of Identity, edited by Anthony D. King. Minneapolis: University of Minnesota Press.

Hanchard, Michael, ed. n.d. Racial Politics in Contemporary Brazil. Durham: Duke University Press.

Hanchett, Thomas W. 1998. Sorting Out the New South City; Race, Class, and Urban Development in Charlotte, 1875-1975. Chapel Hill: The University of North Carolina Press.

- 2010. "Salad-Bowl Suburbs: A History of Charlotte's East Side and South Boulevard Immigrant Corridors." In Charlotte, NC; The Global Evolution of a New South City, edited by Heather A. Smith and William Graves, 247-62. Athens: The University of Georgia Press. 
. 2017. "Charlotte's Neighborhood Planning Tradition.” Charlotte-Mecklenburg Historic Landmarks Commission.

http://www.cmhpf.org/kids/neighborhoods/NeighPlan.html.

Hanchett, Thomas W. 1998. Sorting out the New South; Race, Class and Urban Development in Charlotte 1875-1975. Chapel Hill: The University of North Carolina Press.

Heffernan, Michael. 2001. “'A Dream as Frail as Those of Ancient Time': The inCredible Geographies of Timbuctoo." Environment and Planning D: Society and Space 19 (2): 203-25.

Heisler, Barbara Schmitter. 2008. "The Sociology of Immigration; From Assimilation to Segmented Assimilation, from the American Experience to the Global Arena." In Migration Theory; Talking Across Disciplines. New York: Routledge.

Hintzen, Percy C. 2001. West Indian in the West; Self-Representations in an Immigrant Community. New York: New York University Press.

Hintzen, Percy C., and Jean Muteba Rahier, eds. 2003. Problemetizing Blackness; SelfEthnographies by Black Immigrants to the United States. New York.

- 2010. "Introduction." In Global Circuits of Blackness; Interrogating the African Diaspora, edited by Jean Muteba Rahier, Percy C. Hintzen, and Felipe Smith, ixxxvi. Chicago: University of Illinois Press.

Hintzen, Percy C., Jean Muteba Rahier, and Felipe Smith. 2010. "Introduction; Theorizing the African Diaspora; Metaphor, Miscognition, and Self-Recognition." In Global Circuits of Blackness, ix-1. Urbana: The University of Illinois.

Hoelscher, Steve. 2006. "The White Pillared Past: Landscapes of Memory and Race in the American South." In Landscape and Race in the United States, edited by Richard H. Schein, 39-73. New York: Routledge.

hooks, bell. 1992. "Eating the Other." In Black Looks: Race and Representation, 21-41. Boston: South End Press. 
Howard, David. 2001. Coloring the Nation. Oxford: Signal Books Limited.

"Immigrant Integration Task Force Report; Presented to Charlotte City Council." 2015. Charlotte.

Ingalls, Gerald L., and Isaac Heard Jr. 2010. "Developing a Typology of African American Neighborhoods in the American South; The Case of Charlotte." In Charlotte, NC; The Global Evolution of a New South City, edited by William Graves and Heather A. Smith. Athens: The University of Georgia Press.

Irele, F Abiola. 2005. “'What Is Africa to Me?': Africa in the Black Diaspora Imagination." Souls 7 (3-4): 26-46.

Jaccard, James, and Jacob Jacoby. 2010. Theory Construction and Model-Building Skills; A Practical Guide for Social Scientists. Edited by The Guilford Press. New York.

Johnson, Gaye Theresa. 2013a. Spaces of Conflict, Sounds of Solidarity; Music, Race, And Spatial Entitlement in Los Angele. Los Angeles: University of California Press.

-2013b. Spaces of Conflict, Sounds of Solidarity; Music, Race, and Spatial Entitlement in Los Angeles. Berkeley: University of California Press.

Joseph, Tiffany D. 2015. Race on the Move: Brazilian Migrants and the Global Reconstruction of Race. Stanford: Stanford University Press.

Khabeer, Su'Ad Abdul. 2016. Muslim Cool; Race, Religion, and Hip Hop in the United States. New York: New York University Press.

Lassiter, Matthew D. 2010. "Searching for Respect; From 'New South' to 'World Class' at the Crossroads of the Carolinas." In Charlotte, NC; The Global Evolution of a New South City. Athens: University of Georgia Press.

Latour, Bruno. 2014. "Another Way to Compose the Common World." Hau: Journal of Ethnographic Theory 4 (1): 301-7. 
Lefebvre, Henri. 1974. The Production of Space. Oxford: Blackwell Publishers Ltd.

Leonard, Madeleine, and Martina Mcknight. 2016. "Look and Tell: Using PhotoElicitation Methods with Teenagers." Children's Geographies 13 (6). Taylor \& Francis: 629-42.

"Levine Museum of the New South; Who We Are." 2016. http://www.museumofthenewsouth.org/about-us.

Locke, Alain, ed. 1925. The New Negro; Voices of the Harlem Renaissance. New York: Touchtone.

Low, Setha M., and Denise Lawrence-Zuniga, eds. 2003. The Anthropology of Space and Place; Locating Culture. Malden: Blackwell Publishers Ltd.

Marable, Manning. 2005. "Reconstructing the Radical DuBois." Souls 7 (3): 1-25.

Marcelin, Louis Herns. 2005. "Identity, Power, and Sociocultural Hierarchies Among Haitian Immigrants in Florida." In Neither Enemies nor Friends; Latinos, Blacks, Afro-Latinos. New York: Palgrave MacMillan.

Marquez, John D. 2013. Black-Brown Solidarity; Racial Politics in the New Gulf South. Austin: University of Texas Press.

Marrow, Helen B. 2011. New Destination Dreaming; Immigration, Race and Legal Status in the Rural American South. Stanford: Stanford University Press.

Marston, Sallie A, John Paul Jones III, and Keith Woodward. 2005. "Human Geography without Scale." Transactions of the Institute of British Geographers, no. 30: 416-32.

McClintock, Anne. 1995. Imperial Leather: Race, Gender and Sexuality in the Colonial Conquest. Great Britain: Routledge. 
Miller, Daniel. 1987. Material Culture and Mass Consumption. Oxford: Basil Blackwell Ltd.

—. 1998. A Theory of Shopping. Ithaca: Cornell University Press.

Miller, Daniel, Peter Jackson, Nigel Thrift, Beverly Holbrook, and Michael Rowlands. 1998. Shopping, Place and Identity. New York: Routledge.

Mitchell, Don. 1995. “There's No Such Thing as Culture: Towards a Reconceptualization of the Idea of Culture in Geography." Transactions of the Institute of British Geographers 20 (1): 102-16.

Narayan, Kirin. 1993. "How Native Is a 'Native' Anthropologist ?” American Anthropologist 95 (3): 671-86.

Nassey Brown, Jacqueline. 2005. Dropping Anchor, Setting Sail; Geographies of Race in Black Liverpool. Princeton: Princeton University Press.

Nassy Brown, Jacqueline. 2006. "Diaspora and Desire: Gendering 'Black America' in Black Liverpool." In Globalization and Race: Transformations in the Cultural Production of Blackness. Durham: Duke University Press.

Obi, T.J. Desch. 2008. Fighting For Honor: The History of African Martial Art Traditions in the Atlantic World. Columbia: The University of South Carolina Press.

Okpewho, Isidore, and Nkiru Nzegwu, eds. 2009. The New African Diaspora. Bloomington: Indiana University Press.

Omi, Michael, and Howard Winant. 1994. Racial Formation in the United States; From the 1960s to the 1990s. 2nd ed. New York: Routledge.

Ong, Aihwa, Virginia R Dominguez, Jonathan Friedman, Nina Glick Schiller, David Y H Wu, and Hu Ying. 1996. "Cultural Citizenship as Subject-Making: Immigrants Negotiate Racial and Cultural Boundaries in the United States." Current Anthropology 37 (5): 737-62. 
Ortiz, Fernando. 1947. Cuban Counterpoint: Tobacco and Suga. Fourth. Durham: Duke University Press.

Osumare, Halifu. 2005. "Global Hip-Hop and the African Diaspora." In Black Cultural Traffic; Crossroads in Global Performance and Popular Culture, edited by Harry J. Elam Jr. and Kennell Jackson, 266-88. Ann Arbor: The University of Michigan Press.

Pierre, Jemima. 2004. "Black Immigrants in the United States and the " Cultural Narratives " of Ethnicity." Identities: Global Studies in Culture and Power 11 (November): 141-70.

—2013. The Predicament of Blackness: Postcolonial Ghana and the Politics of Race. Chicago: The University of Chicago Press.

Queeley, Andrea J. 2015. Rescuing Our Roots; The African Anglo-Caribbean Diaspora in Contemporary Cuba. Gainesville: The University of Florida Press.

Rahier, Jean Muteba, ed. 1999. Representations of Blackness and the Performance of Identities. Westport: Bergin and Garvey.

. 2003. "Metis/Mulatre, Mulato, Mullatto, Negro, Moreno, Mundele, Kaki, Black; The Wanderings and Meanderings of Identities." In Problemetizing Blackness; SelfEthnographies by Black Immigrant to the United States, 85-113. New York: Routledge.

. 2010. "The Diversity of Black Subjectivities: Different and Separate Ontologies? A Response to Kamari Clarke's 'New Spheres of Transnational Formations: Mobilization of Humanitarian Diasporas." Transfroming Anthropology 18 (1): 49 52 .

Rahier, Jean Muteba, Percy C. Hintzen, and Felipe Smith, eds. 2010. Global Circuits of Blackness; Interrogating the African Diaspora. Urbana: University of Illinois Press. 
Ransby, Barbara. 2000. "Afrocentrism, Cultural Nationalism, and the Problem with Essentialist Definitions of Race, Gender, and Sexuality." In Dispatches from the Ebony Tower: Intellectuals Confront the African American Experience, edited by Manning Marable. New York: Columbia University Press.

Reyes-Santos, Alai. 2015. Our Caribbean Kin; Race and Nation in the Neoliberal Antilles. New Brunswick: Rutgers University Press.

Richardson, Miles. 2003. "Being-in-the-Market Versus Being-in-the-Plaza: Material Culture and the Construction of Social Reality in Spanish America." In The Anthropology of Space and Place; Locating Culture, edited by Seth M. Low and Denise Lawrence-Zuniga. Malden: Blackwell Publishers Ltd.

Rodman, Margaret C. 2003. "Empowering Place: Multilocality and Multivocality." In The Anthropology of Space and Place: Locating Culture, edited by Seth M. Low and Denise Lawrence-Zuniga, 204-24. Malden: Blackwell Publishing.

Rogers, Ruel. 2001. “'Black Like Who?' Afro-Caribbean Immigrants, African Americans, and the Politics of Group Identity." In Islands in the City; West Indian Migration to New York, edited by Nancy Foner. Berkeley: University of California Press.

Ross, Nicola J, Emma Renold, Sally Holland, and Alexandra Hillman. 2009. "Moving Stories: Using Mobile Methods to Explore the Everyday Lives of Young People in Public Care." Qualitative Research 9 (5): 605-23.

Sagas, Ernesto. 2000. Race and Politics in the Dominican Republic. Gainesville: University Press of Florida.

Sansone, Livio. 2003. Blackness Without Ethnicity; Constructing Race in Brazil. New York: Palgrave MacMillan.

Sawyer, Mark Q. 2008. "DuBois's Double Consciousness Versus Latin American Exceptionalism; Joe Arroyo, Salsa, and Negritude." In Transnational Blackness; Navigating the Global Color Line, edited by Manning Marable and Vanessa AgardJones. New York. 
Schein, Richard H. 2006. "Race and Landscape in the United States." In Landscape and Race in the United States, edited by Richard H. Schein, 1-23. New York: Routledge.

Schuch, Johanna, and Qingfang Wang. 2015. "Immigrant Businesses, Place-Making, and Community Development: A Case from an Emerging Immigrant Gateway.” Journal of Cultural Geography 32 (2): 214-41.

Shaw-Taylor, Yoku. 2007. "The Intersection of Assimilation, Race, Presentation of Self, and Transnationalism in America." In The Other African Americans; Contemporary African and Caribbean Immigrants in the United States, edited by Yoku ShawTaylor and Steven A Tuch, 1-49. Lanham: Rowman and Littlefield Publishers.

Shaw-Taylor, Yoku, and Steven A. Tuch, eds. 2007. The Other African Americans; Contemporary African and Caribbean Immigrants in the United States. Lanham: Rowman and Littlefield Publishers.

Silverstein, Paul A. 2005. "Immigrant Racialization and the New Savage Slot: Race, Migration , and Immigration in the New Europe." Annual Review of Anthropology 34: $363-84$.

Skidmore, Thomas A. 1974. Black Into White: Race and Nationality in Brazilian Thought. Oxford: Oxford University Press.

Smith, Candis Watts. 2014. Black Mosaic; The Politics of Black Pan-Ethnic Diversity. New York: New York University Press.

Stepick, Alex, Guillermo Grenier, Max Castro, and Marvin Dunn. 2003. This Land Is Our Land; Immigrants and Power in Miami. Berkeley: University of California Press.

Stoller, Paul. 2002. Money Has No Smell; The Africanization of New York City. Chicago: The University of Chicago Press. 
Stovall, Tyler. 2005. "Black Community, Black Spectacle: Performance and Race in Transatlantic Perspective." In Black Cultural Traffic; Crossroads in Global Performance and Popular Culture, edited by Harry J. Elam Jr. and Kennell Jackson, 221-41. Ann Arbor: The University of Michigan Press.

Stuesse, Angela. 2016. Scratching Out a Living. Oakland: University of California Press.

Taiwo, Olufemi. 2003. "The Prison Called My Skin: On Being Black in America.” In Problemetizing Blackness; Self-Ethnographies by Black Immigrants to the United States, edited by Percy C. Hintzen and Jean Muteba Rahier, 35-53. New York: Routledge.

Tate, Shirley Anne, and Ian Law. 2015. Caribbean Racisms; Connections and Complexities in the Racialization of the Caribbean Region. New York: Palgrave MacMillan.

Telles, Edward E. 2004. Race in Another America; The Significance of Skin Color in Brazil. Princeton: Princeton University Press.

Thame, Maziki. 2017. "Racial Hiearchy and the Elevation of Brownness." SMALL AXE 21 (3): 111-23.

Thomas, Deborah A. 2004. Modern Blackness: Nationalism, Globalization and the Politics of Culture in Jamaica (Latin America Otherwise). Durham: Duke University Press.

Thomas, Deborah A., and Kamari Maxine Clarke. 2006. "Introduction; Globalization and the Transformation of Race." In Globalization and Race; Transformations in the Cultural Production of Blackness, edited by Kamari Maxine Clarke and Deborah A. Thomas. Durham: Duke University Press.

Thompson, Marie, and Ian Biddle. 2013. "Introduction: Somewhere between the Signifying and the Sublime." In Sound Music Affect; Theorizing Sonic Experience, edited by Marie Thompson and Ian Biddle. New York: Bloomsbury. 
Thrift, Nigel. 2008. Non-Representational Theory; Space, Politics, Affect. New York: Routledge.

Tomlinson, Tommy, and Don Sturkey. 2016. "Dorothy Counts at Harding High: A Story of Pride, Prejudice." Charlotte Observer, March 18.

Torres-Saillant, Silvio. 2006. An Intellectual History of the Caribbean. New York: Palgrave MacMillan.

Urry, John, and Jonas Larsen. 2011. The Tourist Gaze 3.0. Los Angeles: Sage.

Vickerman, Milton. 2001. "Tweaking a Monolith: The West Indian Immigrant Encounter with 'Blackness."' In Islands in the City; West Indian Migration to New York, edited by Nancy Foner. Berkeley: University of California Press.

Wade, Peter. 2010. Race and Ethnicity in Latin America. London: Pluto Press.

Walcott, Rinaldo. 2016. Queer Returns: Essays on Multiculturalism, Diaspora, and Black Studies. Toronto: Insomniac Press.

Waters, Mary C. 1999. Black Identities; West Indian Immigrant Dreams and American Realities. Cambridge: Harvard University Press.

. 2001. "Growing Up West Indian and African American: Gender and Class Differences in the Second Generation." In Islands in the City; West Indian Migration to New York, edited by Nancy Foner. Berkeley: University of California Press.

Willems-Braun, Bruce. 1997. "Buried Epistemologies: The Politics of Nature in ( Post ) Colonial British Columbia." Annals of the Association of American Geographers 87 (1): 3-31.

Wilson, Peter J. n.d. "Reputation and Respectability: A Suggestion for Caribbean Ethnology." Man 4 (1): 70-84. 
Wright, Michelle M. 2004. Becoming Black; Creating Identity in the African Diaspora. Durham: Duke University Press.

2015. Physics of Blackness; Beyond the Middle Passage Epistemology. Minneapolis: University of Minnesota Press.

Wright, Michelle. 2010. "Black in Time: Exploring New Ontologies, New Dimensions, New Epistemologies of the African Diaspora." Transforming Anthropology 18 (1): $70-73$.

Zeleza, Paul Tiyambe. 2009. "Diaspora Dialogues: Engagements Between Africa and Its Diaspora." In The New African Diaspora, edited by Isidore Okpewho and Nkiru Nzegwu, 31-61. Bloomington: Indiana University Press.

Zukin, Sharon. 1995. The Culture of Cities. Malden: Blackwell Publishers Ltd. . 2010. Naked City: The Death and Life of Authentic Urban Places. Oxford: Oxford University Press. 
VITA

MASONYA JOY BENNETT

Born, Charlotte, North Carolina

EDUCATION

2013-2018

Ph.D. Candidate, Global and Socio-Cultural Studies

Florida International University

M.A, African and African Diaspora Studies

Florida International University

Graduate Teaching Assistant, African and African

Diaspora Studies and Global and Socio-Cultural Studies

Florida International University

2008-2010

M.A, Latin American Studies

University of North Carolina at Charlotte

2003-2006

B.A, Africana Studies and International Studies

University of North Carolina at Charlotte

\section{PUBLICATIONS AND PRESENTATIONS}

"Intersections and Exchanges of Blackness among Immigrants of African Descent in the New South" Paper Presentation. Latin American Studies Association Conference. Lima, Peru, May 2017.

"The New Black in the New South." Invited Lecture. Brown Bag Luncheon Lecture Series, University of North Carolina at Charlotte, January 2017

"Exchanges and Intersections of Blackness in the New South." Paper Presentation. The $41^{\text {st }}$ Annual Caribbean Studies Association Conference. Port-Au-Prince, Haiti, June 2016

"Exchanges and Intersections of Blackness in the New South." Paper Presentation. The $40^{\text {th }}$ Annual National Council of Black Studies. Charlotte, March 2016

"The New Black in the New South; Negotiations of Race and Space in North Carolina's Immigrant Communities." Paper Presentation. The 39 ${ }^{\text {th }}$ Annual National Council of Black Studies. Los Angeles, March 2015. 
"The New Black in the New South; Negotiations of Race and Space in North Carolina's Immigrant Communities" Paper Presentation. The 3rd Annual Migration Without Boundaries, Michigan State University, October 2014.

"Dios, Patria y Libertad; A Tale of Dominican National Identity." Paper Presentation. Pacific Coast Council on Latin American Studies Annual Conference, Pepperdine University, November 2010 